\title{
The Role of Rx in Embryonic Retinogenesis: Determining Genetic Influences on Optic Vesicle Formation and Photoreceptor Cell
} Fate

Helen M. Rodgers

Follow this and additional works at: https://researchrepository.wvu.edu/etd

\section{Recommended Citation}

Rodgers, Helen M., "The Role of Rx in Embryonic Retinogenesis: Determining Genetic Influences on Optic Vesicle Formation and Photoreceptor Cell Fate" (2017). Graduate Theses, Dissertations, and Problem Reports. 6520.

https://researchrepository.wvu.edu/etd/6520

This Dissertation is protected by copyright and/or related rights. It has been brought to you by the The Research Repository @ WVU with permission from the rights-holder(s). You are free to use this Dissertation in any way that is permitted by the copyright and related rights legislation that applies to your use. For other uses you must obtain permission from the rights-holder(s) directly, unless additional rights are indicated by a Creative Commons license in the record and/ or on the work itself. This Dissertation has been accepted for inclusion in WVU Graduate Theses, Dissertations, and Problem Reports collection by an authorized administrator of The Research Repository @ WVU.

For more information, please contact researchrepository@mail.wvu.edu. 
THE ROLE OF RX IN EMBRYONIC RETINOGENESIS:

DETERMINING GENETIC INFLUENCES ON OPTIC VESICLE FORMATION

AND PHOTORECEPTOR CELL FATE

\author{
Helen M. Rodgers \\ Dissertation submitted to the \\ School of Medicine at West Virginia University \\ in partial fulfillment of the requirements for the degree of \\ Doctor of Philosophy \\ in \\ Neuroscience
}

\author{
Peter H. Mathers, Ph.D., Chair \\ Maxim Sokolov, Ph.D. \\ Visvanathan Ramamurthy, Ph.D. \\ Stanley Hileman, Ph.D. \\ J. Michael Ruppert, M.D., Ph.D.
}
Neuroscience Graduate Program
Morgantown, West Virginia
2017

Keywords: $R x$, eye, cone photoreceptors, 3D culture, optic vesicle organoids, development

Copyright 2017 Helen M. Rodgers 


\section{Abstract \\ THE ROLE OF RX IN EMBRYONIC RETINOGENESIS: DETERMINING GENETIC INFLUENCES ON OPTIC VESICLE FORMATION AND PHOTORECEPTOR CELL \\ FATE.}

\section{Helen M. Rodgers}

Eye development is a dynamic and complex process that is controlled by the interactions of transcription factors, signaling pathways, and growth factors. Disruption of the developmental process can result in ocular malformations or retinal diseases, which can cause blindness. Developing tools to study embryonic retinogenesis and understanding the molecular mechanisms involved are important for increasing our understanding of neural development, understanding ocular malformations such as anophthalmia, and may improve or lead to new treatments for eye diseases including blindness. This work aims to develop new tools for studying early eye development and explore genes associated with optic vesicle development and photoreceptor cell fate. In Study 1, we sought to identify and characterize markers of embryonic cone photoreceptors. We identified that two genes involved in phototransduction, phosducin and cone transducin $\gamma$, are expressed in developing cones. We characterized the temporal and spatial profile of both genes and their associated proteins over the developmental timeline of retinogenesis. Further, we determined their colocalization with known cone and photoreceptor markers and thus established them as useful markers for further studies of early cone histogenesis. In Study 2, we assessed the role of the homeobox gene, $R x$, in progenitor proliferation and cell fate determination in the mouse retina using a conditional knockout. Deletion of $R x$ in retinal progenitors led to a loss of retinal lamination, depletion of the retinal progenitors and in the mature retina showed changes in retinal cell types. Late-born cells (rods, bipolar cells, and Müller glia) were absent, likely due to the depleted progenitor pool. Cones (an early-born retinal cell type) were also absent; examination of cone histogenesis showed $R x$ is necessary for cone photoreceptor generation. Finally, in Study 3 we identified an effective gene knockdown method for 3D optic vesicle organoid culture that is useful for studying gene expression and early retinal development. Using this method, we assessed the roles of three candidate genes in optic vesicle development and identified one gene that warrants further investigation in vivo. Collectively these studies provide new tools for studying early embryogenesis and further our knowledge of the genetics underlying optic vesicle development and cone photoreceptor formation. 


\section{Dedication}

This dissertation is dedicated to my parents, William and Bernice Rodgers. Who I am today, and what I have accomplished are all due to having remarkable, loving and supportive parents. Your love, encouragement and prayers over the years made completing this dissertation possible. 


\section{Acknowledgements}

I would like to thank the many people who supported me on the long journey of graduate school.

First, I would like to express my sincere gratitude to my advisor Dr. Peter $\mathrm{H}$. Mathers for his support and guidance throughout my PhD. He was always available for my many questions and gave generously of his knowledge and expertise.

Besides my advisor, I would also like to thank my committee members, Dr. Sokolov, Dr. Ramamurthy, Dr. Hileman, and Dr. Ruppert, for their support and insightful comments.

I would like to thank current and past members of the Mathers lab with a special thanks to Dennis Cole, Dr. Zamora, and Dr. Szeszel-Fedorowicz for their technical expertise and assistance with my projects. I would like to thank my fellow graduate students whose help and support made the long road to completion more bearable.

Finally, I cannot end without thanking my family and my husband. I would like to thank my parents and my siblings for all of their love, support and encouragement over the course of this degree. A special thank you to my sister Karen, and niece Brianna for all of the love, and support; your phone calls and messages helped to keep me going even when things were difficult. 


\section{Table of Contents}

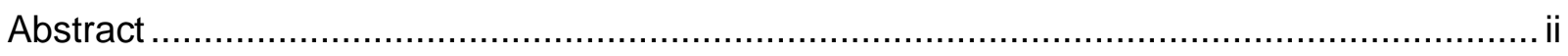

Dedication

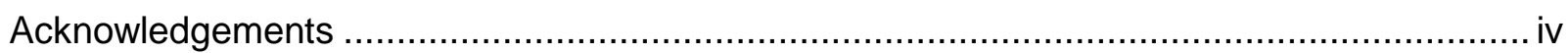

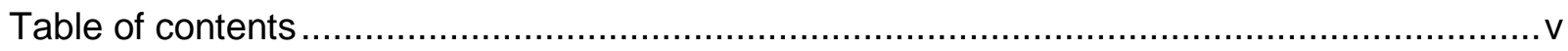

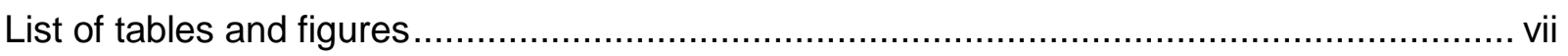

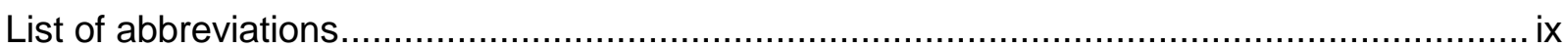

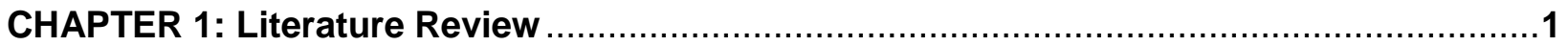

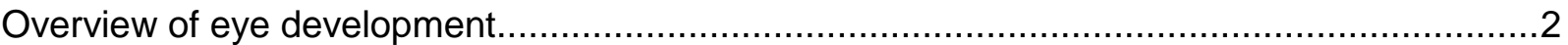

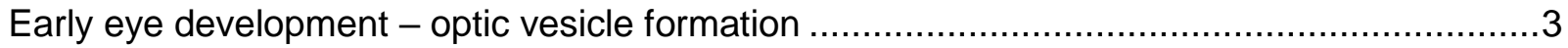

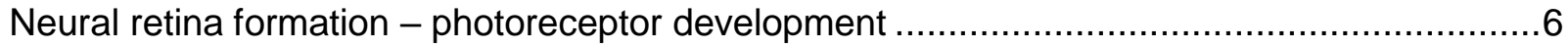

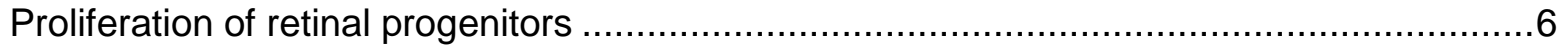

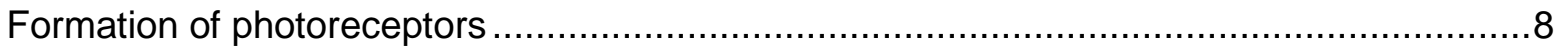

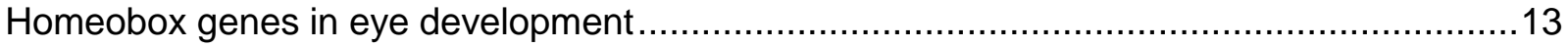

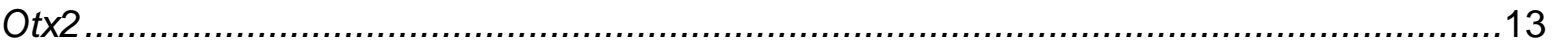

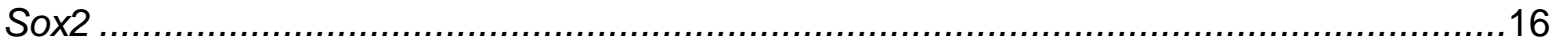

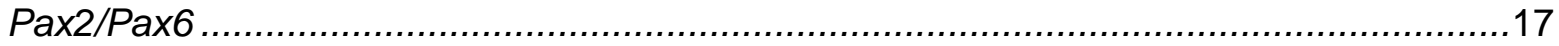

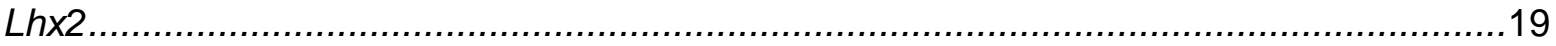

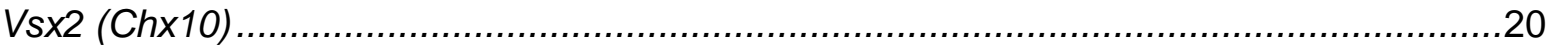

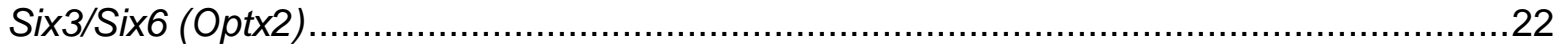

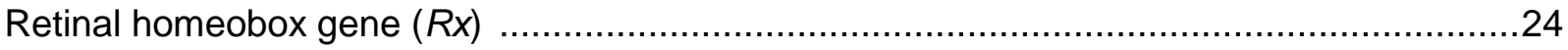

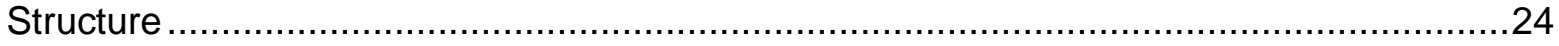

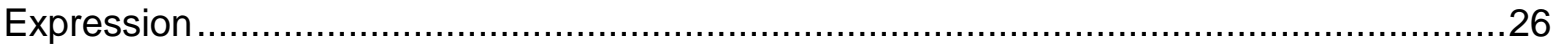

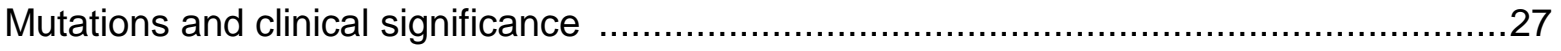

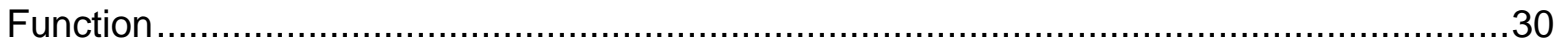

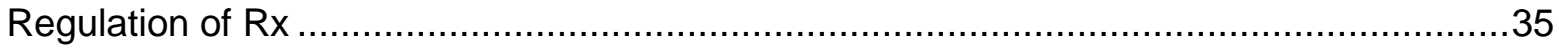

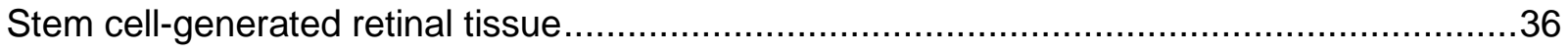

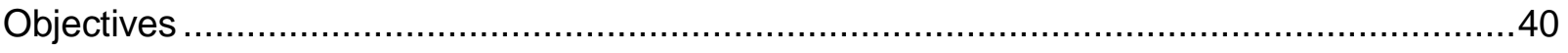

CHAPTER 2: Embryonic Markers of Cone Differentiation.........................................66

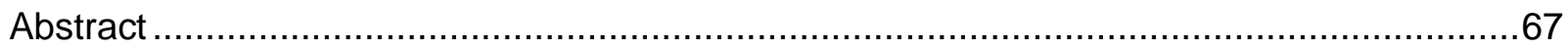

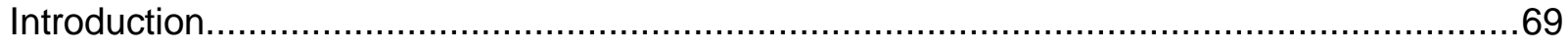

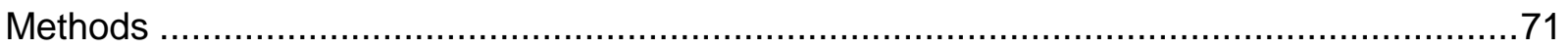




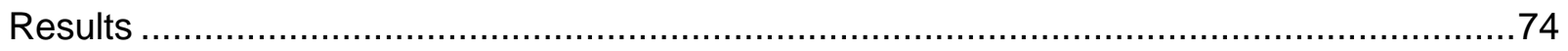

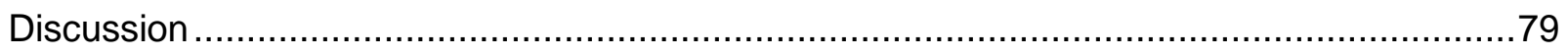

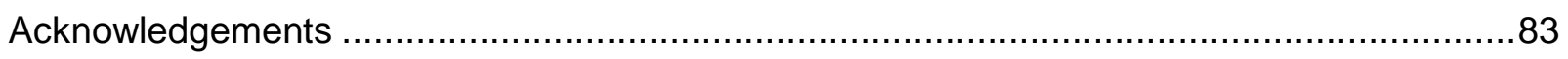

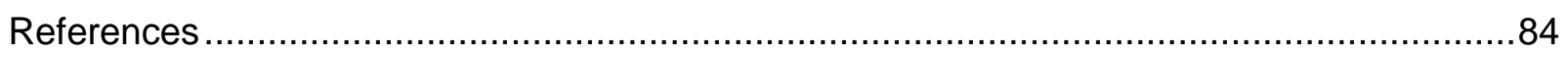

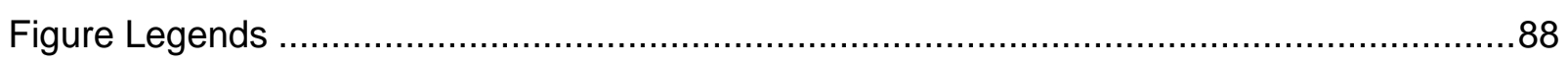

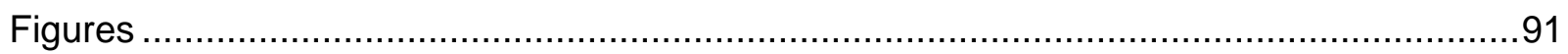

CHAPTER 3: The role of the $R x$ homeobox gene in progenitor proliferation and retinal cell fate specification.

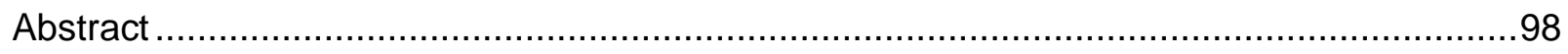

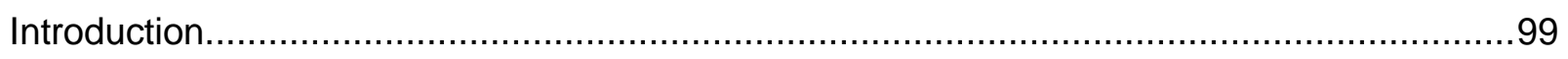

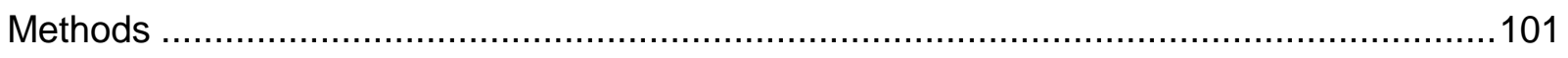

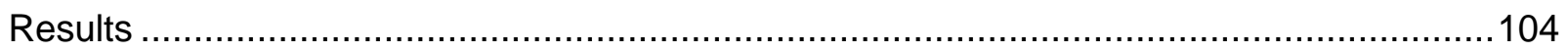

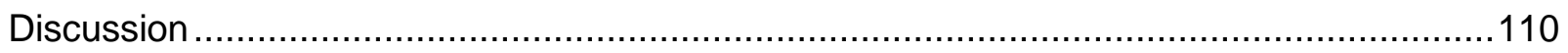

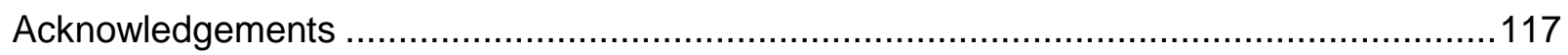

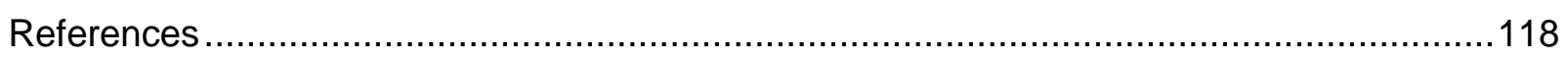

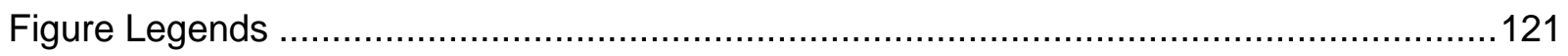

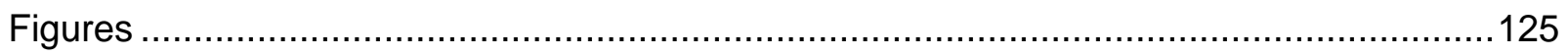

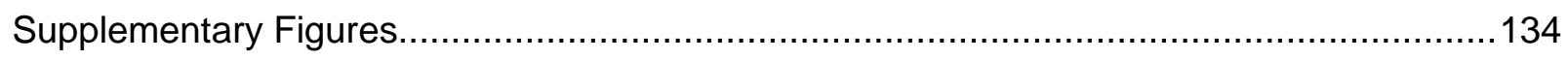

CHAPTER 4: Antisense-mediated gene knockdown in 3D organoid culture: a method for

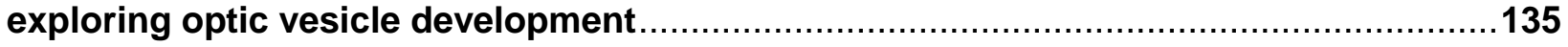

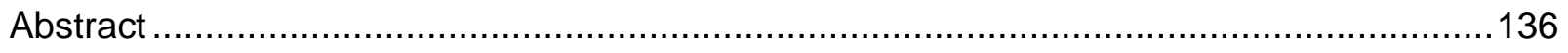

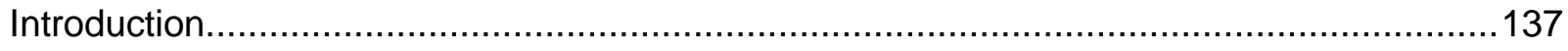

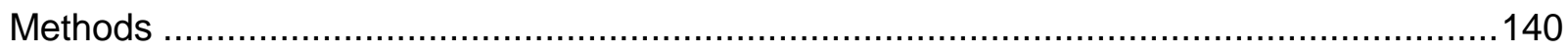

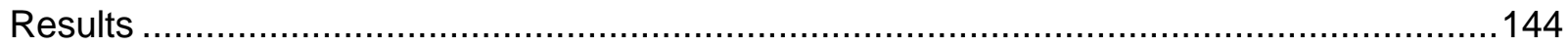

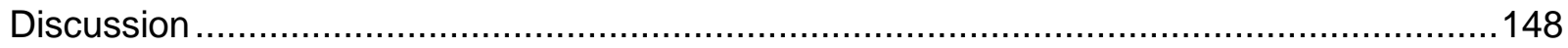

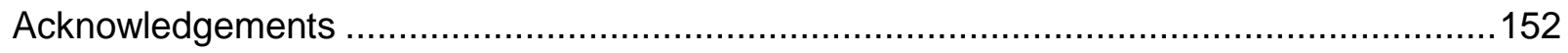

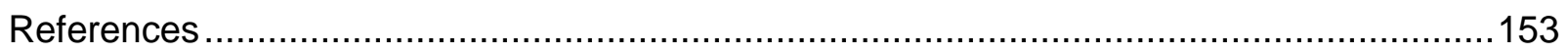

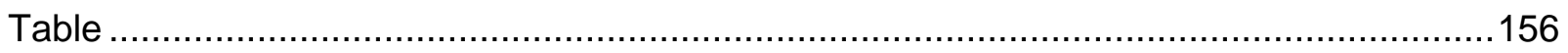

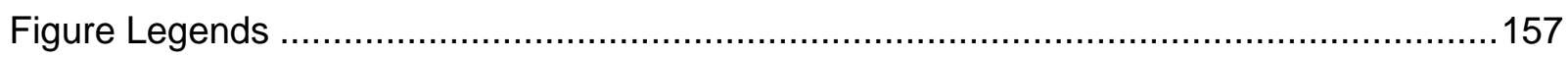

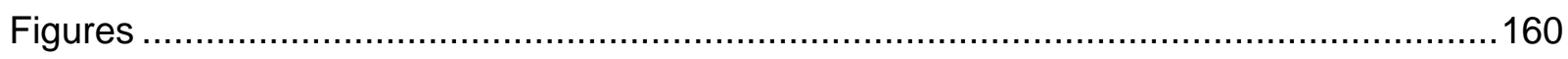

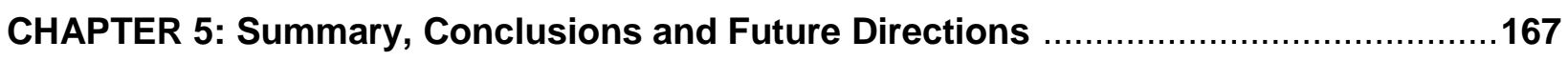

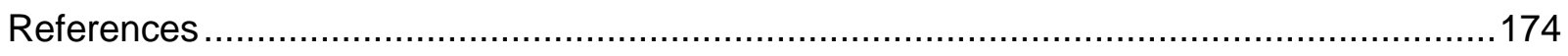

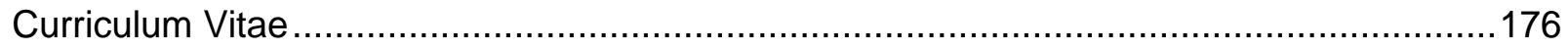




\section{List of Tables and Figures}

\section{CHAPTER 1: Literature review}

Figure 1. The main stages of vertebrate retinal development

Figure 2. Regulation of optic vesicle development

Figure 3. Retinal anatomy and the time course of retinal cell birth

Figure 4. Transcriptional regulation of photoreceptor development

Figure 5. 2D and 3D retinal differentiation protocols

\section{CHAPTER 2: Embryonic Markers of Cone Differentiation}

Figure 1. Developmental expression of phosducin protein in the embryonic and postnatal retina.

Figure 2. Comparison of PdcKO and control retinas.

Figure 3. Colocalization of phosducin with known photoreceptor markers in the embryonic retina.

Figure 4. Developmental expression of cone transducin $\gamma$ protein in the embryonic and postnatal retina.

Figure 5. Colocalization of phosducin and cone transducin $\gamma$ expression in the retina.

Figure 6. mRNA expression across developmental ages measured with qPCR.

\section{CHAPTER 3: The role of the $R x$ homeobox gene in progenitor proliferation and retinal cell fate specification.}

Figure 1. Deletion of $R x$ leads to a reduced Cre-lineage domain and a loss of lamination.

Figure 2. Levels of apoptosis are unaffected by deletion of $R x$.

Figure 3. $R x$ deletion reduces the retinal progenitor pool in an age-dependent manner.

Figure 4. BrdU- and PCNA-labeled progenitors are reduced in $R x$-deleted regions of the $R x$ CKO retina.

Figure 5. $R x$ deletion leads to changes in a subset of early-born cells found in the adult retina.

Figure 6. Early-born cone photoreceptors are lost in the $R x$-deleted P21 retina.

Figure 7. Absence of late-born cell types with the deletion of $R x$ in P21 retinal sections. 
Figure 8. Phosducin expression is reduced in embryonic and early postnatal $R x$ CKO retina.

Figure 9. Decreased Otx2 expression in embryonic $R x$ CKO retina.

\section{Supplemental Figures}

Supplemental Figure 1. Phosducin and cone transducin $\gamma$ labeling are reduced during retinogenesis in $R x$-deleted retina.

\section{Chapter 4: Antisense-mediated gene knockdown in 3D organoid culture: a method for exploring optic vesicle development}

Table 1. Sequences of vMOs

Figure 1. Formation of vesicles expressing Rx-GFP in 3D culture from mouse embryonic stem cells (mESCs).

Figure 2. Schematic of the methods and events in 3D stem cell culture that results in optic vesicle formation.

Figure 3. Accell siRNA treatment in 3D optic vesicle organoid culture.

Figure 4. Day 7 optic vesicle aggregates after the addition of a GFP vMO

Figure 5. Comparison of Day 7 Rx-GFP expression in optic vesicle organoids after addition of $5 \mu \mathrm{M}$ vMOs targeting either GFP or Rx on Day 4.

Figure 6. Imaging of Day 7 optic vesicle organoids after addition of $5 \mu \mathrm{M}$ vMOs on Day 4.

Figure 7. Day 7 optic vesicle organoids after Day 4 addition of $5 \mu \mathrm{M}$ vMOs targeting candidate genes for optic vesicle development. 


\section{List of Abbreviations}

\begin{tabular}{|c|c|}
\hline $2 \mathrm{D}$ & Two-dimensional \\
\hline 2-ME & 2-Mercaptoethanol \\
\hline 3D & Three-dimensional \\
\hline Alx1 & ALX Homeobox 1 \\
\hline aPKC & Atypical protein kinase $\mathrm{C}$ \\
\hline bHLH & Basic helix-loop-helix \\
\hline Blimp1 & PR domain zinc finger protein 1, also known as Prdm1 \\
\hline BMP & Bone morphogenetic protein \\
\hline BrdU & Bromodeoxyuridine \\
\hline Brn3b & Brain-Specific Homeobox/POU Domain Protein 3B \\
\hline cDNA & Complementary DNA \\
\hline cGMP & Cyclic guanosine monophosphate \\
\hline chokh & Zebrafish $R \times 3$ allele \\
\hline Chx10 & Visual system homeobox 2, also known as Vsx2 \\
\hline $\mathrm{CKO}$ & Conditional knockout \\
\hline CNS1 & Conserved non-coding sequence \\
\hline CRALBP & Cellular retinaldehyde binding protein \\
\hline cRax & Chicken retinal homeobox \\
\hline cRaxL & Chicken retinal homeobox-like \\
\hline CRISPR & Clustered regularly interspaced short palindromic repeats \\
\hline Crx & Cone-rod homeobox \\
\hline CVC & Chx10/Vsx-1 and ceh-10 domain \\
\hline Dkk1 & Dickkopf-1 \\
\hline DNA & Deoxyribonucleic acid \\
\hline$d r x$ & Drosophila retinal homeobox \\
\hline$E$ & Embryonic day \\
\hline Edn1 & Endothelin 1 \\
\hline EELPOT & embryonic enhancer locus for photoreceptor Otx2 transactivation \\
\hline EFTF & Eye field transcription factor \\
\hline EGFP & Enhanced green fluorescent protein \\
\hline ERG & Electroretinogram \\
\hline ESC & Embryonic stem cells \\
\hline
\end{tabular}




\begin{tabular}{|c|c|}
\hline ey1 & Mouse eyeless allele \\
\hline FBS & Fetal bovine serum \\
\hline FGF & Fibroblast growth factor \\
\hline FOXE4 & Forkhead box E4 \\
\hline GDF6 & Growth Differentiation Factor 6 \\
\hline GFP & Green fluorescent protein \\
\hline Gli1 & Glioma-Associated Oncogene Homolog 1 \\
\hline GMEM & Glasgow's MEM \\
\hline Gnat2 & Cone Transducin Alpha Subunit \\
\hline Gnbt2 & Cone Transducin Beta Subunit \\
\hline Gngt2 & Cone Transducin Gamma Subunit \\
\hline GPCR & G-protein receptor \\
\hline $\mathrm{hb}$ & Homeobox \\
\hline Hes1 & Hairy and enhancer of split-1 \\
\hline Hes4 & Hairy and enhancer of split-4 \\
\hline $\mathrm{Hh}$ & Hedgehog \\
\hline Hmgb2 & High Mobility Group Box 2 \\
\hline HPE & Holoprosencephaly \\
\hline Hprt & Hypoxanthine guanine phosphoribosyl transferase \\
\hline IGF & Insulin growth factor \\
\hline IPSC & Induced pluripotent stem cells \\
\hline IRBP & Interphotoreceptor retinoid binding protein \\
\hline Klf4 & Krueppel-like factor 4 \\
\hline KSR & KnockOut serum replacement \\
\hline L & Long wavelength \\
\hline LacZ & $\beta$-Galactosidase \\
\hline Ldb1 & LIM Domain Binding 1 \\
\hline Lhx2 & LIM homeobox 2 \\
\hline LIF & Leukemia inhibitory factor \\
\hline M & Medium wavelength \\
\hline MAC & Microphthalmia, anophthalmia and coloboma \\
\hline mESC & Mouse embryonic stem cells \\
\hline Mitf & Microphthalmia-associated transcription factor \\
\hline mRNA & Messenger RNA \\
\hline
\end{tabular}




\begin{tabular}{ll} 
Ndr2 & Nodal-related 2 \\
NeuroD & Neuronal Differentiation 1 \\
NF165 & Neurofilament 165 kD \\
Nlcam & Neurolin-like cell adhesion molecule \\
Nr2e3 & Nuclear Receptor Subfamily 2 Group E Member 3 \\
Nrl & Neural retina-specific leucine zipper \\
Oct4 & Octamer-binding transcription factor 4 \\
Optx2 & Sine Oculis Homeobox Homolog 6, also known as Six6 \\
or & Mouse ocular retardation allele \\
otd & Drosophila orthodenticle \\
Otx1 & Orthodenticle Homeobox 1 \\
Otx2 & Orthodenticle Homeobox 2 \\
P & Postnatal day \\
Pax2 & Paired box 2 \\
Pax6 & Paired box 6 \\
PBS & Phosphate-buffered saline \\
PCE-1 & Photoreceptor conserved element-1 \\
PCNA & Proliferating cell nuclear antigen \\
PCR & Polymerase chain reaction \\
Pdc & Phosducin \\
PdcKO & Phosducin knockout mouse \\
PI & Propidium iodide \\
prd & Paired-like \\
Prdm1 & PR domain zinc finger protein 1, also known as Blimp1 \\
Prox1 & Prospero homeobox protein 1 \\
qPCR & Quantitative reverse transcriptase PCR \\
QRX & Human Rx-like gene \\
Rax & Retinal homeobox also known as Rx \\
rd' & Retinal degeneration allele \\
RNA & Ribonucleic acid \\
Rora & RAR-related orphan receptor alpha \\
Rorß & RAR-related orphan receptor beta \\
RPE & Retinal pigmented epithelium \\
Rpl37 & Ribosomal Protein L37 \\
\hline &
\end{tabular}




$\begin{array}{ll}\text { Rx } & \text { Retinal homeobox } \\ \text { Rx CKO } & \text { Retinal homeobox conditional knockout } \\ \text { RxL } & \text { Retinal homeobox-like } \\ \text { Rxrg } & \text { Retinoid X receptor gamma } \\ \text { S } & \text { Short wavelength } \\ \text { SD } & \text { Standard deviation } \\ \text { Sey } & \text { Small eye allele } \\ \text { SFEBq } & \text { Serum-free floating culture of embryoid body-like aggregates with quick } \\ & \text { reaggregation } \\ \text { Shh } & \text { Sonic hedge hog } \\ \text { shRNA } & \text { short hairpin RNA } \\ \text { siRNA } & \text { small interfering RNA } \\ \text { Six3 } & \text { Sine Oculis Homeobox Homolog 3 } \\ \text { Six6 } & \text { Sine Oculis Homeobox Homolog 6, also known as Optx2 } \\ \text { Sox } & \text { sex determining region Y-box } \\ \text { Sox2 } & \text { sex determining region Y-box 2 } \\ \text { Sufu } & \text { Suppressor of fused } \\ \text { TBS } & \text { Triangle Biomedical Sciences } \\ \text { TGF } \beta & \text { Transforming growth factor-beta } \\ \text { TLE1 } & \text { Transducin Like Enhancer Of Split 1 } \\ \text { TII } & \text { Tailless Homolog } \\ \text { Trß2 } & \text { Thyroid hormone receptor beta } \\ \text { USA } & \text { United States of America } \\ \text { Vax } & \text { Ventral Anterior Homeobox } \\ \text { vMO } & \text { Vivo-morpholino } \\ \text { vol/vol } & \text { volume/volume } \\ \text { Vsx2 } & \text { Visual System Homeobox 2 also known as Chx10 } \\ \text { Xhmgb3 } & \text { Xenopus HMGB3 high mobility group box 3 } \\ \text { Xnr3 } & \text { Xenopus nodal-related 3 } \\ \text { Xrx } & \text { Xenopus Rx } \\ \text { Zrx } & \text { Zebrafish Rx } \\ & \end{array}$




\section{Chapter 1:}

\section{Literature Review}


Approximately 1.02 million Americans are blind and another 3.22 million have visual impairments and those numbers are expected to double in the next 40 years (Varma et al., 2016). Among the causes of blindness are retinal diseases and ocular malformations. Retinal diseases include age-related macular degeneration and inherited retinal dystrophies like retinitis pigmentosa. Ocular malformations include microphthalmia (small eyes) and anophthalmia (a complete absence of eyes). Ocular malformations are a less common cause of blindness with an incidence rate of one in 5300 in the USA (Parker et al., 2010). Studying the genetic and molecular mechanisms involved in eye development will provide valuable information that will aid our understanding of neural development, and provide knowledge that could enhance current therapies, while potentially being a step toward developing new strategies to treat retinal diseases including blindness.

Eye development is a dynamic and intricate process that is controlled by a highly organized sequence of interactions between signaling pathways, growth factors and transcription factors. Disruption of the developmental process can lead to ocular malformations and retinal diseases. This review chapter begins with a focus on eye development and its regulation by transcription factors. Next, the expression, function and clinical significance of one of the main transcription factors in eye development, Rx, will be discussed. Finally, stem cells and stem cell-derived retinal neurons will be examined, including the development of three-dimensional (3D) optic vesicles in culture and their potential for studying retinal development.

\section{Overview of eye development}

The eyes develop as an extension of the developing forebrain. Development begins early in embryogenesis and consists of several overlapping stages starting with the induction of neural tissue and the formation of the anterior neural plate. In the second stage the anterior neural plate is subdivided into fields, one of which is the eye field that subsequently splits from the developing forebrain. The third step is the generation and patterning of bilateral optic vesicles. 
Stage four includes the formation of the lens and formation and regionalization of the optic cup. The optic cup is a bilayered structure, the inner layer of the optic cup becomes neural retina and the outer layer becomes retinal pigmented epithelium (RPE). The final stage is the differentiation of retinal neurons and glia.

As the optic cups form, the first retinal neurons (retinal ganglion cells) are born from retinal progenitors, followed by the remaining differentiated retinal cell types in a characteristic sequence. The cells align in distinct layers, forming the outer nuclear layer, the inner nuclear layer and the retinal ganglion layer. Synapses form between the cellular layers in what are called the plexiform layers of the retina. Visual signaling starts in the retina at postnatal day (P)13-14 in mice (Hoffpauir et al., 2009). Figure 1 displays a schematic of the major events in eye development. A more detailed discussion of eye development follows with a specific focus on the formation of optic vesicles and development of photoreceptors during neurogenesis. The regulation of these two stages of development involves the interaction of many factors, but this discussion will primarily focus on transcriptional regulation.

\section{Early eye development - optic vesicle formation}

In mice, the first visible stage of eye development is the formation of bilateral optic vesicles beginning with the appearance of optic sulci or optic pits at embryonic day (E) 8 (Heavner and Pevny, 2012). Regulation of early eye development occurs through an interaction of extrinsic signaling factors and intrinsic transcription factors. Early in embryogenesis, neural induction of the dorsal ectoderm occurs with the inhibition of bone morphogenetic protein (BMP) signaling via antagonists such as, Noggin, Follistatin, Chordin, Cerberus, and Xnr3 (Weinstein and Hemmati-Brivanlou, 1999; Gestri, 2005) and suppression of BMP signaling by Wnt and fibroblast growth factor (FGF) signaling (Graw, 2010). The induction of neural tissue is followed by specification of the anterior neural plate. The formation of the anterior neural plate is accomplished via the inhibition of the Wnt and/or Nodal signaling pathways by either actions of 
Lefty, Cerberus or Dickkopf-1 (Dkk1) (Bouwmeester et al., 1996; Glinka et al., 1998; Branford and Yost, 2002). These pathways are responsible for organization of left-right axial structures in early embryonic development. A transcription factor, Six3, has also been proposed as playing a role in anterior neural plate specification through promotion of cell proliferation and inhibition of BMP (Graw, 2010).

The anterior neural plate is then subdivided into fields along the anterior-posterior axis, one of which is the eye field. Interactions of Cerberus, Dkk1, Chordin and Noggin, as well as components of the Wnt, Nodal, FGF and insulin-like growth factor (IGF) signaling pathways, work together to generate the appropriate regionalization of the fields of the anterior neural plate (McFarlane et al., 1998; Piccolo et al., 1999; Pera et al., 2001; Houart et al., 2002; Lagutin et al., 2003). Eye field formation requires a series of inductive events including the expression of a combination of transcription factors, known as eye field transcription factors (EFTFs). The expression of the EFTFs are induced by the actions of noggin and Otx2 (Zuber et al., 2003). The anterior neuroectoderm begins to express the transcription factors Otx2 and Sox2, which in combination prime the anterior neural plate for eye field specification and activate the transcription of a crucial EFTF, Rx (Danno et al., 2008). Rx is required for the proliferation of retinal progenitors and leads to an increase in transcription of other transcription factors including Pax6, Six3, Lhx2, and Six6 (also known as Optx2) (Bailey et al., 2004). This group of transcription factors, including $\mathrm{Rx}$, make up the EFTFs, which are expressed in slightly different but overlapping areas of the eye field (Zuber et al., 2003). Otx2 is repressed as the EFTFs are expressed (Zuber et al., 2003). Disruptions during early eye development can lead to ocular malformations such as anophthalmia (absence of eyes) or microphthalmia (small eyes). Mutations in Sox2, Otx2, and $R x$ are all associated with ocular malformations (GonzalezRodriguez et al., 2010; Williamson and FitzPatrick, 2014). Studies utilizing models of over- 
expression and deletion have shown that transcription factors, such as Otx2, Rx, Pax6, Six3 and Lhx2 all play an important role in early eye development (Andreazzoli, 2009).

After eye field specification, the neuroectoderm divides in two. Separation at the midline is controlled by a combination of the activation of sonic hedgehog (Shh) (Chiang et al., 1996) by Six3 expression (Geng et al., 2008; Jeong et al., 2008) and signaling factors such as Ndr2 (Rebagliati et al., 1998). Disruptions in Shh, Six3, or Ndr2 expression result in midline defects such as holoprosencephaly (HPE) that can include the formation of a single eye, cyclopia (Belloni et al., 1996; Roessler et al., 1996; Rebagliati et al., 1998; Muenke and Cohen, 2000; Geng et al., 2016). At approximately E8.5 in the mouse, the walls of the diencephalon form evaginations called optic vesicles. Studies suggest that $R x$, Pax6 and $t / l$ are involved in the evagination of the optic vesicles (Bailey et al., 2004; Chow \& Lang, 2001; Hollemann, Bellefroid, \& Pieler, 1998; Loosli et al., 2001; Loosli et al., 2003; Rembold, Loosli, Adams, \& Wittbrodt, 2006). The optic vesicles contain retinal stem cells that will eventually give rise to all the neuroectoderm-derived cells of the eye (Heavner and Pevny, 2012).

Prior to optic cup formation, the optic vesicle undergoes patterning along the dorsal-ventral axis and along the naso-temporal axis. This patterning results in the formation of regions that correspond to the presumptive neural retina (distal region), RPE (dorsal proximal region) and optic stalk (ventral proximal region). Regulation of optic vesicle patterning involves the expression of several transcription factors in specific regions that are important for the formation of a specific cell type. The presumptive neural retinal in the dorsal region expresses Vsx2 (previously called Chx10) and Pax6 (Adler \& Canto-Soler, 2007; Liu et al., 1994), the dorsal proximal region that will become RPE expresses the basic helix-loop-helix (bHLH) transcription factor Mitf, along with Otx2, and Pax6. Pax2 is expressed in the ventral proximal region of the optic vesicle, which is the presumptive optic stalk (Nornes et al., 1990; Hodgkinson et al., 1993). In addition, extrinsic signals including members of TGF $\beta$, FGF, and Wnt families and Shh are 
involved in optic vesicle patterning prior to it forming the optic cup (Heavner and Pevny, 2012). Once the optic vesicle is formed, it interacts with the overlying ectoderm and will invaginate to create a bilayered optic cup. Figure 2 is a diagram of the events surrounding optic vesicle development, including key transcription factors and signaling pathways that are involved.

\section{Neural Retina Formation - Photoreceptor Development}

The stepwise process of retinal neurogenesis begins early with FGF and Shh signaling along with the expression of transcription factors, Pax6, Pax2, Vax, Rx, Mitf, and Otx2 directing the regionalization of the optic cup (Yang, 2004). The optic cup forms a bilayered structure, where the inner layer will become the retina and the outer layer will become RPE. As the optic cup is forming, the generation of the differentiated retinal cell types begins. The retina contains seven principal cell types, six different neuronal cells (including retinal ganglion cells, amacrine cells, bipolar cells, horizontal cells, cone photoreceptors, and rod photoreceptors) and one glial cell type, Müller glia. All of the different retinal cell types are formed from a common multipotent retinal progenitor (Turner and Cepko, 1987; Holt et al., 1988; Turner et al., 1990).

\section{Proliferation of Retinal Progenitors}

Retinal progenitors are highly proliferative, multipotent cells produced in the neuroblastic layer of the optic cup. Proliferation and cell cycle exit of retinal progenitors is tightly regulated during development to ensure that there is a sufficient pool of progenitors to form all retinal cell types in the appropriate ratios (Dyer and Cepko, 2001) and to maintain proper eye size. Early in development, the retinal progenitors divide symmetrically to increase the number of progenitor cells. Proliferation is regulated by several transcription factors including Hes1, Pax6, Vsx2, Rx, Lhx2, Prox1 and Sox2 (Dyer et al., 2003; Ohsawa and Kageyama, 2008; Sigulinsky et al., 2008; Agathocleous and Harris, 2009; Wall et al., 2009), as well as by neurotransmitters, such as dopamine (Martins and Pearson, 2008) and extrinsic signals, such as Hedgehog signaling 
(Cwinn et al., 2011). Disruption in the regulation of proliferation can result in deficits, which can lead to loss of retinal neurons, alterations in eye size or a complete absence of eyes.

Once a sufficient pool of progenitors forms, the retinal progenitors undergo asymmetric divisions, producing one daughter cell that will differentiate and one daughter cell that will continue to divide as a progenitor. When neurogenesis is near completion, both daughter cells of the dividing retinal progenitor will terminally differentiate and are likely to form Müller glia, depleting the entire retinal progenitor pool. In mouse, the final mitotic divisions occur around P10. The retinal progenitors, although starting off as multipotent, go through a series of stages whereby the range of cell types produced is restricted (Marquardt \& Gruss, 2002). This restriction results in a heterogeneous pool of progenitors with overlapping subpopulations that have a semi-restricted cell fate (Trimarchi et al., 2008), and these progenitors are often called committed progenitors (Wong and Rapaport, 2009). The progression of cell fate determination from multipotent progenitor to a differentiated neuron is shown in Figure $1 \mathrm{C}$.

The birth of neurons from progenitors follows a conserved temporal pattern in vertebrates with two distinct but overlapping phases (Young, 1985; Rapaport et al., 2004). The retinal cells born during the early phase include retinal ganglion cells, amacrine cells, cone photoreceptors and horizontal cells. The late-born retinal cell types include rod photoreceptors, bipolar cells and Müller glia. In the mouse, the early phase of cell birth starts with retinal ganglion cell formation at E10.5, followed by amacrine cells, cone photoreceptors and horizontal cells that start at approximately E11.5. The majority of early born cells are generated before birth, whereas the majority of late born cells are generated postnatally, however the formation of the late-born cells starts during embryogenesis. The late-born cells start with rod photoreceptor generation at E13.5, followed by bipolar cell birth that starts at E15 and finally Müller glia, which are formed starting at approximately E16.5 (See Figure 3C for a schematic showing the time period for the generation of each cell type). 
In addition to the characteristic temporal pattern of retinal cell development, there is also a spatial pattern followed during retinogenesis. The development of the central and peripheral retina shows a difference in timing between these regions (See Figure 1C). The differentiation of retinal neurons occurs first in the central retina and spreads to the periphery (Young, 1985).

Regulation of retinal neurogenesis is controlled by both extrinsic factors (morphogens and growth factors) and intrinsic factors (transcription factors). Transcriptional regulation of the differentiation of retinal neurons generally involves a combination of two main types of transcription factors, homeobox (hb) and basic helix-loop-helix (bHLH), which can act as activators or repressors for certain cell types. Specification of cell fate for a specific retinal cell type results from the combination of actions of activators and repressors. Activators direct a cell toward one fate while the repressors prevent the cell from adopting a different fate. The specification of each retinal cell type requires a unique group of repressors and activators to guide the cell to the appropriate cell fate. Alterations in transcription factors during retinogenesis can lead to changes in cell fate, such that a cell that would become one cell type switches and becomes another. For example, deletion of Pax6 leads to the development of amacrine cells at the expense of all others (Marquardt et al., 2001). A discussion of the transcriptional regulation of each cell type formed during retina development is beyond the scope of this introduction; therefore, the discussion will be limited to the formation of photoreceptors.

\section{Formation of Photoreceptors}

Photoreceptors are the highly specialized cells that form the outer nuclear layer of the retina and are responsible for phototransduction. There are two types of photoreceptors, rods and cones. Each photoreceptor type is responsible for processing different types of light. Rods are highly sensitive, and mediate vision in dimly lit conditions via the photopigment, rhodopsin. Cones mediate vision in brightly lit conditions. There are different subtypes of cones. In mice, the two primary subtypes are S-cones and M-cones, whereas humans contain a third cone type, L- 
cones. Each cone subtype is maximally responsive to a different wavelength of light thus allowing color vision. The photopigments in cones are the opsins. In mice, M-cones primarily express M-opsin (Opn1mw), which has a peak sensitivity to medium wavelength or the green region of the light spectrum. S-cones predominantly express S-opsin (Opn1sw), which has a peak sensitivity to short wavelength or blue region of the light spectrum. Opsin expression in mice occurs in opposing gradients, such that most cones expression both S- and M-opsin but in differing levels (Szél et al., 1996; Applebury et al., 2000). M-opsin is expressed at highest concentrations dorsally and S-opsin ventrally (Szél et al., 1996; Applebury et al., 2000). In humans, cones express one opsin (either L, M or S) per cone subtype.

Photoreceptors display distinct morphology containing 1) an outer segment that is filled with photopigments (opsins) and interacts with the RPE; 2) an inner segment, which is connected to the outer segment via a narrow connecting cilium; 3) a nucleus; and 4) a synaptic terminal. See Figure 3B for a diagram of photoreceptor morphology. Disruption of the factors that regulate photoreceptor development can affect formation, survival and function of photoreceptors, which can lead to vision loss.

The formation of a differentiated and fully functioning photoreceptor is a stepwise process that begins with the proliferation of the multipotent progenitor cells. Next, is the restriction of the competency of the retinal progenitor cells, followed by the cell fate specification and commitment to becoming a photoreceptor. Next, the cell will express photopigment-specific genes, and finally there is a period of synapse formation and the outer segment formation. This process is regulated by the combination of many transcription factors. For an overview of the process and the transcription factors involved, see Figure 4.

One of the earliest identified transcription factors involved in photoreceptor formation is Otx2 (Nishida et al., 2003). Conditional deletion of Otx2 in mice results in a loss of photoreceptors 
(rods and cones), and bipolar cells (Nishida et al., 2003; Koike et al., 2007). Activation of Otx2 in progenitors leads to the activation of other transcription factors involved in photoreceptor cell fate determination. Within the Otx2-positive population of progenitors, the expression of Blimp1 (also known as Prdm1) helps to determine whether the cells will become photoreceptors or bipolar cells. The deletion of Blimp1 in a conditional knockout (CKO) model leads to a decrease in photoreceptor numbers and an increase in bipolar cells (Brzezinski et al., 2010; Katoh et al., 2010). Blimp1 promotes photoreceptor cell fate through the repression of Vsx2, which is required for bipolar cell formation (Brzezinski et al., 2010; Katoh et al., 2010).

Downstream of Otx2 is the transcription factor Crx (Cone-rod homeobox) (Nishida et al., 2003). Crx is expressed in developing and mature photoreceptors in mice starting at E12.5 (Furukawa, Morrow, \& Cepko, 1997). Mice with a Crx deletion still develop photoreceptors, but they fail to express photoreceptor-specific genes, such as the opsins, and they fail to form outer segments (Furukawa, Cepko, Morrow, Li, \& Davis, 1999). Eventually, Crx-deficient mice suffer from retinal degeneration (Furukawa et al., 1999). CRX mutations in humans are associated with cone-rod dystrophy, retinitis pigmentosa and Leber's congential amaurosis (Freund et al., 1997; Sohocki et al., 1998). At later stages of photoreceptor development, Crx acts in concert with Rx to transactivate rhodopsin and opsin promoters and thus promote the expression of photoreceptorspecific genes (Irie et al., 2015). This result suggests that Crx is important in photoreceptor development, playing roles in outer segment formation, photoreceptor gene expression and photoreceptor survival, but it alone does not specify photoreceptor cell fate.

The determination of rod photoreceptor fate is largely mediated through the expression of the transcription factor, $\mathrm{Nrl}$ (Neural retina leucine zipper) (Mears et al., 2001). Nrl is preferentially expressed in rod photoreceptors (Swaroop et al., 1992) and when deleted in mice, results in a loss of rods that instead have adopted a S-cone-like photoreceptor fate and display abnormal outer segments (Mears et al., 2001). Nrl transactivates several genes involved in rod 
development including Nr2e3 (Oh et al., 2008) and Rorß (Fu et al., 2014). Ectopic expression of $\mathrm{Nrl}$ in photoreceptor precursors leads to the induction of rod-like characteristics and suppresses cone-specific gene expression (Oh et al., 2007). In humans, NRL mutation is associated with retinitis pigmentosa (Bessant et al., 1999; Martinez-Gimeno et al., 2001). Together these studies provide evidence that $\mathrm{Nrl}$ is critical in specifying rod photoreceptor fate.

Another transcription factor involved in the development of photoreceptors is Ror $\beta$ (retinoidrelated orphan receptor beta), an orphan nuclear receptor that is expressed in the developing retina with high expression in the presumptive photoreceptor layer (Schaeren-Wiemers et al., 1997; Srinivas et al., 2006). Ror $\beta$-null mice, similar to $\mathrm{Nr}$-null mice, lack rods and have excess S-cone-like photoreceptors, which fail to form outer segments and do not express S-opsin (Srinivas et al., 2006; Jia et al., 2009). Nrl and $\mathrm{Nr2e3}$ are down-regulated in Ror $\beta$-null mice suggesting that Ror $\beta$ acts upstream of $\mathrm{Nrl}$ (Jia et al., 2009). There is also feedback interaction whereby $\mathrm{Nrl}$ can activate Ror $\beta$ and thus reinforce the commitment to rod fate (Fu et al., 2014).

Another important transcription factor in rod cell fate determination is $\mathrm{Nr2e} 3$, an orphan nuclear receptor that is activated by $\mathrm{Nrl}$ (Oh et al., 2008). Nr2e3 mutants display an up-regulation of cone-specific genes and a down-regulation of rod-specific genes (Peng et al., 2005). Nr2e3 acts in concert with Crx to specify rod fate through its repression of cone-specific genes, and it also has the ability to activate certain rod-specific genes, such as rhodopsin (Chen, Rattner, \& Nathans, 2005; Cheng et al., 2004, 2006; Peng et al., 2005).

Whereas the transcriptional network responsible for rod photoreceptor cell fate determination and development is fairly well studied, much less is known about cone photoreceptor specification, and currently there are very few cone-specific markers that have been identified and characterized in embryonic retinogenesis. 
Based off of the evidence from current studies, a model of photoreceptor development has been proposed whereby photoreceptors originate from a common photoreceptor precursor that has been specified by Otx2, Crx and Ror $\beta$ and, without additional regulatory signals (such as Nrl or $\operatorname{Tr} \beta 2)$, will follow a default pathway and develop as an S-cone. This hypothesized model is called 'transcriptional dominance' (Swaroop, Kim, \& Forrest, 2010).

Several transcription factors have been identified that act on cone photoreceptors to activate opsin expression. Thyroid hormone receptor $\beta 2(\operatorname{Tr} \beta 2)$ is expressed transiently in developing cones during embryonic cone histogenesis (Applebury et al., 2007; Ng et al., 2009). NeuroD1 regulates $\operatorname{Tr} \beta 2$ in developing cones (Liu et al., 2008). Deletion of $\operatorname{Tr} \beta 2$ causes a loss of Mcones with an increase in S-cones, and it disrupts the characteristic gradient of opsin expression in the mouse retina ( $\mathrm{Ng}$ et al., 2001). This phenotype indicates that the green cone subtype (M-opsin) requires $\operatorname{Tr} \beta 2$ activity. Since cones are still born but the green subtype is lost in the $\operatorname{Tr} \beta 2$ mutant, this result suggests that $\operatorname{Tr} \beta 2$ is not required for the initiation of cone formation but is necessary for cone subtype specification.

Other transcription factors work in concert with $C r x$ to activate opsin expression. Ror $\beta$, a transcription factor that is important in early rod formation also acts in cooperation with Crx to activate S-opsin expression in cone photoreceptors (Srinivas et al., 2006). Another nuclear receptor, Rora, also works synergistically with Crx to activate S-opsin and M-opsin expression in postnatal cones (Fujieda et al., 2009).

Another transcription factor, $\mathrm{Rxr} \gamma$, is expressed in developing cones and retinal ganglion cells (Mori et al., 2001). Deletion of Rxry does not affect the initiation of cone development, but all cones express S-opsin, while M-opsin expression is unaffected (Roberts et al., 2005). This phenotype suggests that Rxry is not necessary for M-opsin regulation but instead functions to 
suppress S-opsin in the dorsal portion of the retina and therefore helps to form the opsin gradient found in the mouse retina.

\section{Homeobox Genes in Eye Development}

Each step in eye development is regulated by the collaboration of transcription factors, growth factors and signaling pathways. Several of the transcription factors involved in eye development have been identified through their expression patterns, and their functions revealed by mutations, gene knockouts, and overexpression studies. These transcription factors can be classified into three gene families, homeobox, basic helix-loop-helix, and forkhead box. Homeobox genes encode transcription factors that contain a specific DNA sequence of 60 amino acids known as the homeodomain. The DNA binding homeodomain canonically binds to core TAAT/ATTA motifs (Gehring et al., 1994). In addition to the homeodomain, there are unique flanking domains which impart specificity (Gehring et al., 1994). Homeobox genes can be classified based on the presence of these additional domains, for example those containing paired or LIM domains. Homeobox genes are known to play a critical role in numerous aspects of development including eye formation. Homeobox genes are involved with the specification of the eye field, progenitor proliferation, cell fate determination, and retinal neuron differentiation (Zagozewski, Zhang, Pinto, Wigle, \& Eisenstat, 2014). Many of these genes play multiple roles throughout eye development, and mutations affecting these genes can lead to a number of ocular defects. The following are some of the main homeobox genes that play key roles in regulating eye development.

\section{$\underline{\mathrm{Otx} 2}$}

One of the earliest transcription factors expressed in eye development, Otx2 (Orthodenticle homeobox 2), belongs to the orthodenticle-related family of transcription factors. The orthodenticle-related family of genes includes the Drosophila orthodenticle (otd) and the vertebrate Otx1 and Otx2 genes. The orthodenticle-related family genes encode bicoid-like, 
homeodomain-containing transcription factors that play important roles in development. Otx2 is expressed very early in mouse development, as in situ hybridization with an Otx2 probe shows wide spread expression at E5.5 in the embryonic ectoderm (Simeone et al., 1993). As development proceeds, this expression become restricted to anterior regions that correspond to forebrain and midbrain areas, including the eye field (Simeone et al., 1993; Simeone, Acampora, Gulisano, Stornaiuolo, \& Boncinelli, 1992). As the optic vesicle is formed, Otx2 is expressed throughout; however, later in development expression become restricted to the dorsal portion of the optic vesicle (presumptive RPE) (Bovolenta et al., 1997). Around the beginning of neural retinogenesis, Otx2 is expressed strongly in the RPE of the optic cup and weakly in the neural retina (Nishida et al., 2003). By E12.5, the intensity of Otx2 expression has increased in the neural retina and continues to robustly label the RPE (Nishida et al., 2003). Otx2 expression at E17.5 is concentrated in the outer aspect of the neuroblastic layer, which is the location of the photoreceptors in mature retinas (Nishida et al., 2003). In addition to developing photoreceptors, transient expression of Otx2 occurs in ganglion, amacrine, and horizontal cells in mouse embryos (Baas et al., 2000), in contrast to embryonic otx2 expression in the chick, which transiently labels differentiating neuroblasts of all retinal cell types (Bovolenta et al., 1997). Postnatally, as retinogenesis is nearing completion, Otx2 expression decreases in the RPE and is restricted to the bipolar cells within the inner nuclear layer by P6 (Baas et al., 2000; Nishida et al., 2003).

Corresponding to its very early expression pattern in the developing embryo, Otx2 plays an important role in brain development, Otx2-null mice die early in embryogenesis, and they lack presumptive forebrain and midbrain structures (Ang et al., 1996; Matsuo, Kuratani, Kimura, Takeda, \& Aizawa, 1995). Due to a loss of the presumptive forebrain region from which the eye develops in Otx2-null mice, functions of Otx2 in eye development have been gleaned primarily from clinical studies, other vertebrate models such as Xenopus and conditional knockout mice. 
Otx2 is critical very early in eye development. Heterozygous mutations of OTX2 in humans are associated with severe ocular malformations, including anophthalmia (Ragge et al., 2005; Wyatt et al., 2008). The splitting of the eye field in the anterior neural plate leads to the formation of the optic vesicles. Eye field formation requires a series of inductive events, including the expression of a combination of transcription factors, EFTFs. The expression of the EFTFs are induced by the actions of noggin and Otx2 (Zuber et al., 2003). Otx2 is repressed as the EFTFs are expressed (Zuber et al., 2003). Once the eye field is formed, Otx2 in combination with Sox2 interacts to regulate Rx expression in the optic vesicle (Danno et al., 2008). Mutations in Otx2, Sox2 and $R x$ are all associated with ocular malformations in humans (Gonzalez-Rodriguez et al., 2010).

A second function for Otx2 in eye development is its role in retinal neuron cell fate decisions. Conditional deletion of Otx2 in the developing retina results in many changes, including microphthalmia and changes in retinal cell fate. Developing photoreceptors in the Otx2 CKO retina instead become amacrine-like cells (Nishida et al., 2003). Expression of the cone-rod homeobox ( $\mathrm{Crx}$ ) gene is absent in the Otx2 CKO, suggesting that Otx2 is controlling photoreceptor cell fate by being a direct upstream regulator of $\operatorname{Crx}$ (Nishida et al., 2003). Otx2 is expressed in the final cell cycle of photoreceptor precursors (Muranishi et al., 2011). The regulatory locus directing Otx2 expression in photoreceptor precursors has been identified (called embryonic enhancer locus for photoreceptor Otx2 transactivation; EELPOT) (Muranishi et al., 2011). Otx2 retinal expression was found to be dramatically reduced in $R x$ CKO mice, and in retinal progenitors, $R x$ interacts with the EELPOT enhancer to transactivate Otx2 during the final cell cycle (Muranishi et al., 2011). Otx2 is expressed in the progenitors of both photoreceptors and bipolar cells, with transient expression of Blimp1 in a subset of precursors directing their fate towards photoreceptors and preventing them from becoming bipolar cells (Brzezinski et al., 2010). 
$\underline{\text { Sox2 }}$

Another transcription factor, Sox2 belongs to the Sox (sex determining region $Y$-box) gene family, which includes approximately 20 genes. The Sox family is grouped according to their amino acid identity. Sox2 is in the B1 group, which contains a high-mobility-group domain and a C-terminal transactivation domain (Hever et al., 2006). Sox2 is widely expressed very early in embryonic development. Homozygous germline deletion of Sox2 shows normal development to the blastocyst stage but is embryonic lethal at the peri-implantation stage (Avilion et al., 2003). Sox2 expression in eye development appears at the earliest stages. Sox2 is expressed in the anterior neural plate and as development proceeds, in the optic cup it eventually becomes restricted to the neuroblastic layer (Uwanogho et al., 1995; Uchikawa et al., 1999; Inoue et al., 2007). Retinal progenitor cells in the neuroblastic layer express Sox2 until they exit the cell cycle to become differentiated neurons (Taranova et al., 2006). Sox2 expression is also found in Müller glia and a subset of amacrine cells within the mature retina (Le et al., 2002; Lin et al., 2009).

The functions of Sox2 are well studied and include stem cell pluripotency, progenitor maintenance, cell fate determination and cancer (Feng and Wen, 2015). Sox2 is critical for maintaining the pluripotency of embryonic stem cells (Masui et al., 2007) and is often used as a marker for neural stem cells and progenitors. The role of Sox 2 in stem cell maintenance is supported by its use in reprogramming differentiated cells in the generation of induced pluripotent stem cells (Takahashi and Yamanaka, 2006). Sox2 is also important for the induction of neural fate. In embryonic stem cells, Sox2 can promote a neuroectodermal fate (Foshay and Gallicano, 2008). Sox2 induces neural fate through the repression of regulators of mesodermal fates, such as Brachyury (Zhao, Nichols, Smith, \& Li, 2004). Deletion of Sox2 in retinal progenitors of the optic cup results in a cell fate switch from neuronal cell types to non-neural, ciliary body epithelium fate (Matsushima et al., 2011). Taranova et al. (2006) showed that Sox2 
controls retinal progenitor cell proliferation through the activation of Notch1. An additional role for Sox2 was identified in its ability to transactivate $R x$ in combination with Otx2 during eye field specification (Danno et al., 2008). Sox2 also plays a role in lens formation and is expressed in the ventral surface ectoderm prior to lens placode formation (Chow and Lang, 2001).

Dominant mutations in Sox2 are associated with severe ocular defects, such as anophthalmia and microphthalmia (Hever et al., 2006). Sox2 mutations are one of the main genetic causes of these ocular defects. The eye phenotype associated with Sox2 mutations is variable, ranging from bilateral anophthalmia to bilateral microphthalmia (Hever et al., 2006).

\section{$\underline{\text { Pax2/Pax6 }}$}

Several homeobox genes have been identified that contain a paired domain. These genes belong to the paired box (Pax) gene family that encodes transcription factors important in development. Two of these genes, Pax2 and Pax6, have established roles in eye development. Pax6 protein contains two DNA binding regions, the paired domain and a homeodomain, whereas Pax2 contains only a paired domain. While both Pax2 and Pax6 are expressed in the developing eye, they have different expression patterns. Pax6 is expressed early, starting at the end of gastrulation in the anterior neural plate (Kenyon et al., 2001). As development continues, Pax6 expression becomes restricted to the dorsodistal optic vesicle and presumptive lens ectoderm (Grindley et al., 1995). As the optic cup forms, Pax6 is expressed throughout this structure; however, in the differentiated retina, Pax6 expression is limited to ganglion and amacrine cells (Belecky-Adams et al., 1997). In addition to its expression in the developing eye, Pax6 is also expressed in the other developing tissues, including the brain (Grindley et al., 1997), lacrimal gland (Makarenkova et al., 2000), pancreas (St-Onge et al., 1997) and nasal epithelium (Hogan et al., 1986). Pax2 expression starts later at E9 in the optic vesicle (Nornes et al., 1990). During the formation of the optic cup, Pax2 is expressed in the ventral portion and in the optic stalk, and as development proceeds, expression is restricted to the optic disc and 
along the optic nerve (Nornes et al., 1990). At E18, in addition to optic nerve expression, a thin layer of cells on the inner border of the neuroblastic layer also expresses Pax2 (Nornes et al., 1990).

Pax6 has numerous important functions in eye development that are highly conserved between Drosophila and vertebrates (Quiring et al., 1994). Because of this, Pax6 was once proposed to be the master control gene of eye development (Gehring, 1996). Mutations in Pax6 lead to ocular defects. The Small eye (Sey) phenotype occurs in mice and rats that are heterozygous for a semi-dominant mutation of Pax6 (Hill et al., 1991; Hogan et al., 1986; Matsuo et al., 1993), which is characterized by microphthalmia, iris hypoplasia, and cataractogenesis. Similar mutations in humans are associated with aniridia, an absence of the iris (Ton et al., 1991; Glaser et al., 1992; Lee and Colby, 2013). Additionally, microphthalmia/anophthalmia is associated with mutations in PAX6 (Deml et al., 2016). Mice that are homozygous for the Sey mutation have anophthalmia, lack nasal cavities and die around birth (Hogan et al., 1986; Grindley et al., 1995). In Sey/Sey mutants, the optic vesicle forms but is abnormally broad and fails to constrict proximally (Grindley et al., 1995). The optic vesicle contacts the overlying ectoderm, but the lens placode fails to thicken in these mutants (Grindley et al., 1995). An optic cup-like structure eventually forms; however, it lacks the characteristic differentiated layers that correspond to the presumptive neural retina and RPE (Grindley et al., 1995). Studies have shown that Pax6 gene dosage is important for normal eye formation. Transgenic mice with additional copies of Pax6 display eye defects, but the introduction of a single copy of Pax6 can rescue the Sey mutant phenotype in mice with a heterozygous Pax6 mutation (Schedl et al., 1996). A role for Pax6 in retinogenesis was discovered in a conditional deletion model of Pax6. In this model, Pax6 was inactivated in the distal retina using cre-lox recombination. The deletion restricted the potential of retinal progenitors, leading to an overexpression of non-glycinergic amacrine cells at the expense of other retinal cell types (Marquardt et al., 2001). More recently, 
Pax6 was identified as being downstream of suppressor of fused (Sufu), a regulator of hedgehog signaling (Cwinn et al., 2011). Conditional deletion of Sufu leads to a decrease in Pax6 expression and a loss of multipotency in retinal progenitors (Cwinn et al., 2011). These studies indicate that Pax6 is important in maintaining the multipotency of retinal progenitors during retinal development. Pax6 has another important role in eye development; along with Pax2, it is important for patterning of the optic vesicle for optic cup formation. The boundary between the presumptive neural retina and optic stalk forms through the reciprocal actions of Pax6 and Pax2 (Schwarz et al., 2000). Without Pax2, Pax6 expression expands ventrally into the optic stalk, and the tissue develops into neural retina. In Pax6 mutants, Pax2 expression expands dorsally (Schwarz et al., 2000). Pax2 and Pax6 proteins can reciprocally bind to each other's promoter elements and inhibit the other's activity (Schwarz et al., 2000).

\section{$\underline{\operatorname{Lhx}}$}

Lhx2 (LIM homeobox protein 2) encodes a homeodomain transcription factor that is important in eye development. Lhx2 is a member of the LIM-homeodomain subfamily, which in addition to the homeodomain contains two zinc finger-like LIM domains that are involved in protein-protein interactions (Porter et al., 1997). Expression of Lhx2 starts early, appearing in the presumptive eye field of the anterior neural plate (Tétreault et al., 2009). Lhx2 belongs to the group of transcription factors called EFTFs and along with $\mathrm{Rx}$ is one of the earliest expressed transcription factors in the eye field (Zuber et al., 2003; Tétreault et al., 2009). Lhx2 is observed in the optic vesicle by E8.5 in mouse (Porter et al., 1997), and its expression continues as the optic cup is formed where it is localized to the optic stalk and retinal progenitors (Gordon et al., 2013). As the retina matures, Lhx2 expression is limited to the inner nuclear layer and is detected in a subset of amacrine cells and in Müller glia (de Melo et al., 2012; Gordon et al., 2013). 
Lhx2 is important in many developmental processes and can function as a transcriptional activator or repressor (Zagozewski, Zhang, \& Eisenstat, 2014). In mice, homozygous deletion of $L h \times 2$ is lethal late in embryogenesis and results in anophthalmia and cerebral cortex abnormalities (Porter et al., 1997). The optic vesicle develops in Lhx2-null mutants, but the optic cup fails to form (Porter et al., 1997), suggesting a critical role for Lhx2 in the formation of the optic cup. Few incidences of human mutations of LHX2 have been identified and while there are some implications LHX2 mutations may result in anophthalmia, they are not a frequent cause of anophthalmia in humans (Desmaison et al., 2010). Evidence for a role of Lhx2 in very early eye development showed $L h \times 2$ inactivation delayed the expression of three EFTFs- Rx, Pax6 and Six3 (Tétreault et al., 2009). In addition, Lhx2 can activate Rx, Pax6 and Six3 in the presumptive eye field and, in combination with Pax6, can transactivate Six6 (Tétreault et al., 2009). Lhx2 also plays a role in the regionalization of the optic vesicle as it develops into the optic cup. Lhx2-mutant optic vesicles fail to express factors important in patterning the optic vesicle (Vsx2 and Mitf), and eye development arrests at the optic vesicle stage (Yun et al., 2009). Conditional deletion of $L h \times 2$ has identified functions beyond optic cup formation. $L h \times 2$ conditional knockout retinas show a depleted retinal progenitor pool that results in excess retinal ganglion cell formation at the expense of other cell types (Gordon et al., 2013). Conditional deletion of $L h \times 2$ later in retinogenesis results in excess formation of rods (Gordon et al., 2013). Recently, Lhx2 has been shown to have a role in maintaining mature Müller glia in a nonreactive state (de Melo et al., 2012).

\section{$\underline{\operatorname{Vs} \times 2(\operatorname{Ch} \times 10)}$}

Vsx2 (Visual system homeobox 2), which was previously referred to as $C h \times 10$, encodes a transcription factor that belongs to the paired-like (prd) class of homeobox proteins. Vsx2, in addition to containing a homeodomain, also has a CVC domain and an OAR domain (Liang and Sandell, 2008). Expression of Vsx2 starts at approximately E9.5 in mouse in the distal wall of 
the optic vesicle that is in close contact with the overlying surface ectoderm (Liu et al., 1994). This expression is the earliest of transcription factors expressed specifically in tissue that will become the neuroblastic layer of the developing optic cup (presumptive neural retina). As the optic cup forms, Vsx2 is expressed in the outer neuroblastic layer in retinal progenitors, and this expression is down-regulated when the progenitors exit the cell cycle (Liu et al., 1994). Later in development and in the mature retina, Vsx2 expression is limited to the inner nuclear layer where it is expressed in bipolar cells and a subset of Müller glial cells (Liu et al., 1994; Rowan \& Cepko, 2004).

Vsx2 has a role in patterning of the optic vesicle, where it is expressed in what will become presumptive neural retina in the optic cup. In mice with a Vsx2 null allele (or $/ o r$ mice), Mitf is upregulated and there is a transdifferentiation of neural retina into RPE (Horsford et al., 2005; Rowan et al., 2004). A recent study of optic vesicles formed using human induced pluripotent stem cells (IPSCs) from a patient with a VSX2 mutation showed a subset of components of the Wnt signaling pathway were misexpressed and upregulated (Capowski et al., 2016). Thus, these studies suggest that Vsx2 confers neural retina identity through the repression of Mitf (Horsford et al., 2005) and regulation of Wnt signaling (Capowski et al., 2016).

In humans, VSX2 mutations are associated with autosomal recessive microphthalmia (Reis et al., 2011) and non-syndromic microphthalmia/anophthalmia (Bar-Yosef et al., 2004; Ferda Percin et al., 2000; Zhou et al., 2008). The ocular retardation (or') mouse is the result of a premature stop codon in the Vsx2 gene creating a null allele (Burmeister et al., 1996). Mice homozygous for the or allele showed no Vsx2 expression, a reduction of retinal progenitors and a lack of bipolar cells (Burmeister et al., 1996). These changes lead to mice with microphthalmia, thin retinas and optic nerve aplasia (Burmeister et al., 1996). These changes as a result of the $V s \times 2$ mutation suggest important functions for $V s \times 2$ in progenitor proliferation and 
the generation of bipolar cells. Further support for the role of Vsx2 in bipolar cell fate comes from a study of Vsx2 knockdown in postnatal retinas using shRNA, which resulted in a significant decrease in bipolar cells (Green et al., 2003). There is evidence to suggest the mechanism through which Vsx2 influences bipolar cell fate is via the repression of photoreceptor-inducing factors. The conditional knockout of Blimp1, a transcription factor important for photoreceptor cell fate, leads to an increase in Vsx2 and bipolar cells at the expense of photoreceptors (Brzezinski et al., 2010; Katoh et al., 2010).

\section{$\underline{\text { Six3/ Six6 (Optx2) }}$}

The sine oculis homeobox (Six) family of genes was first identified in Drosophila as being important in eye development (Kumar, 2009). Several orthologs have been identified in vertebrates, two of which are important in eye development-Six3 and Six6 (also called Optx2). Six 3 and Six6 encode transcription factors that contain two conserved domains, the DNAbinding homeodomain and the Six domain, which is involved in protein-protein interactions (Kumar, 2009). Six3 and Six6 are expressed multiple times during eye development. Six3 is first expressed in the anterior neural plate around E6.5 in mouse (Oliver et al., 1995; Bovolenta et al., 1998) and is commonly used as an anterior neural plate marker. Six3 is one of the identified EFTFs that are found in the developing eye field of the anterior neural plate (Oliver et al., 1995; Bovolenta et al., 1998; Zuber et al., 2003). Six3 expression continues in the optic vesicles and, as the optic cup forms, is expressed in the neural retina and optic stalk (Bovolenta et al., 1998; Loosli, Köster, Carl, Krone, \& Wittbrodt, 1998; Oliver et al., 1995). As development proceeds, there is differential expression in the neuroblastic layer with strong labeling in the inner portion and weak labeling in the outer neuroblastic layer where progenitors reside; by E18 in mice, the only remaining expression is in the inner neuroblastic layer (Oliver et al., 1995). In the fully differentiated adult eye, Six3 expression is maintained in the inner nuclear layer and in select retinal ganglion cells (Granadino et al., 1999). In addition to its expression in the developing 
eye, Six3 is also expressed in the ventral diencephalon, olfactory placodes, and Rathke's pouch (Oliver et al., 1995).

Similar to Six 3 expression, Six6 is expressed in the eye field of the anterior neural plate and is considered an EFTF (Toy et al., 1998; Toy and Sundin, 1999; Zuber et al., 2003). Expression of Six6 continues in the optic vesicles and through the optic cup stage, where it is expressed in the neuroblastic layer and the optic stalk (Toy et al., 1998; Jean et al., 1999; Toy and Sundin, 1999). In mice at E13.5, Six6 is expressed in the neural retina nearest the RPE, and at birth expression is undetectable (Toy and Sundin, 1999). However, in adults Six6 expression in mice is observed in the inner nuclear and ganglion cell layers (Toy and Sundin, 1999), which differs from the expression in chickens, where it is also found in mature photoreceptors (Toy et al., 1998).

Mutations in SIX3 in humans are associated with holoprosencephaly (Wallis et al., 1999; Lacbawan et al., 2009; Solomon et al., 2009; Ribeiro et al., 2011). Holoprosencephaly (HPE) is a cephalic disorder of varying severity that results when the embryonic forebrain fails to separate properly. Clinically, HPE presents as craniofacial anomalies that, when severe, can include microcephaly, cyclopia, anophthalmia, microphthalmia, formation of a proboscis, and cleft lip/palate (Solomon et al., 2009). Studies show that Six3 is necessary to activate Shh, which normally induces the separation of the embryonic forebrain (including the eye field) and when this process is disrupted, the result is HPE (Geng et al., 2008; Jeong et al., 2008). The brain defects (microcephaly) and eye defects (microphthalmia, anophthalmia, and cyclopia) associated with Six3 mutations provide support that Six3 plays an important role in the development of the anterior neural plate and the eye. Inactivation of Six3 in the mouse provides further support; Six3-null mutants die at birth, lack forebrain structures, eyes and nose (Lagutin et al., 2003). Six3 represses Wnt signaling, which is required for forebrain development, and injections of Six3 can rescue the headless mutation in zebrafish (Lagutin et al., 2003). These 
results show that Six3 acts on Wnt signaling to help form the anterior neural plate and on Shh for midline separation. Both are important to eye development. Six3 may also play a role in retinal determination, as misexpression of Six3 in Medaka results in regions of the midbrain converting to optic-cup like structures (Loosli, Winkler, \& Wittbrodt, 1999). Six6 may also be involved in retinal determination, since overexpression of Six6 in Xenopus at low concentration increases eye size and at higher concentrations can induce the formation of ectopic eyes and transform the midbrain into retina (Bernier et al., 2000).

\section{Retinal Homeobox Gene $(\boldsymbol{R x})$}

The retinal homeobox gene, $R x$ (also called $R a x$ ) is arguably one of the most vital homeobox genes in eye development. $R x$ was first identified in 1997 by three independent labs as a novel homeobox gene expressed in developing forebrain and eye (Casarosa, Andreazzoli, Simeone, \& Barsacchi, 1997; Furukawa, Kozak, \& Cepko, 1997; Mathers, Grinberg, Mahon, \& Jamrich, 1997). Casarosa et al. (1997) first reported the isolation of $R x$ from a stage 24/25 Xenopus cDNA library that was screened with fragments of the murine Orthopedia gene. Mathers et al. (1997) isolated $R x$ by screening a cDNA library made from ammonium chloride-treated Xenopus ectoderm with degenerate primers and then identified homologues in human, mouse, zebrafish and Drosophila. Furukawa et al. (1997) isolated $R x$ from screening a mouse P0-P3 eye cDNA library with a $R x$ cDNA fragment obtained from using degenerate primers to amplify sequences from $\mathrm{E} 18$ and $\mathrm{P} 4$ rat retina.

\section{Structure}

$R x$ is a paired-like homeobox gene that is located in the distal region of chromosome 18 in mice (Furukawa et al., 1997). The identified $R x$ nucleotide and amino acid sequence show two possible translation initiation codons in the same reading frame as the homeodomain (Casarosa et al., 1997; Furukawa et al., 1997; Tucker et al., 2001). Rx encodes a 342 amino acid transcription factor with four conserved motifs. The amino acid sequence of $R x$ shows it has a 
highly conserved homeodomain capable of DNA binding that shares a high degree of homology with the homeodomain of the paired-like homeobox gene Vsx2 (Casarosa et al., 1997; Furukawa et al., 1997). $R x$ has the octapeptide domain that is characteristic in paired-box genes, but $R x$ does not encode a paired-box motif and is classified as paired-like (Casarosa et al., 1997; Furukawa et al., 1997; Mathers et al., 1997). The carboxy-terminal end contains a stretch of 15 amino acids that are homologous to other homeodomain proteins such as Vsx2. This conserved region is known as the OAR region (or paired tail)(Furukawa et al., 1997; Mathers et al., 1997). Additionally, an area between the OAR region and the homeodomain is proline-, serine- and threonine-rich and is a potential activation domain (Casarosa et al., 1997; Furukawa et al., 1997).

$R x$ genes have been identified in many species from Drosophila to humans and are evolutionarily well conserved. The number of $R x$ genes varies between species. In mice, a single $R x$ gene has been identified (Furukawa et al., 1997; Mathers et al., 1997), likewise in Drosophila (Mathers et al., 1997; Eggert et al., 1998; Davis et al., 2003) and in Astyananax mexicanus, the cavefish (Strickler et al., 2002). Two Xenopus genes (Xrx1 and Xrx2) have been identified with expression patterns that appear to be identical (Casarosa et al., 1997; Mathers et al., 1997). In addition, a $R x$-like gene was identified in Xenopus, $R x$-L, which shares homology with $R x$ at the homeodomain, OAR and $R x$ domain but does not have an octapeptide motif (Pan et al., 2006). A single $R x$ gene was identified in humans (Mathers et al., 1997), but like Xenopus, a $R x$-like gene was also identified, called $Q R X$, which is also found in bovine (Wang et al., 2004). In chickens a $R x$ gene (cRax) was identified (Ohuchi et al., 1999), as was a $R x$-like gene, termed $c R a x L$ (Chen \& Cepko, 2002; Ohuchi et al., 1999). In medaka, two $R x$ genes have been identified ( $R \times 2$ and $R \times 3$ ) that display differing expression patterns in the forebrain and eye during development (Deschet, Bourrat, Ristoratore, Chourrout, \& Joly, 1999; Loosli et al., 2003). Three $R x$ genes have been identified in zebrafish (Zrx1/2/3) (Mathers et al., 
1997). $Z r x 1$ and $Z r x 2$ show identical expression patterns in the developing eye, but $Z r x 3$ is mostly limited to the early eye field and ventral forebrain (Mathers et al., 1997; Chuang et al., 1999).

\section{Expression}

The expression of Rx has been well studied and is found in three main areas, early in the developing neural plate, the eye, and in the brain. This expression is conserved in vertebrates, including those with multiple $R x$ gene numbers, where the combined expression pattern of the genes together is similar to that of species with a single $R x$ gene. In Drosophila, $R x(d r x)$, which has a very similar homeodomain to vertebrates, expression is similar and shown in the procephalon, a region that gives rise to the presumptive eye primordia and brain hemispheres (Eggert et al., 1998). Starting early in embryonic development, $R x$ can be detected by in situ hybridization in mice at E7.5 in the cephalic neural fold (head fold), which is the presumptive forebrain and midbrain territory (Furukawa et al., 1997). By E8.5 there is strong expression in the anterior neural plate, which is the prospective forebrain/optic vesicle region (Furukawa et al., 1997; Mathers et al., 1997). Expression of $R x$ is confined to the optic vesicles and developing optic cup, optic stalk and the ventral diencephalon on E9.5-E10.5 (Furukawa et al., 1997; Mathers et al., 1997). As the development of the eye proceeds from E11.5 to E18.5, $R x$ expression within the eye is restricted to the neural retina (Furukawa et al., 1997; Mathers et al., 1997). During retinogenesis, expression of $R x$ within the neural retina corresponds to the location of the retinal progenitors and is down-regulated in areas at approximately the same time that progenitors exit the cell cycle (Furukawa et al., 1997; Mathers et al., 1997). Postnatally (at P6), Rx expression is limited to the photoreceptor layer and inner nuclear layer (Mathers et al., 1997). At P9, expression of $R x$ is restricted to the Müller glia in the inner nuclear layer (Furukawa et al., 2000). Expression of Rx during adulthood in mice has been found in the ciliary body, an area containing multipotent retinal progenitor-like cells (Lord- 
Grignon et al., 2006). Despite widespread expression in the developing eye, $R x$ signal has not been detected in the developing lens or cornea (Furukawa et al., 1997). In addition to expression in the eye, $R x$ is also expressed in the brain. In the developing forebrain at E10.5 and $\mathrm{E} 12.5, R x$ is expressed in the hypothalamus and the posterior pituitary (Mathers et al., 1997; Lu et al., 2013). In the adult brain, $R x$ is expressed in the posterior pituitary, pineal gland, and the hypothalamus (Asbreuk et al., 2002; Rhode et al., 2011).

\section{Mutations and Clinical Significance}

Mutations in $R x$ have been identified in mice, medaka, zebrafish, Xenopus, and humans. These mutations are associated with several eye defects, most notably small eyes or a complete lack of eyes.

In mice, the eyeless mutation (ey1) was identified in the 1940s and has been used as a model of spontaneous human anophthalmia (Chase and Chase, 1941; Tucker et al., 2001). The eyeless phenotype consists of severe eye defects (ranging from a complete lack of eyes, which is most common, to small eyes), and hypothalamic abnormalities (Tucker et al., 2001). During development in eyeless mice, the optic vesicles evaginate normally but are smaller in size and connect poorly with the overlying ectoderm. These mice have a mutation in $R x$ that results in the removal of an alternate start codon (M10L), which leads to a reduction in Rx protein expression (Tucker et al., 2001).

Another eyeless mutant has been described, the eyeless mutation in medaka. This is a temperature-sensitive recessive mutation that affects eye development and results in death at the early larval stage (Winkler et al., 2000). In eyeless medaka mutants, optic vesicle evagination does not occur, and as a result, eyes do not form (Winkler et al., 2000). The gene affected by the eyeless mutation was identified as $R \times 3$ (Loosli et al., 2001). It was shown that 
there was an intronic insertion of a transposon in $R \times 3$ that lead to a disruption of $\mathrm{Rx}$ protein formation (Loosli et al., 2001).

Similar to the eyeless mutation in medaka, zebrafish chokh mutants lack eyes from early stages of development (Kennedy et al., 2004; Loosli et al., 2003; Winkler et al., 2000). Optic vesicles fail to form, and although the chokh mutants hatch, they die at 3-4 weeks (Loosli et al., 2003). The chokh mutation is a nonsense point mutation that results in a premature stop codon in the homeodomain of $R x 3$, creating a null allele (Loosli et al., 2003). The loss of $R x 3$ leads to a reduction in $R \times 1$ and $R \times 2$ in these mutants, but Pax6 and Six3, two other important genes in eye development, are unaffected (Loosli et al., 2003). Injection of medaka $R \times 3$ mRNA was able to rescue the chokh phenotype (Loosli et al., 2003).

Analogous to the mutation in fish, a $R x$ mutant has been identified in Xenopus. A nonsense $R x$ mutation that led to a premature stop codon after the octapeptide domain was identified in a Xenopus mutant with an eyeless phenotype (Fish et al., 2014). In these mutants, eye formation is halted before the optic vesicle is formed, and the tissue that was fated to become retina instead develops diencephalon and telencephalon characteristics (Fish et al., 2014).

In humans, mutations of $R A X$ have been identified in patients with severe ocular disorders, including microphthalmia, anophthalmia and coloboma (MAC disorders). Severe ocular defects are rare, occurring in approximately 1 in every 5300 live births in the USA (Parker et al., 2010). Anophthalmia is characterized by the absence of either one or both eyes, whereas in microphthalmia, the eyes are present but one or both are abnormally small. Coloboma, similar to microphthalmia and anophthalmia, can affect one or both eyes and is characterized by a hole in one or more of the structures of the eye, including cornea, iris, retina, choroid, optic disc and ciliary body (Onwochei et al., 2000). To date, there are six reports of human mutations in $R A X$, identifying 12 patients with a MAC phenotype. In the first report of a human genetic mutation of 
$R A X$, a compound heterozygous $R A X$ mutation was identified in a patient with anophthalmia of the right eye and sclerocornea and retinal detachment in the left eye (Voronina et al., 2004). Two mutations, a truncated allele (Q147X) and a missense mutation (R192Q), both in the DNA binding homeodomain of $R A X$, were found (Voronina et al., 2004). Lequeux et al. (2008), reported a novel heterozygous $R A X$ mutation in a patient with bilateral anophthalmia. Two mutations in exon 3 of $R A X$ were identified. A frameshift deletion and a nonsense mutation both created premature stop codons, which would create a truncated RAX protein that is predicted to lack the OAR domain and thus be nonfunctional (Lequeux et al., 2008). Another report of human $R A X$ mutations identified a patient with a retinal coloboma of the right eye (London et al., 2009). Molecular analysis revealed this patient had a novel missense mutation in exon 1 of $R A X$ and two polymorphisms (E44/D44 and Q294Q) that were previously identified by Voronina et al., 2004 (London et al., 2009). Additional novel human RAX mutations were found in a report that identified two patients, one with right anophthalmia and one with right microphthalmia, both had novel heterozygous $R A X$ mutations (R110G and T50P) (Gonzalez-Rodriguez et al., 2010). Three patients with autosomal recessive bilateral anophthalmia from two unrelated consanguineous families were identified. Molecular analysis showed a novel homozygous splicing mutation affecting the last exon of $R A X$ in these patients that was predicted to result in a truncated RAX protein (Abouzeid et al., 2012). Recently, a large screening of 150 microphthalmic/anophthalmic patients identified four individuals (3\% of those screened) with homozygous or compound heterozygous mutations in RAX (Chassaing et al., 2014). Three of the patients had bilateral anophthalmia and one had bilateral microphthalmia. The mutations in three of the patients affected the homedomain of RAX (Chassaing et al., 2014). In addition to $R A X$, several gene mutations have been linked with a MAC phenotype (See Bardakjian \& Schneider, 2011 for a review of the genetics of ocular malformations). In the report above, they screened seven genes (GDF6, FOXE3, OTX2, PAX6, SOX2, RAX, VSX2) in 150 patients and had a mutation detection rate of $21 \%$ (Chassaing et al., 2014), which highlights the small 
number of known genes responsible for the MAC phenotype, suggesting these conditions are heterogeneous. There are likely many putative genes that have yet to be identified whose mutations lead to ocular defects, and despite the relative rarity of these disorders, identifying the role that these genes play in optic vesicle development is important because of the severity of these disorders and to further understand normal eye development and ocular malformations.

\section{Function}

The conserved expression pattern of Rx during embryogenesis combined with evidence from reports of $R x$ mutations suggest a role for $R x$ in anterior neural plate patterning, eye development, forebrain development and the proliferation of progenitors. This discussion will focus on the role of Rx in development as it relates to eye formation.

\section{Eye Development}

The importance of Rx in eye development was first established in 1997 with its identification and the first functional study of $R x$ in a generated mouse $R x$-null mutant (Mathers et al., 1997). The $R x$-null allele was generated from the targeted deletion of $\mathrm{Rx}$ by the homologous recombination of a $2.7-\mathrm{kb}$ portion of the mouse $R x$ locus with a 1.8-kb neomycin selection gene. The deleted portion included exons 1 and 2, which code for the protein initiation site, the octapeptide, and the N-terminal end of the homeodomain. Homozygous $R x$-null mutants are born without eyes, have varying degrees of forebrain defects, and exhibit perinatal lethality; whereas mice heterozygous for the $R x$-null allele appear phenotypically normal. Phenotypic differences in the $R x$ mutant become apparent as early as E8.5, when the optic pit, the beginning of optic vesicles, fails to form, demonstrating that $R x$ is required for eye formation during the earliest stages.

Since then the functions of $\mathrm{Rx}$ in eye development have been studied in many vertebrate species and in Drosophila. Like the expression of $R x$, the importance of $R x$ in eye formation is 
also conserved in vertebrates, but that is not the case in Drosophila. While the Drosophila $R x$ gene shows a similar expression pattern to that found in vertebrates, it is not necessary for the development of the Drosophila visual system, but does play a role in the development of the brain and clypeus (Davis et al., 2003). The following will review the role of $R x$ in multiple stages of eye development using studies from a variety of vertebrate species.

\section{$R x$ is involved in anterior neural plate patterning and eye field formation}

The earliest function of $\mathrm{Rx}$ in eye development is in eye field formation. Patterning of the anterior neural plate leads to the formation of the eye field from which the optic vesicles are produced. Specification of the anterior neural plate requires the activation of several homeobox transcription factors. Studies of Rx expression initially detect it in the anterior neural plate (Zhang, Mathers, \& Jamrich, 2000). Rx belongs to a group of transcription factors that are expressed in the eye field (EFTF). In Xenopus, eye field specification occurs through the expression of these transcription factors (Zuber et al., 2003). Overexpression of the EFTFs along with Otx2 leads to the formation of secondary eye fields that develop into ectopic eyes (Zuber et al., 2003). The Xenopus $R x$ mutant provides further evidence of the role of $R x$ in eye field specification. The expression of the other EFTFs was initially normal, suggesting they did not require $\mathrm{Rx}$ for their initial activation and gene analysis showed a down-regulation of genes important in eye development and an up-regulation in those involved in forebrain development (Fish et al., 2014). These results suggest that $R x$ is involved in the specification of the eye field through the repression of genes involved in patterning the forebrain and in activating eye fieldpromoting genes (Fish et al., 2014). A similar conclusion was drawn from whole transcriptomic sequencing data of zebrafish $r \times 3^{-/}$mutants showing genes involved in eye development were downregulated and genes involved in brain formation were upregulated (Yin et al., 2014).

The importance of Rx in anterior neural plate patterning and eye field specification has also been shown in mice. The $R x$-null mouse mutant phenotype is the earliest known eye 
development defect, showing no optic vesicle formation and preceding other microphthalmic/anophthalmic mutant phenotypes, including Pax6 mutations. Forebrain abnormalities are also a characteristic of the $R x$-null mutant phenotype (Mathers et al., 1997).

\section{$R x$ in optic vesicle development.}

Evagination of the optic pits is considered the first morphological sign of eye development. Deletion of $R x$ in mice leads to a complete lack of optic vesicle formation resulting in anophthalmia (Mathers et al., 1997). Studies in medaka provide additional evidence of the function of $R x$ in optic vesicle development. The eyeless mutation in medaka (Loosli et al., 2001) leads to a failure of the optic vesicles to evaginate despite the presence of retinal progenitor cells (Winkler et al., 2000). In vivo imaging at single-cell resolution showed retinal progenitor cells in $R \times 3$ eyeless mutants adopt a migration pattern similar to forebrain progenitors. In addition, this aberrant migration pattern could be rescued by individual wild-type cells; thus, the chimeras show optic vesicle evagination (Rembold et al., 2006). These data suggest that $R x$ is involved in cellular movement that is necessary for evagination. Nlcam (neurolin-like cell adhesion molecule) was identified as a potential target for Rx3 (Brown et al., 2010). In $R \times 3$ mutants, Nlcam is up-regulated, and overexpression of Nlcam results in smaller eyes and midline migration of progenitors (Brown et al., 2010), suggesting that $R x$ is repressing Nlcam for the appropriate migration of cells during optic vesicle evagination.

\section{$R x$ in retinal progenitor proliferation.}

One of the first observations when Rx was identified was its localization with retinal progenitors (Furukawa et al., 1997; Mathers et al., 1997). Since then, several studies have shown that Rx is important for retinal progenitor proliferation and multipotency. Studies of the overexpression of $R x$ in Xenopus embryos show ectopic RPE, and hyperproliferation of retinal progenitors, neural tube and retinal cells (Mathers et al., 1997; Casarosa et al., 2003; Andreazzoli et al., 1999). Xhmgb3 (Xenopus high mobility group B3 gene) was identified as a downstream target of $R x$ 
that regulates proliferation in the developing eye (Terada et al., 2006). Overexpression of $R x$ in Xenopus embryos did not change the proportion of cell types formed, suggesting a possible role for $R x$ in maintaining the multipotency of retinal progenitors (Casarosa et al., 2003). Inhibition of $R x$ in Xenopus results in decreases in brain and eye size, likely due to reduction in progenitor proliferation (Casarosa et al., 2003; Andreazzoli et al., 2003).

Several species (frogs, chickens and fish) have the capacity for retinal regeneration (MartinezDe Luna et al., 2011). A study of Xenopus laevis showed that following an injury retinal progenitors expressing progenitor marker genes, including $R x$, are found at the site of injury. If $R x$ expression is lost due to gene knockdown, the capacity for retinal regeneration is impaired (Martinez-De Luna et al., 2011). The impaired regeneration suggests that $R x$ is necessary for retinal regeneration in Xenopus and may be required for the generation of retinal progenitors for this regeneration.

Additionally, $R x$, functioning through the transcriptional activation of Hes1 and Notch1, is important for Müller glia formation (Furukawa et al., 2000). Müller glia in zebrafish can act as radial glia-like neural stem cells, express low levels of multipotent progenitor markers and can proliferate at low frequency in uninjured retinas (Bernardos et al., 2007). If injury does occur, the Müller glia can dedifferentiate to form retinal progenitors to generate the missing neurons (Bernardos et al., 2007; Lenkowski and Raymond, 2014).

\section{$R x$ in photoreceptor cell fate determination}

Studies in zebrafish, chicken, and humans provide evidence that $R x$ and the $R x$-like gene play a role in photoreceptor development. In zebrafish, morpholino knockdown of $R \times 1$ during retinal neurogenesis leads to a decrease in photoreceptor-specific genes (rod opsin, cone opsins and transducin), and knockdown of $R \times 2$ during the same time period resulted in a decrease in a select subset of photoreceptor genes (rod opsin, red opsin and transducin) (Nelson et al., 2009). 
Combined knockdown of $R \times 1$ and $R \times 2$ decreased development of both rods and cones but did not affect the expression of $C r x$ or NeuroD (Nelson et al., 2009). These data suggest a function for $\mathrm{Rx}$ in photoreceptor development and suggest that zebrafish $R \times 1$ and $R \times 2$ may have different roles in photoreceptor formation or different downstream targets. In chickens, the $R x$ like gene, $c R a x L$, is expressed in cells migrating to the photoreceptor layer, and introduction of a dominant-negative allele of $c R a x L$ into the developing chick eye leads to a decrease in the expression of photoreceptor markers and an increase in cell death within the retina (Chen \& Cepko, 2002). In mammals, a homologue of chicken $c R a x L$ is $Q R X$ in humans. $Q R X$ is expressed in the inner and outer nuclear layers of the retina and has an almost identical homeodomain to $R X / R A X$ (Wang et al., 2004). $Q R X$ can transactivate the Ret-1 element in the rhodopsin promoter in the presence of $C r x$ and $N R L$, and $Q R X$ interacts with $\operatorname{Crx}$ (Wang et al., 2004). No $R x$-like gene has been identified in mice, which leads to the possibility that the single murine $R x$ gene has similar functions to the $R x$-like gene in photoreceptor development. Human RAX can transactivate photoreceptor-specific gene promoters, including IRBP and PCE1 (Kimura et al., 2000). In mice, $\mathrm{Rx}$ can regulate Otx2 through interactions with the EELPOT in the final cell cycle of retinal progenitor cells, and conditional deletion of $R x$ at $E 11.5$ decreases Otx2 and Crx expression (Muranishi et al., 2011). $R x$, in cooperation with $C r x$, can transactivate photoreceptor genes, such as rhodopsin and cone opsin (Irie et al., 2015). Finally, conditional deletion of $R x$ in maturing photoreceptors leads to a decrease in photoreceptor-specific genes and an increase in cell death in the postnatal mouse retina (Irie et al., 2015), suggesting that $R x$ is necessary for photoreceptor maturation and survival. The above data provide evidence of a role for $R x$-like genes in photoreceptor development and mouse $R x$ in photoreceptor maturation and survival; the necessity of $R x$ in photoreceptor histogenesis in mice is not well understood, but will be addressed below in Chapter 3 . 


\section{$\underline{\text { Regulation of } \mathrm{Rx}}$}

Despite its initial discovery almost two decades ago, the regulation of $\mathrm{Rx}$ and the downstream targets of Rx are still not completely understood. Regulation of Rx early in development was first studied in Xenopus. Activation of Rx expression in Xenopus embryos can be achieved by chordin, noggin, Hedgehog, and wnt pathways (Andreazzoli et al., 2003; Rasmussen et al., 2001; Zuber, Perron, Philpott, Bang, \& Harris, 1999), whereas neurogenin and retinoic acid can repress $R x$ (Andreazzoli et al., 2003). Additionally, the interaction of Sox2 and Otx2 via a conserved non-coding sequence (CNS1) acts as an upstream transcriptional activator of Rx in Xenopus embryos (Danno et al., 2008). Recently, in Xenopus tadpoles it was shown that $R x$ transcription in the ciliary marginal zone (area containing progenitors) is controlled, in part, by autoregulation (Kelly et al., 2016). In mice conditionally deleted of Sufu, a regulator of hedgehog signaling, $R x$ expression is decreased (Cwinn et al., 2011a), suggesting that, similar to Xenopus, hedgehog signaling may be an upstream regulator of $\mathrm{Rx}$.

Both Xenopus laevis and $X$. tropicalis contain a cis-regulatory element in the 5 ' upstream regions of $R x$ that directs Rx expression (Hirsch et al., 2002; Zhang, Fu, \& Barnstable, 2002). The regulation of $R x$ in mice is less well studied. However, Swindell et al. (2006) showed that $R x$ regulatory sequences are conserved among vertebrates with their creation of a transgenic mouse using the 4kb DNA fragment 5' upstream of medaka $R x$, showing similar temporal and spatial patterns to that of endogenous mouse $R x$.

Several downstream targets of Rx in early development have been identified in Xenopus, including Otx2, Six6, Pax6, TLE1, Hes4 and Hmgb2 (Andreazzoli, Gestri, Angeloni, Menna, \& Barsacchi, 1999; Massimiliano Andreazzoli et al., 2003; Giannaccini et al., 2013; Terada, Kitayama, Kanamoto, Ueno, \& Furukawa, 2006; Zuber et al., 2003). Additionally, Nlcam was identified as a downstream target of Rx in Zebrafish (Brown et al., 2010). 
Some of the downstream targets of $R x$ later in eye development have been discerned. $R x$ binds with PCE-1 elements (Pan et al., 2010; Kimura et al., 2000), which are found in photoreceptor genes. Rx can transactivate promoters for the arrestin and IRBP (interphotoreceptor binding protein) genes, and $R x$ can weakly transactivate cone opsins and can interact with $C r x$ to synergistically transactivate rhodopsin and $S$ - and M-opsin (Irie et al., 2015). Additionally, $R x$ can regulate Otx2 (Muranishi et al., 2011). In rat retina, during glial formation, $R x$ overexpression leads to the transcriptional activation of the Hes1 and Notch1 promoters (Furukawa et al., 2000).

\section{Stem Cell-Generated Retinal Tissue}

Stem cells have three unique characteristics including the capacity for self-renewal, an undifferentiated state, and the ability to develop into many different cell types (NIH, 2009). These characteristics make their use in biomedical research and medical treatment appealing. Currently there are two types of pluripotent stem cells available to researchers, either embryonic or induced pluripotent, and each has their own benefits and challenges. Embryonic stem cells (ESCs) are derived from the inner cell mass of embryos at the blastocyst stage. They are pluripotent cells that are capable of long-term growth and self-renewal. They were first derived from mice in 1981 (Martin, 1981) and later from humans in 1998 (Thomson et al., 1998). Human ESCs offer promise for treatment and research, but ethical concerns make their use challenging. More recently, the development of induced pluripotent stem cells (IPSCs) in 2006 by Takahashi and Yamanaka helps to avoid some of the ethical challenges and immunological rejection issues associated with ESCs. IPSCs were originally generated using the viral transduction of four genes Oct4, Sox2, KIf4, and c-myc to reprogram differentiated cells into cells with ESC-like properties (Takahashi \& Yamanaka, 2006). Researchers have been refining the protocol for the induction of IPSCs, and now they can be generated without the use of $c$-myc (an oncogene) (Nakagawa et al., 2008), and there are alternatives to viral induction (Kaji et al., 
2009; Kim et al., 2009; Okita, Nakagawa, Hyenjong, Ichisaka, \& Yamanaka, 2008; Zhou et al., 2009; Zhou \& Freed, 2009).

Both ESCs and IPSCs have great potential for research and clinical applications because of their ability to develop into multiple cell types. Researchers have capitalized on this characteristic and developed protocols to generate many different cell types from stem cells. Early reports of retinal cells grown in monolayer culture derived from ESCs showed an infrequent expression of photoreceptor markers and problems with internal structures and cellular morphology (Hirano et al., 2003; Zhao, Liu, \& Ahmad, 2002). Improving upon the earlier protocols, combinations of WNT and Nodal signaling antagonists on serum-free cultures of mouse ESC aggregates showed the ability to generate photoreceptors, although at low efficiency, in a stepwise fashion that was similar to in vivo retinogenesis (lkeda et al., 2005). With refinement of the protocol, improved efficiency was demonstrated and the procedure was shown to work using monkey and human ESCs in addition to mouse ESCs (Osakada et al., 2008, Osakada et al., 2009). Other protocols using human ESCs and Wnt antagonists also showed generation of retinal cells; however, the timeline of development was accelerated compared to in vivo retinogenesis (Lamba, Karl, Ware, \& Reh, 2006). The functionality of these ESC-derived cells was demonstrated by their ability to integrate into retinal explants (Lamba et al., 2006) and in vivo mouse retina, where they integrated into the correct retinal layers (Lamba, Gust, \& Reh, 2009). Additionally, these ESC-derived retinal cells can partially restore the ERG (electroretinogram) of Crx-/- mice (Lamba et al., 2009). Generation of retinal cells has also been shown using IPSCs (Hirami et al., 2009; Lamba et al., 2010). Key protocols in the development of retinal cells from stem cells in monolayer cultures are shown in Figure 5.

These two-dimensional (2D) monolayer culture methods generated retinal neurons, which is beneficial for cell replacement therapies, but did not allow the formation of 3D tissues in culture, which limits their usefulness in studying development and other potential applications. A large 
step forward in generating 3D tissues occurred with the use of cell culture inserts to generate retinal cells in 3D laminar structures that included RPE (Nistor et al., 2010). A large breakthrough in stem cell technology was the creation of self-organizing organoids, which are organs generated in 3D stem cell culture. Organoids have tremendous potential for research, including as a method to model human disease, study development and for drug screening, among others. A wide range of tissues have now been generated as organoids including brain, retina, kidney, testes, liver, stomach and intestines (Eiraku and Sasai, 2011; Eiraku et al., 2011; Koo et al., 2011; Finkbeiner et al., 2015; Little and Takasato, 2015; Flanagan et al., 2016; Pendergraft et al., 2017). An innovative study in retinal generation from stem cells was a protocol for 3D formation of self-organizing optic vesicles/retina developed by Sasai and colleagues (Eiraku et al., 2011). This protocol used mouse ESCs that had GFP knocked into the $R x$ locus to label retinal induction. The Rx-GFP ESCs were plated on a low-adhesion, 96-well plate, which allowed them to form floating aggregates, which were then cultured starting at day 1 with growth factor-reduced matrigel. These conditions lead to the formation of retinal neuroepithelia (labeled with GFP) that on Culture Day 7 evaginate and form optic vesicle organoids. If left in culture, these vesicles will invaginate and form a bilayered optic cup-like structure. Isolating the optic cups and culturing for an additional two weeks results in the formation of a retinal organoid that is laminated and contains the appropriate retinal cell types (Eiraku and Sasai, 2011). The culture conditions for this protocol are shown in Figure 5. The formation of these retinal organoids goes through a stepwise developmental process that is similar to in vivo eye development, making this the first paper to demonstrate in cell culture the process of retinal development including morphogenesis from stem cells (Eiraku and Sasai, 2011; Eiraku et al., 2011).

Since this seminal paper on the formation of self-organizing retinal organoids was published, there have been many publications involving the formation of optic vesicles, optic cups and 
stratified retinal tissue as organoids (Chen, Kaya, Dong, \& Swaroop, 2016; Eiraku et al., 2011; Eiraku \& Sasai, 2011; Meyer et al., 2011; Nakano et al., 2012; Ohlemacher, Iglesias, Sridhar, Gamm, \& Meyer, 2015; Völkner et al., 2016; Zhong et al., 2014). These protocols use a variety of defined culture conditions to promote retinal differentiation (Figure 5). A common component in all of these protocols is the use of extracellular matrix proteins (matrigel or lamnin), which are necessary to support the maintenance of continuous neuroepithelial structures. In addition to mouse ESCs, organoids are being formed from human ESCs that are proportionally larger than those from mouse ESCs (Nakano et al., 2012), and optic vesicle/retinal organoids have now also been generated with human IPSCs (Meyer et al., 2011; Zhong et al., 2014; Ohlemacher et al., 2015; Chen et al., 2016).

The ability to use stem cells to generate retinal neurons has progressed rapidly within the last decade, going from simple monolayer culture using mouse ESCs to the formation of retinal organoids and the ability to use ESC or IPSCs from either mouse or human sources. These techniques are being tested for clinical applications such as cell replacement therapy, for drug screening and for studying embryonic development. This development process in optic vesicle/retinal organoids shows similar morphology, timing and cellular marker expression to in vivo development (Eiraku et al., 2011), which makes it an excellent model for studying embryonic eye development. Researchers are already using optic vesicle/retinal organoid cultures generated from patient-derived IPSCs to create disease models from a specific gene mutation and explore their development (Meyer et al., 2011; Capowski et al., 2014; Phillips et al., 2014; Lukovic et al., 2015; Ohlemacher et al., 2016). The potential to use these cultures to study retinal development is just beginning. Researchers are already using them to study the dynamics of tissue morphogenesis during eye development (Eiraku et al., 2012), and the transcriptomics of photoreceptor development (Kaewkhaw et al., 2015). Using this system to 
study other areas of eye development or examine the effects of gene knockdown has not yet been explored but shows strong potential.

\section{Objectives}

To better understand eye development my dissertation focused on developing new tools to studying early eye formation and then using those tools to investigate which genes, in addition to $R x$, are important for optic vesicle formation and to explore the role of $\mathrm{Rx}$ in eye development following optic vesicle initiation. First, we sought to identify and characterize embryonic cone markers. Then using a $R x$ conditional knockout model we designed a series of experiments to explore the functions of $\mathrm{Rx}$ in proliferation and cell fate specification during retinogenesis following neural retina induction. We also sought to determine if $\mathrm{Rx}$ has a specific role in cone formation. Finally, we tested methods for exploring gene function in early optic vesicle development using 3D optic vesicle organoid cultures and employed this method to test potential candidate genes for their involvement in optic vesicle formation. 


\section{References}

Abouzeid H, Youssef M a, Bayoumi N, ElShakankiri N, Marzouk I, Hauser P, Schorderet DF (2012) RAX and anophthalmia in humans: evidence of brain anomalies. Mol Vis 18:14491456.

Adler R, Canto-Soler MV (2007) Molecular mechanisms of optic vesicle development: complexities, ambiguities and controversies. Dev Biol 305:1-13.

Agathocleous M, Harris WA (2009) From Progenitors to Differentiated Cells in the Vertebrate Retina. Annu Rev Cell Dev Biol 25:45-69.

Andreazzoli M (2009) Molecular regulation of vertebrate retina cell fate. Birth Defects Res Part C Embryo Today Rev 87:284-295.

Andreazzoli M, Gestri G, Angeloni D, Menna E, Barsacchi G (1999) Role of Xrx1 in Xenopus eye and anterior brain development. Development 126:2451-2460.

Andreazzoli M, Gestri G, Cremisi F, Casarosa S, Dawid IB, Barsacchi G (2003) Xrx1 controls proliferation and neurogenesis in Xenopus anterior neural plate. Development 130:51435154.

Ang SL, Jin O, Rhinn M, Daigle N, Stevenson L, Rossant J (1996) A targeted mouse Otx2 mutation leads to severe defects in gastrulation and formation of axial mesoderm and to deletion of rostral brain. Development 122:243-252.

Applebury ML, Antoch MP, Baxter LC, Chun LL, Falk JD, Farhangfar F, Kage K, Krzystolik MG, Lyass LA, Robbins JT (2000) The murine cone photoreceptor: a single cone type expresses both $S$ and $M$ opsins with retinal spatial patterning. Neuron 27:513-523.

Applebury ML, Farhangfar F, Glösmann M, Hashimoto K, Kage K, Robbins JT, Shibusawa N, Wondisford FE, Zhang H (2007) Transient expression of thyroid hormone nuclear receptor TRbeta2 sets S opsin patterning during cone photoreceptor genesis. Dev Dyn 236:12031212.

Asbreuk CH., van Schaick HS., Cox J., Smidt M., Burbach JP. (2002) Survey for paired-like homeodomain gene expression in the hypothalamus: restricted expression patterns of $R x$, Alx4 and goosecoid. Neuroscience 114:883-889.

Avilion AA, Nicolis SK, Pevny LH, Perez L, Vivian N, Lovell-Badge R (2003) Multipotent cell lineages in early mouse development depend on SOX2 function. Genes Dev 17:126-140.

Baas D, Bumsted KM, Martinez JA, Vaccarino FM, Wikler KC, Barnstable CJ (2000) The subcellular localization of Otx2 is cell-type specific and developmentally regulated in the mouse retina. Brain Res Mol Brain Res 78:26-37.

Bailey TJ, El-Hodiri H, Zhang L, Shah R, Mathers PH, Jamrich M (2004) Regulation of vertebrate eye development by Rx genes. Int J Dev Biol 48:761-770.

Bar-Yosef U, Abuelaish I, Harel T, Hendler N, Ofir R, Birk O (2004) CHX10 mutations cause non-syndromic microphthalmia/anophthalmia in Arab and Jewish kindreds. Hum Genet 115.

Bardakjian TM, Schneider A (2011) The genetics of anophthalmia and microphthalmia. Curr Opin Ophthalmol 22:309-313. 
Belecky-Adams T, Tomarev S, Li HS, Ploder L, Mclnnes RR, Sundin O, Adler R (1997) Pax-6, Prox 1, and Chx10 homeobox gene expression correlates with phenotypic fate of retinal precursor cells. Investig Ophthalmol Vis Sci 38:1293-1303.

Belloni E, Muenke M, Roessler E, Traverse G, Siegel-Bartelt J, Frumkin A, Mitchell HF, DonisKeller H, Helms C, Hing AV, Heng HHQ, Koop B, Martindale D, Rommens JM, Tsui L-C, Scherer SW (1996) Identification of Sonic hedgehog as a candidate gene responsible for holoprosencephaly. Nat Genet 14:353-356.

Bernardos RL, Barthel LK, Meyers JR, Raymond PA (2007) Late-Stage Neuronal Progenitors in the Retina Are Radial Muller Glia That Function as Retinal Stem Cells. J Neurosci 27:7028-7040.

Bernier G, Panitz F, Zhou X, Hollemann T, Gruss P, Pieler T (2000) Expanded retina territory by midbrain transformation upon overexpression of Six6 (Optx2) in Xenopus embryos. Mech Dev 93:59-69.

Bessant DA, Payne AM, Mitton KP, Wang QL, Swain PK, Plant C, Bird AC, Zack DJ, Swaroop A, Bhattacharya SS (1999) A mutation in NRL is associated with autosomal dominant retinitis pigmentosa. Nat Genet 21:355-356.

Bilitou A, Ohnuma S (2010) The role of cell cycle in retinal development: Cyclin-dependent kinase inhibitors co-ordinate cell-cycle inhibition, cell-fate determination and differentiation in the developing retina. Dev Dyn 239:727-736.

Bouwmeester T, Kim S-H, Sasai Y, Lu B, Robertis EM De (1996) Cerberus is a head-inducing secreted factor expressed in the anterior endoderm of Spemann's organizer. Nature 382:595-601.

Bovolenta P, Mallamaci A, Briata P, Corte G, Boncinelli E (1997) Implication of OTX2 in pigment epithelium determination and neural retina differentiation. J Neurosci 17:4243-4252.

Bovolenta P, Mallamaci A, Puelles L, Boncinelli E (1998) Expression pattern of cSix3, a member of the Six/sine oculis family of transcription factors. Mech Dev 70:201-203.

Branford WW, Yost HJ (2002) Lefty-dependent inhibition of Nodal- and Wnt-responsive organizer gene expression is essential for normal gastrulation. Curr Biol 12:2136-2141.

Brown KE, Keller PJ, Ramialison M, Rembold M, Stelzer EHK, Loosli F, Wittbrodt J (2010) Nlcam modulates midline convergence during anterior neural plate morphogenesis. Dev Biol 339:14-25.

Brzezinski JA, Lamba DA, Reh TA (2010) Blimp1 controls photoreceptor versus bipolar cell fate choice during retinal development. Development 137:619-629.

Burmeister M, Novak J, Liang M-Y, Basu S, Ploder L, Hawes NL, Vidgen D, Hoover F, Goldman D, Kalnins VI, Roderick TH, Taylor BA, Hankin MH, Mclnnes RR (1996) Ocular retardation mouse caused by Chx10 homeobox null allele: impaired retinal progenitor proliferation and bipolar cell differentiation. Nat Genet 12:376-384.

Capowski EE, Simonett JM, Clark EM, Wright LS, Howden SE, Wallace KA, Petelinsek AM, Pinilla I, Phillips MJ, Meyer JS, Schneider BL, Thomson JA, Gamm DM (2014) Loss of MITF expression during human embryonic stem cell differentiation disrupts retinal pigment epithelium development and optic vesicle cell proliferation. Hum Mol Genet 23:6332-6344.

Capowski EE, Wright LS, Liang K, Phillips MJ, Wallace K, Petelinsek A, Hagstrom A, Pinilla I, 
Borys K, Lien J, Min JH, Keles S, Thomson JA, Gamm DM (2016) Regulation of WNT Signaling by VSX2 During Optic Vesicle Patterning in Human Induced Pluripotent Stem Cells. Stem Cells.

Casarosa, Andreazzoli M, Simeone A, Barsacchi G (1997) Xrx1, a novel Xenopus homeobox gene expressed during eye and pineal gland development. Mech Dev 61:187-198.

Chase HB, Chase EB (1941) Studies on an anophthalmic strain of mice I. Embryology of the eye region. J Morphol 68:279-301.

Chassaing $\mathrm{N}$ et al. (2014) Molecular findings and clinical data in a cohort of 150 patients with anophthalmia/microphthalmia. Clin Genet 86:326-334.

Chen C-MA, Cepko CL (2002) The chicken RaxL gene plays a role in the initiation of photoreceptor differentiation. Development 129:5363-5375.

Chen HY, Kaya KD, Dong L, Swaroop A (2016) Three-dimensional retinal organoids from mouse pluripotent stem cells mimic in vivo development with enhanced stratification and rod photoreceptor differentiation. Mol Vis 22:1077-1094.

Chen J, Rattner A, Nathans J (2005) The rod photoreceptor-specific nuclear receptor Nr2e3 represses transcription of multiple cone-specific genes. J Neurosci 25:118-129.

Cheng H, Aleman TS, Cideciyan A V, Khanna R, Jacobson SG, Swaroop A (2006) In vivo function of the orphan nuclear receptor NR2E3 in establishing photoreceptor identity during mammalian retinal development. Hum Mol Genet 15:2588-2602.

Cheng H, Khanna H, Oh ECT, Hicks D, Mitton KP, Swaroop A (2004) Photoreceptor-specific nuclear receptor NR2E3 functions as a transcriptional activator in rod photoreceptors. Hum Mol Genet 13:1563-1575.

Chiang C, Litingtung Y, Lee E, Young KE, Corden JL, Westphal H, Beachy PA (1996) Cyclopia and defective axial patterning in mice lacking Sonic hedgehog gene function. Nature 383:407-413.

Chow RL, Lang RA (2001) Early eye development in vertebrates. Annu Rev Cell Dev Biol 17:255-296.

Chuang JC, Mathers PH, Raymond PA (1999) Expression of three Rx homeobox genes in embryonic and adult zebrafish. Mech Dev 84:195-198.

Cwinn MA, Mazerolle C, McNeill B, Ringuette R, Thurig S, Hui C, Wallace VA (2011b) Suppressor of fused is required to maintain the multipotency of neural progenitor cells in the retina. J Neurosci 31:5169-5180.

Danno H, Michiue T, Hitachi K, Yukita A, Ishiura S, Asashima M (2008) Molecular links among the causative genes for ocular malformation: Otx2 and Sox2 coregulate Rax expression. Proc Natl Acad Sci 105:5408-5413.

Davis RJ, Tavsanli BC, Dittrich C, Walldorf U, Mardon G (2003) Drosophila retinal homeobox $(\mathrm{drx})$ is not required for establishment of the visual system, but is required for brain and clypeus development. Dev Biol 259:272-287.

de Melo J, Miki K, Rattner A, Smallwood P, Zibetti C, Hirokawa K, Monuki ES, Campochiaro PA, Blackshaw S (2012) Injury-independent induction of reactive gliosis in retina by loss of function of the LIM homeodomain transcription factor Lhx2. Proc Natl Acad Sci 109:4657- 
4662.

Deml B, Reis LM, Lemyre E, Clark RD, Kariminejad A, Semina E V (2016) Novel mutations in PAX6, OTX2 and NDP in anophthalmia, microphthalmia and coloboma. Eur J Hum Genet 24:535-541.

Deschet K, Bourrat F, Ristoratore F, Chourrout D, Joly JS (1999) Expression of the medaka (Oryzias latipes) OI-Rx3 paired-like gene in two diencephalic derivatives, the eye and the hypothalamus. Mech Dev 83:179-182.

Desmaison A, Vigouroux A, Rieubland C, Peres C, Calvas P, Chassaing N (2010) Mutations in the LHX2 gene are not a frequent cause of micro/anophthalmia.

Dyer MA, Cepko CL (2001) Regulating proliferation during retinal development. Nat Rev Neurosci 2:333-342.

Dyer MA, Livesey FJ, Cepko CL, Oliver G (2003) Prox1 function controls progenitor cell proliferation and horizontal cell genesis in the mammalian retina. Nat Genet 34:53-58.

Eggert T, Hauck B, Hildebrandt N, Gehring WJ, Walldorf U (1998) Isolation of a Drosophila homolog of the vertebrate homeobox gene $\mathrm{Rx}$ and its possible role in brain and eye development. Proc Natl Acad Sci U S A 95:2343-2348.

Eiraku M, Adachi T, Sasai Y (2012) Relaxation-expansion model for self-driven retinal morphogenesis: a hypothesis from the perspective of biosystems dynamics at the multicellular level. Bioessays 34:17-25.

Eiraku M, Sasai Y (2011) Mouse embryonic stem cell culture for generation of threedimensional retinal and cortical tissues. Nat Protoc 7:69-79.

Eiraku M, Takata N, Ishibashi H, Kawada M, Sakakura E, Okuda S, Sekiguchi K, Adachi T, Sasai $Y$ (2011) Self-organizing optic-cup morphogenesis in three-dimensional culture. Nature 472:51-56.

Feng R, Wen J (2015) Overview of the roles of Sox2 in stem cell and development. Biol Chem 396.

Ferda Percin E, Ploder LA, Yu JJ, Arici K, Horsford DJ, Rutherford A, Bapat B, Cox DW, Duncan AM, Kalnins VI, Kocak-Altintas A, Sowden JC, Traboulsi E, Sarfarazi M, Mclnnes RR (2000) Human microphthalmia associated with mutations in the retinal homeobox gene CHX10. Nat Genet 25:397-401.

Finkbeiner SR, Freeman JJ, Wieck MM, El-Nachef W, Altheim CH, Tsai Y-H, Huang S, Dyal R, White ES, Grikscheit TC, Teitelbaum DH, Spence JR (2015) Generation of tissueengineered small intestine using embryonic stem cell-derived human intestinal organoids. Biol Open 4:1462-1472.

Fish MB, Nakayama T, Fisher M, Hirsch N, Cox A, Reeder R, Carruthers S, Hall A, Stemple DL, Grainger RM (2014) Xenopus mutant reveals necessity of rax for specifying the eye field which otherwise forms tissue with telencephalic and diencephalic character. Dev Biol 395:317-330.

Flanagan DJ, Schwab RHM, Tran BM, Phesse TJ, Vincan E (2016) Isolation and Culture of Adult Intestinal, Gastric, and Liver Organoids for Cre-recombinase-Mediated Gene Deletion. Methods Mol Biol. 
Foshay KM, Gallicano GI (2008) Regulation of Sox2 by STAT3 Initiates Commitment to the Neural Precursor Cell Fate. Stem Cells Dev 17:269-278.

Freund CL, Gregory-Evans CY, Furukawa T, Papaioannou M, Looser J, Ploder L, Bellingham J, $\mathrm{Ng}$ D, Herbrick J-AS, Duncan A, Scherer SW, Tsui L-C, Loutradis-Anagnostou A, Jacobson SG, Cepko CL, Bhattacharya SS, McInnes RR (1997) Cone-Rod Dystrophy Due to Mutations in a Novel Photoreceptor-Specific Homeobox Gene (CRX) Essential for Maintenance of the Photoreceptor. Cell 91:543-553.

Fu Y, Liu H, Ng L, Kim J-W, Hao H, Swaroop A, Forrest D (2014) Feedback induction of a photoreceptor-specific isoform of retinoid-related orphan nuclear receptor $\beta$ by the rod transcription factor NRL. J Biol Chem 289:32469-32480.

Fujieda H, Bremner R, Mears AJ, Sasaki H (2009) Retinoic acid receptor-related orphan receptor alpha regulates a subset of cone genes during mouse retinal development. $J$ Neurochem 108:91-101.

Furukawa T et al. (2000) rax, Hes1, and notch1 Promote the Formation of Müller Glia by Postnatal Retinal Progenitor Cells. Neuron 26:383-394.

Furukawa T, Cepko CL, Morrow EM, Li T, Davis FC (1999) Retinopathy and attenuated circadian entrainment in Crx-deficientmice. Nat Genet 23:466-470.

Furukawa T, Kozak CA, Cepko CL (1997a) rax, a novel paired-type homeobox gene, shows expression in the anterior neural fold and developing retina. Proc Natl Acad Sci U S A 94:3088-3093.

Furukawa T, Morrow EM, Cepko CL (1997b) Crx, a novel otx-like homeobox gene, shows photoreceptor-specific expression and regulates photoreceptor differentiation. Cell 91:531541.

Gehring WJ (1996) The master control gene for morphogenesis and evolution of the eye. Genes Cells 1:11-15.

Gehring WJ, Affolter M, Burglin T (1994) Homeodomain Proteins. Annu Rev Biochem 63:487526.

Geng X, Acosta S, Lagutin O, Gil H, Oliver G (2016) Six3 dosage mediates the pathogenesis of holoprosencephaly. Development:dev.132142.

Geng X, Speirs C, Lagutin O, Inbal A, Liu W, Solnica-Krezel L, Jeong Y, Epstein DJ, Oliver G (2008) Haploinsufficiency of Six3 fails to activate Sonic hedgehog expression in the ventral forebrain and causes holoprosencephaly. Dev Cell 15:236-247.

Gestri G (2005) Six3 functions in anterior neural plate specification by promoting cell proliferation and inhibiting Bmp4 expression. Development 132:2401-2413.

Giannaccini M, Giudetti G, Biasci D, Mariotti S, Martini D, Barsacchi G, Andreazzoli M (2013) Brief Report: Rx1 Defines Retinal Precursor Identity by Repressing Alternative Fates Through the Activation of TLE2 and Hes4. Stem Cells 31:2842-2847.

Glaser T, Walton DS, Maas RL (1992) Genomic structure, evolutionary conservation and aniridia mutations in the human PAX6 gene. Nat Genet 2:232-239.

Glinka A, Wu W, Delius H, Monaghan AP, Blumenstock C, Niehrs C (1998) Dickkopf-1 is a member of a new family of secreted proteins and functions in head induction. Nature 
391:357-362.

Gonzalez-Rodriguez J, Pelcastre EL, Tovilla-Canales JL, Garcia-Ortiz JE, Amato-Almanza M, Villanueva-Mendoza C, Espinosa-Mattar Z, Zenteno JC (2010) Mutational screening of CHX10, GDF6, OTX2, RAX and SOX2 genes in 50 unrelated microphthalmiaanophthalmia-coloboma (MAC) spectrum cases. Br J Ophthalmol 94:1100-1104.

Gordon PJ, Yun S, Clark AM, Monuki ES, Murtaugh LC, Levine EM (2013) Lhx2 Balances Progenitor Maintenance with Neurogenic Output and Promotes Competence State Progression in the Developing Retina. J Neurosci 33:12197-12207.

Granadino B, Gallardo ME, López-Ríos J, Sanz R, Ramos C, Ayuso C, Bovolenta P, Rodríguez de Córdoba S (1999) Genomic Cloning, Structure, Expression Pattern, and Chromosomal Location of the HumanSIX3Gene.

Graw J (2010) Eye development. Curr Top Dev Biol 90:343-386.

Green ES, Stubbs JL, Levine EM (2003) Genetic rescue of cell number in a mouse model of microphthalmia: interactions between $\mathrm{Chx10}$ and $\mathrm{G} 1$-phase cell cycle regulators. Development 130:539-552.

Grindley JC, Davidson DR, Hill RE (1995) The role of Pax-6 in eye and nasal development. Development 121:1433-1442.

Grindley JC, Hargett LK, Hill RE, Ross A, Hogan BL (1997) Disruption of PAX6 function in mice homozygous for the Pax6Sey-1Neu mutation produces abnormalities in the early development and regionalization of the diencephalon. Mech Dev 64:111-126.

Heavner W, Pevny L (2012) Eye Development and Retinogenesis. Cold Spring Harb Perspect Biol 4:a008391-a008391.

Hever A, Williamson K, Van Heyningen V (2006) Developmental malformations of the eye: the role of PAX6, SOX2 and OTX2. Clin Genet 69:459-470.

Hill RE, Favor J, Hogan BL, Ton CC, Saunders GF, Hanson IM, Prosser J, Jordan T, Hastie ND, van Heyningen V (1991) Mouse small eye results from mutations in a paired-like homeobox-containing gene. Nature 354:522-525.

Hirami Y, Osakada F, Takahashi K, Okita K, Yamanaka S, Ikeda H, Yoshimura N, Takahashi M (2009) Generation of retinal cells from mouse and human induced pluripotent stem cells. Neurosci Lett 458:126-131.

Hirano M, Yamamoto A, Yoshimura N, Tokunaga T, Motohashi T, Ishizaki K, Yoshida H, Okazaki K, Yamazaki H, Hayashi S-I, Kunisada T (2003) Generation of structures formed by lens and retinal cells differentiating from embryonic stem cells. Dev Dyn 228:664-671.

Hirsch N, Zimmerman LB, Gray J, Chae J, Curran KL, Fisher M, Ogino H, Grainger RM (2002) Xenopus tropicalis transgenic lines and their use in the study of embryonic induction. Dev Dyn 225:522-535.

Hodgkinson CA, Moore KJ, Nakayama A, Steingrímsson E, Copeland NG, Jenkins NA, Arnheiter $\mathrm{H}$ (1993) Mutations at the mouse microphthalmia locus are associated with defects in a gene encoding a novel basic-helix-loop-helix-zipper protein. Cell 74:395-404.

Hoffpauir BK, Marrs GS, Mathers PH, Spirou GA (2009) Does the brain connect before the periphery can direct? A comparison of three sensory systems in mice. Brain Res 
1277:115-129.

Hogan BL, Horsburgh G, Cohen J, Hetherington CM, Fisher G, Lyon MF (1986) Small eyes (Sey): a homozygous lethal mutation on chromosome 2 which affects the differentiation of both lens and nasal placodes in the mouse. J Embryol Exp Morphol 97:95-110.

Hollemann T, Bellefroid E, Pieler T (1998) The Xenopus homologue of the Drosophila gene tailless has a function in early eye development. Development 125:2425-2432.

Holt CE, Bertsch TW, Ellis HM, Harris WA (1988) Cellular determination in the Xenopus retina is independent of lineage and birth date. Neuron 1:15-26.

Horsford DJ, Nguyen M-TT, Sellar GC, Kothary R, Arnheiter H, Mclnnes RR (2005) Chx10 repression of Mitf is required for the maintenance of mammalian neuroretinal identity. Development 132:177-187.

Houart C, Caneparo L, Heisenberg C, Barth K, Take-Uchi M, Wilson S (2002) Establishment of the telencephalon during gastrulation by local antagonism of Wnt signaling. Neuron 35:255-265.

Ikeda H, Osakada F, Watanabe K, Mizuseki K, Haraguchi T, Miyoshi H, Kamiya D, Honda Y, Sasai N, Yoshimura N, Takahashi M, Sasai Y (2005) Generation of Rx+/Pax6+ neural retinal precursors from embryonic stem cells. Proc Natl Acad Sci 102:11331-11336.

Inoue M, Kamachi Y, Matsunami H, Imada K, Uchikawa M, Kondoh H (2007) PAX6 and SOX2dependent regulation of the Sox2 enhancer N-3 involved in embryonic visual system development. Genes to Cells 12:1049-1061.

Irie S, Sanuki R, Muranishi Y, Kato K, Chaya T, Furukawa T (2015) Rax Homeoprotein Regulates Photoreceptor Cell Maturation and Survival in Association with Crx in the Postnatal Mouse Retina. Mol Cell Biol 35:2583-2596.

Jayakody SA, Gonzalez-Cordero A, Ali RR, Pearson RA (2015) Cellular strategies for retinal repair by photoreceptor replacement. Prog Retin Eye Res 46:31-66.

Jean D, Bernier G, Gruss P (1999) Six6 (Optx2) is a novel murine Six3-related homeobox gene that demarcates the presumptive pituitary/hypothalamic axis and the ventral optic stalk. Mech Dev 84:31-40.

Jeong Y, Leskow FC, El-Jaick K, Roessler E, Muenke M, Yocum A, Dubourg C, Li X, Geng X, Oliver G, Epstein DJ (2008) Regulation of a remote Shh forebrain enhancer by the Six3 homeoprotein. Nat Genet 40:1348-1353.

Jia L, Oh ECT, Ng L, Srinivas M, Brooks M, Swaroop A, Forrest D (2009) Retinoid-related orphan nuclear receptor RORbeta is an early-acting factor in rod photoreceptor development. Proc Natl Acad Sci U S A 106:17534-17539.

Kaewkhaw R, Kaya KD, Brooks M, Homma K, Zou J, Chaitankar V, Rao M, Swaroop A (2015) Transcriptome Dynamics of Developing Photoreceptors in Three-Dimensional Retina Cultures Recapitulates Temporal Sequence of Human Cone and Rod Differentiation Revealing Cell Surface Markers and Gene Networks. Stem Cells 33:3504-3518.

Kaji K, Norrby K, Paca A, Mileikovsky M, Mohseni P, Woltjen K (2009) Virus-free induction of pluripotency and subsequent excision of reprogramming factors. Nature 458:771-775.

Katoh K, Omori Y, Onishi A, Sato S, Kondo M, Furukawa T (2010) Blimp1 suppresses Chx10 
expression in differentiating retinal photoreceptor precursors to ensure proper photoreceptor development. J Neurosci 30:6515-6526.

Kelly LE, Martinez-De Luna RI, El-Hodiri HM (2016) Autoregulation of retinal homeobox ( rax ) gene promoter activity through a highly conserved genomic element. genesis 54:562-567.

Kennedy BN, Stearns GW, Smyth VA, Ramamurthy V, van Eeden F, Ankoudinova I, Raible D, Hurley JB, Brockerhoff SE (2004) Zebrafish rx3 and mab21l2 are required during eye morphogenesis. Dev Biol 270:336-349.

Kenyon KL, Zaghloul N, Moody SA (2001) Transcription Factors of the Anterior Neural Plate Alter Cell Movements of Epidermal Progenitors to Specify a Retinal Fate. Dev Biol 240:7791.

Kim D, Kim C-H, Moon J-I, Chung Y-G, Chang M-Y, Han B-S, Ko S, Yang E, Cha KY, Lanza R, Kim K-S (2009) Generation of human induced pluripotent stem cells by direct delivery of reprogramming proteins. Cell Stem Cell 4:472-476.

Kimura A, Singh D, Wawrousek EF, Kikuchi M, Nakamura M, Shinohara T (2000) Both PCE$1 / R X$ and OTX/CRX interactions are necessary for photoreceptor-specific gene expression. J Biol Chem 275:1152-1160.

Koike C, Nishida A, Ueno S, Saito H, Sanuki R, Sato S, Furukawa A, Aizawa S, Matsuo I, Suzuki N, Kondo M, Furukawa T (2007) Functional Roles of Otx2 Transcription Factor in Postnatal Mouse Retinal Development. Mol Cell Biol 27:8318-8329.

Koo B-K, Stange DE, Sato T, Karthaus W, Farin HF, Huch M, van Es JH, Clevers H (2011) Controlled gene expression in primary Lgr5 organoid cultures. Nat Methods 9:81-83.

Kumar JP (2009) The sine oculis homeobox (SIX) family of transcription factors as regulators of development and disease. Cell Mol Life Sci 66:565-583.

Lacbawan F et al. (2009) Clinical spectrum of SIX3-associated mutations in holoprosencephaly: correlation between genotype, phenotype and function. J Med Genet 46:389-398.

Lagutin O V, Zhu CC, Kobayashi D, Topczewski J, Shimamura K, Puelles L, Russell HRC, McKinnon PJ, Solnica-Krezel L, Oliver G (2003) Six3 repression of Wnt signaling in the anterior neuroectoderm is essential for vertebrate forebrain development. Genes Dev 17:368-379.

Lamba DA, Gust J, Reh TA (2009) Transplantation of Human Embryonic Stem Cell-Derived Photoreceptors Restores Some Visual Function in Crx-Deficient Mice. Cell Stem Cell 4:7379.

Lamba DA, Karl MO, Ware CB, Reh TA (2006) Efficient generation of retinal progenitor cells from human embryonic stem cells. Proc Natl Acad Sci 103:12769-12774.

Lamba DA, McUsic A, Hirata RK, Wang P-R, Russell D, Reh TA (2010) Generation, Purification and Transplantation of Photoreceptors Derived from Human Induced Pluripotent Stem Cells Linden R, ed. PLoS One 5:e8763.

Le RD, Rayner K, Rex M, Wigmore PM, Scotting PJ (2002) The transcription factor cSox2 and Neuropeptide $Y$ define a novel subgroup of amacrine cells in the retina. J Anat 200:51-56.

Lee HJ, Colby KA (2013) A review of the clinical and genetic aspects of aniridia. Semin Ophthalmol 28:306-312. 
Lenkowski JR, Raymond PA (2014) Müller glia: Stem cells for generation and regeneration of retinal neurons in teleost fish. Prog Retin Eye Res 40:94-123.

Lequeux L, Rio M, Vigouroux A, Titeux M, Etchevers H, Malecaze F, Chassaing N, Calvas P (2008) Confirmation of RAX gene involvement in human anophthalmia. Clin Genet 74:392395.

Liang L, Sandell JH (2008) Focus on molecules: Homeobox protein Chx10. Exp Eye Res 86:541-542.

Lin Y, Ouchi Y, Satoh S, Watanabe S (2009) Sox2 plays a role in the induction of amacrine and Müller glial cells in mouse retinal progenitor cells. Invest Ophthalmol Vis Sci 50:68-74.

Little MH, Takasato M (2015) Generating a self-organizing kidney from pluripotent cells. Curr Opin Organ Transplant 20:178-186.

Liu H, Etter P, Hayes S, Jones I, Nelson B, Hartman B, Forrest D, Reh TA (2008) NeuroD1 Regulates Expression of Thyroid Hormone Receptor 2 and Cone Opsins in the Developing Mouse Retina. J Neurosci 28:749-756.

Liu ISC, Chen J, Ploder L, Vidgen D, van der Kooy D, Kalnins VI, Mclnnes RR (1994) Developmental expression of a novel murine homeobox gene (Chx10): Evidence for roles in determination of the neuroretina and inner nuclear layer. Neuron 13:377-393.

London NJS, Kessler P, Williams B, Pauer GJ, Hagstrom SA, Traboulsi El (2009) Sequence alterations in $\mathrm{RX}$ in patients with microphthalmia, anophthalmia, and coloboma. Mol Vis 15:162-167.

Loosli F, Köster RW, Carl M, Krone A, Wittbrodt J (1998) Six3, a medaka homologue of the Drosophila homeobox gene sine oculis is expressed in the anterior embryonic shield and the developing eye. Mech Dev 74:159-164.

Loosli F, Staub W, Finger-Baier KC, Ober EA, Verkade H, Wittbrodt J, Baier H (2003) Loss of eyes in zebrafish caused by mutation of chokh/rx3. EMBO Rep 4:894-899.

Loosli F, Winkler S, Burgtorf C, Wurmbach E, Ansorge W, Henrich T, Grabher C, Arendt D, Carl M, Krone A, Grzebisz E, Wittbrodt J (2001) Medaka eyeless is the key factor linking retinal determination and eye growth. Development 128:4035-4044.

Loosli F, Winkler S, Wittbrodt J (1999) Six3 overexpression initiates the formation of ectopic retina. Genes Dev 13:649-654.

Lord-Grignon J, Abdouh M, Bernier G (2006) Identification of genes expressed in retinal progenitor/stem cell colonies isolated from the ocular ciliary body of adult mice.

Lu F, Kar D, Gruenig N, Zhang ZW, Cousins N, Rodgers HM, Swindell EC, Jamrich M, Schuurmans C, Mathers PH, Kurrasch DM (2013) Rax is a selector gene for mediobasal hypothalamic cell types. J Neurosci 33:259-272.

Lukovic D, Artero Castro A, Delgado ABG, Bernal M de los AM, Luna Pelaez N, Díez Lloret A, Perez Espejo R, Kamenarova K, Fernández Sánchez L, Cuenca N, Cortón M, Avila Fernandez A, Sorkio A, Skottman H, Ayuso C, Erceg S, Bhattacharya SS (2015) Human iPSC derived disease model of MERTK-associated retinitis pigmentosa. Sci Rep 5:12910.

Makarenkova HP, Ito M, Govindarajan V, Faber SC, Sun L, McMahon G, Overbeek PA, Lang RA (2000) FGF10 is an inducer and Pax6 a competence factor for lacrimal gland 
development. Development 127:2563-2572.

Marquardt T, Ashery-Padan R, Andrejewski N, Scardigli R, Guillemot F, Gruss P (2001) Pax6 is required for the multipotent state of retinal progenitor cells. Cell 105:43-55.

Marquardt T, Gruss P (2002) Generating neuronal diversity in the retina: one for nearly all. Trends Neurosci 25:32-38.

Martin GR (1981) Isolation of a pluripotent cell line from early mouse embryos cultured in medium conditioned by teratocarcinoma stem cells. Proc Natl Acad Sci U S A 78:76347638.

Martinez-De Luna RI, Kelly LE, El-Hodiri HM (2011) The Retinal Homeobox (Rx) gene is necessary for retinal regeneration. Dev Biol 353:10-18.

Martinez-Gimeno M, Maseras M, Baiget M, Beneito M, Antiñolo G, Ayuso C, Carballo M (2001) Mutations P51U and G122E in retinal transcription factor NRL associated with autosomal dominant and sporadic retinitis pigmentosa. Hum Mutat 17:520-520.

Martins RAP, Pearson RA (2008) Control of cell proliferation by neurotransmitters Martins, R.A.P., Pearson, R.A., 2008. Control of cell proliferation by neurotransmitters in the developing vertebrate retina. Brain Res. 1192, 37-60. doi:10.1016/j.brainres.2007.04.076in the developing ve. Brain Res 1192:37-60.

Masui S, Nakatake Y, Toyooka Y, Shimosato D, Yagi R, Takahashi K, Okochi H, Okuda A, Matoba R, Sharov AA, Ko MSH, Niwa H (2007) Pluripotency governed by Sox2 via regulation of Oct3/4 expression in mouse embryonic stem cells. Nat Cell Biol 9:625-635.

Mathers PH, Grinberg A, Mahon KA, Jamrich M (1997) The Rx homeobox gene is essential for vertebrate eye development. Nature 387:603-607.

Matsuo I, Kuratani S, Kimura C, Takeda N, Aizawa S (1995) Mouse Otx2 functions in the formation and patterning of rostral head. Genes Dev 9:2646-2658.

Matsuo T, Osumi-Yamashita N, Noji S, Ohuchi H, Koyama E, Myokai F, Matsuo N, Taniguchi S, Doi H, Iseki S (1993) A mutation in the Pax-6 gene in rat small eye is associated with impaired migration of midbrain crest cells. Nat Genet 3:299-304.

Matsushima D, Heavner W, Pevny LH (2011) Combinatorial regulation of optic cup progenitor cell fate by SOX2 and PAX6. Development 138:443-454.

McFarlane S, Zuber ME, Holt CE (1998) A role for the fibroblast growth factor receptor in cell fate decisions in the developing vertebrate retina. Development 125:3967-3975.

Mears AJ, Kondo M, Swain PK, Takada Y, Bush RA, Saunders TL, Sieving PA, Swaroop A (2001) Nrl is required for rod photoreceptor development. Nat Genet 29:447-452.

Meyer JS, Howden SE, Wallace KA, Verhoeven AD, Wright LS, Capowski EE, Pinilla I, Martin JM, Tian S, Stewart R, Pattnaik B, Thomson JA, Gamm DM (2011) Optic vesicle-like structures derived from human pluripotent stem cells facilitate a customized approach to retinal disease treatment. Stem Cells 29:1206-1218.

Mori M, Ghyselinck NB, Chambon P, Mark M (2001) Systematic immunolocalization of retinoid receptors in developing and adult mouse eyes. Invest Ophthalmol Vis Sci 42:1312-1318.

Muenke M, Cohen MM (2000) Genetic approaches to understanding brain development: Holoprosencephaly as a model. Ment Retard Dev Disabil Res Rev 6:15-21. 
Muranishi Y, Terada K, Inoue T, Katoh K, Tsuji T, Sanuki R, Kurokawa D, Aizawa S, Tamaki Y, Furukawa T (2011) An essential role for RAX homeoprotein and NOTCH-HES signaling in Otx2 expression in embryonic retinal photoreceptor cell fate determination. J Neurosci 31:16792-16807.

Nakagawa M, Koyanagi M, Tanabe K, Takahashi K, Ichisaka T, Aoi T, Okita K, Mochiduki Y, Takizawa N, Yamanaka S (2008) Generation of induced pluripotent stem cells without Myc from mouse and human fibroblasts. Nat Biotechnol 26:101-106.

Nakano T, Ando S, Takata N, Kawada M, Muguruma K, Sekiguchi K, Saito K, Yonemura S, Eiraku M, Sasai Y (2012) Self-formation of optic cups and storable stratified neural retina from human ESCs. Cell Stem Cell 10:771-785.

Nelson SM, Park L, Stenkamp DL (2009) Retinal homeobox 1 is required for retinal neurogenesis and photoreceptor differentiation in embryonic zebrafish. Dev Biol 328:2439.

Ng L, Hurley JB, Dierks B, Srinivas M, Saltó C, Vennström B, Reh TA, Forrest D (2001) A thyroid hormone receptor that is required for the development of green cone photoreceptors. Nat Genet 27:94-98.

$\mathrm{Ng} \mathrm{L}$, Ma M, Curran T, Forrest D (2009) Developmental expression of thyroid hormone receptor beta2 protein in cone photoreceptors in the mouse. Neuroreport 20:627-631.

NIH Stem Cell Information Home Page. In Stem Cell Information [World Wide Web site]. Bethesda, MD: National Institutes of Health, U.S. Department of Health and Human Services, 2016 [cited April 2, 2017] Available at <//stemcells.nih.gov/info/basics/1.htm>

Nishida A, Furukawa A, Koike C, Tano Y, Aizawa S, Matsuo I, Furukawa T (2003) Otx2 homeobox gene controls retinal photoreceptor cell fate and pineal gland development. Nat Neurosci 6:1255-1263.

Nistor G, Seiler MJ, Yan F, Ferguson D, Keirstead HS (2010) Three-dimensional early retinal progenitor 3D tissue constructs derived from human embryonic stem cells. J Neurosci Methods 190:63-70.

Nornes HO, Dressler GR, Knapik EW, Deutsch U, Gruss P (1990) Spatially and temporally restricted expression of Pax2 during murine neurogenesis. Development 109:797-809.

Oh ECT, Cheng H, Hao H, Jia L, Khan NW, Swaroop A (2008) Rod differentiation factor NRL activates the expression of nuclear receptor NR2E3 to suppress the development of cone photoreceptors. Brain Res 1236:16-29.

Oh ECT, Khan N, Novelli E, Khanna H, Strettoi E, Swaroop A (2007) Transformation of cone precursors to functional rod photoreceptors by bZIP transcription factor NRL. Proc Natl Acad Sci U S A 104:1679-1684.

Ohlemacher SK, Iglesias CL, Sridhar A, Gamm DM, Meyer JS (2015) Generation of highly enriched populations of optic vesicle-like retinal cells from human pluripotent stem cells. Curr Protoc Stem Cell Biol 32:1H.8.1-20.

Ohlemacher SK, Sridhar A, Xiao Y, Hochstetler AE, Sarfarazi M, Cummins TR, Meyer JS (2016) Stepwise Differentiation of Retinal Ganglion Cells from Human Pluripotent Stem Cells Enables Analysis of Glaucomatous Neurodegeneration. Stem Cells 34:1553-1562.

Ohsawa R, Kageyama R (2008) Regulation of retinal cell fate specification by multiple 
transcription factors. Brain Res 1192:90-98.

Ohuchi H, Tomonari S, Itoh H, Mikawa T, Noji S (1999) Identification of chick rax/rx genes with overlapping patterns of expression during early eye and brain development. Mech Dev 85:193-195.

Okita K, Nakagawa M, Hyenjong H, Ichisaka T, Yamanaka S (2008) Generation of Mouse Induced Pluripotent Stem Cells Without Viral Vectors. Science (80- ) 322:949-953.

Oliver G, Mailhos A, Wehr R, Copeland NG, Jenkins NA, Gruss P (1995) Six3, a murine homologue of the sine oculis gene, demarcates the most anterior border of the developing neural plate and is expressed during eye development. Development 121:4045-4055.

Onwochei BC, Simon JW, Bateman JB, Couture KC, Mir E (2000) Ocular colobomata. Surv Ophthalmol 45:175-194.

Osakada F, Ikeda H, Mandai M, Wataya T, Watanabe K, Yoshimura N, Akaike A, Sasai Y, Takahashi M (2008) Toward the generation of rod and cone photoreceptors from mouse, monkey and human embryonic stem cells. Nat Biotechnol 26:215-224.

Osakada F, Jin Z-B, Hirami Y, Ikeda H, Danjyo T, Watanabe K, Sasai Y, Takahashi M (2009) In vitro differentiation of retinal cells from human pluripotent stem cells by small-molecule induction. J Cell Sci 122:3169-3179.

Pan Y, Nekkalapudi S, Kelly LE, El-Hodiri HM (2006) The Rx-like homeobox gene (Rx-L) is necessary for normal photoreceptor development. Invest Ophthalmol Vis Sci 47:42454253.

Parker SE, Mai CT, Canfield MA, Rickard R, Wang Y, Meyer RE, Anderson P, Mason CA, Collins JS, Kirby RS, Correa A (2010) Updated national birth prevalence estimates for selected birth defects in the United States, 2004-2006. Birth Defects Res Part A Clin Mol Teratol 88:1008-1016.

Pendergraft SS, Sadri-Ardekani H, Atala A, Bishop CE (2017) Three-dimensional testicular organoid: a novel tool for the study of human spermatogenesis and gonadotoxicity in vitro†. Biol Reprod 96:720-732.

Peng G-H, Ahmad O, Ahmad F, Liu J, Chen S (2005) The photoreceptor-specific nuclear receptor Nr2e3 interacts with Crx and exerts opposing effects on the transcription of rod versus cone genes. Hum Mol Genet 14:747-764.

Pera EM, Wessely O, Li SY, De Robertis EM (2001) Neural and head induction by insulin-like growth factor signals. Dev Cell 1:655-665.

Phillips MJ, Perez ET, Martin JM, Reshel ST, Wallace KA, Capowski EE, Singh R, Wright LS, Clark EM, Barney PM, Stewart R, Dickerson SJ, Miller MJ, Percin EF, Thomson JA, Gamm DM (2014) Modeling human retinal development with patient-specific induced pluripotent stem cells reveals multiple roles for visual system homeobox 2 . Stem Cells 32:1480-1492.

Piccolo S, Agius E, Leyns L, Bhattacharyya S, Grunz H, Bouwmeester T, De Robertis EM (1999) The head inducer Cerberus is a multifunctional antagonist of Nodal, BMP and Wnt signals. Nature 397:707-710.

Porter FD, Drago J, Xu Y, Cheema SS, Wassif C, Huang SP, Lee E, Grinberg A, Massalas JS, Bodine D, Alt F, Westphal H (1997) Lhx2, a LIM homeobox gene, is required for eye, forebrain, and definitive erythrocyte development. Development 124:2935-2944. 
Quiring R, Walldorf U, Kloter U, Gehring WJ (1994) Homology of the eyeless gene of Drosophila to the Small eye gene in mice and Aniridia in humans. Science 265:785-789.

Ragge NK et al. (2005) Heterozygous mutations of OTX2 cause severe ocular malformations. Am J Hum Genet 76:1008-1022.

Rapaport DH, Wong LL, Wood ED, Yasumura D, LaVail MM (2004) Timing and topography of cell genesis in the rat retina. J Comp Neurol 474:304-324.

Rasmussen JT, Deardorff MA, Tan C, Rao MS, Klein PS, Vetter ML (2001) Regulation of eye development by frizzled signaling in Xenopus. Proc Natl Acad Sci 98:3861-3866.

Rebagliati MR, Toyama R, Haffter P, Dawid IB (1998) cyclops encodes a nodal-related factor involved in midline signaling. Proc Natl Acad Sci U S A 95:9932-9937.

Reis LM, Khan A, Kariminejad A, Ebadi F, Tyler RC, Semina E V (2011) VSX2 mutations in autosomal recessive microphthalmia. Mol Vis 17:2527-2532.

Rembold M, Loosli F, Adams RJ, Wittbrodt J (2006) Individual Cell Migration Serves as the Driving Force for Optic Vesicle Evagination. Science (80- ) 313.

Rhode K, Klein DC, Morten Mo, Rath MF (2011) Developmental and daily expression patterins in the rat pineal gland and retina. 118:999-1007.

Ribeiro LA, Bertolacini CDP, Quiezi RG, Richieri-Costa A (2011) A novel heterozygous missense mutation G316D of SIX3 gene in a Brazilian patient with holoprosencephaly-like phenotype and Langerhans cell histiocytosis. Clin Dysmorphol 20:160-162.

Roberts MR, Hendrickson A, McGuire CR, Reh TA (2005) Retinoid X receptor (gamma) is necessary to establish the S-opsin gradient in cone photoreceptors of the developing mouse retina. Invest Ophthalmol Vis Sci 46:2897-2904.

Roessler E, Belloni E, Gaudenz K, Jay P, Berta P, Scherer SW, Tsui L-C, Muenke M (1996) Mutations in the human Sonic Hedgehog gene cause holoprosencephaly. Nat Genet 14:357-360.

Rowan S, Cepko CL (2004) Genetic analysis of the homeodomain transcription factor Chx10 in the retina using a novel multifunctional BAC transgenic mouse reporter. Dev Biol 271:388402.

Rowan S, Chen C-MA, Young TL, Fisher DE, Cepko CL (2004) Transdifferentiation of the retina into pigmented cells in ocular retardation mice defines a new function of the homeodomain gene Chx10. Development 131:5139-5152.

Schaeren-Wiemers N, André E, Kapfhammer JP, Becker-André M (1997) The expression pattern of the orphan nuclear receptor RORbeta in the developing and adult rat nervous system suggests a role in the processing of sensory information and in circadian rhythm. Eur J Neurosci 9:2687-2701.

Schedl A, Ross A, Lee M, Engelkamp D, Rashbass P, van Heyningen V, Hastie ND (1996) Influence of PAX6 gene dosage on development: overexpression causes severe eye abnormalities. Cell 86:71-82.

Schwarz M, Cecconi F, Bernier G, Andrejewski N, Kammandel B, Wagner M, Gruss P (2000) Spatial specification of mammalian eye territories by reciprocal transcriptional repression of Pax2 and Pax6. Development 127:4325-4334. 
Sigulinsky CL, Green ES, Clark AM, Levine EM (2008) Vsx2/Chx10 ensures the correct timing and magnitude of Hedgehog signaling in the mouse retina. Dev Biol 317:560-575.

Simeone A, Acampora D, Gulisano M, Stornaiuolo A, Boncinelli E (1992) Nested expression domains of four homeobox genes in developing rostral brain. Nature 358:687-690.

Simeone A, Acampora D, Mallamaci A, Stornaiuolo A, D’Apice MR, Nigro V, Boncinelli E (1993) A vertebrate gene related to orthodenticle contains a homeodomain of the bicoid class and demarcates anterior neuroectoderm in the gastrulating mouse embryo. EMBO J 12:27352747.

Sohocki MM, Sullivan LS, Mintz-Hittner HA, Birch D, Heckenlively JR, Freund CL, Mclnnes RR, Daiger SP (1998) A Range of Clinical Phenotypes Associated with Mutations in CRX, a Photoreceptor Transcription-Factor Gene. Am J Hum Genet 63:1307-1315.

Solomon BD, Lacbawan F, Jain M, Domené S, Roessler E, Moore C, Dobyns WB, Muenke M (2009) A novel SIX3 mutation segregates with holoprosencephaly in a large family. Am J Med Genet A 149A:919-925.

Srinivas M, Ng L, Liu H, Jia L, Forrest D (2006) Activation of the blue opsin gene in cone photoreceptor development by retinoid-related orphan receptor beta. Mol Endocrinol 20:1728-1741.

St-Onge L, Sosa-Pineda B, Chowdhury K, Mansouri A, Gruss P (1997) Pax6 is required for differentiation of glucagon-producing $\alpha$-cells in mouse pancreas. Nature 387:406-409.

Strickler AG, Famuditimi K, Jeffery WR (2002) Retinal homeobox genes and the role of cell proliferation in cavefish eye degeneration. Int J Dev Biol 46:285-294.

Sung C-H, Chuang J-Z (2010) The cell biology of vision. J Cell Biol 190:953-963.

Swaroop A, Kim D, Forrest D (2010) Transcriptional regulation of photoreceptor development and homeostasis in the mammalian retina. Nat Rev Neurosci 11:563-576.

Swaroop A, Xu JZ, Pawar H, Jackson A, Skolnick C, Agarwal N (1992) A conserved retinaspecific gene encodes a basic motif/leucine zipper domain. Proc Natl Acad Sci U S A 89:266-270.

Szél Á, Röhlich P, Caffé AR, van Veen T (1996) Distribution of cone photoreceptors in the mammalian retina. Microsc Res Tech 35:445-462.

Takahashi K, Yamanaka S (2006) Induction of Pluripotent Stem Cells from Mouse Embryonic and Adult Fibroblast Cultures by Defined Factors. Cell 126:663-676.

Taranova O V, Magness ST, Fagan BM, Wu Y, Surzenko N, Hutton SR, Pevny LH (2006) SOX2 is a dose-dependent regulator of retinal neural progenitor competence. Genes Dev 20:1187-1202.

Terada K, Kitayama A, Kanamoto T, Ueno N, Furukawa T (2006) Nucleosome regulator Xhmgb3 is required for cell proliferation of the eye and brain as a downstream target of Xenopus rax/Rx1. Dev Biol 291:398-412.

Tétreault N, Champagne M-P, Bernier G (2009) The LIM homeobox transcription factor Lhx2 is required to specify the retina field and synergistically cooperates with Pax6 for Six6 transactivation. Dev Biol 327:541-550.

Thomson JA, Itskovitz-Eldor J, Shapiro SS, Waknitz MA, Swiergiel JJ, Marshall VS, Jones JM 
(1998) Embryonic stem cell lines derived from human blastocysts. Science 282:11451147.

Ton CC, Hirvonen H, Miwa H, Weil MM, Monaghan P, Jordan T, van Heyningen V, Hastie ND, Meijers-Heijboer H, Drechsler M (1991) Positional cloning and characterization of a paired box- and homeobox-containing gene from the aniridia region. Cell 67:1059-1074.

Toy J, Sundin OH (1999) Expression of the optx2 homeobox gene during mouse development. Mech Dev 83:183-186.

Toy J, Yang JM, Leppert GS, Sundin OH (1998) The optx2 homeobox gene is expressed in early precursors of the eye and activates retina-specific genes. Proc Natl Acad Sci U S A 95:10643-10648.

Trimarchi JM, Stadler MB, Cepko CL (2008) Individual Retinal Progenitor Cells Display Extensive Heterogeneity of Gene Expression Callaerts P, ed. PLoS One 3:e1588.

Tucker P, Laemle L, Munson A, Kanekar S, Oliver ER, Brown N, Schlecht H, Vetter M, Glaser T (2001) The eyeless mouse mutation (ey1) removes an alternative start codon from the $\mathrm{Rx} / \mathrm{rax}$ homeobox gene. Genesis 31:43-53.

Turner DL, Cepko CL (1987) A common progenitor for neurons and glia persists in rat retina late in development. Nature 328:131-136.

Turner DL, Snyder EY, Cepko CL (1990) Lineage-independent determination of cell type in the embryonic mouse retina. Neuron 4:833-845.

Uchikawa M, Kamachi Y, Kondoh H (1999) Two distinct subgroups of Group B Sox genes for transcriptional activators and repressors: their expression during embryonic organogenesis of the chicken. Mech Dev 84:103-120.

Uwanogho D, Rex M, Cartwright EJ, Pearl G, Healy C, Scotting PJ, Sharpe PT (1995)

Embryonic expression of the chicken Sox2, Sox3 and Sox11 genes suggests an interactive role in neuronal development. Mech Dev 49:23-36.

Varma R, Vajaranant TS, Burkemper B, Wu S, Torres M, Hsu C, Choudhury F, McKean-Cowdin R (2016) Visual Impairment and Blindness in Adults in the United States: Demographic and Geographic Variations From 2015 to 2050. JAMA Ophthalmol 134:802-809.

Völkner M, Zschätzsch M, Rostovskaya M, Overall RW, Busskamp V, Anastassiadis K, Karl MO (2016) Retinal Organoids from Pluripotent Stem Cells Efficiently Recapitulate Retinogenesis. Stem cell reports 6:525-538.

Voronina V a, Kozhemyakina E a, O'Kernick CM, Kahn ND, Wenger SL, Linberg J V, Schneider AS, Mathers PH (2004) Mutations in the human RAX homeobox gene in a patient with anophthalmia and sclerocornea. Hum Mol Genet 13:315-322.

Wall DS, Mears AJ, McNeill B, Mazerolle C, Thurig S, Wang Y, Kageyama R, Wallace VA (2009) Progenitor cell proliferation in the retina is dependent on Notch-independent Sonic hedgehog/Hes1 activity. J Cell Biol 184:101-112.

Wallis DE, Roessler E, Hehr U, Nanni L, Wiltshire T, Richieri-Costa A, Gillessen-Kaesbach G, Zackai EH, Rommens J, Muenke M (1999) Mutations in the homeodomain of the human SIX3 gene cause holoprosencephaly. Nat Genet 22:196-198.

Wang Q, Chen S, Esumi N, Swain PK, Haines HS, Peng G, Melia BM, Mclntosh I, Heckenlively 
JR, Jacobson SG, Stone EM, Swaroop A, Zack DJ (2004) QRX, a novel homeobox gene, modulates photoreceptor gene expression. Hum Mol Genet 13:1025-1040.

Weinstein DC, Hemmati-Brivanlou A (1999) Neural Induction. Annu Rev Cell Dev Biol 15:411433.

Williamson KA, FitzPatrick DR (2014) The genetic architecture of microphthalmia, anophthalmia and coloboma. Eur J Med Genet 57:369-380.

Wilson-Pauwels L (2010) Cranial nerves : function and dysfunction. People's Medical Pub. House.

Winkler S, Loosli F, Henrich T, Wakamatsu Y, Wittbrodt J (2000) The conditional medaka mutation eyeless uncouples patterning and morphogenesis of the eye. Development 127:1911-1919.

Wong LL, Rapaport DH (2009) Defining retinal progenitor cell competence in Xenopus laevis by clonal analysis. Development 136:1707-1715.

Wyatt A, Bakrania P, Bunyan DJ, Osborne RJ, Crolla JA, Salt A, Ayuso C, Newbury-Ecob R, Abou-Rayyah Y, Collin JRO, Robinson D, Ragge N (2008) Novel heterozygous OTX2 mutations and whole gene deletions in anophthalmia, microphthalmia and coloboma. Hum Mutat 29:E278-83.

Yang X-J (2004) Roles of cell-extrinsic growth factors in vertebrate eye pattern formation and retinogenesis. Semin Cell Dev Biol 15:91-103.

Yin J, Morrissey ME, Shine L, Kennedy C, Higgins DG, Kennedy BN (2014) Genes and signaling networks regulated during zebrafish optic vesicle morphogenesis. BMC Genomics 15:825.

Young RW (1985) Cell differentiation in the retina of the mouse. Anat Rec 212:199-205.

Yun S, Saijoh Y, Hirokawa KE, Kopinke D, Murtaugh LC, Monuki ES, Levine EM (2009) Lhx2 links the intrinsic and extrinsic factors that control optic cup formation. Development 136:3895-3906.

Zagozewski JL, Zhang Q, Eisenstat DD (2014a) Genetic regulation of vertebrate eye development. Clin Genet 86:453-460.

Zagozewski JL, Zhang Q, Pinto VI, Wigle JT, Eisenstat DD (2014b) The role of homeobox genes in retinal development and disease. Dev Biol 393:195-208.

Zhang L, Mathers PH, Jamrich M (2000) Function of Rx, but not Pax6, is essential for the formation of retinal progenitor cells in mice. Genesis 28:135-142.

Zhang SS, Fu X-Y, Barnstable CJ (2002) Molecular aspects of vertebrate retinal development. Mol Neurobiol 26:137-152.

Zhao S, Nichols J, Smith AG, Li M (2004) SoxB transcription factors specify neuroectodermal lineage choice in ES cells. Mol Cell Neurosci 27:332-342.

Zhao X, Liu J, Ahmad I (2002) Differentiation of embryonic stem cells into retinal neurons. Biochem Biophys Res Commun 297:177-184.

Zhong X, Gutierrez C, Xue T, Hampton C, Vergara MN, Cao L-H, Peters A, Park TS, Zambidis ET, Meyer JS, Gamm DM, Yau K-W, Canto-Soler MV (2014) Generation of three- 
dimensional retinal tissue with functional photoreceptors from human iPSCs. Nat Commun 5:4047.

Zhou H, Wu S, Joo JY, Zhu S, Han DW, Lin T, Trauger S, Bien G, Yao S, Zhu Y, Siuzdak G, Schöler HR, Duan L, Ding S (2009) Generation of Induced Pluripotent Stem Cells Using Recombinant Proteins. Cell Stem Cell 4:381-384.

Zhou J, Kherani F, Bardakjian TM, Katowitz J, Hughes N, Schimmenti LA, Schneider A, Young TL (2008) Identification of novel mutations and sequence variants in the SOX2 and CHX10 genes in patients with anophthalmia/microphthalmia. Mol Vis 14:583-592.

Zhou W, Freed CR (2009) Adenoviral Gene Delivery Can Reprogram Human Fibroblasts to Induced Pluripotent Stem Cells. Stem Cells 27:2667-2674.

Zuber ME, Gestri G, Viczian AS, Barsacchi G, Harris W a (2003) Specification of the vertebrate eye by a network of eye field transcription factors. Development 130:5155-5167.

Zuber ME, Perron M, Philpott A, Bang A, Harris WA (1999) Giant Eyes in Xenopus laevis by Overexpression of XOptx2. Cell 98:341-352. 


\section{Figure Legends}

\section{Figure 1. The main stages of vertebrate retinal development}

(A) Early eye formation starts with the generation of the eye field in the anterior neural plate and its subsequent split into two optic primordia. (B) Formation of bilateral optic vesicle from the evagination of the walls of the diencephalon, which occurs around E8.5-E9 in the mouse. When the optic vesicles reach the overlying surface ectoderm at approximately E9.5 in the mouse, they invaginate, forming the bilayered optic cup, and the surface ectoderm forms the lens placode. The layers of the optic cup will form the neural retina and the retinal pigmented epithelium. The lens placode will go on to form the lens vesicle and eventually the crystalline lens. (C) Development of the neural retina begins as the optic cup is forming. Retinal progenitor cell proliferation creates a pool of progenitors, which go through a series of steps during cell fate determination; multipotent retinal progenitors become committed progenitors before they go on to form one of the differentiated retinal cell types. This process starts in the central retina and, as development proceeds, extends to the periphery. (Adapted from Bilitou and Ohnuma, 2010).

\section{Figure 2. Regulation of optic vesicle development}

The factors involved in the regulation of early eye development from formation of the eye field in the anterior neural plate through patterning of the optic vesicle include extracellular molecules (shown in blue) and transcription factors (shown in red).

\section{Figure 3. Retinal anatomy and the time course of retinal cell birth}

(A) Organization of the mature retina. The retinal pigmented epithelium (RPE) borders the highly organized neural retina. The neural retina consists of six neuron types and one glial cell type. The cells capable of phototransduction are photoreceptors, rods ( $R$; shown in blue) and cones (C; shown in purple), which reside in the outermost layer of the retina. The nuclei of photoreceptors make up the outer nuclear layer. The photoreceptors synapse in the outer 
plexiform layer with interneurons, bipolar cells $(\mathrm{B}$; shown in light teal) and horizontal cells $(\mathrm{H}$; shown in pale pink), which are located in the inner nuclear layer. Bipolar cells synapse at the inner plexiform layer with retinal ganglion cells (G; shown in royal blue), which reside in the ganglion cell layer. Amacrine cells (A; shown in grey) are found in the inner nuclear layer and some are displaced in the ganglion cell layer. The sole type of glia, Müller glia (M; shown in light

green), spans the width of the retina. (Adapted from Sung \& Chuang, 2010). (B) Photoreceptors show highly polarized morphology. The discs (in rods) and folds (in cones) in the outer segment are responsible for capturing light. The outer segment connects to the inner segment via a thin connecting cilium. Photoreceptor axons extend from the cell body containing the nucleus to the synaptic terminals in the outer plexiform layer. Synaptic terminals are typically larger and multisynaptic in cones (adapted from (Wilson-Pauwels, 2010). (C) The timing of cell cycle exit (cell birth) during mouse retinogenesis shows a group of early-born retinal cells, including cone photoreceptors, that are primarily born during the embryonic period, and a group of late-born cells, including rod photoreceptors, that are primarily born postnatally (adapted from Ohsawa \& Kageyama, 2008).

\section{Figure 4. Transcriptional regulation of photoreceptor development}

In retinogenesis, retinal progenitors become restricted in their competence, such that they can give rise to photoreceptors or non-photoreceptor retinal cells. This pool of cells will become further restricted such that the cells can give rise to either rod or cone photoreceptors, and finally the cone photoreceptors will further differentiate based on opsin expression. Several transcription factors play a crucial role in photoreceptor cell fate and development. Otx2 is necessary in forming lineage-restricted cells that can form photoreceptors, Blimp1 is necessary to promote photoreceptor precursor formation over bipolar cell formation. Expression of Nrl, Ror $\beta$ and Nr2e3 specifies rod photoreceptor cell fate. Currently, the model of cone formation suggests that S-cones are the default pathway, and without regulatory signals directing the cell 
to become a rod or an M-cone, the photoreceptor precursor will develop as an S-cone. Signals involved in M-cone formation and opsin patterning in mice include $\operatorname{Tr} \beta 2, \mathrm{Rxr} \gamma$, Rora, and Ror $\beta$.

\section{Figure 5. 2D and 3D retinal differentiation protocols}

Schematic diagram comparing protocols for the induction of retinal cells from stem cells in monolayer (2D) and organoid (3D) cultures. Protocols listed represent key publications in retinal differentiation protocols in the last decade. Adapted from Jayakody, Gonzalez-Cordero, Ali, \& Pearson, 2015. 
A. Formation and separation of the eye field
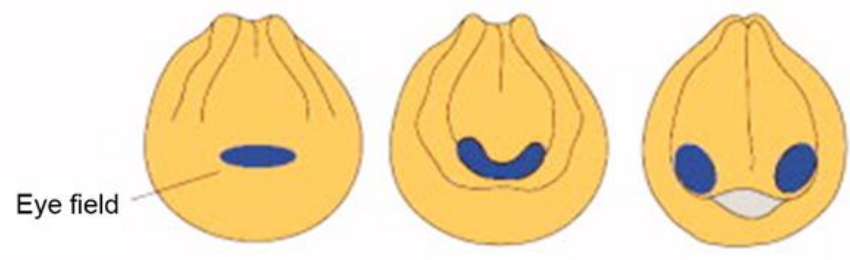

B. Formation of the optic vesicle and optic cup

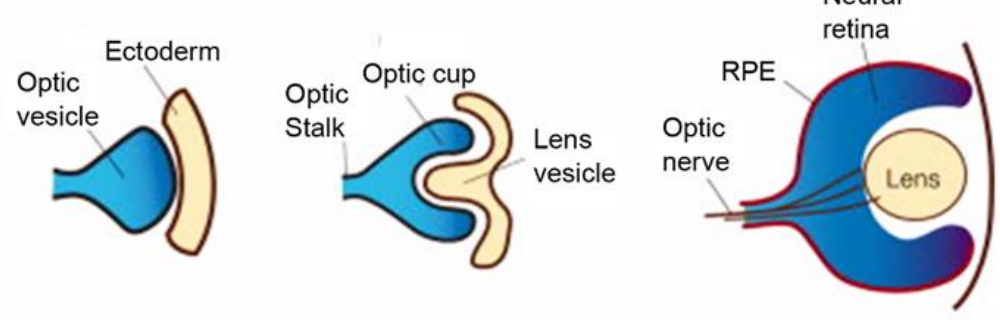

C. Proliferation and differentiation of the neural retina
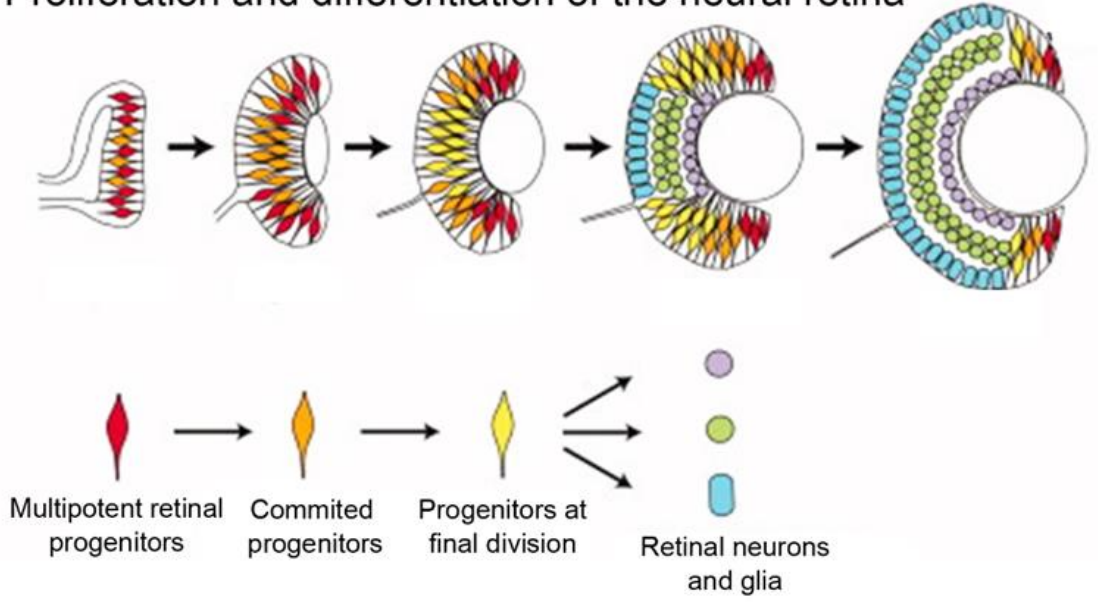

Figure 1. The main stages of vertebrate retinal development 


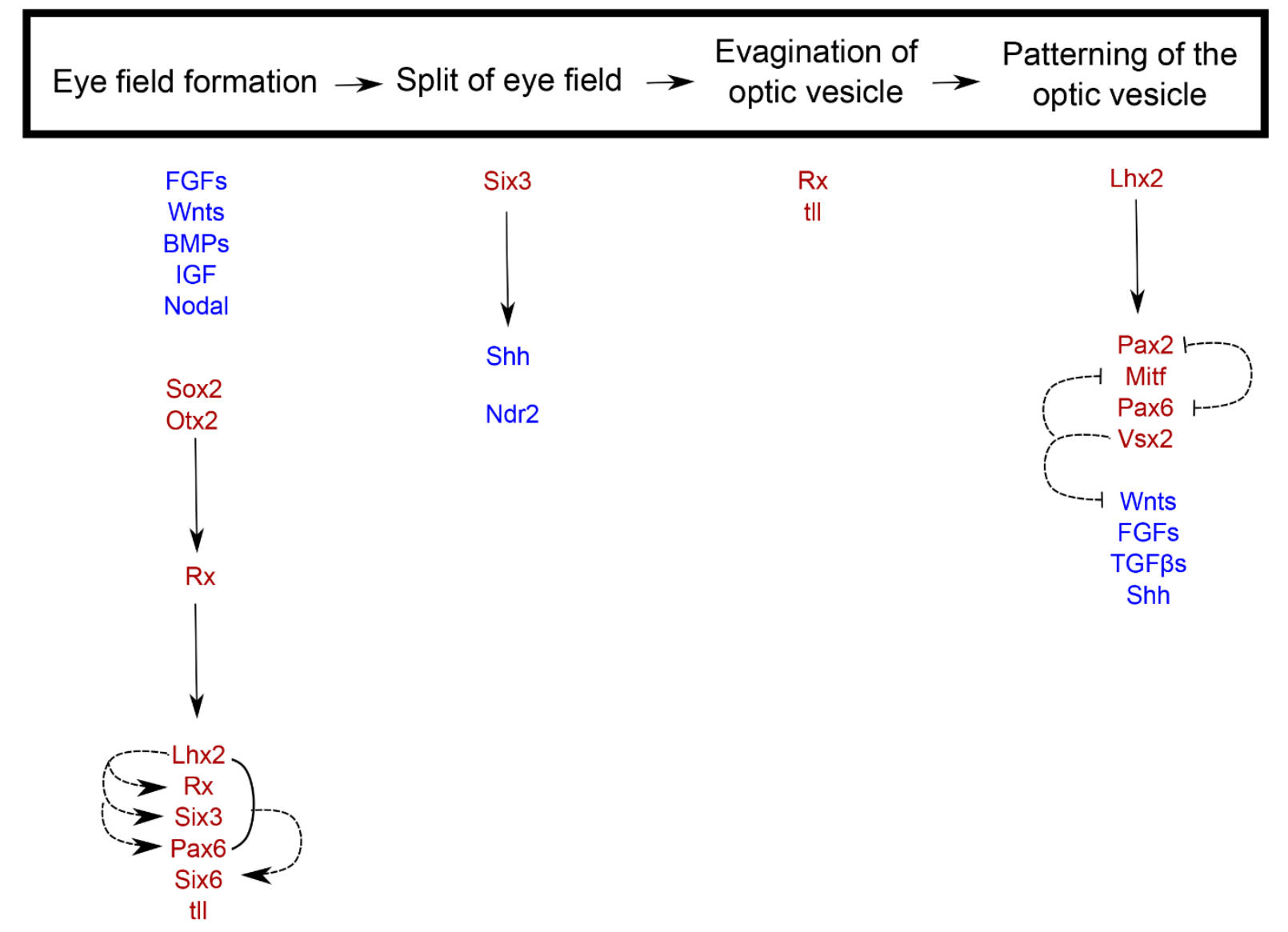

Figure 2. Regulation of optic vesicle development 
A

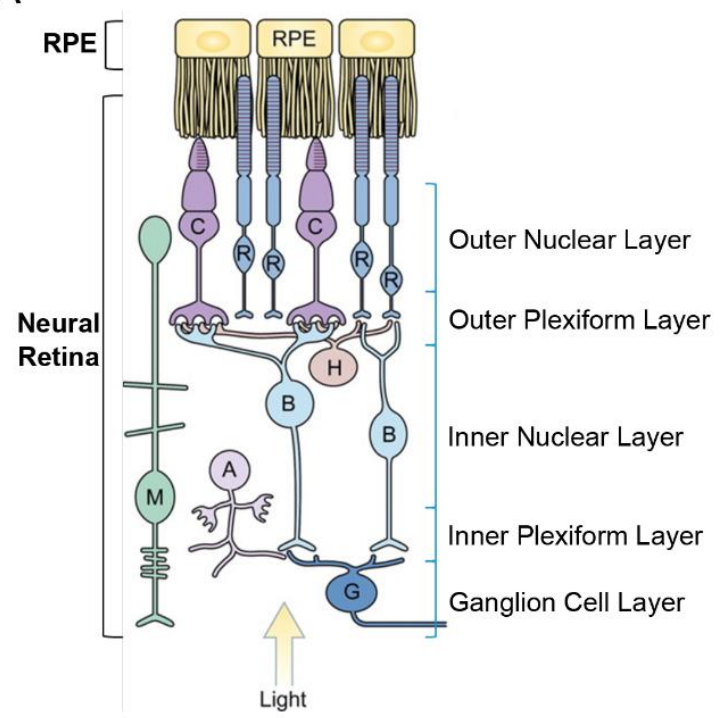

B

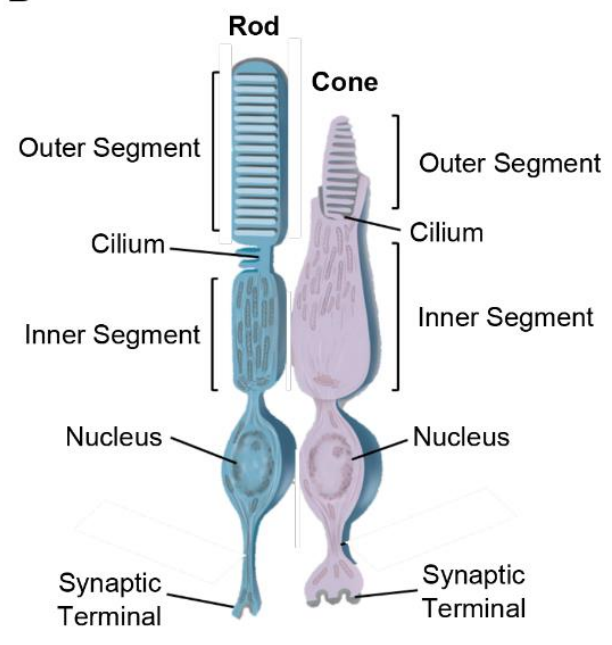

C

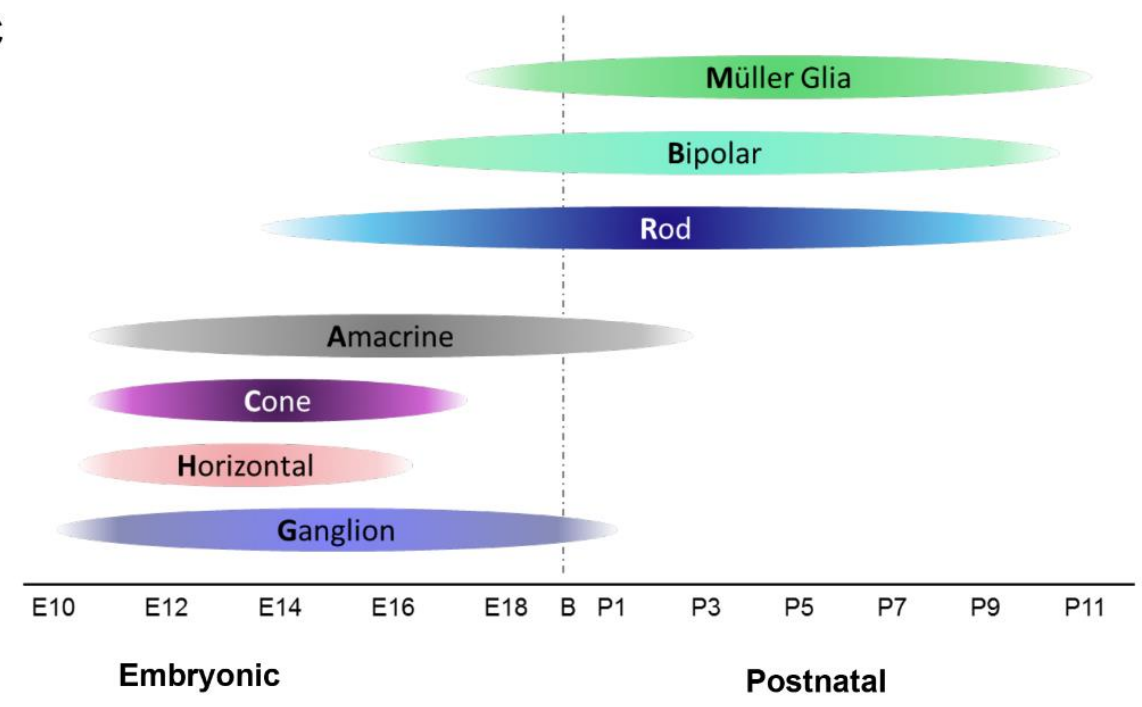

Figure 3. Retinal anatomy and the time course of retinal cell birth 


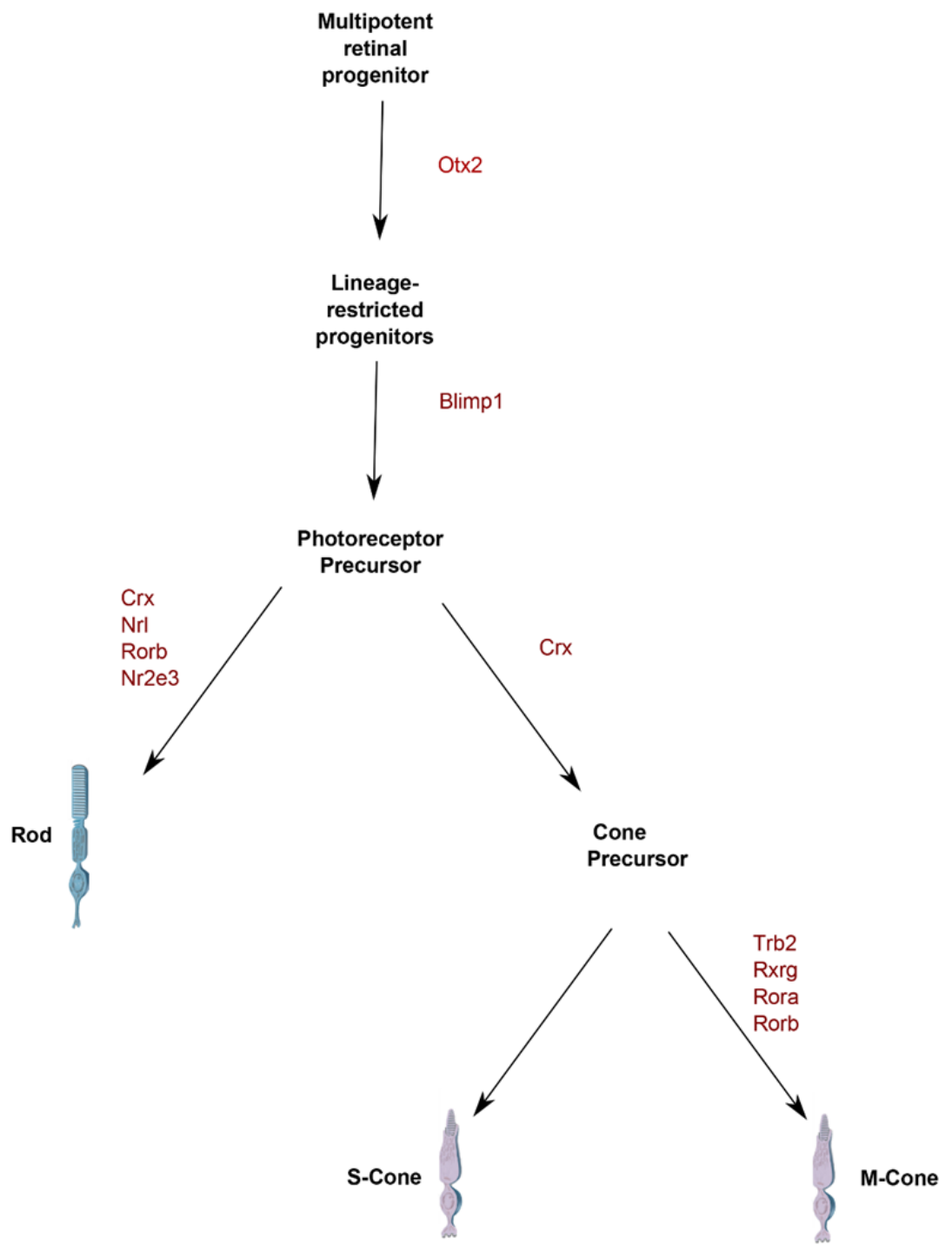

Figure 4. Transcriptional regulation of photoreceptor development 


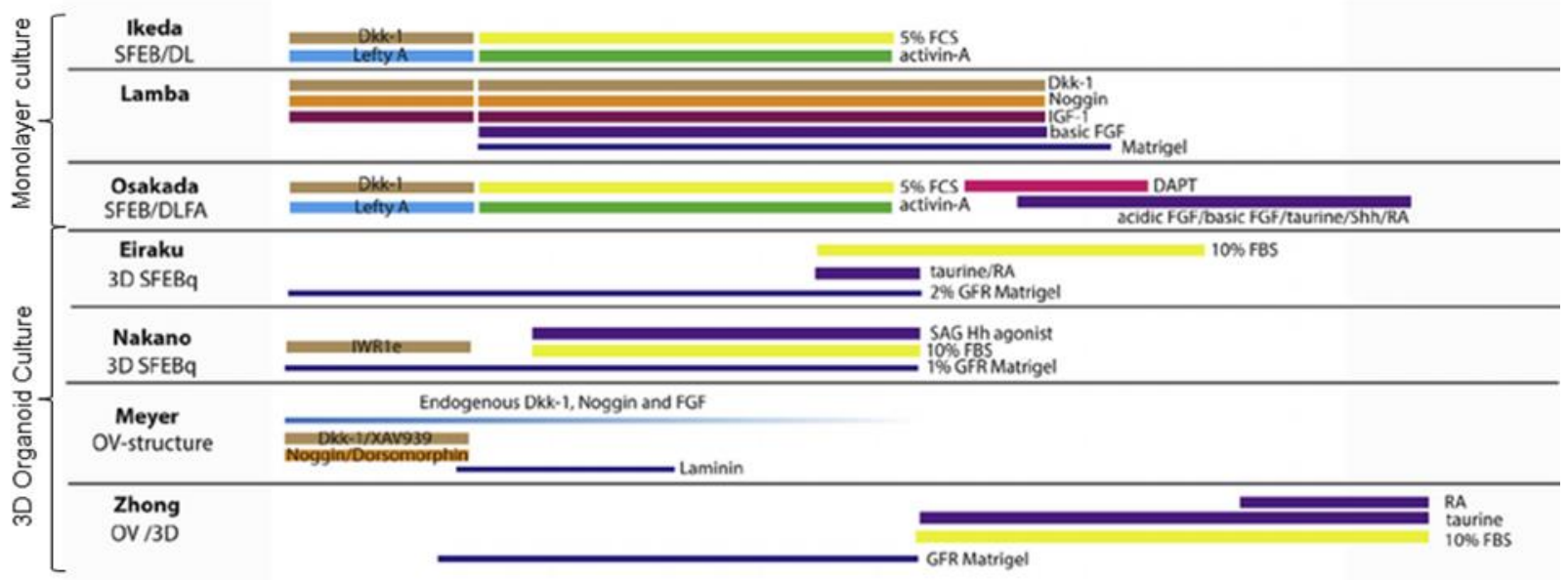

Figure 5. 2D and 3D retinal differentiation protocols 


\section{Chapter 2: \\ Embryonic Markers of Cone Differentiation}

Rodgers HM, Belcastro M, Sokolov M, \& Mathers PH

Rodgers HM, Belcastro M, Sokolov M, Mathers PH. (2016). Embryonic markers of cone differentiation. Molecular Vision 22:1455-1467. 


\begin{abstract}
Purpose- Photoreceptor cells are born in two distinct phases of vertebrate retinogenesis. In the mouse retina, cones are born primarily during embryogenesis, while rod formation occurs later in embryogenesis and early postnatal ages. Despite this dichotomy in photoreceptor birthdates, the visual pigments and phototransduction machinery are not reactive to visual stimulus in either photoreceptor cell until the second postnatal week. Several markers of early cone formation have been identified, including Otx2, Crx, Blimp1, NeuroD, $\operatorname{Tr} \beta 2, \operatorname{Ror} \beta$ and $\operatorname{Rxr} \gamma$, and all are thought to be involved in cellular determination. However, little is known about the expression of proteins involved in cone visual transduction during early retinogenesis. Therefore, we sought to characterize visual transduction proteins that are expressed specifically in photoreceptors during mouse embryogenesis.
\end{abstract}

Methods- Eye tissue was collected from control and phosducin-null mice at embryonic and early postnatal ages. Immunohistochemistry and quantitative reverse transcriptase-PCR (qPCR) were used to measure the spatial and temporal expression patterns of phosducin $(P d c)$ and cone transducin $\gamma$ (Gngt2) proteins and transcripts in the embryonic and early postnatal mouse retina.

Results- We identified the embryonic expression of phosducin (Pdc) and cone transducin $\gamma$ (Gngt2) that coincides temporally and spatially with the earliest stages of cone histogenesis. Using immunohistochemistry, the phosducin protein was first detected in the retina at embryonic day $(E) 12.5$ and cone transducin $\gamma$ was observed at E13.5. The phosducin and cone transducin $\gamma$ proteins were seen only in the outer neuroblastic layer, consistent with their expression in photoreceptors. At the embryonic ages, phosducin is coexpressed with Rxr $\gamma$, a known cone marker, and with Otx2, a marker of photoreceptors. Pdc and Gngt2 mRNAs were detected as early as E10.5 with qPCR, although at very low levels. 
Conclusions- Visual transduction proteins are expressed at the earliest stages in developing cones, well before the onset of opsin gene expression. Given the delay in opsin expression in rods and cones, we speculate on the embryonic function of these G-protein signaling components beyond their roles in the visual transduction cascade. 


\section{Introduction}

Over the past two decades, components of the vertebrate visual transduction cascade have been characterized, and their functions in light-regulated signaling are well established. Visual signaling in the mouse retina does not begin until postnatal day (P) 13-14 (Hoffpauir et al., 2009). Correspondingly, the onset of expression for rhodopsin and the cone opsins precedes eye opening and visual signaling by several days. However, rod and cone histogenesis begins even earlier, occurring in two distinct phases in vertebrate retinogenesis, with cones born embryonically and rods formed primarily during late embryogenesis and the postnatal period in rodents (Carter-Dawson and LaVail, 1979; Rapaport et al., 2004).

One of the mysteries of vertebrate retinogenesis is the lag between cone histogenesis and cone opsin expression. A similar lag exists between rod histogenesis and rhodopsin expression, although the delay is not as extended and occurs postnatally (al-Ubaidi et al., 1990). In mouse cone development, the earliest cones become postmitotic around embryonic day (E)11.5 while cone opsin transcription starts days later, with S-cone opsin mRNA being expressed by E15.5 (Fei, 2003; Applebury et al., 2007) followed by faint mRNA expression for M-cone opsin around P7 (Fei, 2003; Fujieda et al., 2009). Cone histogenesis and cone opsin protein expression shows an even greater lag, with S-cone opsin protein expression detected at P0 (Applebury et al., 2007) and M-cone opsin protein expression detected around P14 (Glaschke et al., 2010; Katoh et al., 2010).

Several genes involved in photoreceptor fate specification and differentiation are expressed during early cone histogenesis, including $\operatorname{Otx} 2$, NeuroD, Blimp1, Ror $\beta$ and $\operatorname{Crx}$ (Chen et al., 1997; Morrow et al., 1999; Baas et al., 2000; Martinez-Morales et al., 2001; Nishida et al., 2003; Roberts et al., 2006; Samson et al., 2009; Brzezinski et al., 2010), but these factors are all expressed in both rods and cones. Early determinants of cone differentiation include, Rxr $\gamma$ and 
$\operatorname{Tr} \beta 2$, though again these factors are thought to regulate cone cell fate $(\mathrm{Ng}$ et al., 2001, 2009; Roberts et al., 2005; Applebury et al., 2007). Alternatively, proteins involved in visual transduction (potential markers of differentiated cones) are expressed at or slightly preceding the onset of cone opsin expression, which is still days before the onset of visual transduction. However, one cone marker involved in visual transduction is expressed embryonically; cone transducin $\gamma$ expression was detected at E15.5 in mice (Sakagami et al., 2009).

Transducin is a heterotrimeric G-protein found in rod and cone photoreceptors. Transducin is composed of three subunits, designated as $\mathrm{G}_{\mathrm{t}_{1}} \beta_{1} \gamma_{1}$ and $\mathrm{G} \alpha_{\mathrm{t} 2} \beta_{3} \gamma_{8}$ in rods and cones, respectively. The genes encoding the transducin subunits in cones are Gnat2, Gnbt2, and Gngt2. Transducin is an essential component of the phototransduction cascade. When photons are absorbed by either rhodopsin or cone opsin, transducin is activated. Once activated, transducin separates into $\alpha$-and $\beta \gamma$-subunits. The $\alpha$-subunit subsequently activates phosphodiesterase 6 , which, in turn reduces the intracellular cGMP levels and leads to hyperpolarization. The $\beta \gamma$-subunit forms a complex with phosducin, a cytosolic phosphoprotein expressed in rods and cones (Lee et al., 1987, 1988, 1990; von Schantz et al., 1994; Gaudet et al., 1996; Loew et al., 1998). Phosducin is involved in the translocation of transducin $\beta \gamma$ within photoreceptors during light adaptation (Sokolov et al., 2004).

We sought to characterize the expression of visual transduction proteins that are active embryonically during cone histogenesis. We report that phosducin and cone transducin $\gamma$ are expressed early in cone histogenesis, with phosducin expression detected at E12.5 and cone transducin $\gamma$ at E13.5. Here, we show the spatial and temporal profiles for expression of these two genes and their corresponding proteins during the embryonic and postnatal periods. 


\section{Materials and Methods}

\section{Animals and Tissue Collection}

Embryonic and postnatal eyes were collected from time-pregnant FVB/N females that had been mated with $\mathrm{C} 57 \mathrm{BI} / 6 \mathrm{~J}$ male mice to prevent the retinal degeneration $\left(r d^{1} / r d^{1}\right)$ present in the FVB/N strain (Sidman et al.; Taketo et al., 1991; Yang et al., 2015). Eyes from mice at selected ages (E13.5 and P0) were also collected from pure C57BI/6J mice (to test for strain differences) and from a phosducin-null strain (Sokolov et al., 2004) (to test for antibody and primer specificity). Midnight of the mating date was considered embryonic day (E)0. The day of birth was counted as postnatal day $(P) 0$. For mouse pups E10.5-E17.5, the mother was euthanized by cervical dislocation, fetuses were then surgically dissected from the uterus and decapitated. Newborn mouse pups (P0) were euthanized via decapitation following induced hypothermia and P21 pups were euthanized by cervical dislocation followed by decapitation. Following euthanasia, whole eyes were removed from the orbit using either a $26 \mathrm{~g}$ beveled needle (E10.5E13.5) or forceps (E15.5-P21). Eyes for immunohistology were fixed as whole heads (E10.517.5) or just eyes (P0-P21) in a 4\% paraformaldehyde solution of phosphate-buffered saline (1x PBS; $\left.150 \mathrm{mM} \mathrm{NaCl}, 1.06 \mathrm{mM} \mathrm{KH}_{2} \mathrm{PO}_{4}, 2.97 \mathrm{mM} \mathrm{Na}_{2} \mathrm{HPO}_{4}-7 \mathrm{H}_{2} \mathrm{O}, \mathrm{pH} 7.4\right)$ at $4^{\circ} \mathrm{C}$ overnight, and cryoprotected in $30 \%$ sucrose, $1 \times$ PBS. The eyes for quantitative reverse-transcriptase-PCR (qPCR) analysis were frozen on dry ice in pairs. All animal procedures were approved by the West Virginia University (WVU) Institutional Animal Care and Use Committee and followed the guidelines set out by the Association for Research in Vision and Ophthalmology.

\section{Immunohistochemistry and Immunofluorescence}

Cryoprotected eyes ( $n=6$ for each age) were mounted in TBS tissue freezing media (Triangle Biomedical Sciences, Durham, NC), frozen and sectioned on a Leica CM3050S cryostat (Buffalo Grove, IL) at $10 \mu \mathrm{m}$ thickness, then transferred to glass slides. Before the antibody processing, as part of our standard protocol, samples were subjected to an antigen retrieval 
procedure of $0.1 \mathrm{M}$ Tris $\mathrm{pH} 9.5$ incubation at $95^{\circ} \mathrm{C}$ for $20 \mathrm{~min}$. Test runs with and without antigen retrieval showed similar labeling for phosducin and cone transducin $\gamma$ antibodies. Following antigen retrieval, sections were blocked with normal serum and treated with primary and secondary antibodies, following our published procedure (Howell et al., 2007). The primary antibodies used in this study were: anti-phosducin (as previously described by Sokolov et al.(Sokolov et al., 2004; 1:1000); anti-cone transducin $\gamma$ (rabbit; CytoSignal, Irvine, CA; 1:5001000); anti-S cone opsin (rabbit; Chemicon, Temecula, CA; 1:100); anti-mouse cone arrestin (mouse; gift from Dr. Cheryl Craft; 1:500); anti-retinoid X receptor $\gamma$ (rabbit; Santa Cruz Biotechnology, Dallas, TX; 1:1000); anti-cone phosphodiesterase (rabbit; Thermo Fisher Scientific, Waltham, MA; 1:500) and anti-Otx2 (rabbit; Millipore, Billerica, MA; 1:1000). Secondary antibodies were anti-sheep, anti-mouse, or anti-rabbit antibodies that were either biotin-labeled for Elite-ABC reactions (Vector Laboratories Inc; Burlingame, CA) or fluorophoretagged for immunofluorescence (Molecular Probes, Eugene, OR). Images were captured on an Olympus AX70 microscope (Olympus, Center Valley, PA) equipped with a MicroFire digital camera (Optronics; Goleta, CA) or a Zeiss 710 confocal microscope (Carl Zeiss, Inc.; Thornwood, NY).

\section{Quantification of Co-Labeled Cells}

Eyes from E13.5, E15.5, E17.5 and P0 mouse pups were sectioned at $12 \mu \mathrm{m}$ thickness. Immunofluorescence following the above protocol was performed on the retinal sections using anti-phosducin and anti-cone transducin $\gamma$ antibodies and propidium iodide as a nuclear counterstain. Three animals per age, with multiple quadrants of at least three sections per animal, were imaged on a Zeiss 710 confocal microscope. Labeled cells were counted within the imaged Z-stacks using the cell counter plugin of Fiji imaging software (Madison, WI) (Schindelin et al., 2012). All labeled cells were counted and designated as colabeled, phosducin only or cone transducin $\gamma$ only. Percentage of labeled cells was then calculated by 
dividing the number of cells in each category by the total number of labeled cells for each age. Data are presented as percentage \pm standard deviation (SD) for each category.

\section{Quantitative reverse transcriptase-PCR}

Total RNA was isolated from pairs of eyes from three mice at each age according to the manufacturer's instructions using either the Absolutely RNA Miniprep kit (Agilent Technologies, Inc.; Santa Clara, CA) with modifications for small samples for E13.5-P8 or the Absolutely RNA Nanoprep kit (Agilent Technologies) for E10.5-12.5. Each RNA sample was double DNasetreated, and the RNA concentration was quantified with a Nanodrop ND-1000 spectrophotometer (Thermo Scientific; West Palm Beach, FL). Select RNA samples were also analyzed on Bioanalyzer chips (Agilent Technologies). Fifty ng of total RNA were reverse transcribed using oligo(dT) primers and the AffinityScript QPCR cDNA Synthesis kit (Agilent Technologies), and cDNA samples originating from the same animals were pooled. Primers were designed using GenBank mouse mRNA sequences so that the amplimer would cover an exon-exon boundary. The following primer sequences were synthesized and high-performance liquid chromatography (HPLC)-purified by Integrated DNA Technologies (IDT; Coralville, IA); phosducin $(P d c)$ (5'-GCA CAC AGG ACC CAA AGG AGT AAT-3' and 5'-ACA CAA ACC CAT ACC TAG GCC CAA-3'), cone transducin $\gamma$ (Gngt2) (5'-GGA AGT GAA GAA CCC ACG TGA TCT GA-3' and 5'-AGC ACA CAA GTG CCT TTC TCC TTG-3'), hypoxanthine-guanine phosphoribosyltransferase (Hprt) (5'-CAG GCC AGA CTT TGT TGG AT-3' and 5'- GGA CGC AGC AAC TGA CAT T-3'). Before beginning, primer concentrations were optimized for each forward and reverse primer. The qPCR reaction efficiencies for each pair were confirmed to be within a range of $90-110 \%$. Reactions were prepared in technical triplicate using Brilliant SYBR Green QPCR Master Mix (Agilent Technologies), including reference dye, and $5 \mathrm{ng}$ of each cDNA with $100 \mathrm{nM}$ of each forward and reverse primer. Reactions were incubated at $95^{\circ} \mathrm{C}$ for $10 \mathrm{~min}$, and then cycled at $95^{\circ} \mathrm{C}$ for $30 \mathrm{~s}, 55^{\circ} \mathrm{C}$ for $60 \mathrm{~s}$, and $72^{\circ} \mathrm{C}$ for $60 \mathrm{~s}$ using a Stratagene 
(San Diego, CA) Mx3000P real-time PCR system. A melting curve analysis was added at the end to verify a single product from each reaction, and the fluorescence was recorded during every PCR cycle at the annealing step $\left(55^{\circ} \mathrm{C}\right)$ and the extension step $\left(72^{\circ} \mathrm{C}\right)$. Finally, select PCR products were also verified by size on agarose gels to ensure single band amplifications. The final relative quantities of $P d c$ and Gngt2 expression were determined after normalization to Hprt by the MxPro ${ }^{\mathrm{TM}}$ QPCR software version 3.00 (Stratagene). In addition, three reference P0 samples were run in triplicate on every plate so that interplate variations could be controlled. As a result, the data presented are also normalized to P0 expression levels.

\section{Results}

\section{Expression of phosducin in the developing mouse retina}

Phosducin (Pdc) expression is known to be specific to photoreceptors in the retina, with expression found in rods and cones (Lee et al., 1988; von Schantz et al., 1994). Previous studies have shown phosducin expression primarily in the early postnatal and adult retina (Lee et al., 1990; Babila et al., 1992; Brown et al., 2002), but the expression of phosducin during embryogenesis has not been explored. Using a well-characterized sheep antibody against phosducin (Sokolov et al., 2004; Krispel et al., 2007; Song et al., 2007), we identified phosducin expression in sections of embryonic mouse retina (Figure 1). This prompted us to perform a developmental series of phosducin expression, covering the earliest stages of mouse retinogenesis (E10.5) until after the maturation of rod photoreceptors (P21, Figure 1I). No phosducin protein expression was detectable at E10.5 or E11.5 (Figure 1A,B). Starting at E12.5, a small number of cells expressing phosducin protein were present in the central retina (arrows in Figure 1C). Most reactive cells were present in the outer neuroblastic layer (Figure 1D). This location is consistent with the position of the future outer nuclear layer, where differentiated photoreceptors will reside. Given the ventricular location of these phosducin-positive cells and the reported expression specificity of phosducin (Lee et al., 1988; von Schantz et al., 1994), the 
labeled cells likely represent photoreceptors that have either fully or nearly completed migration into their mature location within the neural retina.

As development proceeds, a rapid increase in the number of phosducin-expressing cells occurred between E12.5 and E13.5 (compare Figure 1C,D). As might be expected from the central to peripheral gradient of retinal differentiation (Young, 1985), no phosducin-positive cells are found in the distal retina at this age. From E13.5 to E15.5, a gradual increase in the number of phosducin-reactive cells was observed, with the further progression of stained cells toward the distal retina. By E17.5, the number of phosducin-positive cells increased, and this trend continued through the last stage tested, P21 (Figure 1F-I). To demonstrate that the staining observed in these images accurately represents the expression of phosducin protein, retinal sections from a phosducin knockout mouse line (Sokolov et al., 2004) were processed and reacted with anti-phosducin antibody. No reactivity was observed anywhere within the phosducin-knockout retinas at either E13.5 (Figure 2A) or P0 (Figure 2B), demonstrating that the antibody shows no cross-reactivity in the retina at embryonic or neonatal ages. For positive controls, phosducin-knockout retinas and similarly aged controls were colabeled with antiphosducin and either anti-Otx2 at E13.5 or anti-cone transducin $\gamma$ at P0. Expression of Otx2 (Figure 2A) and cone transducin $\gamma$ (Figure 2B) was observed in the control and phosducinknockout retinas, whereas phosducin expression was lacking in the phosducin-knockout retinal sections.

\section{Colocalization of phosducin and photoreceptor markers}

Examination of the coexpression of phosducin with a known photoreceptor marker, orthodenticle homeobox 2 protein (Otx2) and a known cone-specific marker, retinoid X receptor gamma (Rxry), was performed to determine the cellular specificity of phosducin labeling in the embryonic retina. Otx2 is important for cell fate determination of photoreceptors and is 
expressed in photoreceptors and the RPE until P6 (Nishida et al., 2003). Expression of Otx2 is seen in migrating and post-migratory developing photoreceptors. We used immunofluorescence to determine whether phosducin and Otx2 are expressed in the same cells. Both proteins localize to the ventricular surface with a large amount of colocalization (Figure 3A). Phosducinpositive cells almost always expressed Otx2; however, not all Otx2-positive cells expressed phosducin. Otx2 is expressed prominently in migrating (arrows in Figure 3A) photoreceptor precursors and post-migratory photoreceptor cells. Thus, these expression patterns support the supposition that phosducin labels post-migratory photoreceptors during embryonic ages.

Rxry is involved in the formation of the S-opsin gradient of cone photoreceptors and is expressed in the embryonic neural retina in postmitotic cones and retinal ganglion cells with peak expression at E17.5 (Mori et al., 2001; Roberts et al., 2005). To examine the cellular specificity of phosducin expression in developing cones, we performed immunofluorescence with anti-phosducin and anti-Rxry antibodies in E17.5 retinal sections. Both proteins were expressed along the ventricular border of the retina and colocalized (Figure 3B), suggesting that the majority of phosducin-labeled cells in the embryonic retina, up to and including $\mathrm{E} 17.5$, are cones.

\section{Expression of cone transducin $\gamma$ in the developing mouse retina}

Since phosducin is known to interact with transducin $\beta \gamma$ and cone transducin $\gamma$ is expressed embryonically (Sakagami et al., 2009), we sought to determine the earliest age at which cone transducin $\gamma$ could be detected. Similar to the results seen for phosducin expression, cone transducin $\gamma$ is expressed in the outer neuroblastic layer of the embryonic mouse retina (Figure 4). Cone transducin $\gamma$ protein cannot be detected through E12.5 (Figure $4 \mathrm{~A}-\mathrm{C}$ ), but is detected at E13.5 (Figure 4D). As with phosducin expression, cone transducin $\gamma$-immunoreactive cells were observed only along the ventricular edge of the retina. The expression timing and limited 
expression domain suggest that cone transducin $\gamma$ may only be expressed in differentiated cones once they have fully migrated into position, similar to phosducin. Expression continued to expand from the central retina into the periphery over the course of embryonic retinal development (Figure 4D-F), similar to the pattern seen with phosducin expression (Figure 1). Unlike the expression pattern of phosducin, cone transducin $\gamma$-reactive cell numbers appear to remain fairly constant from E17.5 to P21 (Figure 4F-I), consistent with the findings that $95 \%$ of cones are born by the day of birth (Carter-Dawson and LaVail, 1979; Rapaport et al., 2004).

\section{Colocalization of phosducin and cone transducin $\gamma$ protein expression}

Given the similar embryonic localization patterns seen between phosducin and cone transducin $\gamma$, we used immunofluorescence to determine whether these two proteins colocalize in retinal cells. Examination of the expression of both proteins from E13.5 to P8 (Figure 5A-E) showed they were distributed widely across the retina along the central to peripheral axis, but are restricted to the ventricular layer. Prominent colocalization of phosducin and cone transducin $\gamma$ was seen in coronal eye sections at all ages examined. Using E13.5-P0 retinal sections, we quantified the amount of coexpression by determining the percentage of cells that were labeled with phosducin only, cone transducin $\gamma$ only and those colabeled with phosducin and cone transducin $\gamma$. At E13.5, $97 \%( \pm 0.4 \% ; S D)$ of the labeled cells in the retina were colableled. The percentage of colabeled cells dropped at E15.5 and E17.5 to 88\% ( $\pm 1.1 \%$; SD) and $87 \%$ $( \pm 2.4 \%$; SD) respectively, and by P0, the percentage of colabeled cells was $79 \%( \pm 6.2 \%$; SD)

(Figure 5F). This quantification of colocalization suggests that most phosducin-labeled cells are cones at most embryonic ages, although rod histogenesis has begun by this time (CarterDawson and LaVail, 1979; Rapaport et al., 2004). 


\section{Phosducin and cone transducin $\gamma$ mRNA expression levels show different dynamics}

After early detection of phosducin and cone transducin $\gamma$ expression in the developing mouse retina with immunohistochemistry (E12.5; Figure $1 \mathrm{C}$ and E13.5; Figure 4D), we sought to explore phosducin and cone transducin $\gamma$ gene expression. We analyzed mRNA expression levels for phosducin (Pdc) and cone transducin $\gamma(G n g t 2)$ by qPCR, using gene-specific primer sets. Samples were tested from littermates used for the immunolocalizations presented above for consistency. A minimum of three biologic replicates were analyzed and averaged for each age. Pdc expression above threshold was detected at both E10.5 and E11.5, but these levels are only $0.4 \%$ and $0.2 \%$ that of P0 levels, respectively (Figure $6 \mathrm{~A}$ ). The extremely low expression levels and relative decrease from E10.5 to E11.5 suggest that these values may reflect the sporadic phosducin-positive protein staining seen at E12.5, and that decreases between E10.5 and E11.5 could represent stochastic variations in small numbers. No values above threshold were detected in samples from either the E13.5 or P0 phosducin-knockout animals, suggesting that other cellular RNAs do not contribute a background signal and that these extremely low levels of phosducin expression at E10.5 and E11.5 may represent real expression.

The relative $P d c$ expression levels increased dramatically at E12.5, with levels six-fold higher than E11.5 and approximately 1.3\% those of P0 samples (Figure 6A). Given that the phosducin protein is first detected at this stage, this would seem to be a minimum age at which $P d c$ expression can reliably be demonstrated, but earlier expression is certainly a distinct possibility. Dramatic increases in Pdc mRNA levels were observed between E13.5 (3.7\% of P0 levels) and E15.5 (19.7\% of P0 levels). While E17.5 levels for Pdc were roughly one-third those of P0, the levels at P8 were more than 9-fold greater than P0 levels. This large increase in postnatal phosducin levels is consistent with the increase seen in phosducin protein expression and could reflect the fact that rod photoreceptors are primarily formed during postnatal stages of mouse 
development (Carter-Dawson and LaVail, 1979; Young, 1985) and rods represent about $97 \%$ of the photoreceptors in the mouse retina (Carter-Dawson and LaVail, 1979; Jeon et al., 1998).

As with Pdc gene activation, expression of Gngt2 mRNA was detected at E10.5 with qPCR, with levels at $1.4 \%$ of those values at P0 (Figure 6B). A similar decrease was observed for Pdc and Gngt2 from E10.5 to E11.5, with levels jumping up 2.6-fold by E12.5. A steady increase in Gngt2 expression occurs from E12.5 to P0. However, unlike the situation with Pdc in which a large increase in mRNA expression occurs between P0 and P8, relative Gngt2 levels at P8 decrease to $61.5 \%$ of those seen at P0. This decrease potentially reflects an overall dilution of cone photoreceptor cell contribution to the total RNA pool with the rapid growth of the retina during the postnatal time period and the paucity of new cone histogenesis that takes place postnatally.

\section{Discussion}

\section{Embryonic photoreceptor-specific expression for visual transduction proteins}

We present evidence that proteins important for phototransduction are expressed early in embryonic photoreceptors. We show the onset of phosducin protein expression at E12.5, which precedes earlier reports by nearly 2 weeks (E12.5 vs. P5; (Lee et al., 1990; Brown et al., 2002), and cone transducin $\gamma$ protein expression at E13.5, preceding the earliest reported detection by 2 days (Sakagami et al., 2009). Expression of both these proteins is nearly 3 weeks before the onset of M-opsin protein expression at P14 and nearly 1 week before to S-opsin protein expression at P0 (Applebury et al., 2007; Katoh et al., 2010).

We infer that the embryonic expression of phosducin and cone transducin $\gamma$ is labeling cone photoreceptors. Several lines of evidence support this inference. First, in the postnatal retina, cone transducin $\gamma$ is specific for cones, and phosducin is specific for photoreceptors (Lee et al., 1988; Ong et al., 1995). Second, cone transducin $\gamma$-and phosducin-positive cells reside along 
the ventricular border, the location of photoreceptors. Additionally, immunofluorescence showed phosducin and cone transducin $\gamma$ to be coexpressed in cells. Given the regionalized expression and colocalization of these proteins, these findings suggest that cone transducin $\gamma$ and phosducin are expressed in photoreceptors that have migrated into their adult location, similar to the expression pattern seen for early photoreceptor markers, Crx (Chen et al., 1997; Furukawa et al., 1997) and $\operatorname{Tr} \beta 2$ (Ng et al., 2001; Brzezinski et al., 2010). Third, colocalization of phosducin with Otx2 and Rxry, known markers for photoreceptors and cones respectively, suggests cone-specific labeling of phosducin at embryonic ages. Quantification of colocalization data suggests that, at E13.5, virtually all of phosducin-labeled cells are cones and by E17.5, most labeled cells (87\%) are still cones, as they are phosducin- and cone transducin $\gamma$-positive.

\section{Rapid increases in phosducin, but not cone transducin $\gamma$, in the postnatal retina}

From P0 to P8, we observed a nine-fold increase in Pdc mRNA expression with qPCR. This increase likely reflects the massive production of rod photoreceptors that occurs during early postnatal development, such that $50 \%$ of all retinal cells and $97 \%$ of all mouse photoreceptors are rods (Carter-Dawson and LaVail, 1979; Jeon et al., 1998). The possibility also exists that, in addition to a dramatic increase in rod cell number during this period, the expression levels of phosducin within each photoreceptor could be increasing. With this caveat in mind, however, the magnitude of change for phosducin expression was consistent with the increase in rod cell number during early postnatal retinal development (Rapaport et al., 2004).

\section{Potential functions for visual transduction proteins in the embryonic retina}

Surprisingly, the temporal pattern of phosducin and cone transducin $\gamma$ was coincident with the expression of early cone-determining transcription factors, suggesting that photoreceptor precursor cells are fully committed to a cone differentiation pattern at these early ages. Since 
the phototransduction process is weeks removed from this expression, these visual transduction factors likely play other functional roles in the embryonic photoreceptor cell. We observed an absence of other visual transduction proteins (mouse cone arrestin, cone phosphodiesterase and S-cone opsin) in the mouse retina at E15.5. Although visual transduction proteins have been found embryonically in primate retina (Sears et al., 2000; Ross et al., 2015), this expression is at a stage of development that matches the postnatal period in rodents, suggesting that cone transducin $\gamma$ and phosducin may have specific functions in the embryonic retina unrelated to their roles in visual transduction.

As a result, we sought clues in the literature to identify potential activity of cone transducin $\gamma$ and phosducin in the embryonic mouse retina, if any. Previous studies on phosducin show that it can interact with Crx in cultured cells, where it acts to inhibit Crx-mediated transcription at the interphotoreceptor retinoid-binding protein (IRBP) promoter (Zhu and Craft, 2000a). In addition, phosducin possesses a transcriptional activation domain at its C-terminal end (Zhu and Craft, 2000b), although this would appear to conflict with the reported repression of Crx transcriptional activity (Zhu and Craft, 2000a). Previous studies have yielded conflicting information regarding the localization of phosducin. Whereas Zhu et al. (2000a) demonstrated that phosducin colocalized to the nucleus when coexpressed with $\mathrm{Crx}$ in $\operatorname{Cos} 7$ cells and in the adult bovine retina (where phosducin shows nuclear and cytoplasmic localization), the same group (Zhu and Craft, 2000b) and others (Schulz et al., 1998; Wehmeyer and Schulz, 1998) found phosducin to be cytoplasmic. If phosducin localized to the nucleus, this finding would suggest a possible role in transcription; however, the cytoplasmic localization seen in our study would suggest that perhaps there is an additional function for embryonic phosducin beyond any transcriptional activities. 
Another possible function for embryonic phosducin expression is that phosducin may interact with cone transducin $\beta \gamma$ as phosducin does postnatally (Willardson and Howlett, 2007). This possibility would lead to the obvious question regarding the potential function for $G$ protein $\beta \gamma$ at embryonic ages. Although the transducin $\beta \gamma$ complex is only known to function in phototransduction, the function of the transducin $\beta \gamma$ complex during embryonic stages has not been explored to our knowledge. Given the large number of $\mathrm{G}$ protein-coupled receptors (GPCRs) and their expression in multiple tissues and cell types, it is conceivable that the transducin $\beta \gamma$ complex has additional functions during embryonic retinal development that have yet to be fully understood or explored. Some potential GPCR signaling pathways involved in retinal function include dopamine signaling (Reis et al., 2007; Deming et al., 2015), hedgehog (Hh) signaling (Levine et al., 1997; Stenkamp et al., 2000), and Wnt signaling (Westenskow et al., 2009), along with others (Odani et al., 2007; Perry et al., 2010). Wnt signaling in the retina appears to function primarily in the RPE at embryonic ages (Westenskow et al., 2009), and therefore is unlikely to involve phosducin and cone transducin $\gamma$ activity in photoreceptor cell differentiation. Dopamine signaling appears to occur at later embryonic and postnatal stages than seen for the earliest phosducin and cone transducin $\gamma$ expression (Reis et al., 2007). Hh signaling plays a significant role in retinal progenitor cell proliferation (Wallace, 2008), and factors induced by Hh signaling (e.g.- Gli1) overlap both spatially and temporally with the expression for phosducin shown above (Wang et al., 2005). However, functional manipulation of Hh signaling (Wang et al., 2005; Yu et al., 2006; Cwinn et al., 2011) suggests that it either antagonizes cone photoreceptor specification or has a transient role in cone differentiation. Therefore, further work will be necessary to elucidate the early functions for phosducin and cone transducin $\gamma$ in the developing retina and their potential roles in photoreceptor cell differentiation. 


\section{Acknowledgements}

We are grateful to D. Cole for his technical assistance with the immunological studies, and V. Ramamurthy for cone PDE antibody and helpful suggestions.

Imaging experiments were performed in the West Virginia University Microscope Imaging Facility, which has been supported by the WVU Cancer Institute and NIH grants P20RR016440, P30GM103488 and P20GM103434. This project was supported in part by grants from the NEI RO1EY012152 (P.H.M.) and RO1EY019665 (M.S.), as well as WVU institutional funding

(P.H.M), NCRR RR015574 to support the Sensory Neuroscience Research Center, and a Research to Prevent Blindness unrestricted grant to the WVU Eye Institute. 


\section{References}

al-Ubaidi MR, Pittler SJ, Champagne MS, Triantafyllos JT, McGinnis JF, Baehr W (1990) Mouse opsin. Gene structure and molecular basis of multiple transcripts. J Biol Chem 265:2056320569.

Applebury ML, Farhangfar F, Glösmann M, Hashimoto K, Kage K, Robbins JT, Shibusawa N, Wondisford FE, Zhang H (2007) Transient expression of thyroid hormone nuclear receptor TRbeta2 sets S opsin patterning during cone photoreceptor genesis. Dev Dyn 236:12031212.

Baas D, Bumsted KM, Martinez JA, Vaccarino FM, Wikler KC, Barnstable CJ (2000) The subcellular localization of Otx2 is cell-type specific and developmentally regulated in the mouse retina. Brain Res Mol Brain Res 78:26-37.

Babila T, Schaad NC, Simonds WF, Shinohara T, Klein DC (1992) Development of MEKA (phosducin), G beta, G gamma and S-antigen in the rat pineal gland and retina. Brain Res 585:141-148.

Brown BM, Carlson BL, Zhu X, Lolley RN, Craft CM (2002) Light-driven translocation of the protein phosphatase $2 \mathrm{~A}$ complex regulates light/dark dephosphorylation of phosducin and rhodopsin. Biochemistry 41:13526-13538.

Brzezinski JA, Lamba DA, Reh TA (2010) Blimp1 controls photoreceptor versus bipolar cell fate choice during retinal development. Development 137:619-629.

Carter-Dawson LD, LaVail MM (1979) Rods and cones in the mouse retina. II. Autoradiographic analysis of cell generation using tritiated thymidine. J Comp Neurol 188:263-272.

Chen S, Wang QL, Nie Z, Sun H, Lennon G, Copeland NG, Gilbert DJ, Jenkins NA, Zack DJ (1997) Crx, a novel Otx-like paired-homeodomain protein, binds to and transactivates photoreceptor cell-specific genes. Neuron 19:1017-1030.

Cwinn MA, Mazerolle C, McNeill B, Ringuette R, Thurig S, Hui C, Wallace VA (2011) Suppressor of fused is required to maintain the multipotency of neural progenitor cells in the retina. J Neurosci 31:5169-5180.

Deming JD, Shin J-A, Lim K, Lee E-J, Van Craenenbroeck K, Craft CM (2015) Dopamine receptor D4 internalization requires a beta-arrestin and a visual arrestin. Cell Signal 27:2002-2013.

Fei $Y$ (2003) Development of the cone photoreceptor mosaic in the mouse retina revealed by fluorescent cones in transgenic mice. Mol Vis 9:31-42.

Fujieda H, Bremner R, Mears AJ, Sasaki H (2009) Retinoic acid receptor-related orphan receptor alpha regulates a subset of cone genes during mouse retinal development. $J$ Neurochem 108:91-101.

Furukawa T, Morrow EM, Cepko CL (1997) Crx, a novel otx-like homeobox gene, shows photoreceptor-specific expression and regulates photoreceptor differentiation. Cell 91:531541.

Gaudet R, Bohm A, Sigler PB (1996) Crystal structure at 2.4 angstroms resolution of the complex of transducin betagamma and its regulator, phosducin. Cell 87:577-588.

Glaschke A, Glösmann M, Peichl L (2010) Developmental changes of cone opsin expression 
but not retinal morphology in the hypothyroid Pax8 knockout mouse. Invest Ophthalmol Vis Sci 51:1719-1727.

Hoffpauir BK, Marrs GS, Mathers PH, Spirou GA (2009) Does the brain connect before the periphery can direct? A comparison of three sensory systems in mice. Brain Res 1277:115-129.

Howell DM, Morgan WJ, Jarjour AA, Spirou GA, Berrebi AS, Kennedy TE, Mathers PH (2007) Molecular guidance cues necessary for axon pathfinding from the ventral cochlear nucleus. J Comp Neurol 504:533-549.

Jeon CJ, Strettoi E, Masland $\mathrm{RH}$ (1998) The major cell populations of the mouse retina. J Neurosci 18:8936-8946.

Katoh K, Omori Y, Onishi A, Sato S, Kondo M, Furukawa T (2010) Blimp1 suppresses Chx10 expression in differentiating retinal photoreceptor precursors to ensure proper photoreceptor development. J Neurosci 30:6515-6526.

Krispel CM, Sokolov M, Chen Y-M, Song H, Herrmann R, Arshavsky VY, Burns ME (2007) Phosducin regulates the expression of transducin betagamma subunits in rod photoreceptors and does not contribute to phototransduction adaptation. J Gen Physiol 130:303-312.

Lee $\mathrm{RH}$, Lieberman BS, Lolley RN (1987) A novel complex from bovine visual cells of a 33,000dalton phosphoprotein with beta- and gamma-transducin: purification and subunit structure. Biochemistry 26:3983-3990.

Lee $\mathrm{RH}$, Lieberman BS, Lolley RN (1990) Retinal accumulation of the phosducin/T beta gamma and transducin complexes in developing normal mice and in mice and dogs with inherited retinal degeneration. Exp Eye Res 51:325-333.

Lee RH, Whelan JP, Lolley RN, McGinnis JF (1988) The photoreceptor-specific 33 kDa phosphoprotein of mammalian retina: generation of monospecific antibodies and localization by immunocytochemistry. Exp Eye Res 46:829-840.

Levine EM, Roelink H, Turner J, Reh TA (1997) Sonic hedgehog promotes rod photoreceptor differentiation in mammalian retinal cells in vitro. J Neurosci 17:6277-6288.

Loew A, Ho YK, Blundell T, Bax B (1998) Phosducin induces a structural change in transducin beta gamma. Structure 6:1007-1019.

Martinez-Morales JR, Signore M, Acampora D, Simeone A, Bovolenta P (2001) Otx genes are required for tissue specification in the developing eye. Development 128:2019-2030.

Mori M, Ghyselinck NB, Chambon P, Mark M (2001) Systematic Immunolocalization of Retinoid Receptors in Developing and Adult Mouse Eyes. Invest Ophthalmol Vis Sci 42:67-1318.

Morrow EM, Furukawa T, Lee JE, Cepko CL (1999) NeuroD regulates multiple functions in the developing neural retina in rodent. Development 126:23-36.

$\mathrm{Ng} \mathrm{L,} \mathrm{Hurley} \mathrm{JB,} \mathrm{Dierks} \mathrm{B,} \mathrm{Srinivas} \mathrm{M,} \mathrm{Saltó} \mathrm{C,} \mathrm{Vennström} \mathrm{B,} \mathrm{Reh} \mathrm{TA,} \mathrm{Forrest} \mathrm{D} \mathrm{(2001)} \mathrm{A}$ thyroid hormone receptor that is required for the development of green cone photoreceptors. Nat Genet 27:94-98.

Ng L, Ma M, Curran T, Forrest D (2009) Developmental expression of thyroid hormone receptor beta2 protein in cone photoreceptors in the mouse. Neuroreport 20:627-631. 
Nishida A, Furukawa A, Koike C, Tano Y, Aizawa S, Matsuo I, Furukawa T (2003) Otx2 homeobox gene controls retinal photoreceptor cell fate and pineal gland development. Nat Neurosci 6:1255-1263.

Odani N, Pfaff SL, Nakamura H, Funahashi J-I (2007) Cloning and developmental expression of a chick G-protein-coupled receptor SCGPR1. Gene Expr Patterns 7:375-380.

Ong OC, Yamane HK, Phan KB, Fong HK, Bok D, Lee RH, Fung BK (1995) Molecular cloning and characterization of the $\mathrm{G}$ protein gamma subunit of cone photoreceptors. J Biol Chem 270:8495-8500.

Perry KJ, Johnson VR, Malloch EL, Fukui L, Wever J, Thomas AG, Hamilton PW, Henry JJ (2010) The G-protein-coupled receptor, GPR84, is important for eye development in Xenopus laevis. Dev Dyn 239:3024-3037.

Rapaport DH, Wong LL, Wood ED, Yasumura D, LaVail MM (2004) Timing and topography of cell genesis in the rat retina. J Comp Neurol 474:304-324.

Reis RAM, Ventura ALM, Kubrusly RCC, de Mello MCF, de Mello FG (2007) Dopaminergic signaling in the developing retina. Brain Res Rev 54:181-188.

Roberts MR, Hendrickson A, McGuire CR, Reh TA (2005) Retinoid X receptor (gamma) is necessary to establish the S-opsin gradient in cone photoreceptors of the developing mouse retina. Invest Ophthalmol Vis Sci 46:2897-2904.

Roberts MR, Srinivas M, Forrest D, Morreale de Escobar G, Reh TA (2006) Making the gradient: thyroid hormone regulates cone opsin expression in the developing mouse retina. Proc Natl Acad Sci U S A 103:6218-6223.

Ross EJ, Graham DL, Money KM, Stanwood GD (2015) Developmental consequences of fetal exposure to drugs: what we know and what we still must learn. Neuropsychopharmacology 40:61-87.

Sakagami K, Gan L, Yang X-J (2009) Distinct effects of Hedgehog signaling on neuronal fate specification and cell cycle progression in the embryonic mouse retina. J Neurosci 29:6932-6944.

Samson M, Emerson MM, Cepko CL (2009) Robust marking of photoreceptor cells and pinealocytes with several reporters under control of the Crx gene. Dev Dyn 238:32183225.

Schindelin J, Arganda-Carreras I, Frise E, Kaynig V, Longair M, Pietzsch T, Preibisch S, Rueden C, Saalfeld S, Schmid B, Tinevez J-Y, White DJ, Hartenstein V, Eliceiri K, Tomancak P, Cardona A (2012) Fiji: an open-source platform for biological-image analysis. Nat Methods 9:676-682.

Schulz R, Schulz K, Wehmeyer A, Murphy J (1998) Translocation of phosducin in living neuroblastoma $x$ glioma hybrid cells (NG 108-15) monitored by red-shifted green fluorescent protein. Brain Res 790:347-356.

Sears S, Erickson A, Hendrickson A (2000) The spatial and temporal expression of outer segment proteins during development of Macaca monkey cones. Invest Ophthalmol Vis Sci 41:971-979.

Sidman RL, Green, M C Retinal degeneration in the the mouse: location of the rd locus in linkage group XVII. J Hered 56:23-29. 
Sokolov M, Strissel KJ, Leskov IB, Michaud NA, Govardovskii VI, Arshavsky VY (2004) Phosducin facilitates light-driven transducin translocation in rod photoreceptors. Evidence from the phosducin knockout mouse. J Biol Chem 279:19149-19156.

Song H, Belcastro M, Young EJ, Sokolov M (2007) Compartment-specific phosphorylation of phosducin in rods underlies adaptation to various levels of illumination. J Biol Chem 282:23613-23621.

Stenkamp DL, Frey RA, Prabhudesai SN, Raymond PA (2000) Function for Hedgehog genes in zebrafish retinal development. Dev Biol 220:238-252.

Taketo M, Schroeder AC, Mobraaten LE, Gunning KB, Hanten G, Fox RR, Roderick TH, Stewart CL, Lilly F, Hansen CT (1991) FVB/N: an inbred mouse strain preferable for transgenic analyses. Proc Natl Acad Sci U S A 88:2065-2069.

von Schantz M, Szél A, van Veen T, Farber DB (1994) Expression of soluble phototransductionassociated proteins in ground squirrel retina. Invest Ophthalmol Vis Sci 35:3922-3930.

Wallace VA (2008) Proliferative and cell fate effects of Hedgehog signaling in the vertebrate retina. Brain Res 1192:61-75.

Wang Y, Dakubo GD, Thurig S, Mazerolle CJ, Wallace VA (2005) Retinal ganglion cell-derived sonic hedgehog locally controls proliferation and the timing of RGC development in the embryonic mouse retina. Development 132:5103-5113.

Wehmeyer A, Schulz R (1998) Phosducin expression in NG 108-15 hybrid cells enhances prostaglandin E1 stimulated adenylate cyclase activity. Life Sci 62:PL127-34.

Westenskow P, Piccolo S, Fuhrmann S (2009) Beta-catenin controls differentiation of the retinal pigment epithelium in the mouse optic cup by regulating Mitf and Otx2 expression. Development 136:2505-2510.

Willardson BM, Howlett AC (2007) Function of phosducin-like proteins in G protein signaling and chaperone-assisted protein folding. Cell Signal 19:2417-2427.

Yang J, Nan C, Ripps H, Shen W (2015) Destructive Changes in the Neuronal Structure of the FVB/N Mouse Retina. PLoS One 10:e0129719.

Young RW (1985) Cell differentiation in the retina of the mouse. Anat Rec 212:199-205.

Yu C, Mazerolle CJ, Thurig S, Wang Y, Pacal M, Bremner R, Wallace VA (2006) Direct and indirect effects of hedgehog pathway activation in the mammalian retina. Mol Cell Neurosci 32:274-282.

Zhu X, Craft CM (2000a) Modulation of CRX transactivation activity by phosducin isoforms. Mol Cell Biol 20:5216-5226.

Zhu X, Craft CM (2000b) The carboxyl terminal domain of phosducin functions as a transcriptional activator. Biochem Biophys Res Commun 270:504-509. 


\section{Figure Legends}

Figure 1. Developmental expression of phosducin protein in the embryonic and postnatal retina.

Immunohistochemcial staining was performed on coronal sections starting at (A) E10.5 (before cone birth) through (I) P21. Anti-phosducin antibody labeled photoreceptors starting at E12.5 (arrows in $\mathbf{C}$ ) and continued through all time points tested. Arrowhead indicates RPE. Scale bars $=100 \mu \mathrm{m}$.

\section{Figure 2. Comparison of PdcKO and control retinas.}

Immunofluorescence was performed on coronal sections of control and phosducin knockout (PdcKO) mice at ages E13.5 (A) using anti-Pdc and anti-Otx2 antibodies and P0 (B) using antiPdc and anti-cone transducin $\gamma$ (Gngt2) antibodies. Pdc expression is seen in control retinas and is absent in the PdcKO retinas whereas Otx2 and Gngt2 are expressed in both control and PdcKO retinas. Scale bars $=100 \mu \mathrm{m}$.

\section{Figure 3. Colocalization of phosducin with known photoreceptor markers in the embryonic retina.}

A: Fluorescent imaging of coronal sections of mouse retina at E15.5 shows the colocalization of phosducin and Otx2, a photoreceptor marker, along the ventricular surface. Otx2 shows RPE labeling (arrowheads) in addition to photoreceptor labeling. Otx2-positive, Pdc-negative migrating cells are also seen interior to the ventricular surface (arrows). B: Immunofluorescent imaging of retinal sections at E17.5 for phosducin and the cone marker, Rxr $\gamma$, shows consistent colocalization along the ventricular surface of the retina. Scale bars $=50 \mu \mathrm{m}$. 
Figure 4. Developmental expression of cone transducin $\gamma$ protein in the embryonic and postnatal retina.

Immunohistochemcial staining was performed in coronal sections starting at (A) E10.5 (before cone birth) through (I) P21. Beginning at E13.5, cone transducin $\gamma$ expression is observed in cells along the ventricular surface (arrows in D), and this expression continues through all ages tested. Scale bars $=100 \mu \mathrm{m}$.

Figure 5. Colocalization of phosducin and cone transducin $\gamma$ expression in the retina. Fluorescent imaging of coronal sections of mouse retina from E13.5-P8 (A-E) was performed using anti-phosducin and anti-cone transducin $\gamma$ antibodies. Both markers localize almost exclusively to the ventricular surface at all ages tested. Scale bars $=50 \mu \mathrm{m}$. Quantification of the colabeled cell for ages E13.5-P0 (F) shows a high percentage of colabeled cells $(97 \% \pm 0.4 \%$; SD) at E13.5 that progressively decreased with age (E15.5 was $88 \% \pm 1.1 \%$; E17.5 was $87 \% \pm$ $2.3 \%$; P0 was $79 \% \pm 6.2 \%$ ). Phosducin-only cells comprised $2.4 \% \pm 1.1 \%$ at $\mathrm{E} 13.5,11.3 \%$ $\pm 1.3 \%$, at $\mathrm{E} 15.5,12.3 \% \pm 2.2 \%$ at $\mathrm{E} 17.5$ and $20 \% \pm 6.6 \%$ at P0. Cone transducin $\gamma$-only cells constituted $0.8 \% \pm 0.7 \%$ at $\mathrm{E} 13.5,1 \% \pm 0.04 \%$ at $\mathrm{E} 15.5,1 \% \pm 0.4 \%$ at $\mathrm{E} 17.5$ and $1.2 \% \pm 0.7 \%$ at P0. Blue bars indicate cells that are colabeled, the phosducin-only cells are shown in red, cone transducin $\gamma$-only cells appear in green, and error bars represent standard deviations.

Figure 6. mRNA expression across developmental ages measured with qPCR.

A:Pdc expression above the threshold was detected with qPCR at E10.5 and E11.5, but at extremely low levels. The relative Pdc expression levels increase at E12.5, which is consistent with protein expression (see Figure 1). Expression increases gradually through P0, and then at P8 there is a dramatic increase in Pdc mRNA levels. B: Expression of Gngt2 mRNA is detected with qPCR at E10.5 and E11.5, but similar to phosducin, at low levels. A steady increase in Gngt2 expression occurs from E12.5 to P0. The Gngt2 levels at P8 decrease slightly relative to P0 values. All numbers are expressed relative to PO and normalized to Hprt levels in each 
sample and graphed on a log scale. At each age, three independent samples were collected, and each of these samples was run in triplicate as technical replicates. Red lines indicate the average for that age group; black circles are individual samples at each age group. 

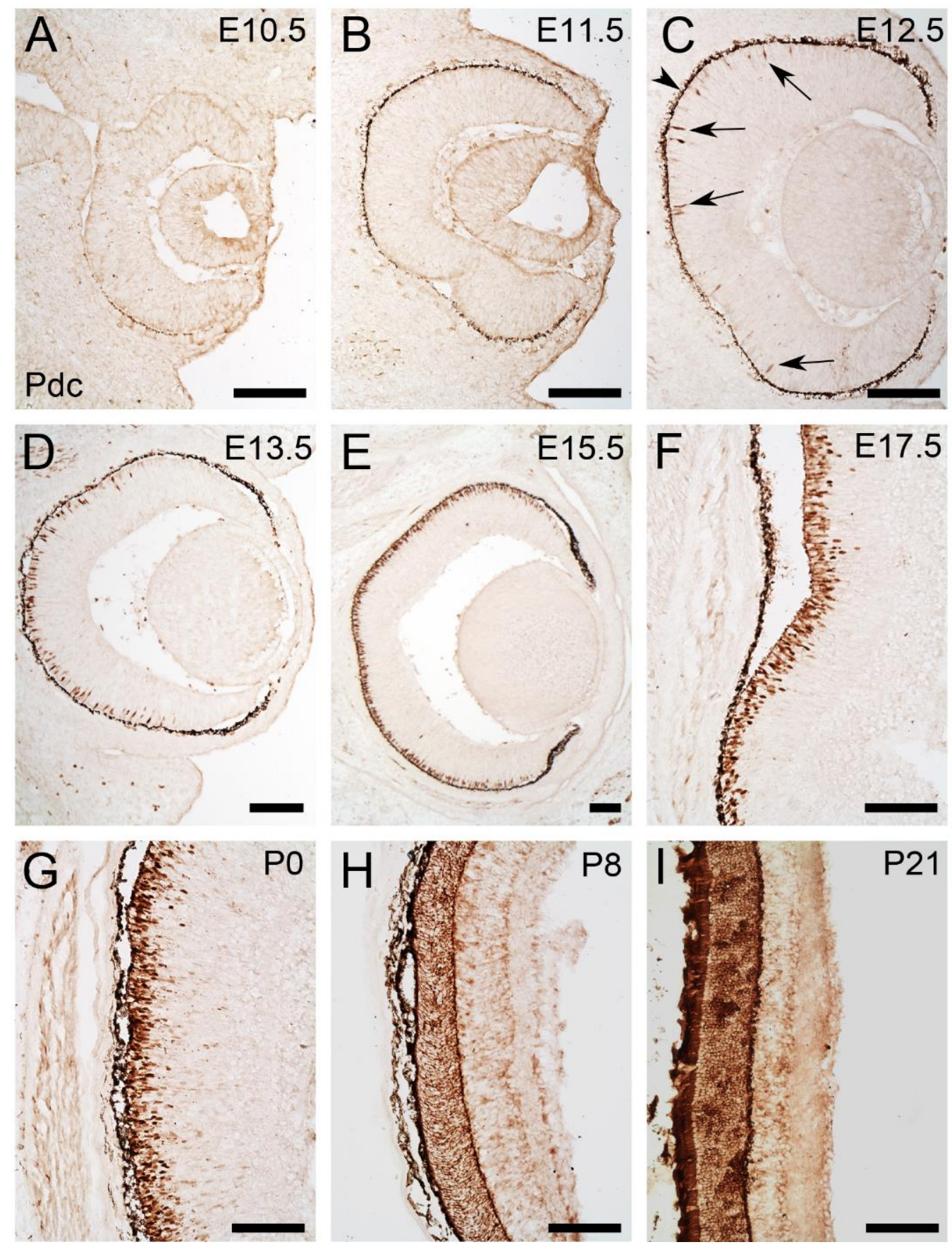

Figure 1. Developmental expression of phosducin protein in the embryonic and postnatal retina. 


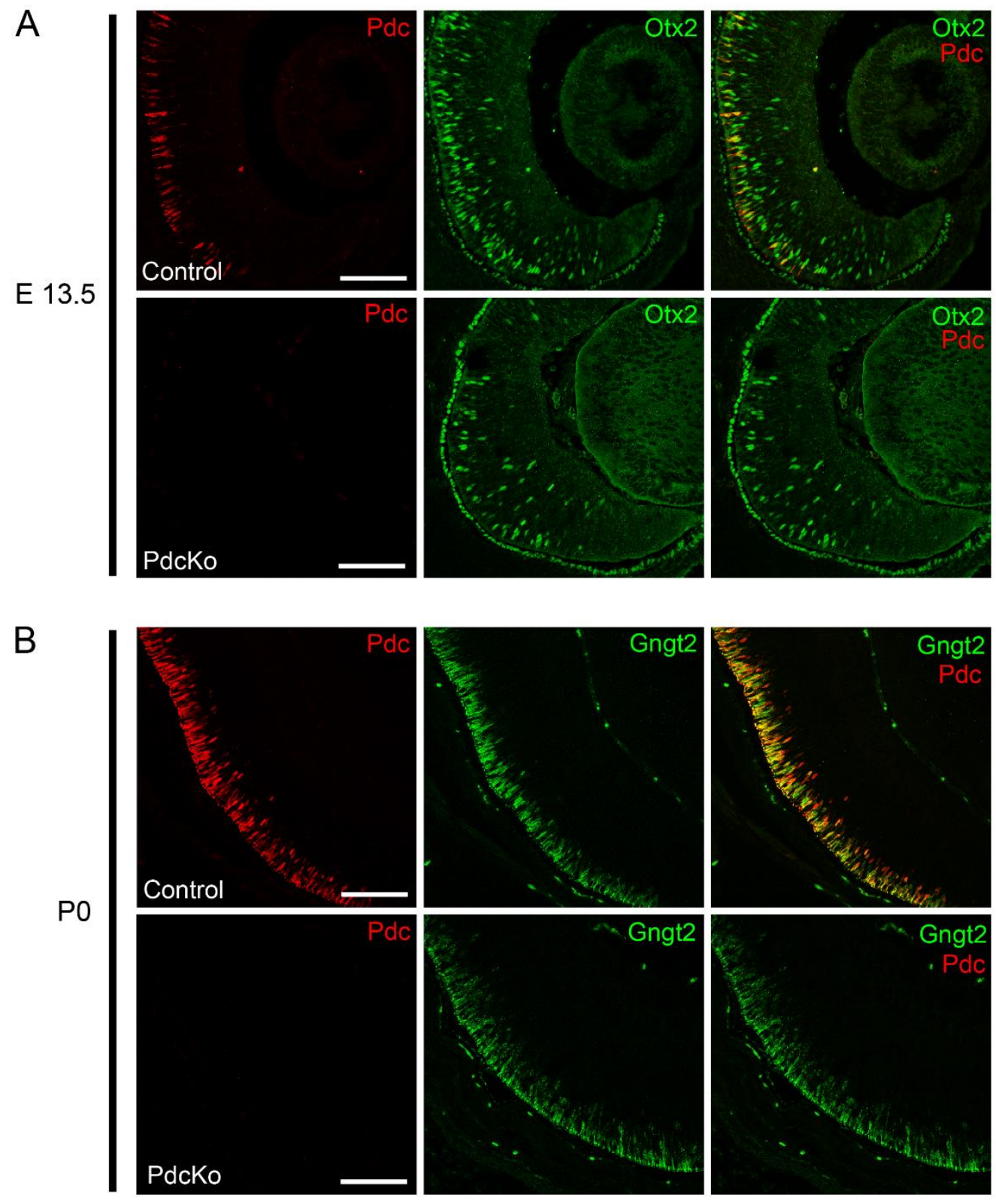

Figure 2. Comparison of PdcKO and control retinas. 

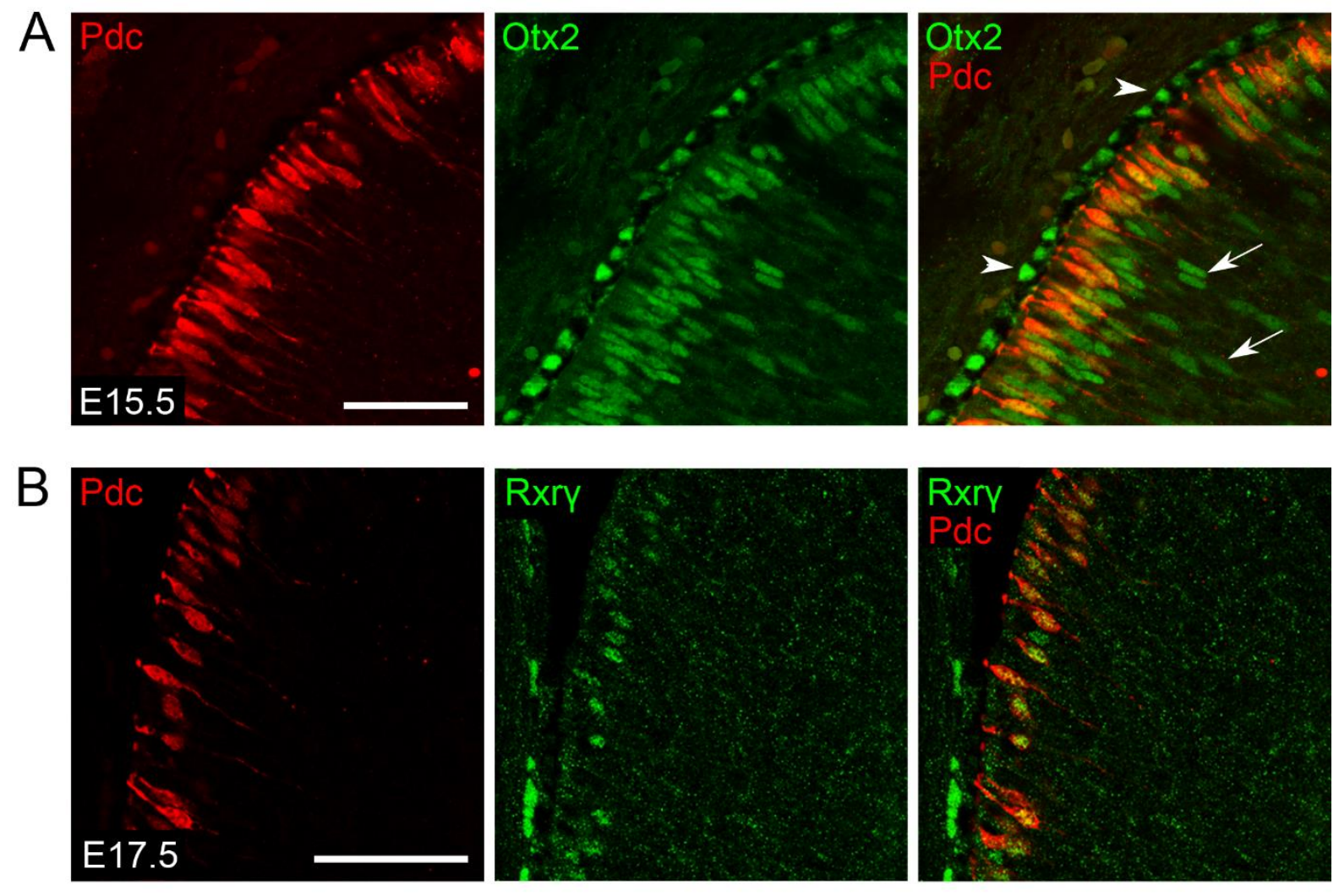

Figure 3. Colocalization of phosducin with known photoreceptor markers in the embryonic retina. 

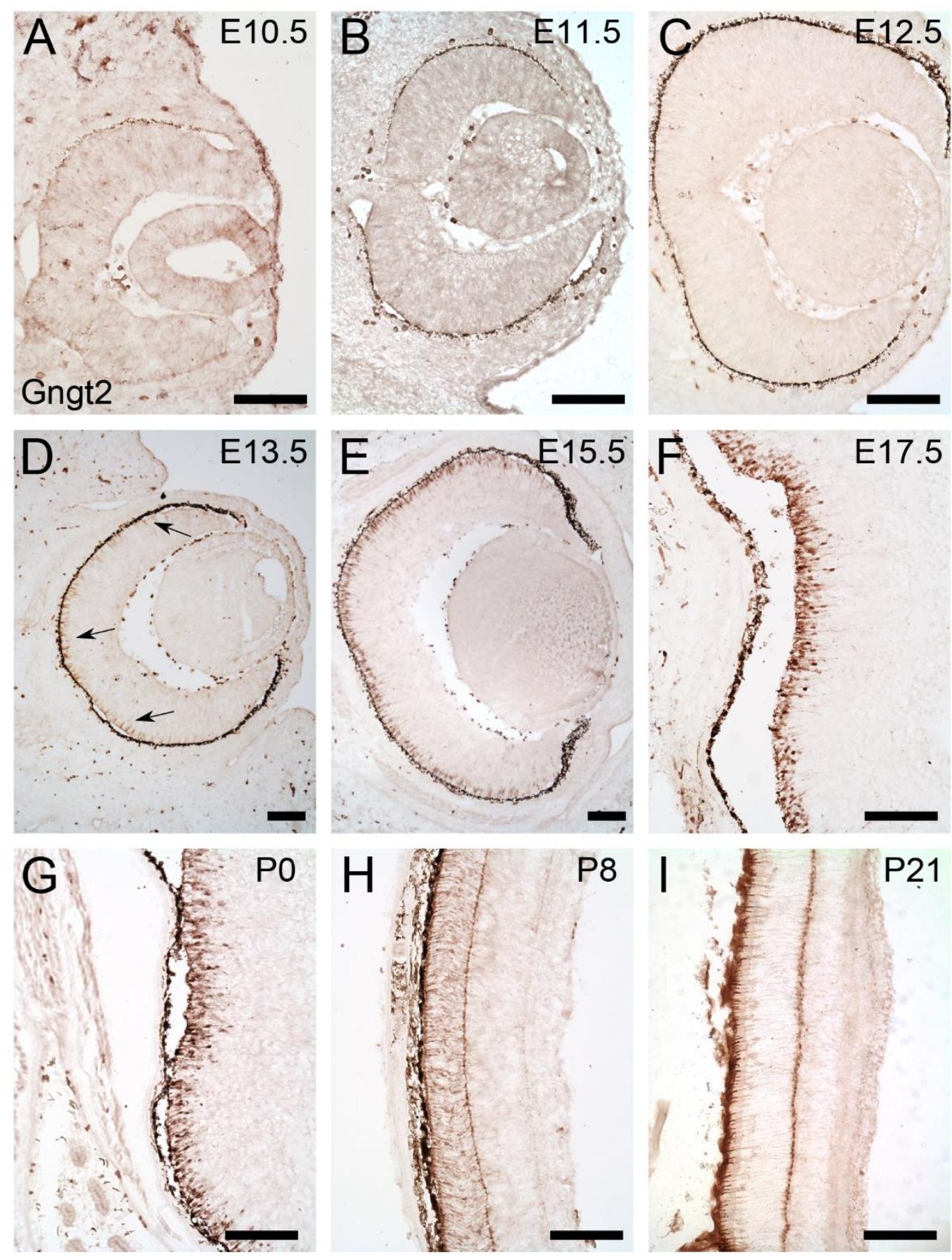

Figure 4. Developmental expression of cone transducin $\gamma$ protein in the embryonic and postnatal retina. 

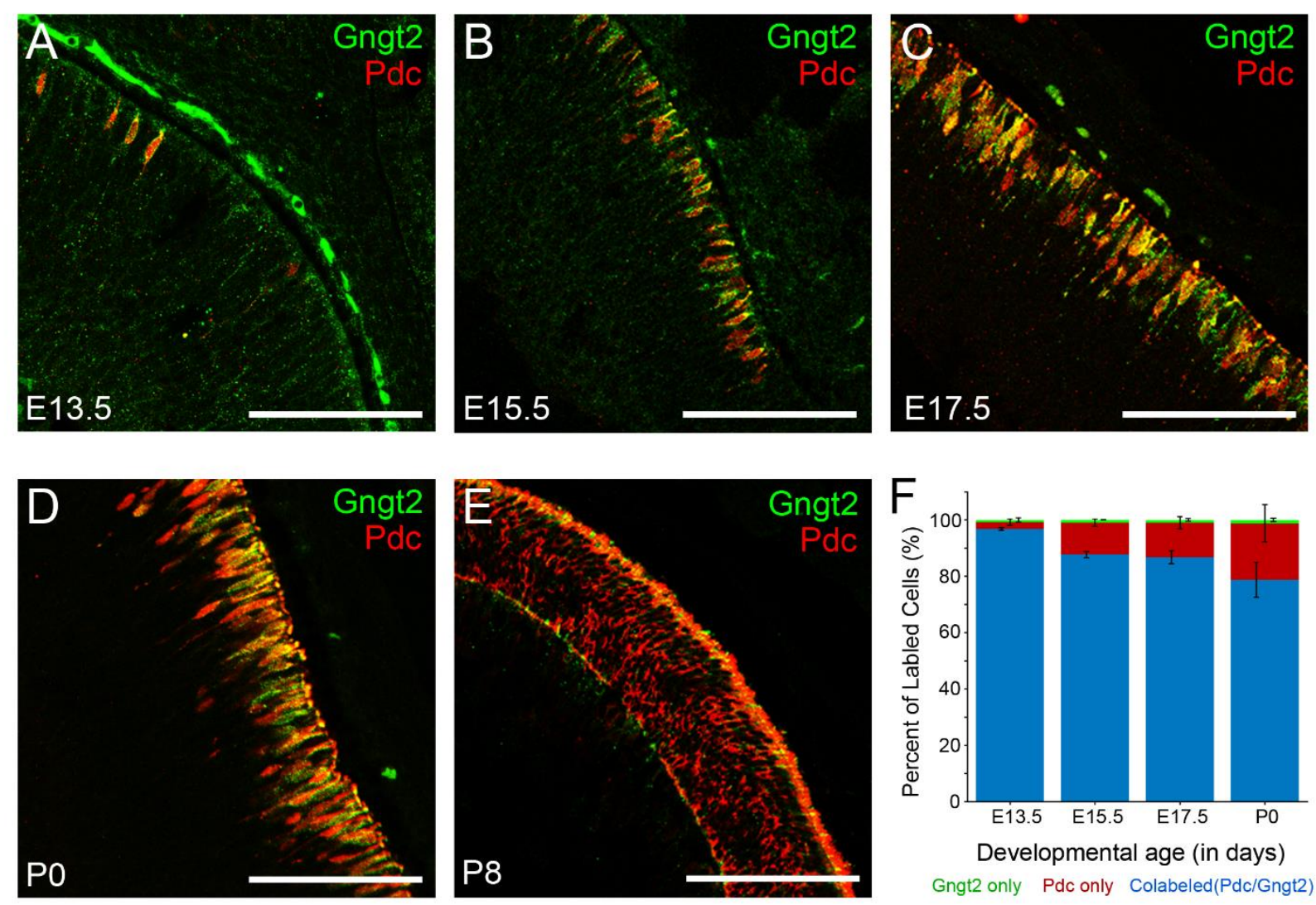

Figure 5. Colocalization of phosducin and cone transducin $\gamma$ expression in the retina. 

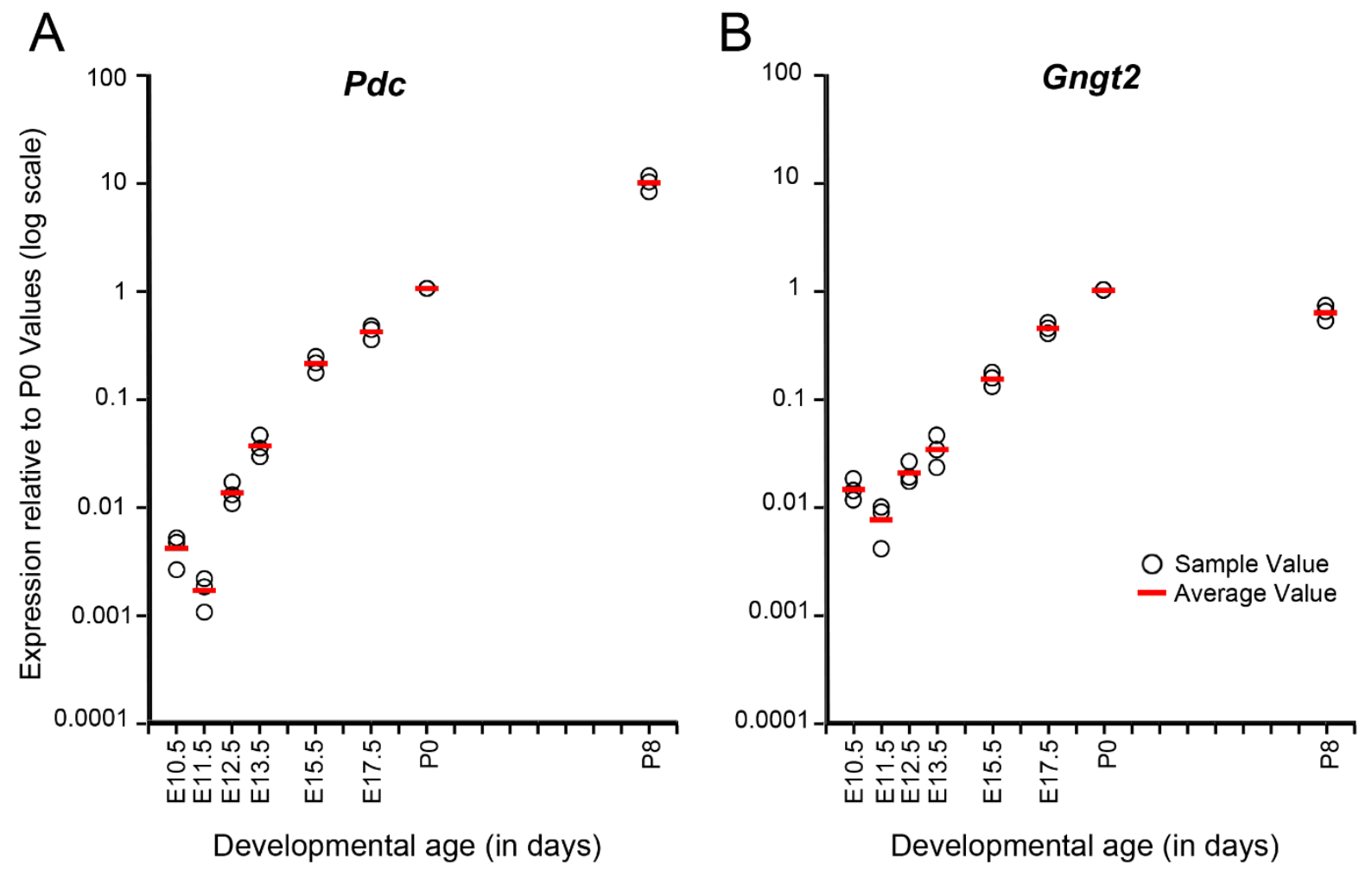

Figure 6. mRNA expression across developmental ages measured with qPCR. 
Chapter 3:

The role of the $\boldsymbol{R x}$ homeobox gene in progenitor proliferation and retinal cell fate specification.

Rodgers $\mathrm{HM}^{\#}$, Huffman VJ\#, Voronina VA, Lewandoski M, and Mathers, $\mathrm{PH}$

\#Contributed equally 


\begin{abstract}
The Retinal homeobox gene ( $R x$; also Rax) plays a crucial role in the early development of the vertebrate eye. Germline deletion of $R x$ in mice results in the failure of optic vesicle formation, leading to anophthalmia. Studying the role of $\mathrm{Rx}$ in subsequent eye development, therefore, requires the use of a conditional knockout strategy in mice. Recent research using conditional mouse knockout models provide some clues to the role of $\mathrm{Rx}$ in eye development following optic vesicle formation. However, the functions of $\mathrm{Rx}$ in embryonic retinogenesis are still not fully understood. We investigated the function of $R x$ in the mouse neural retina using a conditional knockout where the Pax6 $\alpha$ Cre driver deletes $R x$ in early retinal progenitors. The deletion of $R x$ causes a loss of retinal lamination, a depletion of retinal progenitors, and a change in retinal cell fate in our conditional knockout model. The deletion of $R x$ leads to an absence of late-born retinal neurons (rods, bipolar cells) and Müller glia at postnatal ages, as well as a loss of the early-born cone photoreceptors. Decreased BrdU and PCNA labeling in the $R x-$ deleted portion of the retina suggests a loss of retinal progenitors via early cell cycle exit, which likely prevents the formation of late-born cells. Cone photoreceptors are born early and therefore, are not as dependent on progenitor proliferation and should not be as affected by early cell cycle exit. However, embryonic cone photoreceptor labeling is also markedly reduced in $R x$-deleted retinas. Together these data support and extend earlier findings of the involvement of Rx in photoreceptor formation, specifically in cones and demonstrate the importance of $\mathrm{Rx}$ for retinal progenitor proliferation.
\end{abstract}




\section{Introduction}

Vertebrate eye development begins with the formation of the optic vesicles at embryonic day (E) 8.5 in the mouse. The optic vesicle folds inward forming the optic cup, with the innermost layer becoming the neural retina. The neural retina is a highly organized structure arranged in layers of specific cell types. Generation of the retinal cells types follows a conserved developmental pattern in vertebrates. Retinal progenitor cells generate neural retinal cells in a biphasic temporal order, resulting in early- and lateborn retinal cell types. Birthdating studies show the first cell type to be generated is retinal ganglion cells around E10.5 followed by horizontal cells, cones, and amacrine cells (Young, 1985; Rapaport et al., 2004). All early-born cells are primarily born during the embryonic period, whereas late-born cell generation starts in the embryonic period but the majority of cells are born postnatally, including rods, bipolar cells and Müller glia (Carter-Dawson and LaVail, 1979; Young, 1985; Rapaport et al., 2004). Many factors regulate cell proliferation, specification and differentiation for retinal formation, including the transcription factors, Pax6, Six3, Otx2, and Rx (also known as Rax)(Zagozewski et al., 2014).

The $R x$ homeobox gene is highly conserved among vertebrates and plays multiple important roles in eye development (Bailey et al., 2004). Mice have a single $R x$ gene (Furukawa et al., 1997; Mathers et al., 1997), whereas the number of $R x$ genes is variable among other species. Germline deletion of $R x$ in mice leads to anophthalmia (no eyes) as a result of a failure of the optic vesicles to form (Mathers et al., 1997). In humans, $R A X$ has been associated with anophthalmia, microphthalmia (small eyes) and coloboma (Voronina et al., 2004; Lequeux et al., 2008; London et al., 2009; Gonzalez- 
Rodriguez et al., 2010; Abouzeid et al., 2012; Chassaing et al., 2014). Due to the very early requirement for $\mathrm{Rx}$ activity at the optic vesicle/cup stages, there is a relative paucity of information on the role $R x$ plays following mammalian eye initiation. Conditional alleles for the embryonic inactivation of the $R x$ gene in mice allows the investigation of $R x$ gene function during this time period (Muranishi et al., 2011; Voronina et al., 2005). Embryonic conditional knockout (CKO) of $R x$ was briefly explored using a Chx10-Cre driver to inactivate $R x$ in retinal progenitors at $\mathrm{E} 11.5$ and using an inducible Crx-CreERT2 to inactivate $R x$ at E14.5 (Muranishi et al., 2011). Decreases in Otx2 and Crx were observed in both CKO models at E15.5 suggesting a possible role for $\mathrm{Rx}$ in the formation of photoreceptors (Muranishi et al., 2011). An inducible conditional knockout model that deleted $R x$ postnatally showed that $R x$, along with $C r x$, is important for photoreceptor maturation and survival during the postnatal period of retinal development (Irie et al., 2015).

The role of $R x$ in embryonic retinal development from optic vesicle formation through birth is still not well understood. Using an embryonic conditional deletion of $R x$ in mice, we sought to assess its role following initial eye development, specifically examining retinal progenitor proliferation and cell fate decisions. We focused on progenitor proliferation and cell fate decisions for several reasons. Research shows Rx expression correlates with proliferation (Furukawa et al., 1997; Mathers et al., 1997; Rohde et al., 2011), and Xenopus Rx is important for both proliferation and multipotency of retinal progenitors (Andreazzoli et al., 2003; Casarosa et al., 2003). However, whether Rx is necessary for retinal progenitor proliferation in mammals has not yet been established. 
Studies also suggests a role for Rx in photoreceptor determination. Embryonic conditional deletion models of $R x$ in mice showed decreases in Crx and Otx2 and showed that Rx can transactivate Otx2 (Muranishi et al., 2011). Postnatal conditional deletion of $R x$ showed that $\mathrm{Rx}$ is necessary for photoreceptor survival (Irie et al., 2015). Further, evidence for a role of $\mathrm{Rx}$ in photoreceptor development is provided in studies of other species such as Xenopus (Pan et al., 2010). Despite this evidence, several questions remain unclear in the functions of $\mathrm{Rx}$ during retinogenesis including its effects on cell fate beyond photoreceptors, possible differences in the functions of Rx between cone and rod photoreceptor development, and whether Rx is necessary for photoreceptor generation or just maturation and survival.

In the present study, we performed an embryonic conditional deletion of $R x$ using Pax6a-Cre to delete $R x$ in very early retinal progenitors, and assessed the effects on retinal development. We show that $\mathrm{Rx}$ is important in maintaining the proliferative state of retinal progenitors in mice, and therefore indirectly important for the development of late-born retinal neurons, which are lost in the $R x$ conditional knockout. Finally, we show that $\mathrm{Rx}$ has a direct role in the development of cone photoreceptors.

\section{Methods}

\section{Animals and Tissue Collection}

All animal procedures were approved by the WVU Institutional Animal Care and Use Committee and followed the guidelines set out by the Association for Research in Vision and Ophthalmology. Conditional deletion of $R x$ was achieved using $R x^{\text {flox }}$ transgenic mice (as described in Voronina et al., 2005). In these mice exon 2 of the $R x$ gene is flanked by loxP sites. In the presence of Cre recombinase, exon 2 is then excised, thus 
creating a nonfunctional allele. Two strains of reporter mice were used, from Jackson Laboratory (Bar Harbor, ME), Rosa26R and Rosa26EGFP (Soriano, 1999; Mao et al., 2001). $R x^{\text {flox }}$ mice were mated with reporter mice to generate a strain in which either $\beta$ galactosidase or EGFP activity is activated upon exposure to Cre-recombinase, thus allowing us to visualize cells where $R x$ has been inactivated. Our conditional knockout was generated using mice expressing Cre recombinase under the control of Pax6a enhancer (supplied by P. Gruss, Max-Planck) that were crossed with $R x$ null $\left(R x^{\Delta 1,2}\right)$ mice (Mathers et al., 1997). The Pax6a enhancer is active in the distal neural retina only starting at embryonic day (E)10.5 (Marquardt et al., 2001). Thus, the final cross for our $R x$ conditional deletion was homozygous $R x^{\text {flox; }}$ Rosa (EGFP or LacZ) mice crossed with mice heterozygous for $\alpha$-cre; $R x^{\Delta 1,2}$. From this cross we used Pax6a Cre/+; $R x^{f l o x} / R x$-null; Rosa/+ mice, the conditional knockout mice hereafter called $R x \mathrm{CKO}$, and Pax6a Cre/+; Rx flox/+; Rosa/+ mice were used as controls. Tail DNA was collected for genotyping by PCR using the primers described in Voronina et al. (2005).

Eyes were collected at a variety of time points: E12.5, E13.5, E14.5, E16.5, E17.5, E18.5, postnatal day (P) 0 and P21. Following euthanasia, whole eyes were removed from the orbit and fixed in a $4 \%$ paraformaldehyde solution of phosphate-buffered saline (1x PBS) overnight at $4^{\circ} \mathrm{C}$. After fixation, eyes were cryoprotected in $30 \%$ sucrose in PBS. Cryoprotected eyes were frozen in TBS tissue freezing media (Triangle Biomedical Sciences, Durham, NC), and sectioned on a Leica CM3050S cryostat at a thickness of $12 \mu \mathrm{m}$, then transferred to Super Frost plus-coated glass slides (Thermo Fisher Scientific, Waltham, MA). 


\section{BrdU Labeling}

Timed pregnancies were determined by the presence of a vaginal plug the morning after mating; noon the day after mating was considered E0.5. Time-mated female mice received an intraperitoneal injection of BrdU at a dose of $50 \mathrm{mg} / \mathrm{kg}$ bodyweight and then were sacrificed 2 hours later. Heads (E12.5) or whole eyes (E14.5 and E18.5) were collected and processed as described below for immunofluorescence. To calculate the percentage of BrdU-positive cells, the total number of cells (labeled by propidium iodide) and the number of BrdU-labeled cells were counted in three separate slices from at least four eyes of both control and $R x$ CKO mice.

\section{Histology}

Frozen sections were stained with either hematoxylin and eosin or X-gal. For hematoxylin and eosin staining ( $\mathrm{H}$ \& E staining), slides were processed by the Pathology/Histology Core Facility at West Virginia University.

For X-gal staining, frozen sections were rinsed with $1 \times$ PBS and incubated with X-gal staining solution as described in Marrs et al., 2013. After histological staining, images were visualized using an Olympus AX70 microscope (Olympus, Center Valley, PA) equipped with a MicroFire digital camera (Optronics; Goleta, CA)

\section{Immunofluorescence}

Sections were subjected to an antigen retrieval procedure of $0.1 \mathrm{M}$ Tris $\mathrm{pH} 9.5$ incubation at $95^{\circ} \mathrm{C}$ for 20 min prior to antibody processing. Following antigen retrieval, sections were blocked with normal serum at room temperature and treated with primary and secondary antibodies, following our published procedure (Howell et al., 2007). 
Additionally, select retinas were counterstained with propidium iodide (Molecular Probes, Eugene, OR; 1:200).

Primary antibodies used were: anti-activated caspase 3 (Sigma-Aldrich, St Louis, MO; 1:600), anti-BrdU (Abcam, Cambridge, MA: 1:10), anti-Brn3b (Santa Cruz Biotechnology, Dallas, TX; 1:50), anti-blue cone opsin (Chemicon, Temecula, CA ; 1:100), anti-calbindin (Swant, Marly, Switzerland; $1: 2000$ ), anti-cone transducin $\gamma$ (CytoSignal, Irvine, CA; 1:500), anti-Chx10 (Exalpha Biologicals, Shirley, MA; 1:1000), anti-CRALBP (Abcam; 1:1000), anti-GFP (chicken; Abcam; 1:1500), anti-GFP (rabbit; Abcam; 1:1000), anti-neurofilament 165kD (Hybridoma bank, lowa City, IA; 1:1000), anti-Otx2 (Millipore, Billerica, MA; 1:1000), anti-proliferating cell nuclear antigen (PCNA; Dako, Santa Clara, CA; 1:200), anti-phosducin (as previously described by Sokolov et al., 2004; 1:1000), anti-red/green cone opsin (Chemicon; 1:100), and anti-syntaxin 1A (Sigma-Aldrich; 1:1000). Secondary antibodies were fluorophore-tagged for immunofluorescence (Molecular Probes). Images were captured on an Olympus AX70 microscope (Olympus, Center Valley, PA) equipped with a MicroFire digital camera (Optronics; Goleta, CA), an LSM 510 Meta confocal microscope (Carl Zeiss, Inc.; Thornwood, NY) or an LSM 710 confocal microscope (Carl Zeiss, Inc.; Thornwood, NY).

\section{Results}

\section{$R x$ deletion results in histological changes in the retina}

To study the functions of $\mathrm{Rx}$ during retinogenesis, we generated a retinal specific conditional knockout using the Pax6a-Cre driver (Marquardt et al., 2001) to induce recombination in retinal progenitors of the distal retina. The resulting Cre recombination excises exon 2 of $R x$ at approximately E10.5, the beginning of retinal neurogenesis. 
X-gal staining to detect $\beta$-galactosidase activity from the Rosa26R reporter shows $R x$ deletion results in a decreased area of $\mathrm{X}$-gal staining in the distal retina in $R x \mathrm{CKO}$ mice compared to control mice (Figure 1A). Further histological analysis shows that deletion of $R x$ leads to a disruption in retinal lamination and creates an expanded mass in the distal portion of the P21 retina as shown by $\mathrm{H}$ \& E staining in comparison to control (Figure 1B). However, the central retina (the non-deleted portion) in $R x \mathrm{CKO}$ mice appear normal and show well defined layers and normal retinal thickness.

\section{Deletion of $R x$ in the embryonic retina does not increase cell death}

Next, we assessed if the reduction in X-gal labeling upon $R x$ deletion was caused by cell death in the retina. To determine the role of apoptosis in the $R x$ CKO phenotype, we performed immunolabeling using the cell death marker, activated caspase-3 and GFP, which labels cells that have undergone Cre recombination and thus $R x$ deletion. Examination of retinal sections across various ages (E13.5- P21; Figure 2 shows P0 labeling as a representative sample) shows no differences between $R x \mathrm{CKO}$ and control retinas at any of the ages tested. Counting the activated caspase-3- and GFP-positive cells showed an average of $1.5 \pm 0.5$ (SD) activated caspase 3-positive cells in the control and $2.1 \pm 1.4(\mathrm{SD})$ activated caspase 3-positive cells in the $R x \mathrm{CKO}$, t-test analysis was nonsignificant $(\mathrm{p}>0.05)$. The limited activated caspase- 3 labeling in the $R x-$ deleted portion of the retina indicates that the embryonic loss of $R x$ in the retina does not significantly increase cell death. 


\section{Rx is important for retinal progenitor proliferation}

The reduction in the X-gal-labeled domain of $R x$ CKO mice combined with previous research that proposes a role for $\mathrm{Rx}$ in proliferation (Furukawa et al., 1997; Mathers et al., 1997; Casarosa et al., 2003) suggests a possible decline in the number of retinal progenitors. Therefore we sought to determine whether deletion of $R x$ affects retinal progenitors and proliferation. To assess changes in proliferation in the $R x$-deleted retina, we used two proliferation markers, BrdU incorporation and immunoreactivity for proliferating cell nuclear antigen (PCNA), and compared $R x$ CKO mice with littermate controls. For BrdU immunostaining, which labels cells in the $\mathrm{S}$ phase of mitosis, we counterstained with the nuclear marker, propidium iodide $(\mathrm{PI})$, at three ages (E12.5, E14.5 and E18.5, see Figure 3). We observed an age-related decrease in the percentage of BrdU-positive cells in the $R x$ CKO distal retina compared to controls (Figure 3). At E12.5, there is no significant difference in BrdU incorporation in the distal retina of $R x$ CKO and control mice (Figure 3A-C). By E14.5, a significant difference emerges such that the percentage of BrdU-positive cells in the control retinas is $37.0 \pm$ $2.1 \%$ and in the $R x \mathrm{CKO}$ is $34.3 \pm 2.1 \%(\mathrm{P}<0.05)$ (Figure $3 \mathrm{D}-\mathrm{F})$. Finally, at $\mathrm{E} 18.5$ the percentage of BrdU-positive cells in the controls is $33.9 \pm 1.4 \%$, and the central retina of $R x$ CKO mice is comparable at $34.4 \pm 2.3 \%$, whereas the distal, deleted portion of the $R x \mathrm{CKO}$ shows a drastic reduction $(\mathrm{P}<0.001)$, with only $3.6 \pm 1.1 \%$ BrdU-positive cells (Figure 3G-J). An overview of a whole retinal section at E18.5 shows the dramatic decrease in $\mathrm{BrdU}$ labeling in the distal regions of the $R x$ CKO retina compared to control (Figure 4A). Examining the expression of GFP and BrdU incorporation in the $R x$ CKO (Figure 4B) allows the determination of proliferation within the areas of the distal retinal 
that have undergone $R x$ deletion. The non-GFP labeled areas show robust BrdU expression whereas the GFP-positive region shows a paucity of BrdU labeling (Figure 4B). To further analyze $R x$-dependent proliferation effects, we performed immunostaining with another proliferation marker, PCNA, which labels retinal progenitors in all phases of the cell cycle and decreases upon cell cycle exit (Barton and Levine, 2008). Immunostaining for PCNA and GFP at P0 shows strong PCNA labeling in the control and central portion of the $R x$ CKO retina (Figure $4 \mathrm{C}$ ), indicating an abundance of retinal progenitors. The Cre-recombined portion of the $R x$ CKO retina shows a sharp decrease in PCNA labeling compared to control (Figure 4C), similar to that seen in our BrdU-labeled $R x$ CKO retina at E18.5 (Figure 4A). Taken together, the BrdU and PCNA results suggest that $R x$ is important in maintaining mouse retinal progenitor proliferation and that deletion of $R x$ results in a decrease in the progenitor pool likely due to early cell cycle exit.

\section{$R x$ deletion alters cell fate specification}

Since the loss of $R x$ significantly reduces the number of retinal progenitors and affects retinal lamination, we sought to determine if there are any changes in cell fate specification in the $R x$-deleted portion of the $R x$ CKO retina. To determine the identity of cells in the deleted portion of the $R x$ CKO retina, we conducted immunolabeling studies using retinal cell-specific markers in mature retinas. Comparing control and $R x \mathrm{CKO}$ retinas at P21, we observed GFP- and Brn3b-colabeled cells, indicating the presence of ganglion cells in the $R x$-deleted distal retina (Figure 5A,B). Immunolabeling with syntaxin $1 \mathrm{~A}$ shows extensive labeling in the distal (GFP-positive) portion of the $R x$ CKO retina, suggesting an increase in amacrine expression in the $R x$-deleted retina (Figure 
5D) compared to control retinas (Figure 5C). The presence of horizontal cells was detected using immunolabeling of calbindin $28 \mathrm{kD}$ and neurofilament $165 \mathrm{kD}$. Colabeling of these markers with GFP indicates the presence of horizontal cells in both control retinas (Figure 5E,G) and portions of the retina where $R x$ is deleted (Figure $5 F, H)$. Examination of P21 retinal sections using cone-specific markers (S-opsin, and M-opsin) shows opsin expression within the control retinas (Figure $6 A, C$ ) and a marked decrease in labeling in the distal retina of $R x$ CKO mice (Figure 6B,D). Labeling with GFP shows the GFP-positive region overlapping with the region lacking cone photoreceptors. The results of immunolabeling for early-born retinal cell types in the $R x$ CKO retina revealed a reduction in cone photoreceptors and an apparent increase in amacrine cell labeling.

Due to the reduction in the retinal progenitor pool, we hypothesized that the late-born retinal cell types would be affected by the loss of $R x$. To test this prediction, we performed immunolabeling on $\mathrm{P} 21 R \times \mathrm{CKO}$ and control retinas with antibodies against rhodopsin, Chx10 and CRALBP, which label rod photoreceptors, bipolar cells and Müller glia, respectively. Labeling for all three cell types was observed in the control retinas (Figure $7 \mathrm{~A}, \mathrm{C}, \mathrm{E}$ ) and in the central region of the $R x \mathrm{CKO}$ retina (Figure $7 \mathrm{~B}, \mathrm{D}, \mathrm{F}$ ). Examining the area of Cre recombination in the $R x \mathrm{CKO}$, as demarcated by GFP expression, shows an absence of rhodopsin, Chx10 and CRALBP labeling (Figure 7 $\mathrm{B}, \mathrm{D}, \mathrm{F})$, demonstrating a total loss of the late-born retinal cell types in the $R x$-deleted region. 


\section{Deletion of $\boldsymbol{R x}$ directly affects cone photoreceptor generation}

The loss of the late-born cell types is consistent with Rx expression in the retinal progenitor pool (Furukawa et al., 1997; Mathers et al., 1997; Andreazzoli et al., 2003; Casarosa et al., 2003). The loss of the early-born cones was suggested in previous $R x$ CKO models showing a lack of Crx and Otx2 activity. However, the loss of cones is unlikely to be solely the result of a premature cell cycle exit phenotype. There are two possible explanations for the loss of cones-1) Rx is necessary for cone histogenesis; or 2) the cones are initially formed but subsequently degenerate, suggesting a role for $R x$ in embryonic cone survival similar to the role of $\mathrm{Rx}$ in postnatal cones (Irie et al., 2015). To test these possibilities, we sought to explore the expression of cone markers in embryonic retinogenesis to determine if cones were being born normally in the $R x$ deleted retina. Cone histogenesis begins around E11.5 and is complete just prior to birth (Carter-Dawson and LaVail, 1979; Young, 1985; Rapaport et al., 2004). During retinogenesis, cells are first born in the central retina and then a wave of differentiation progresses to the periphery. The Pax6a-Cre expression domain is in the distal retina; therefore, the earliest we could examine cone generation in this model and expect to find cones in the periphery is during late cone histogenesis (Young, 1985; Rodgers et al., 2016). Since cone opsins are not expressed in the embryonic retina, we used the markers phosducin and cone transducin $\gamma$. A previous study showed phosducin at E17.5 shows $87 \%$ co-expression with the cone specific marker, cone transducin $\gamma$ thus making them useful markers of embryonic cones (Sakagami et al., 2009; Rodgers et al., 2016). Immunolabeling with phosducin and GFP at E17.5 and P0 shows robust phosducin labeling along the entire length of the retina at the ventricular surface in 
control samples (Figure $8 \mathrm{~A}, \mathrm{C}$ ). In the $R x$ CKO retina, the central portion of the retina displays phosducin, but the expression is greatly reduced in the distal portion of the retina (Figure $8 \mathrm{~B}, \mathrm{C}$ ). To determine the location of the $R x$ deletion in the CKO retina in relation to phosducin labeling, we examined GFP expression from the Rosa26EGFP reporter. We observe mosaic GFP expression in the distal retina, and in the GFPlabeled areas, there is a sharp decrease in phosducin-positive cells compared to non GFP-labeled areas of the $R x$ CKO distal retina (Figure 8). Phosducin and cone transducin $\gamma$ expression in the $R x$ CKO shows strong co-labeling of the cone markers in the control and central retina of the $R x \mathrm{CKO}$ and reduced expression in the distal $R x$ CKO retina (Supplemental figure 1). To further test our findings, we next examined the expression of Otx2. Otx2 is known to label photoreceptors in the embryonic retina; however, it is not photoreceptor-specific. Immunolabeling using Otx2 and GFP in E17.5 retinal sections of control and $R x$ CKO show strong Otx2 expression in the control (Figure 9A) and central portion of the $R x$ CKO (Figure 9B). In the distal portion of the $R x$ CKO retina, there is sharp decline in Otx2-labeled cells (Figure 9B), with GFP-labeled cells indicating those cells have undergone recombination and thus $R x$ deletion. Taken together, the cone marker immunolabeling data suggest that there is a large decrease in cone expression during cone histogenesis. Based off of the lack of cell death and the presence of other early-born cell types it is probable that $R x$ is necessary for cone photoreceptor generation.

\section{Discussion}

The role of $R x$ in retinogenesis following optic vesicle/cup initiation is not well understood. Here, we investigated the functions of $R x$ during embryonic neural retinal 
formation. Our data indicates that $R x$ plays multiple roles in eye development during retinal formation.

\section{$R x$ is required for appropriate retinal morphology}

Conditional deletion of $R x$ at E10.5 in the Pax6a-Cre-mediated $R x$ CKO leads to several abnormalities in the postnatal retina. The first noted difference was a decrease in the clone size of Cre-marked lineage domain in the $R x \mathrm{CKO}$, which complements the finding in other embryonic $R x$ CKO mice that showed a decrease in eye size (Muranishi et al., 2011). Additional histological examination reveals that $R x$ deletion leads to an enlarged disorganized retina that had lost its typical lamination at postnatal ages. The enlargement of the disorganized region starts around P0 and becomes very prominent by P21. Disruptions in retinal lamination are seen in conditional knockout models of Sufu, a regulator of hedgehog signaling (Cwinn et al., 2011), and Pax6, Lhx2, and Otx2, retinal transcription factors (Marquardt et al., 2001; Nishida et al., 2003; Gordon et al., 2013). Similar to our $R x$ CKO mice, these models all show alterations in cell type specification, including a loss of photoreceptors. Koike et al. (2005) showed that aPKC lambda in differentiating photoreceptors is necessary for proper retinal lamination, suggesting that the loss of photoreceptors may have resulted in the abnormal retinal lamination seen in our $R x$ CKO mice and the other models. However, mice with a Chx10 (Vsx2) homeobox null allele (Burmeister et al., 1996) show a disruption in normal retinal lamination and a lack of bipolar cells but retain their photoreceptors, demonstrating the possibility that the disruption in lamination may not solely be due to a lack of photoreceptors. 


\section{$R x$ maintains mouse retinal progenitors}

Our study extends previous studies showing that $\mathrm{Rx}$ is expressed in retinal progenitors (Furukawa et al., 1997; Mathers et al., 1997; Casarosa et al., 2003) by providing evidence that $R x$ is necessary in maintaining the murine retinal progenitor pool. Using two markers of proliferation, BrdU and PCNA, we show a decrease in retinal progenitors in the $R x$-deleted retina. We propose that deletion of $R x$ from the retinal progenitors at E10.5 causes premature cell cycle exit. Assessment of the retinal cell types found in the $R x$-deleted portion of the retina show a loss of all late-born cell types, suggesting that the loss of the progenitor pool prevented their formation while allowing the generation of the early-born cell types. In addition, the decrease in retinal progenitors explains the decrease in clone size of the Cre-marked lineage domain in the $R x \mathrm{CKO}$ as observed by X-gal staining (Figure 1). Further, the difference in activated caspase-3 labeling between control and $R \times$ CKO retinal sections is too small to account for the changes seen in the retina, suggesting apoptosis is not the reason for the reduction in the Cre recombination domain or loss of retinal progenitors in the $R x \mathrm{CKO}$.

Several genes have been associated with decreases in the retinal progenitor pool, including Pax6, Ldb1, and Lhx2 (Marquardt et al., 2001; Gordon et al., 2013; Gueta et al., 2016). Rx is necessary for functional Pax6 expression (Zhang et al., 2000), and conditional knockout of Pax6 does not affect expression of retinal progenitor markers, including $R x$ (Marquardt et al., 2001), suggesting that Rx functions upstream of Pax6 in its role in progenitor proliferation. Conditional knockout of Ldb1/Ldb2 (Lim domain binding 1/2) decreases $R x$ expression, suggesting that $R x$ may be downstream of the 
Ldb-Lhx2 complex in the maintenance of the retinal progenitor pool (de Melo et al., 2016; Gueta et al., 2016).

\section{Early deletion of $R x$ in retinal progenitors leads to alterations in cell type in the postnatal retina}

Deletion of $R x$ in retinal progenitors at E10.5, the very beginning of neural retinal cell birth, leads to many changes in cell type in the postnatal retina. Late-born cell types were absent, along with early-born cone photoreceptors; in addition, amacrine cells, an early-born cell type, were increased. Previous studies of conditional $R x$ deletion in retinal progenitors did not explore cell types in the postnatal retina, however, they did show ectopic Pax6 expression in the embryonic $R x$ CKO retina which labels amacrine cells and retinal progenitors (Muranishi et al., 2011), which fits with our finding of increased amacrine marker labeling at postnatal ages.

These alterations in cell type follow a pattern seen in other homeobox gene knockouts that show changes in cell fate specification, where some cell types are decreased and others are increased. Conditional knockout of Otx2 results in an increase in amacrine cells, a decrease in rods and an absence of cones (Nishida et al, 2003) similar to what is seen in our $R x$ CKO. However, unlike our $R x$ CKO, Müller glia are unaffected in the Otx2 CKO and there is a large amount of cell death (Nishida et al., 2003). Lhx2 conditional knockout at E10.5 shows an overproduction of retinal ganglion cells and a decrease in all other cell types (Gordon et al, 2013). Conditional deletion of Pax6 allows only amacrine cells, with all other cell types absent (Marquardt et al, 2001). 
Similarly, changes in cell fate are observed in the conditional knockout of the transmembrane receptor, Notch1 (Jadhav et al., 2006; Yaron et al., 2006). Notch1 CKO mice generated with Pax6a-Cre display altered retinal morphology, decreased retinal progenitors and an increase in cone photoreceptor at the expense of other early born cell types (Yaron et al., 2006). A similar phenotype was observed in Notch1 CKO mice generated using Chx10 Cre; Notch1 CKO mice showed alterations in retinal morphology, a decrease in retinal progenitors and an increase in rod and cone photoreceptors (Jadhav et al., 2006).

The absence of all late-born cell types within the early $R x$-deleted retina at postnatal ages coupled with the large decrease in proliferation suggests an indirect effect of $R x$ deletion on these late-born cell types. Changes in proliferation are known to affect the type of cell generated; late-born cells require a sufficient pool of progenitors for their formation (Dyer and Cepko, 2001). Therefore, the absence of the late-born cells is likely due to the loss of the progenitor pool in our $R x$ CKO model.

\section{$R x$ is important for the formation of cone photoreceptors}

Previous studies on Rx suggest it has a function in photoreceptor development. In our model, the loss of rods is likely due to the lack of progenitors so we chose to specifically focus on further studying cone photoreceptors. The loss of cone photoreceptors in the $R x \mathrm{CKO}$ at $\mathrm{P} 21$ could be the result of a lack of cone formation, suggesting a role in cone cell fate, or degeneration suggesting a role in cone survival. Thus, we proceeded to investigate cone histogenesis in the $R x$ CKO. Our results show that deletion of $R x$ leads to a large decrease in the birth of cone photoreceptors without increases in cell death. 
Our study did not show a complete absence of cones in the distal portion of the $R x$ CKO. The few cells that were labeled with cone markers could be the result of the mosaic nature of Pax6a-Cre expression.

We propose that $R x$ is necessary for cone histogenesis because we observe a lack of cones in embryonic $R x$-deleted retina with no evidence of increased cell death suggesting that the absence of cones is due to a failure to form and not due to degeneration. A possible role of mouse $\mathrm{Rx}$ in early photoreceptor development was previously suggested in a study using two conditional knockout models of $R x$ (Muranishi et al., 2011). Conditional deletion of $R x$ at E11.5 and E14.5 results in reduced levels of Otx2 and Crx expression at E15.5 (Muranishi et al, 2011), which is similar to our results showing decreased levels of Otx2. However, our results show a less dramatic Otx2 decrease possibly due to the mosaic nature of the Pax6a-Cre expression. Our results are consistent with those previous findings showing decreases in the embryonic retina of photoreceptor markers. We extended those findings by studying cell death in the $R x$ CKO models and more fully exploring proliferation and specific cell types produced. Postnatal conditional deletion of $R x$ showed decreases in photoreceptor markers and increases in cell death, suggesting $R x$ is necessary for maturation and survival of photoreceptors during the postnatal time period (Irie et al., 2015). Taken together the results of the $R x$ conditional knockout models suggest that $R x$ has multiple roles in photoreceptor development including the formation of cones and survival of photoreceptors.

The mechanism of action for $\mathrm{Rx}$ in photoreceptor development has been partially explored. In Xenopus and humans, $R x$ can bind with PCE-1, a conserved element found 
in the promoter regions of photoreceptor-specific genes (Kimura et al., 2000; Pan et al., 2010). Further, the expression of $\mathrm{Rx}$ in Xenopus co-localizes with red opsin and rhodopsin promoters in photoreceptors (Pan et al., 2010). A group of genes phylogenetically related to $R x$ have been identified, termed $R x$-like. $R x$-like genes, are found in humans, frogs, and chickens and are expressed in photoreceptors and activate photoreceptor genes (QRX: Wang et al., 2004; Rx-L: Pan et al., 2006 and RaxL; Chen and Cepko, 2002). Mice have a single $R x$ gene and lack $R x$-like genes, suggesting that the single $R x$ gene may play a similar role to the multiple $R x$ and $R x$-like genes found in other species in photoreceptor development. Studies in mice show that Rx can transactivate Otx2 and along with Crx can transactivate photoreceptor genes (Irie et al., 2015; Muranishi et al., 2011).

Further studies are needed to fully determine if $\mathrm{Rx}$ plays separate roles in rod versus cone photoreceptor development. In chickens, RaxL, plays a role in cone differentiation (Chen and Cepko, 2002) and the results of our study suggest that murine $R x$ has a direct role in cone photoreceptor development.

In summary, the data presented here suggests multiple roles for $R x$ during neural retinogenesis, including proper retinal lamination, maintenance of retinal progenitors and cone photoreceptor generation. 


\section{Acknowledgements}

We are grateful to D. Cole for his technical assistance with the immunological studies, and M. Sokolov for the phosducin and cone transducin $\gamma$ antibodies.

Imaging experiments were performed in the West Virginia University Microscope Imaging Facility, which has been supported by the WVU Cancer Institute and NIH grants P20 RR016440, P30 GM103488 and P20 GM103434.

This work was supported in part by grants from the NEI EY012152 (P.H.M.) as well as WVU institutional funding and a Fight for Sight Research Foundation postdoctoral fellowship (V.J.H.). The authors declare no conflicts of interest. 


\section{References}

Abouzeid H, Youssef M a, Bayoumi N, EIShakankiri N, Marzouk I, Hauser P, Schorderet DF (2012) RAX and anophthalmia in humans: evidence of brain anomalies. Mol Vis 18:14491456.

Andreazzoli M, Gestri G, Cremisi F, Casarosa S, Dawid IB, Barsacchi G (2003) Xrx1 controls proliferation and neurogenesis in Xenopus anterior neural plate. Development 130:51435154.

Bailey TJ, El-Hodiri H, Zhang L, Shah R, Mathers PH, Jamrich M (2004) Regulation of vertebrate eye development by Rx genes. Int J Dev Biol 48:761-770.

Barton KM, Levine EM (2008) Expression patterns and cell cycle profiles of PCNA, MCM6, cyclin D1, cyclin A2, cyclin B1, and phosphorylated histone $\mathrm{H} 3$ in the developing mouse retina. Dev Dyn 237:672-682.

Burmeister M, Novak J, Liang M-Y, Basu S, Ploder L, Hawes NL, Vidgen D, Hoover F, Goldman D, Kalnins VI, Roderick TH, Taylor BA, Hankin MH, Mclnnes RR (1996) Ocular retardation mouse caused by $\mathrm{Chx10}$ homeobox null allele: impaired retinal progenitor proliferation and bipolar cell differentiation. Nat Genet 12:376-384.

Carter-Dawson LD, LaVail MM (1979) Rods and cones in the mouse retina. II. Autoradiographic analysis of cell generation using tritiated thymidine. J Comp Neurol 188:263-272.

Casarosa S, Amato MA, Andreazzoli M, Gestri G, Barsacchi G, Cremisi F (2003) Xrx1 controls proliferation and multipotency of retinal progenitors. Mol Cell Neurosci 22:25-36.

Chassaing $\mathrm{N}$ et al. (2014) Molecular findings and clinical data in a cohort of 150 patients with anophthalmia/microphthalmia. Clin Genet 86:326-334.

Chen C-MA, Cepko CL (2002) The chicken RaxL gene plays a role in the initiation of photoreceptor differentiation. Development 129:5363-5375.

Cwinn MA, Mazerolle C, McNeill B, Ringuette R, Thurig S, Hui C, Wallace VA (2011) Suppressor of fused is required to maintain the multipotency of neural progenitor cells in the retina. J Neurosci 31:5169-5180.

de Melo J, Zibetti C, Clark BS, Hwang W, Miranda-Angulo AL, Qian J, Blackshaw S (2016) Lhx2 Is an Essential Factor for Retinal Gliogenesis and Notch Signaling. J Neurosci 36.

Dyer MA, Cepko CL (2001) Regulating proliferation during retinal development. Nat Rev Neurosci 2:333-342.

Furukawa T, Kozak CA, Cepko CL (1997) rax, a novel paired-type homeobox gene, shows expression in the anterior neural fold and developing retina. Proc Natl Acad Sci U S A 94:3088-3093.

Gonzalez-Rodriguez J, Pelcastre EL, Tovilla-Canales JL, Garcia-Ortiz JE, Amato-Almanza M, Villanueva-Mendoza C, Espinosa-Mattar Z, Zenteno JC (2010) Mutational screening of CHX10, GDF6, OTX2, RAX and SOX2 genes in 50 unrelated microphthalmiaanophthalmia-coloboma (MAC) spectrum cases. Br J Ophthalmol 94:1100-1104.

Gordon PJ, Yun S, Clark AM, Monuki ES, Murtaugh LC, Levine EM (2013) Lhx2 Balances Progenitor Maintenance with Neurogenic Output and Promotes Competence State Progression in the Developing Retina. J Neurosci 33:12197-12207. 
Gueta K, David A, Cohen T, Menuchin-Lasowski Y, Nobel H, Narkis G, Li L, Love P, de Melo J, Blackshaw S, Westphal H, Ashery-Padan R (2016) The stage-dependent roles of Ldb1 and functional redundancy with Ldb2 in mammalian retinogenesis. Development 143:41824192.

Howell DM, Morgan WJ, Jarjour AA, Spirou GA, Berrebi AS, Kennedy TE, Mathers PH (2007) Molecular guidance cues necessary for axon pathfinding from the ventral cochlear nucleus. J Comp Neurol 504:533-549.

Irie S, Sanuki R, Muranishi Y, Kato K, Chaya T, Furukawa T (2015) Rax Homeoprotein Regulates Photoreceptor Cell Maturation and Survival in Association with Crx in the Postnatal Mouse Retina. Mol Cell Biol 35:2583-2596.

Jadhav AP, Mason HA, Cepko CL (2006) Notch 1 inhibits photoreceptor production in the developing mammalian retina. Development 133.

Kimura A, Singh D, Wawrousek EF, Kikuchi M, Nakamura M, Shinohara T (2000) Both PCE$1 / R X$ and OTX/CRX interactions are necessary for photoreceptor-specific gene expression. J Biol Chem 275:1152-1160.

Koike C, Nishida A, Akimoto K, Nakaya M, Noda T, Ohno S, Furukawa T (2005) Function of Atypical Protein Kinase C in Differentiating Photoreceptors Is Required for Proper Lamination of Mouse Retina. J Neurosci 25:10290-10298.

Lequeux L, Rio M, Vigouroux A, Titeux M, Etchevers H, Malecaze F, Chassaing N, Calvas P (2008) Confirmation of RAX gene involvement in human anophthalmia. Clin Genet 74:392395.

London NJS, Kessler P, Williams B, Pauer GJ, Hagstrom SA, Traboulsi El (2009) Sequence alterations in $\mathrm{RX}$ in patients with microphthalmia, anophthalmia, and coloboma. Mol Vis 15:162-167.

Mao X, Fujiwara Y, Chapdelaine A, Yang H, Orkin SH (2001) Activation of EGFP expression by Cre-mediated excision in a new ROSA26 reporter mouse strain. Blood 97:324-326.

Marquardt T, Ashery-Padan R, Andrejewski N, Scardigli R, Guillemot F, Gruss P (2001) Pax6 is required for the multipotent state of retinal progenitor cells. Cell 105:43-55.

Marrs GS, Morgan WJ, Howell DM, Spirou GA, Mathers PH (2013) Embryonic origins of the mouse superior olivary complex. Dev Neurobiol 73:384-398.

Mathers PH, Grinberg a, Mahon K a, Jamrich M (1997) The Rx homeobox gene is essential for vertebrate eye development. Nature 387:603-607.

Muranishi Y, Terada K, Inoue T, Katoh K, Tsujii T, Sanuki R, Kurokawa D, Aizawa S, Tamaki Y, Furukawa T (2011b) An essential role for RAX homeoprotein and NOTCH-HES signaling in Otx2 expression in embryonic retinal photoreceptor cell fate determination. J Neurosci 31:16792-16807.

Nishida A, Furukawa A, Koike C, Tano Y, Aizawa S, Matsuo I, Furukawa T (2003) Otx2 homeobox gene controls retinal photoreceptor cell fate and pineal gland development. Nat Neurosci 6:1255-1263.

Pan Y, Martinez-De Luna RI, Lou C-H, Nekkalapudi S, Kelly LE, Sater AK, El-Hodiri HM (2010a) Regulation of photoreceptor gene expression by the retinal homeobox ( $R x)$ gene product. Dev Biol 339:494-506. 
Pan Y, Nekkalapudi S, Kelly LE, El-Hodiri HM (2006) The Rx-like homeobox gene (Rx-L) is necessary for normal photoreceptor development. Invest Ophthalmol Vis Sci 47:42454253.

Rapaport DH, Wong LL, Wood ED, Yasumura D, LaVail MM (2004) Timing and topography of cell genesis in the rat retina. J Comp Neurol 474:304-324.

Rodgers HM, Belcastro M, Sokolov M, Mathers PH (2016) Embryonic markers of cone differentiation. Mol Vis 22:1455-1467.

Rohde K, Klein DC, Møller M, Rath MF (2011) Rax: developmental and daily expression patterns in the rat pineal gland and retina. J Neurochem 118:999-1007.

Sakagami K, Gan L, Yang X-J (2009) Distinct effects of Hedgehog signaling on neuronal fate specification and cell cycle progression in the embryonic mouse retina. J Neurosci 29:6932-6944.

Sokolov M, Strissel KJ, Leskov IB, Michaud NA, Govardovskii VI, Arshavsky VY (2004) Phosducin facilitates light-driven transducin translocation in rod photoreceptors. Evidence from the phosducin knockout mouse. J Biol Chem 279:19149-19156.

Soriano P (1999) Generalized lacZ expression with the ROSA26 Cre reporter strain. Nat Genet 21:70-71.

Voronina V a, Kozhemyakina E a, O'Kernick CM, Kahn ND, Wenger SL, Linberg J V, Schneider AS, Mathers PH (2004) Mutations in the human RAX homeobox gene in a patient with anophthalmia and sclerocornea. Hum Mol Genet 13:315-322.

Voronina V a, Kozlov S, Mathers PH, Lewandoski M (2005) Conditional alleles for activation and inactivation of the mouse Rx homeobox gene. Genesis 41:160-164.

Wang Q, Chen S, Esumi N, Swain PK, Haines HS, Peng G, Melia BM, Mclntosh I, Heckenlively JR, Jacobson SG, Stone EM, Swaroop A, Zack DJ (2004) QRX, a novel homeobox gene, modulates photoreceptor gene expression. Hum Mol Genet 13:1025-1040.

Yaron O, Farhy C, Marquardt T, Applebury M, Ashery-Padan R (2006) Notch1 functions to suppress cone-photoreceptor fate specification in the developing mouse retina. Development 133:1367-1378.

Young RW (1985) Cell differentiation in the retina of the mouse. Anat Rec 212:199-205.

Zagozewski JL, Zhang Q, Eisenstat DD (2014) Genetic regulation of vertebrate eye development. Clin Genet 86:453-460.

Zhang L, Mathers PH, Jamrich M (2000) Function of Rx, but not Pax6, is essential for the formation of retinal progenitor cells in mice. Genesis 28:135-142. 
Figure Legends

Figure 1. Deletion of $\boldsymbol{R x}$ leads to a reduced Cre-lineage domain and a loss of lamination. (A) X-gal staining of P21 retinal sections from control (Pax6a Cre/+; Rx-flox/+; R26R/+) and $R x$ CKO mice (Pax6a Cre/+; Rx-flox/Rx-null; R26R/+) show a reduction in the lineage of Crerecombined cells in the $R x$-deleted retina. Scale bar is $400 \mu \mathrm{m}(\mathrm{B}) \mathrm{H} \& \mathrm{E}$ staining on $\mathrm{P} 21$ retinal sections of control and $R x$ CKO mice demonstrate a loss of lamination and an expansion in the distal portion of the $R x$ CKO retina. Light eosin staining is likely indicative of cellular processes rather than cell bodies. Scale bar is $200 \mu \mathrm{m}$.

\section{Figure 2. Levels of apoptosis are unaffected by deletion of $R x$.}

Retinal sections at P0 from control mice (A) immunolabeled with the programmed cell death marker, activated capase-3, and GFP show similar numbers of activated caspase-3- and GFPco-labeled cells compared to $R x$ CKO mice $(\mathrm{B})$. Dashed line indicates the approximate region of $R x$ deletion based on GFP-positive cell labeling. Arrows indicate cells that are labeled for both GFP and caspase-3. Scale bars are $100 \mu \mathrm{m}$.

Figure 3. $R x$ deletion reduces the retinal progenitor pool in an age-dependent manner. The distal region of retinal sections from control and $R x$ CKO mice were labeled with the nuclear marker, propidium iodide, and the progenitor marker, BrdU, at E12.5 (A,B), E14.5 (D,E) and E18.5 $(\mathrm{G}, \mathrm{I})$. The central (non $R x$-deleted) region of $\mathrm{E} 18.5$ retinas were examined $(\mathrm{H})$ as an internal control in an otherwise $R x$-deleted retina. Scale bars are $50 \mu \mathrm{m}$. Quantitative analysis of progenitor cells at E12.5 (C), E14.5 (F), and E18.5 (J) in retinal sections show a decrease in the percentage of BrdU-positive cells in the $R x$ CKO distal region. The decrease in progenitors was age dependent. There was no detectable difference between control and $R x$-deleted retinas at $\mathrm{E} 12.5$, but at $\mathrm{E} 14.5$ a small difference emerged and at E18.5 there was a drastic reduction in progenitors in the $R x$-deleted region. Open bars represent control retinas and 
closed bars represent $R x \mathrm{CKO}$ distal retinas. The grey bars in $\mathrm{J}$ represents $R x \mathrm{CKO}$ central retinas. All bars are the mean $\pm S D$ of 3 retinal slices from at least 4 separate eyes. Statistical significance is based on t-test analysis between percentages from control and $R x$ CKO distal region and is indicated by asterisks ( ${ }^{*}$ indicates $p<0.05$ and ${ }^{* *}$ indicates $p<0.001$ ).

Figure 4. BrdU- and PCNA-labeled progenitors are reduced in $R x$-deleted regions of the $R x$ CKO retina.

(A) Sections from control and $R x$ CKO mice showing the span of the retina were labeled with the progenitor marker, Brdu, at E18.5 showing the decrease in retinal progenitors in the distal region of the $R x$ CKO. (B) Higher magnification images including GFP labeling (marking Cre activity) in the retina show BrdU expression throughout the control section but predominantly in areas lacking GFP expression within the $R x$ CKO indicating the loss of progenitors in the $R x$ CKO mice occurs within the $R x$-deleted regions. (C) Immunolabeling of proliferating cell nuclear antigen (PCNA), another progenitor marker, and GFP was performed in control and $R x$ CKO retinal sections at P0. PCNA labeling shows a decrease in progenitor proliferation in $R x$-deleted regions of the retina. Dashed lines represent the approximate boundary of the $R x$-deleted region in the $R x$ CKO retina. Scale bars are $100 \mu \mathrm{m}$ in $\mathrm{A}$ and $\mathrm{C}$ and $50 \mu \mathrm{m}$ in $\mathrm{B}$.

\section{Figure 5. $R x$ deletion leads to changes in a subset of early-born cells found in the adult} retina.

Immunolabeling for Brn3b and GFP in retinal sections from control $(\mathrm{A})$ and $R x \mathrm{CKO}(\mathrm{B})$ shows the presence of retinal ganglion cells in the control and $R x$-deleted retina. Arrows indicate examples of Brn3B-expressing cells. An abundance of amacrine cells in the $R x$-deleted portion

of the $R x$ CKO retina (D) is shown by the labeling of synataxin $1 A$ and GFP compared to control retinal sections $(\mathrm{C})$. Calbindin and GFP immunolabeling in retinal sections of control $(\mathrm{E})$ and $R x$ CKO $(F)$ show the presence of amacrine and horizontal cells in both control retina and in $R x$ CKO. (D) Co-labeling of neurofilament $165 \mathrm{kD}$ and GFP shows the presence of horizontal cells 
in the $R x$ CKO retina $(\mathrm{G})$ as well as in control retinal sections $(\mathrm{H})$. Dashed lines indicate the approximate boundary of the $R x$-deleted portion in the $R x$ CKO retina. Scale bars are $100 \mu \mathrm{m}$.

\section{Figure 6. Early-born cone photoreceptors are lost in the $R x$-deleted P21 retina.}

Co-labeling with GFP and M-opsin shows expression of M-cones along the ventricular surface of the control retina $(\mathrm{A})$ and the central portion of the $R x$ CKO retina $(\mathrm{B})$; however, the $R x$ deleted portion of the $R x$ CKO retina shows a lack of M-opsin labeling (B). The presence of Scones using S-cone opsin co-labeled with GFP shows normal cone expression in the control (C) and central region of the $R x$ CKO retina (D), whereas the distal portion of the $R x$ CKO (D) labeled with GFP shows a lack of S-opsin expression. Dashed boxes indicate a region that was magnified by $2 x$ in the lower left hand corner of the opsin images. Dashed curved lines indicate the approximate boundary of the $R x$-deleted region in the $R x$ CKO retina. Scale bars are 100 $\mu \mathrm{m}$.

Figure 7. Absence of late-born cell types with the deletion of $R x$ in P21 retinal sections. Immunolabeling against Chx10 shows the presence of bipolar cells in the control $(\mathrm{A})$ and central region of the $R x \mathrm{CKO}(\mathrm{B})$, whereas co-labeling with GFP shows a loss of bipolar cells in the $R x$ deleted portion of the $R x$ CKO retina (B). Retinal sections labeled with CRALBP and GFP show Müller glia in the control (C) and central part of the $R x$ CKO (D). The region of the $R x$ CKO (D) where $R x$ deletion occurred (labeled with GFP) shows a loss of Müller glia. Labeling with rhodopsin displays rod photoreceptors throughout control retinal sections (E) but only in the central portion in the $R x$ CKO retina $(F)$. Co-labeling with GFP shows a lack of rhodopsin expression in the GFP-labeled region of the $R x \mathrm{CKO}$, which demarcates where $R x$ has been deleted. Dashed lines represent the approximate boundary of the $R x$-deleted portion of the retina. Scale bars are $100 \mu \mathrm{m}$. 
Figure 8. Phosducin expression is reduced in embryonic and early postnatal $R x$ CKO retina.

Co-labeling with phosducin and GFP, to visualize the regions of the $R x$ CKO retina (B) where $R x$ deletion occurred shows a decrease in phosducin-labeling at E17.5 compared to control (A). Similarly at P0, co-labeling with GFP and phosducin shows a decrease in phosducin expression in the $R x$-deleted portion of the $R x$ CKO retina (D) compared to control (C). Phosducin-labeled cells in the distal retina are primarily in regions that have not undergone Cre-mediated recombination (i.e. -GFP-negative). Dashed lines represent the approximate region of $R x$ deletion. Scale bars are $100 \mu \mathrm{M}$.

\section{Figure 9. Decreased Otx2 expression in embryonic $R x$ CKO retina.}

(A) Immunolabeling in control retinal sections with GFP and Otx2 (labeling photoreceptors) shows strong Otx2 labeling along the length of the retina at E17.5. (B) Retinal sections of E17.5 $R x$ CKO mice show strong Otx2 labeling in the central portion of the retina, but decreased labeling in the distal region that corresponds with the area labeled by the GFP reporter. Scale bars are $100 \mu \mathrm{m}$. 


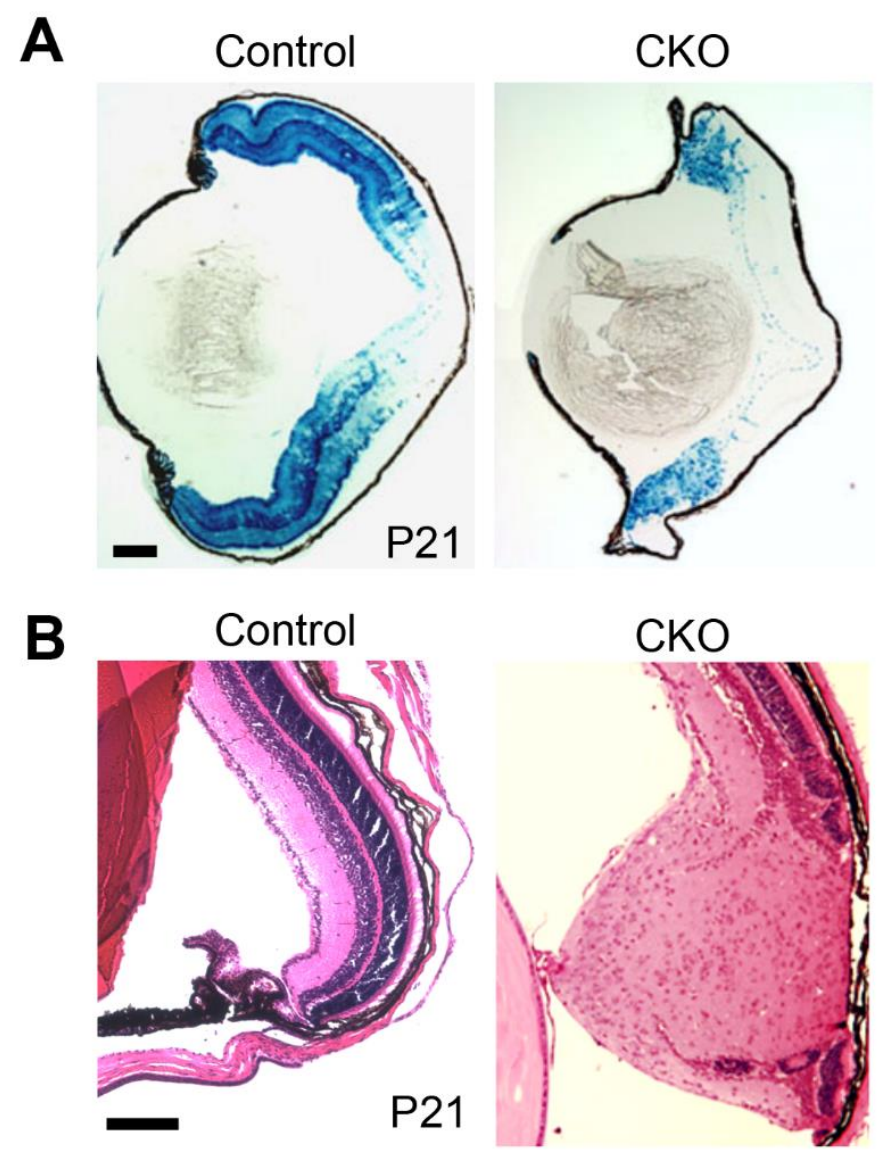

Figure 1. Deletion of $\boldsymbol{R x}$ leads to a reduced Cre-lineage domain and a loss of lamination. 

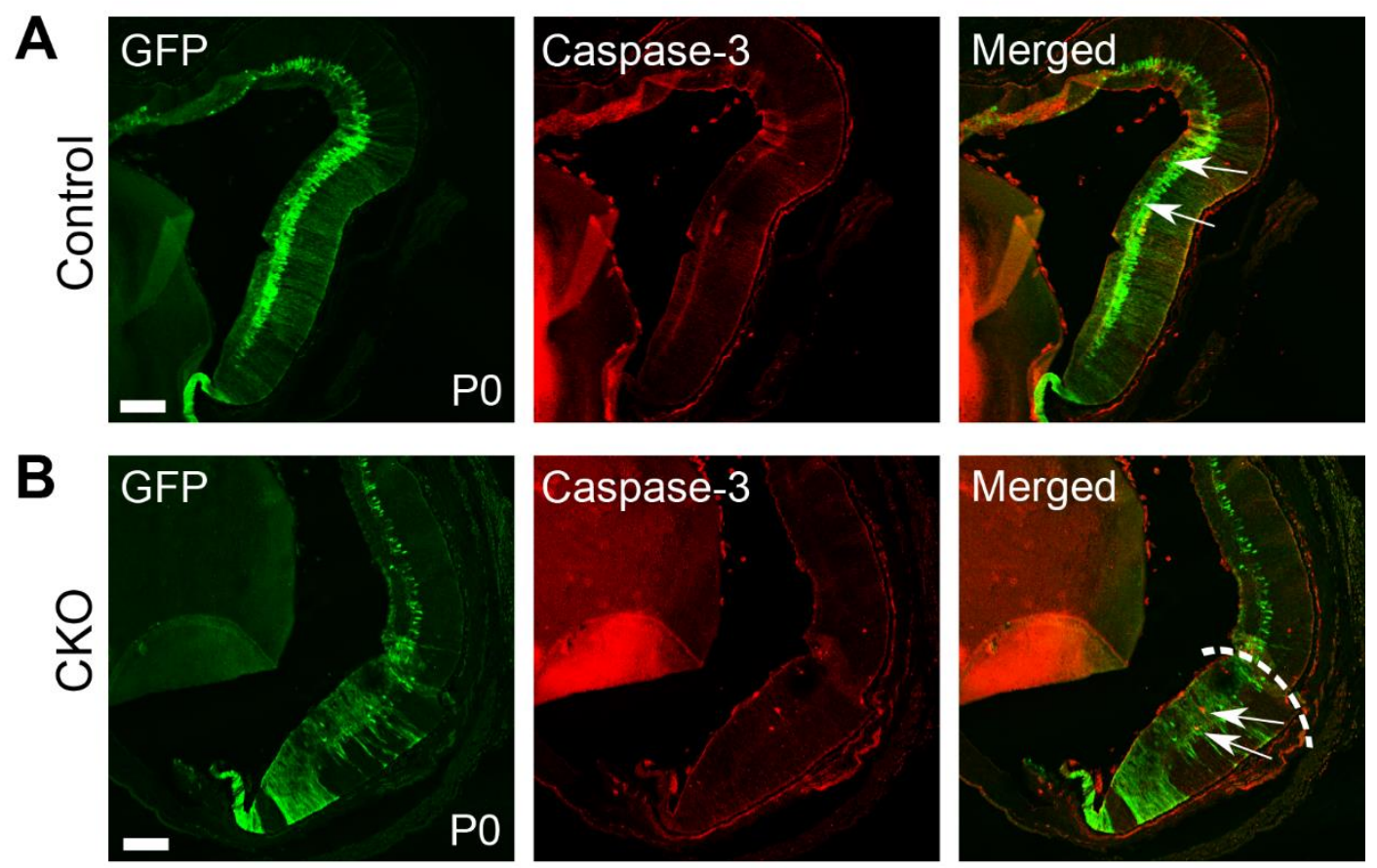

Figure 2. Levels of apoptosis are unaffected by deletion of $R \boldsymbol{x}$. 

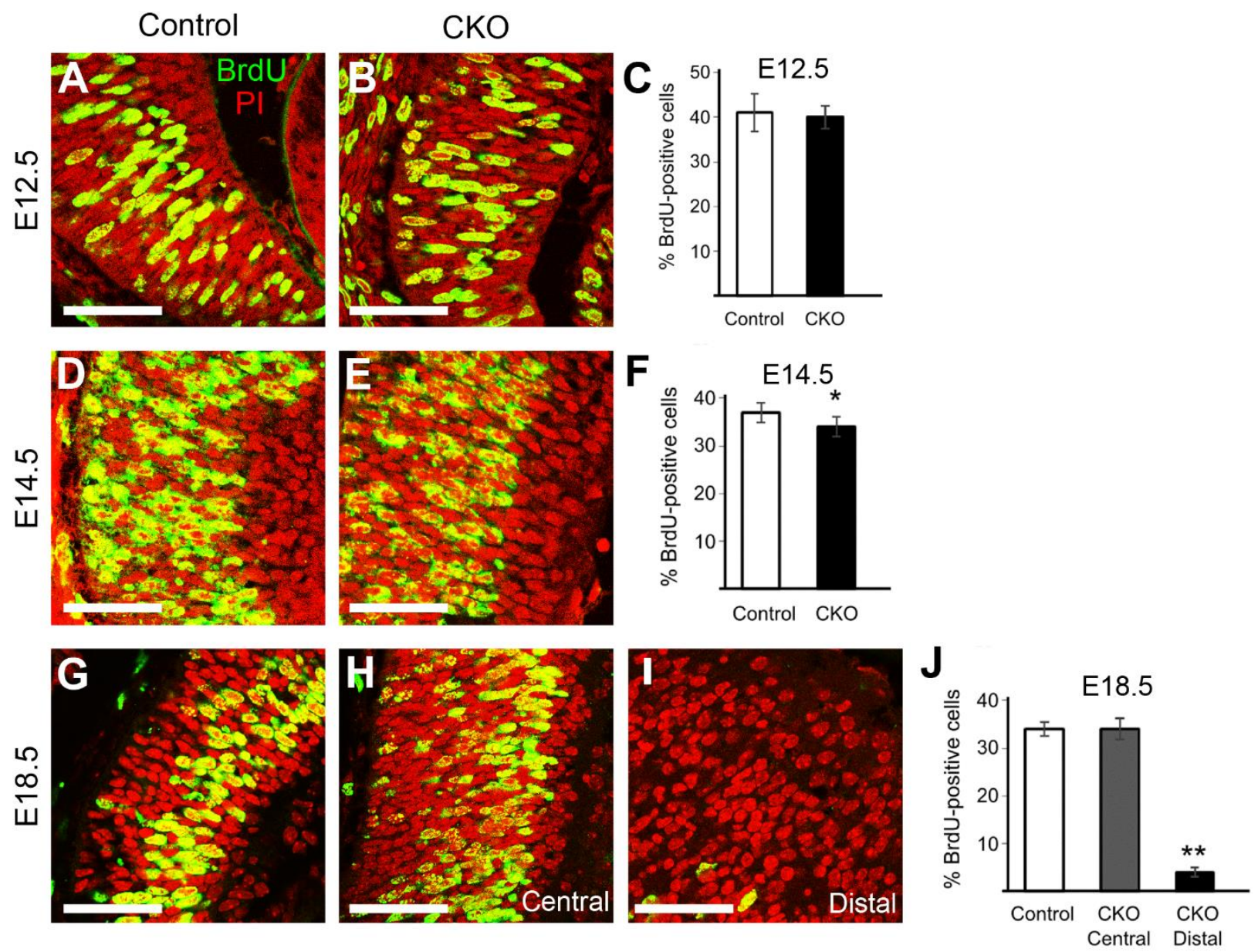

Figure 3. $R x$ deletion reduces the retinal progenitor pool in an age-dependent manner. 

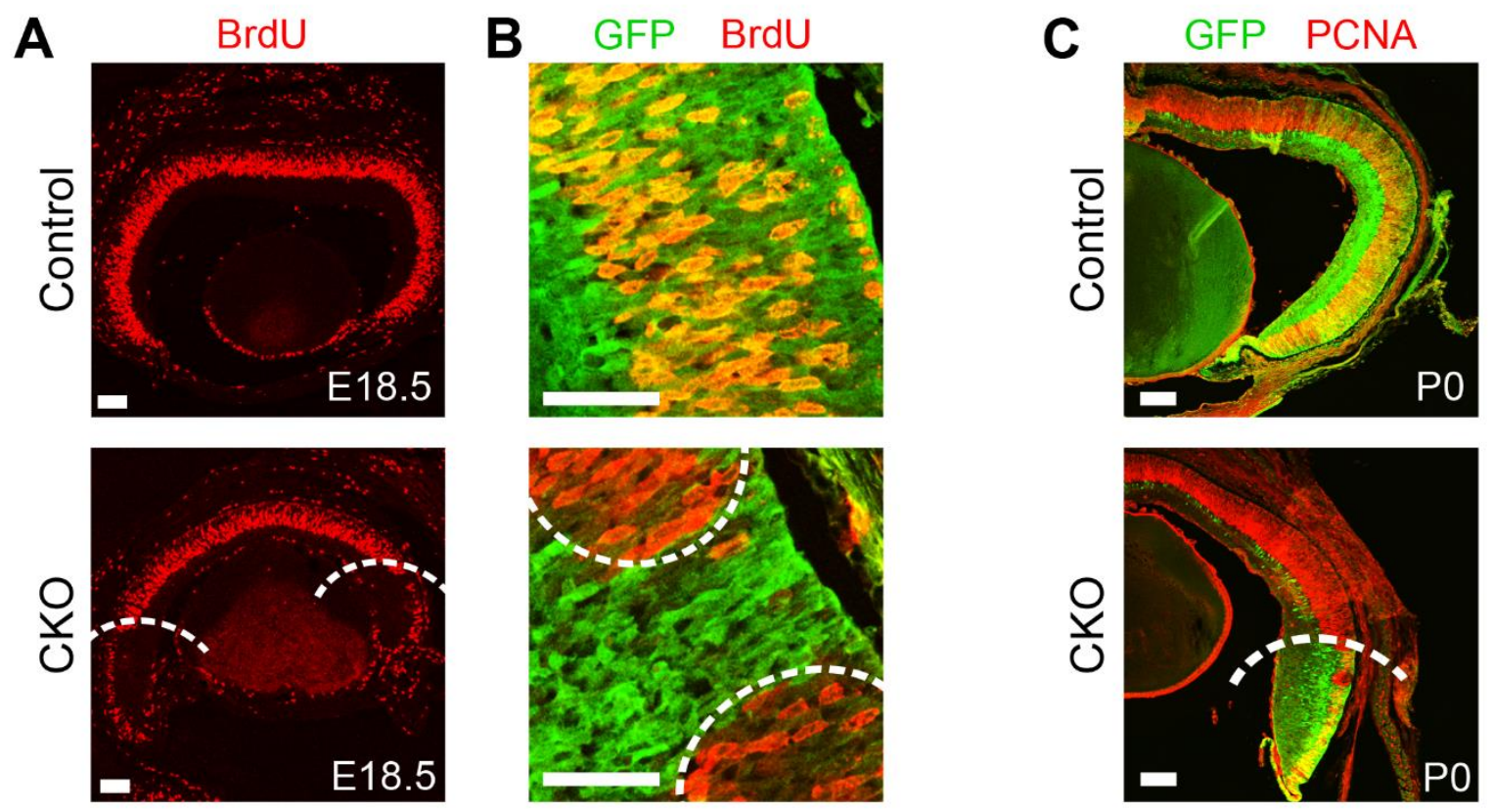

Figure 4. BrdU- and PCNA-labeled progenitors are reduced in $\boldsymbol{R x}$-deleted regions of the $R x$ CKO retina. 

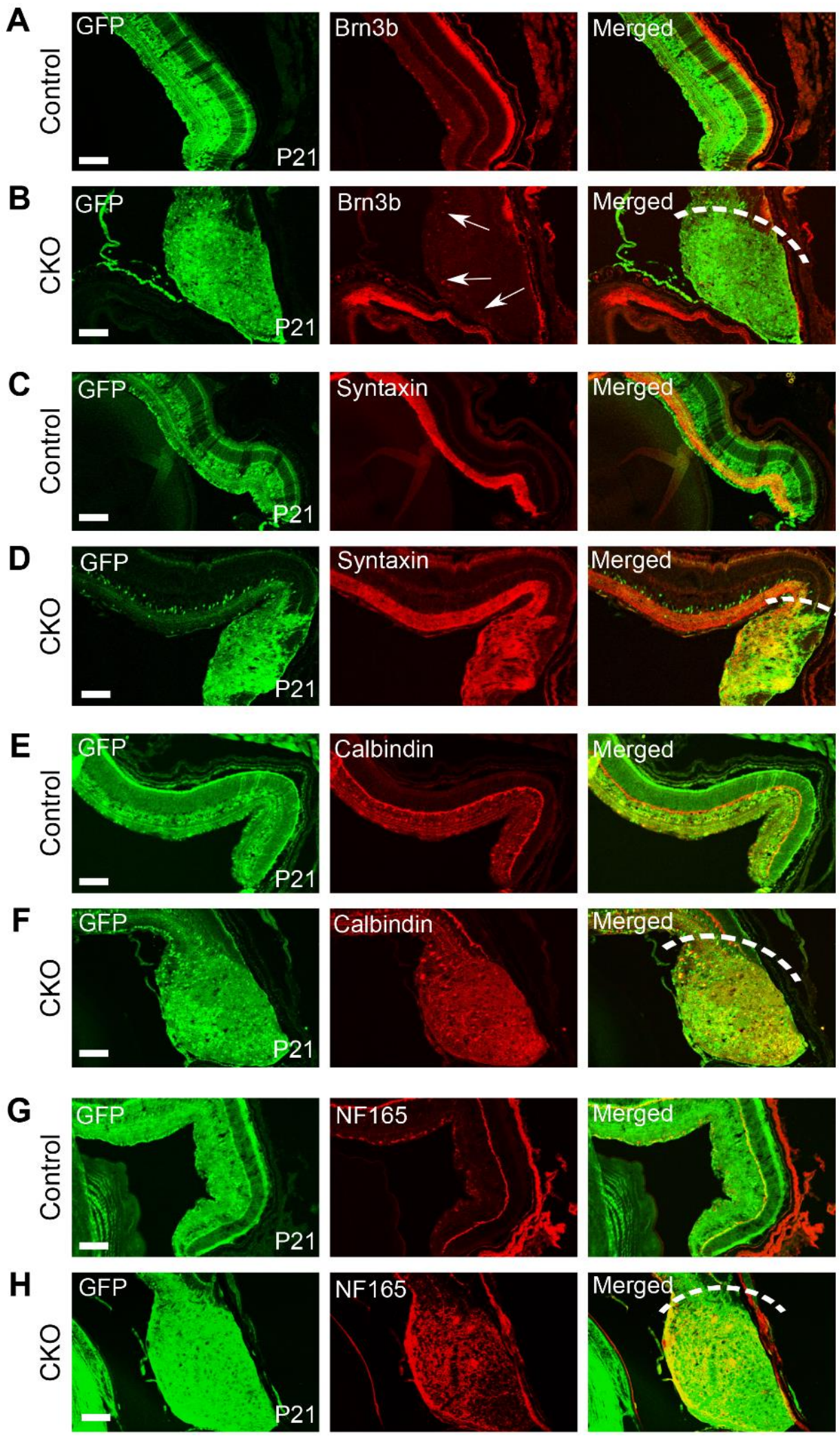

Figure 5. $R x$ deletion leads to changes in a subset of early-born cells found in the adult retina. 

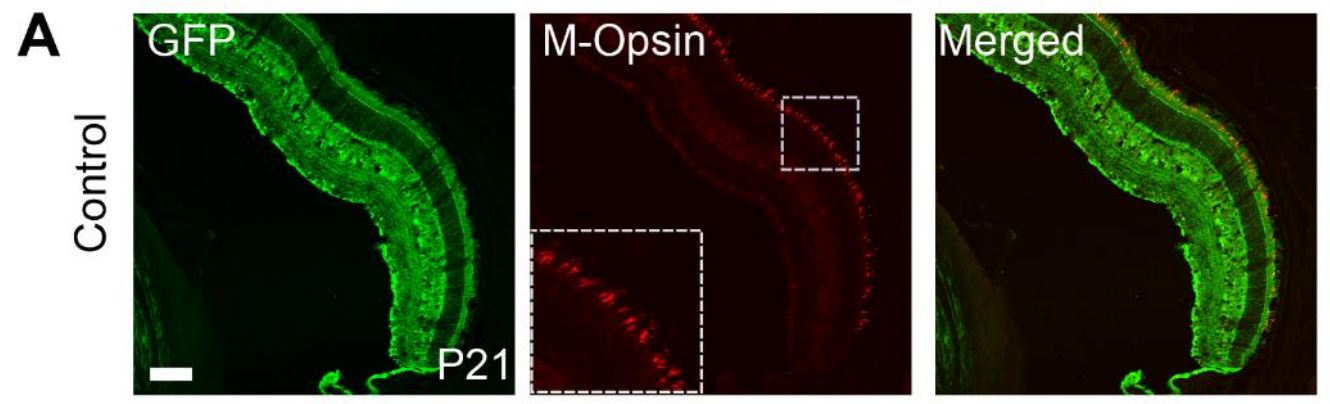

B
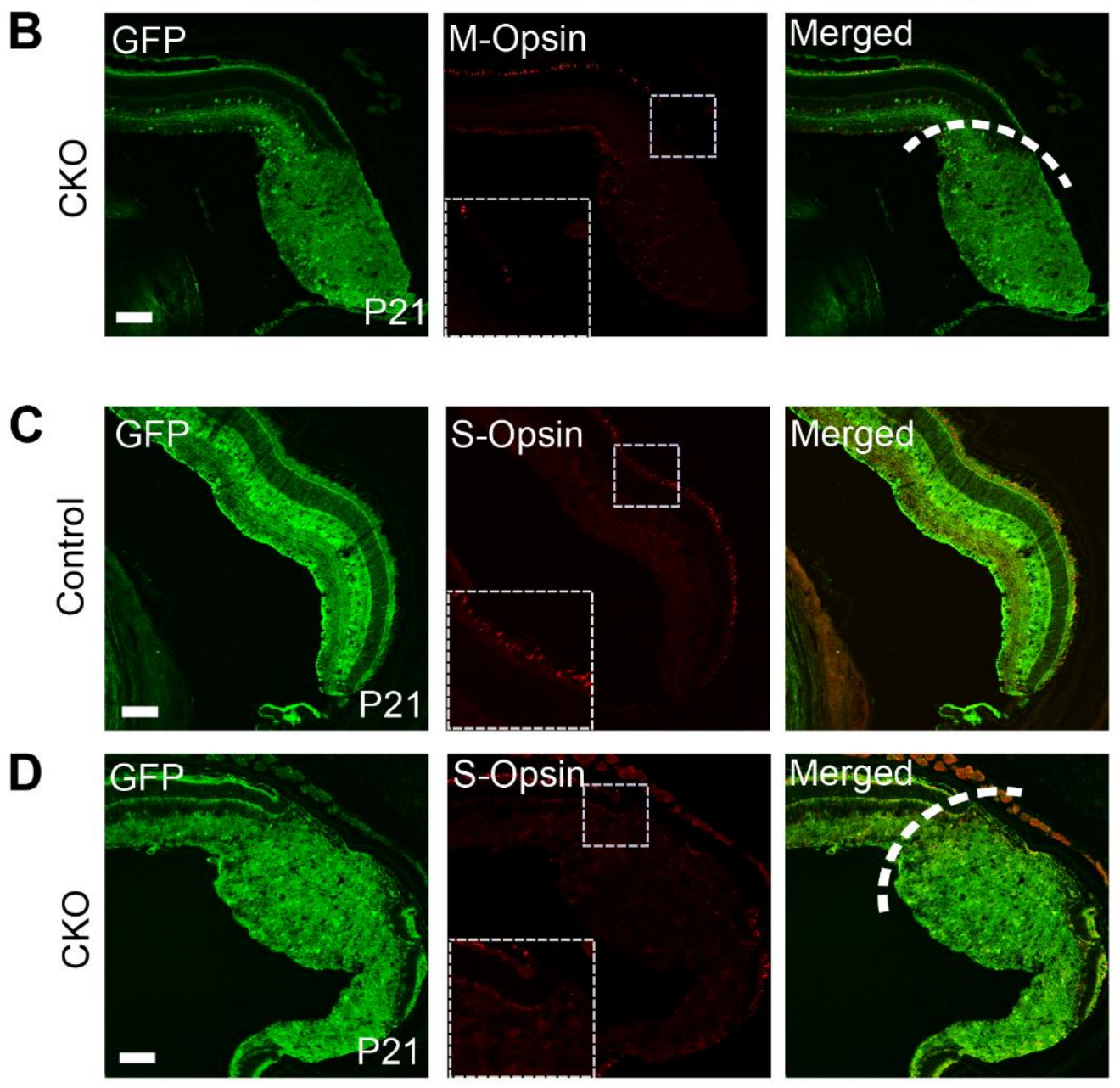

Figure 6. Early-born cone photoreceptors are lost in the $R x$-deleted P21 retina. 

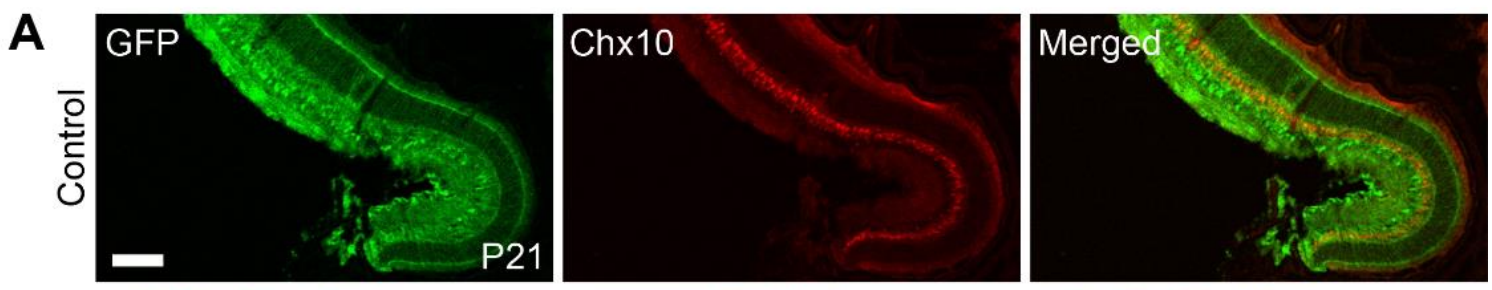

B
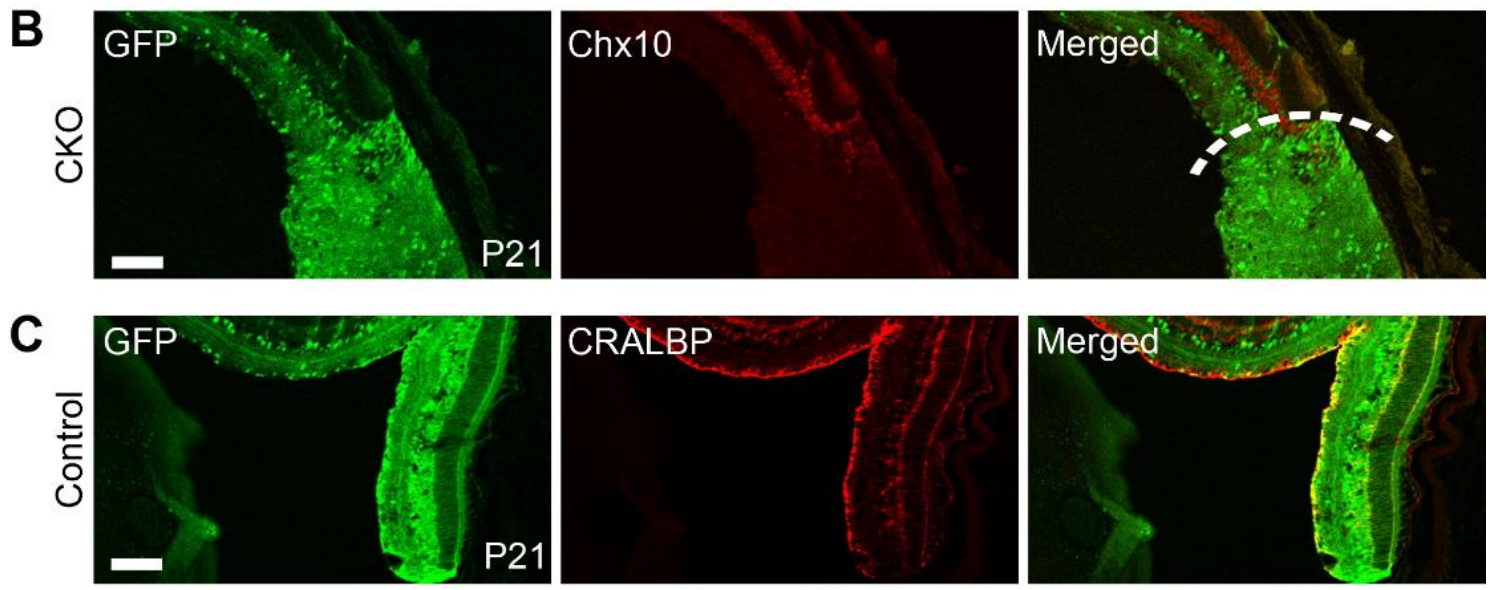

D
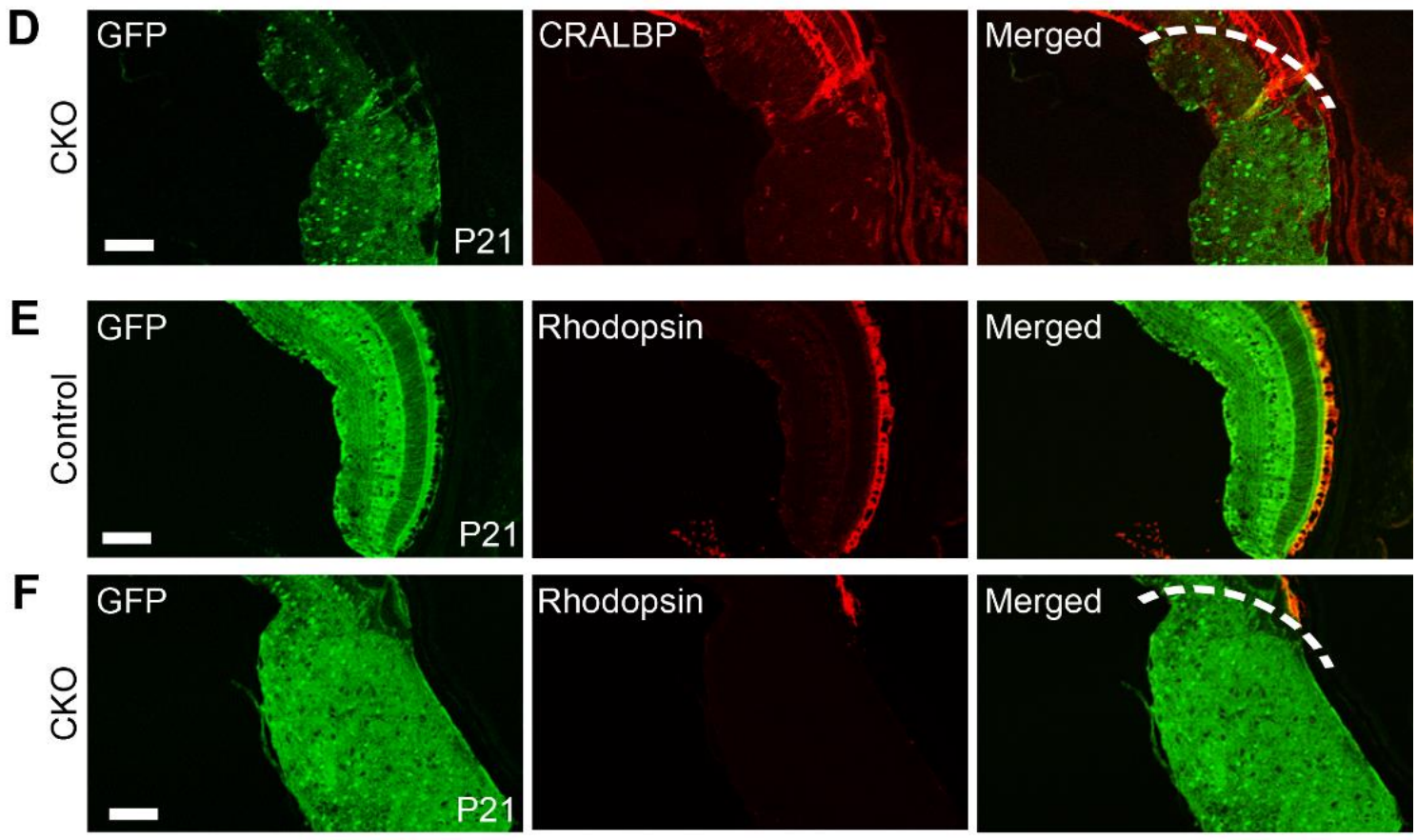

Figure 7. Absence of late-born cell types with the deletion of $R x$ in P21 retinal sections. 


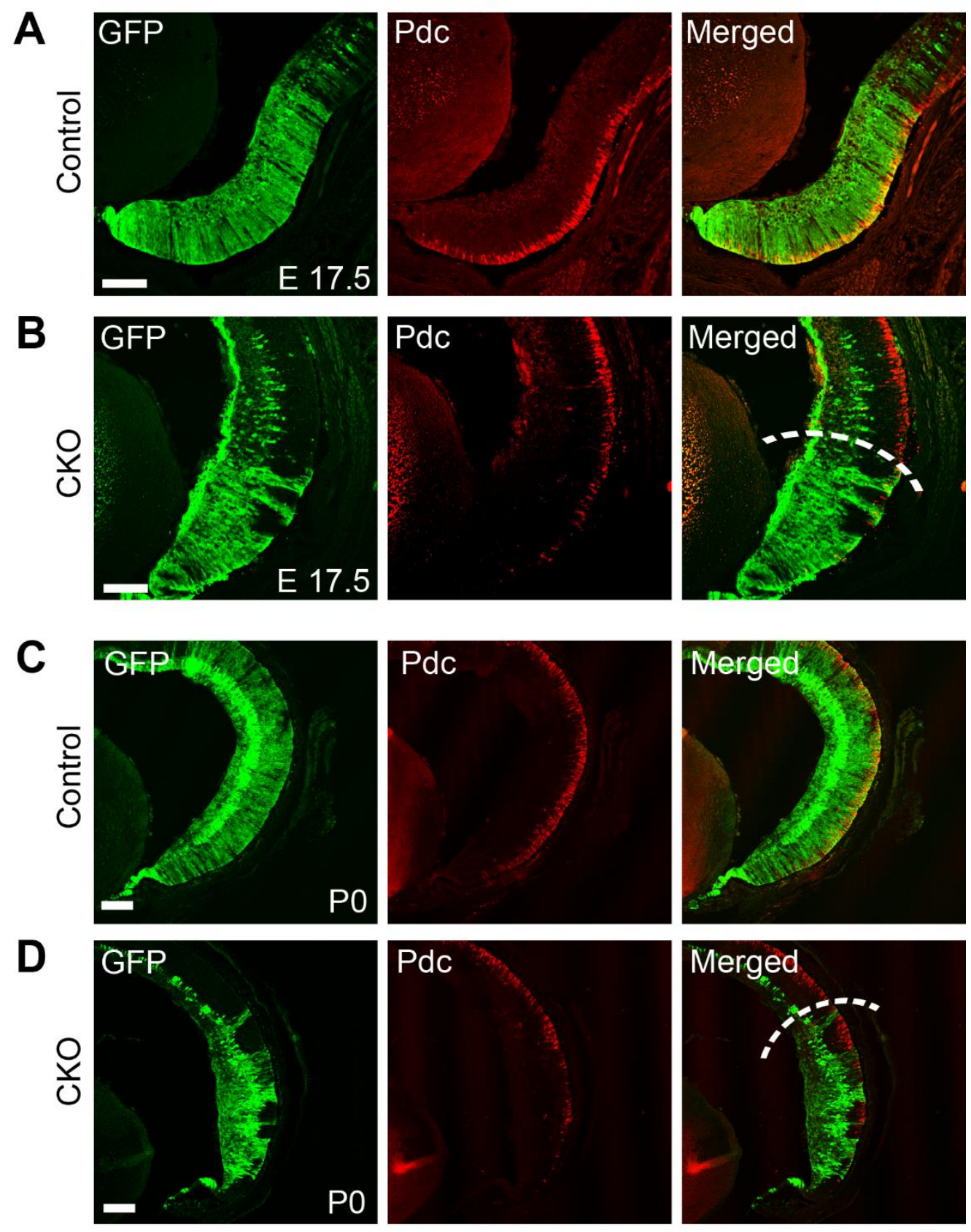

Figure 8. Phosducin expression is reduced in embryonic and early postnatal $R \times$ CKO retina. 

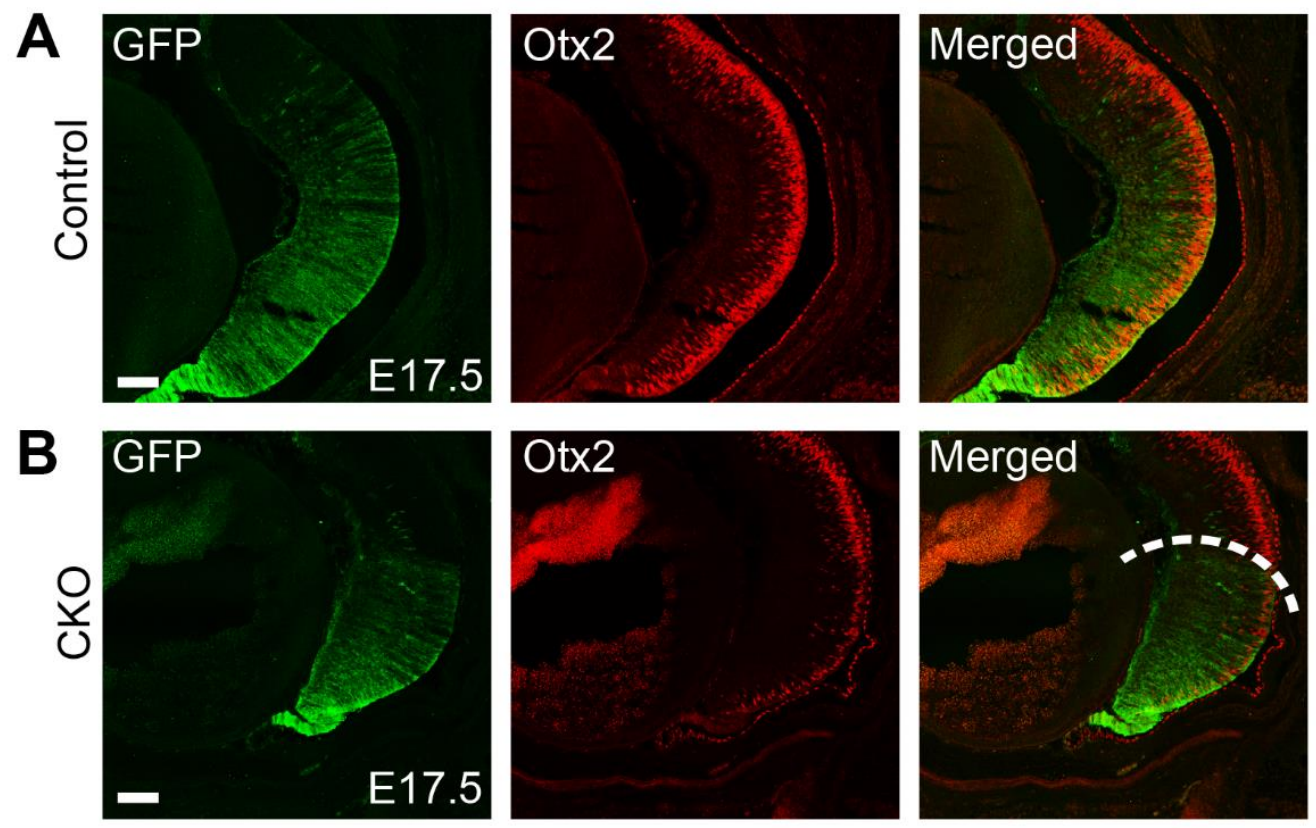

Figure 9. Decreased Otx2 expression in embryonic $R x$ CKO retina. 


\section{Supplementary Figures}
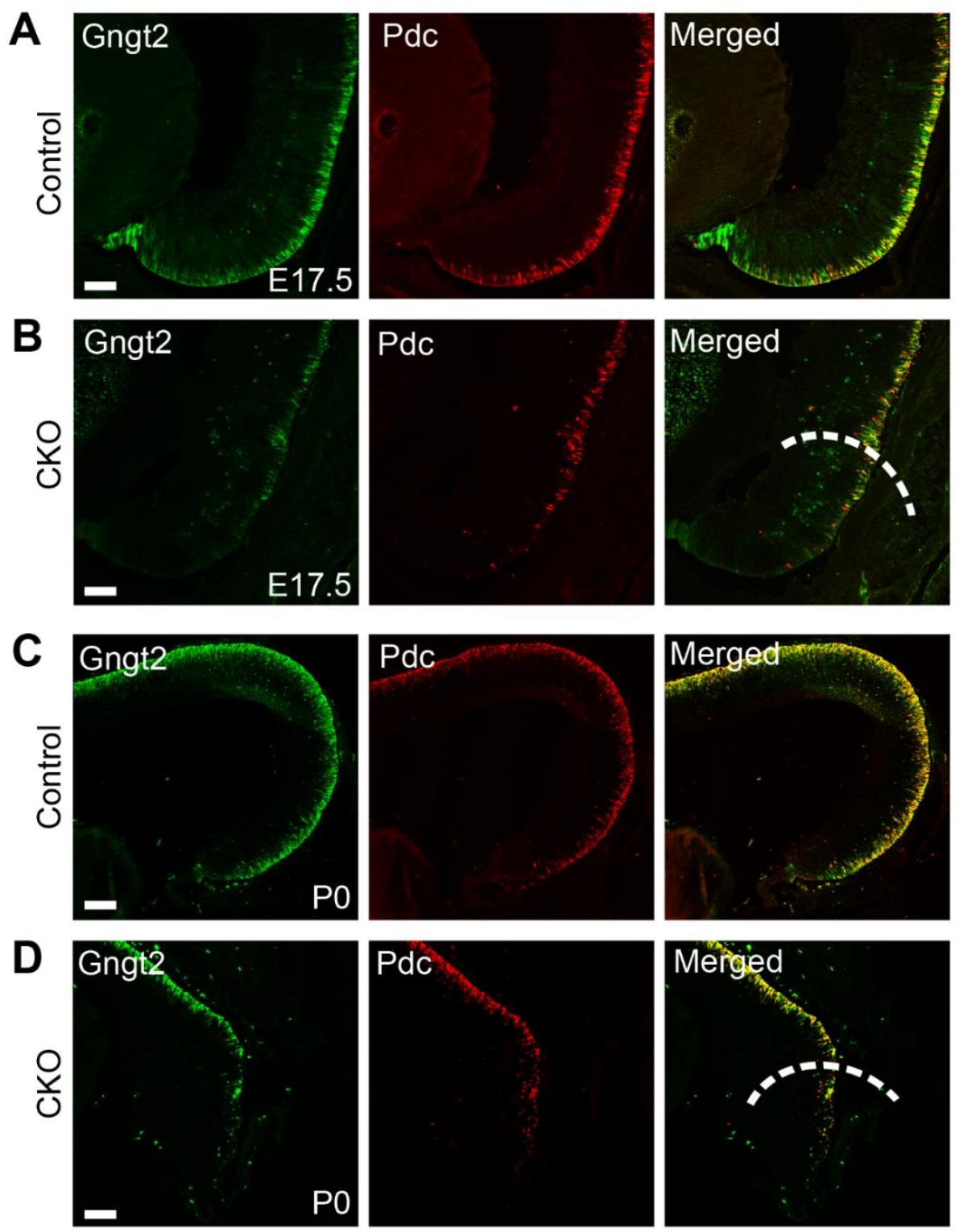

\section{Supplemental Figure 1. Phosducin and cone transducin $\gamma$ labeling are reduced during retinogenesis in $R x$-deleted retina.}

(A) Colabeling with early cone markers, phosducin and cone transducin $\gamma$, in E17.5 retinal sections shows strong co-expression along the ventricular border in the control $(A)$ and central portion of the $R x$ CKO retina (B). Expression in the distal portion of the $R x$ CKO retina (B), where $R x$ was presumably deleted, shows a large reduction in both phosducin and cone transducin $\gamma$ expression. Retinal sections immunolabeled for phosducin and cone transducin $\gamma$ at P0 show similar pattern of expression to E17.5 with strong co-expression in control (C) and central retina of the $R x$ CKO retina (D) and greatly reduced labeling in the distal region of the $R x$ CKO retina (D). Scale bars are $100 \mu \mathrm{m}$. 


\section{Chapter 4: \\ Antisense-mediated gene knockdown in 3D organoid culture: a method for exploring optic vesicle development}

Rodgers HM, \& Mathers $\mathrm{PH}$. 


\begin{abstract}
The development of organoids (stem cell-generated organs) has opened up new avenues for research, including the possibility of using organoids to study gene function during development. Using organoids to study development offers the advantages of cell culture manipulations while still displaying morphological patterning. We chose to compare two antisense-mediated gene knockdown techniques, Vivo-morpholinos (vMO) and Accell siRNA in optic vesicle organoid cultures. We assessed general toxicity, efficiency of gene knockdown and whether experimental manipulation, the addition of an antisense oligo, would affect the development of the optic vesicle organoids. Both vMOs and Accell siRNA were successfully delivered to cells via bath application. Addition of either standard negative control vMOs or Accell siRNA nonsense control oligomers did not alter the development of optic vesicles. To explore the possibility of using antisense-mediated gene knockdown in these cultures, the first genes we chose to test were GFP and the $R x$ homeobox gene, an important regulator of optic vesicle formation. In the embryonic stem cells used, GFP expression is under the control of the $R x$ promoter. Therefore, GFP labels retinal induction. Expression of GFP is significantly reduced in cultures treated with vMOs against GFP. Conversely, addition of Accell siRNA against GFP results in no change in GFP expression regardless of concentration. Therefore, in the remaining studies we chose to use only vMOs for gene knockdown. The $R x$ knockdown cultures show a significant decrease in Rx-controlled GFP expression in comparison to controls. Having established that vMOs are effective at gene knockdown in organoid cultures, we tested three genes that are candidates for being necessary for optic vesicle development (previously determined through microarray comparison of $R x$-mutant and control tissue). Knockdown of those genes results in three different phenotypes, one of which indicates a possible role in optic vesicle development. Thus, we have established that the ability to use knockdown techniques to reduce gene expression in organoids is a promising tool for studying gene expression during early eye development.
\end{abstract}




\section{Introduction}

Ocular malformations, including micropthalmia, anophthalmia, and coloboma (MAC), result from defects in eye development and are a prevalent cause of childhood blindness (Ragge et al. 2007; Williamson and FitzPatrick 2014). One in every 5300 babies born in the USA is born with either microphthalmia or anophthalmia (Parker et al. 2010). Several gene mutations have been linked with a MAC phenotype including SOX2, PAX6, CHX10, RAX, and OTX2 (See Bardakjian and Schneider 2011 for a review of the genetics of ocular malformations). However, mutations in these genes only account for a small portion of patients with MAC suggesting that these conditions are genetically heterogeneous. There are likely putative genes that have yet to be identified whose mutations lead to ocular defects. Identifying the role these genes play in optic vesicle development is important to further understand ocular malformations, such as MAC.

To determine the genes and molecular mechanisms of early embryonic development requires techniques that allow for spatially and temporally precise specific inhibition of gene function. Traditionally, researchers have used germline and conditional knockout models, and gene knockdown techniques to study gene function during embryogenesis. Each of these techniques have their own benefits, limitations and disadvantages, most notably they tend to be timeintensive and expensive, especially if multiple genes are to be studied. In addition, they may not allow for the precise temporal or spatial control needed to get a clear understanding of gene function during development. Some of these challenges have been overcome with the development of CRISPR/Cas9 mouse genome editing (Cong et al. 2013; Mojica and Montoliu 2016), which is more precise, less expensive and faster than previous methods. However, the creation of mutations, even with CRISPR/Cas9 genome editing, is a less desirable method for screening candidate genes because it requires generating and maintaining multiple mutations (Wang et al. 2014). Prior to developing mutant models, it would be beneficial to be able to rapidly screen for possible effects of gene candidates involved in development. 
Recent advances in stem cell technology have led to the development of tissue/organs grown from stem cells in 3D culture, termed organoids (Huch and Koo 2015; Kretzschmar and Clevers 2016; Völkner et al. 2016). These organoids are opening new and exciting possibilities for research, including the study of embryonic development and may be useful as a model for rapid gene screening.

Multiple different organ systems allow successful generation of organoids, including: the nervous system, the urinary system, reproductive system, and the gastrointestinal system (Eiraku and Sasai 2011; Koo et al. 2011; Sasai et al. 2012; Finkbeiner et al. 2015; Little and Takasato 2015; Pendergraft et al. 2017). Several groups have used organoids to study the formation of optic vesicles, optic cups and stratified retinal tissue (Eiraku and Sasai 2011; Eiraku et al. 2011; Meyer et al. 2011; Nakano et al. 2012; Sasai et al. 2012; Zhong et al. 2014; Ohlemacher et al. 2015; Chen et al. 2016; Völkner et al. 2016). In the development of these organoids, researchers have noted some interesting characteristics that make them ideal to studying eye development. The developmental progression from stem cells to 3D-organoid follows a similar morphological pattern and timing to that of in vivo neural development. The first noted development of optic vesicle/retinal organoids used mouse embryonic stem cells (ESCs) with GFP inserted into the $R x$ locus to label presumptive retinal tissue. The method for organoid formation involves plating the Rx-GFP stem cells on a low adhesion plate where they form aggregates, then on Day 5 in culture GFP-labeled regions form and on Day 7 those regions evaginate and thus form optic vesicle organoids (Eiraku and Sasai 2011; Eiraku et al. 2011). With further experimental manipulation, researchers show that these optic vesicle organoids can go on to form optic cups and eventually stratified retina (Eiraku et al., 2011; Eiraku \& Sasai, 2011). A similar procedure has also been done using the organoids formed from human ESCs. These human retinal organoids are proportionally larger than those from mouse ESCs (Nakano et al. 2012). Additionally, optic vesicle/retinal organoids have now also been generated with 
human induced pluripotent stem cells (IPCs) (Meyer et al. 2011; Zhong et al. 2014; Ohlemacher et al. 2016).

These organoids offer the possibility of studying gene function during development with some advantages over embryological investigations in that they have the benefits of cell culture, including the ease of genetic manipulation and relative low cost, while still displaying the morphological patterning and timing of natural embryonic development. In order to establish gene knockdown in optic vesicle organoids as a method for studying development, several issues need to be addressed including transfection, toxicity and whether the technique would affect the development of optic vesicles.

Currently, the only methods of studying gene expression in organoid cultures is viral (retroviral/lentiviral) transfection in endodermal (stomach/intestine) organoids (Koo et al. 2011, 2013; Van Lidth de Jeude et al. 2015) and a CRISPR/Cas9-mediated knockout in cerebral organoids (Wang et al., 2017). To our knowledge, other methods of gene knockdown have not been studied in organoids, and no gene knockdown method has been investigated in optic vesicle/retinal organoid cultures.

In this study, we assessed two antisense-mediated gene knockdown techniques in optic vesicle organoid culture. Organoids are structurally more complex than monolayer or suspension cell culture; therefore, transfection may be difficult. To address this issue, we chose two techniques: Accell siRNAs (Dharmacon) and Vivo-morpholinos (vMOs, GeneTools), that have been modified to cross cell membranes without the need for transfection reagents or electroporation and are often used for in vivo applications. Our observations suggest that both Accell siRNA and vMOs readily enter the cells without adversely affecting development of the organoids; however, in our assessment only vMOs achieved a significant gene knockdown. Here we show 
the potential of using vMOs in 3D-organoid culture as a rapid screen for candidate genes required for optic vesicle formation.

\section{Methods}

\section{Mouse embryonic stem cell (mESC) culture}

Mouse ES cells (Rx-GFP K/I EB5) from Riken (AES0145) were maintained under feeder-free conditions following a modified protocol of Eiraku and Sasai (2011). Maintenance media was prepared as follows: Glasgow minimum essential medium (GMEM; Gibco) supplemented with 10\% Knockout Serum Replacement (KSR; Invitrogen), 1\% FBS (fetal bovine serum; Gibco), 1 $\mathrm{mM}$ sodium pyruvate (Sigma-Aldrich), $0.1 \mathrm{mM}$ nonessential amino acids (Sigma-Aldrich), and 0.1 mM 2-Mercaptoethanol (2-ME, Sigma-Aldrich). Additionally, leukemia inhibitory factor (LIF, 1:250, EMD Millipore Corporation), and blasticidin (1:500, Invitrogen) were added to maintenance media immediately prior to use. Cells were maintained on gelatin-coated $60 \mathrm{~mm}$ cell culture dishes and passaged every 3 days.

\section{Optic vesicle formation in 3D culture}

To differentiate stem cells into retinal tissue, the protocol described by Eiraku and Sasai (2011) was followed. SFEBq (serum-free floating culture of embryoid body-like aggregates with quick reaggregation) culture was used to promote the differentiation of ESC into neuroepithelial tissue (Eiraku \& Sasai, 2011). While SFEBq promotes differentiation, it does not support the formation of 3D structures; therefore, matrigel was added to allow the formation of 3D structures in culture. Retinal differentiation media was prepared as follows: G-MEM supplemented with $1.5 \% \mathrm{KSR}, 1$ $\mathrm{mM}$ sodium pyruvate, $0.1 \mathrm{mM}$ nonessential amino acids, and $0.1 \mathrm{mM}$ 2-ME.

Cultured mESC were dissociated to single cells using .25\% trypsin-EDTA (Gibco) and were quickly reaggregated in differentiation media by plating on low-adhesion, 96-well plates (Lipidure®-Coat Plate A-U96, NOF) at 4000 cells/100 $1 /$ well. The day of plating is defined as Day 0 in culture. For a diagram of the events of development in culture, see Figure 1. On Day 


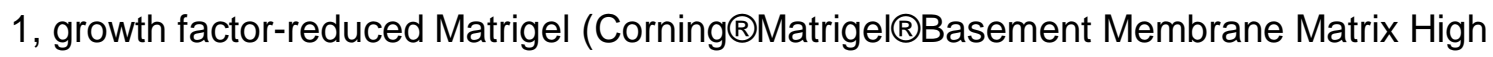
Concentration Growth Factor-Reduced) was added to the media of each well at a final concentration of $2 \%$ (vol $/ \mathrm{vol})$. Following addition of matrigel, cells continue to be incubated for 6 days at $5 \% \mathrm{CO}_{2}$. Knockdown manipulations occurred on Day 4 (see below). On Day 7, GFPpositive outpockets (optic vesicles) are visible on the aggregates (See Figure 1B). A timeline of events occurring in culture and experimental manipulations is shown in Figure 2. On Day 7, aggregates were collected for imaging and transferred from the 96 -well plate to a $35 \mathrm{~mm}$ petri dish, and washed twice with $1 \times$ phosphate buffered saline (PBS).

\section{Antisense-mediated gene knockdown}

To assess the ability for successful gene knockdown in optic vesicle organoid cultures, two different antisense-mediated techniques, siRNA and morpholinos, were used. Due to the increased structural complexity of 3D culture, techniques that have been designed to easily cross the cell membrane for use in in vivo procedures were chosen. These techniques included: Accell siRNA and vMO oligomers.

\section{Accell siRNA}

Accell siRNA (Dharmacon; Lafayette, $\mathrm{CO}$ ) is modified to readily cross the cell membrane and therefore is designed to be used without the use of transfection reagents, viruses or electroporation. This modification made it an ideal candidate to test in 3D culture. To assess Accell siRNA uptake in the aggregates, DY-547-labeled non-targeting control Accell siRNA

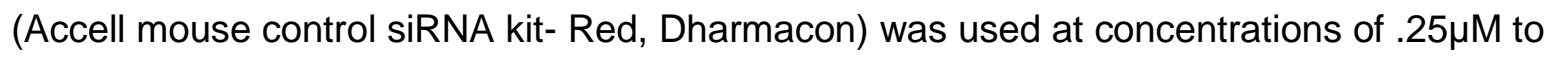
$1 \mu \mathrm{M}$.

Accell eGFP pool siRNA (D-001940-10-05, Dharmacon) was used to knockdown GFP in the aggregates. The sequences in the pool were as follows: GCCACAACGUCUAUAUCAU, GCAAAGACCCCAACGAGAA, CCAUCUUCUUCAAGGACGA, GCAUCGACUUCAAGGAGGA. 
A non-targeting Accell siRNA control pool was also used (D-001910-10-05; Dharmacon). Accell siRNA was applied to aggregates via bath application and added directly to the serum-free differentiation media on Day 4 . A concentration range of $.25 \mu \mathrm{M}$ to $3 \mu \mathrm{M}$ was tested for nontargeting control and eGFP pool siRNAs. The rationale for this concentration range was to assess the effectiveness of concentrations both above and below the manufacturer's recommended concentration of $1 \mu \mathrm{M}$.

\section{Vivo-morpholinos (vMOs)}

Another antisense-mediated gene knockdown technique tested was vMOs (Gene Tools, LLC; Philomath, OR). vMOs are morpholino oligomers that have been covalently linked to an octaguanidine dendrimer delivery moiety (Morcos et al. 2008). This modification allows it to cross cell membranes, thus making it a good choice for 3D culture. Morpholinos can be designed to block either translation or splicing. The majority of vMOs tested were translation blocking; however, one splice-blocking vMO was also tested. GFP-targeted control vMOs and standard negative control vMOs were used in the experiments below. In addition, custom vMOs were designed to target $R x$ (translation and splice-blocking), $A / x 1, E d n 1$, and $R p / 37$ (all translation blocking). Sequences of vMOs used are listed in Table 1. The vMOs were diluted from sterile PBS stock solution $(0.5 \mathrm{mM})$ to the appropriate concentration with differentiation media and then added directly to the aggregates in culture. Vivo-morpholinos were tested in concentrations ranging from $3 \mu \mathrm{M}$ to $7.5 \mu \mathrm{M}$. To determine optimal timing for morpholino addition, vMOs were added to separate wells on Days 3, 4, 5, 6 or 7 . After the initial timing experiment, all further experiments added morpholinos on Day 4.

\section{Selection of Optic Vesicle Test Genes}

To identify genes involved in early optic vesicle formation, we previously conducted a differential microarray between control and optic vesicle-deficient ( $R x$-null) embryos at E8.5. In mice, the deletion of the $R x$ homeobox gene results in a failure of the optic vesicles to form and blocks 
subsequent eye development (Mathers et al. 1997), and human $R X$ gene mutations are associated with anophthalmia and microphthalmia (Voronina et al. 2004). Affymetrix mouse exon arrays were probed with RNA from both control and $R x$-null embryos. The analysis showed numerous genes with differential expression between the genotypes. Thirteen of those genes were then confirmed using qPCR. Three genes that showed differential expression were then selected to test for knockdown in the 3D optic vesicle organoid cultures, these genes included: $A / x 1, R p / 37$, and Edn1. The genes were down-regulated in the microarray and were selected because their $p$-value and fold-changes were significant. Of the candidate genes, Alx 1 and Edn1 have a known function in craniofacial development, but their involvement in eye development is unknown.

\section{Immunofluorescence}

Aggregates were mounted in TBS tissue-freezing media (Triangle Biomedical Sciences, Durham, NC), and sectioned on a Leica CM 3050 S cryostat (Leica Biosystems, Buffalo Grove, IL) at 10-micron thickness, then transferred to glass slides. Samples were subjected to an antigen retrieval procedure of $0.1 \mathrm{M}$ Tris $\mathrm{pH} 9.5$ incubation at $95^{\circ} \mathrm{C}$ for $20 \mathrm{~min}$. Following antigen retrieval, sections were blocked with serum and treated with primary and secondary antibodies, following a published procedure (Howell et al. 2007). Primary antibodies used in this study were anti-GFP (chicken; Abcam; 1:1500), and anti-Pax6 (mouse; Santa Cruz; 1:150). Secondary antibodies were fluorophore-tagged for immunofluorescence (Molecular Probes, Eugene, OR). Images were captured on a LSM 710 confocal microscope (Carl Zeiss, Inc.; Thornwood, NY).

\section{Imaging of aggregates}

After being washed, aggregates were transferred to a new $35 \mathrm{~mm}$ petri dish containing $1 \times$ PBS. Epifluorescent images were then captured on a Leica MZFLIII fluorescence stereomicroscope (Leica Biosystems; Buffalo Grove, IL) equipped with a MicroFire digital camera (Optronics; Golenta, CA). For confocal imaging, washed aggregates were transferred to a $35 \mathrm{~mm}$ petri dish 
containing 500nM MitoTracker Deep Red FM (Molecular Probes Eugene, OR) in 1x PBS and placed in a $37^{\circ} \mathrm{C}$ incubator for 1 hour. After incubation in MitoTracker, aggregates were washed with 1x PBS and transferred to a glass-bottomed $35 \mathrm{~mm} / 10 \mathrm{~mm}$ well fluorodish (World Precision Instruments; Sarasota, FL) with 1x PBS. Z-stack images were captured on a Zeiss 510 confocal microscope (Carl Zeiss Inc; Thornwood, NY).

\section{Results}

\section{Successful transfection via bath application of Accell siRNA fails to knockdown gene expression}

In order to determine if bath application of Accell siRNA is a viable method of transfection in the stem cell aggregates, we used red non-targeting control siRNA labeled with DY-547 to allow visualization of siRNA uptake into the aggregates. In addition, we ran a concentration series using the red non-targeting control siRNA ranging from $0.25 \mu \mathrm{M}$ to $1 \mu \mathrm{M}$ to assess the optimal concentration of siRNA for transfection. Addition of Accell siRNA to the culture media on Day 4 resulted in visible uptake at all concentrations tested (Figure 3A). The amount of siRNA incorporated into the aggregates increased as the concentration increased. The manufacturer's recommended concentration of $1 \mu \mathrm{M}$ showed a large amount of siRNA was transfected into the stem cell aggregates suggesting that bath application is a viable transfection method for Accell siRNA into aggregates in 3D culture. Next, we wanted to examine the ability of Accell siRNA to knockdown gene expression in the 3D organoid culture. Since these aggregates produce GFP expression with the induction of retinal tissue, we choose to test gene knockdown using an eGFP pool of Accell siRNA. We tested a total of 5 different concentrations (ranging from 0.25 $\mu \mathrm{M}-3 \mu \mathrm{M})$, to determine the optimal siRNA concentration for gene knockdown. The concentrations were chosen based on their known ability to be successfully transfected into the aggregates and included three concentrations below and one above the manufacturer's recommended amount of $1 \mu \mathrm{M}$. Addition of GFP siRNA ( $n=8 /$ concentration) via bath application 
on Culture Day 4 was compared to nonsense siRNA controls $(n=8)$ at the same concentrations and untreated controls $(n=8)$. No toxic effects were noted at any of the concentrations tested, and there were no detectable changes in morphology. GFP expression, however, was not notably reduced at any of the concentrations tested using Accell siRNA (Figure 3B).

\section{vMOs successfully knockdown GFP expression in optic vesicle organoid cultures}

The next knockdown technique we tested in organoid cultures was application of vMOs. Incorporation of vMOs could not be tested in a similar manner to the labeled-siRNA because the vMOs are not available fluorescently tagged; therefore, we went directly to testing the ability of vMOs to successfully knockdown genes in developing optic vesicles. We opted to first test the GFP translation-blocking vMO since GFP is expressed with the induction of retinal tissue and thus provides a visual measure of the success of GFP knockdown in these cultures. A concentration series (ranging from $1 \mu \mathrm{M}-10 \mu \mathrm{M}$ ) was performed using bath application of GFP translation-blocking vMOs ( $\mathrm{n}=18$ per concentration) and standard negative control vMOs $(n=18$ per concentration) at culture day 4. A comparison of GFP translation-blocking vMOs, negative control vMOs, with untreated organoids across the concentration range shows no detectable signs of toxicity or alterations in morphology as a result of vMO addition (Figure 4A). Negative control vMOs did not affect GFP expression or optic vesicle formation. Examining the effects of GFP translation-blocking vMOs showed that at the lowest concentrations ( 1 and $3 \mu \mathrm{M})$ of GFP translation-blocking vMOs did not alter GFP expression, suggesting a failure to effectively knockdown GFP. At $4 \mu \mathrm{M}$ GFP translation-blocking vMO, there was a decrease in GFP expression compared to negative and untreated control suggesting a partial knockdown of GFP. The four highest concentrations $(5,6,7.5$, and $10 \mu \mathrm{M})$ all resulted in undetectable GFP expression in the aggregates, suggesting that at those concentrations, GFP translation-blocking vMOs are effective at gene knockdown. To confirm the loss of GFP after the addition of GFP translation-blocking vMO $(5 \mu \mathrm{M})$, we performed immunofluorescence on sectioned aggregates 
using an anti-GFP antibody. Labeled sections showed a drastic decrease in GFP expression compared to the standard negative control vMO treated aggregate and untreated aggregate (Figure 4B). In addition, to confirm that optic vesicle development was not affected by the knockdown, we used an anti-Pax6 antibody along with anti-GFP to label aggregate sections. Pax6 and GFP both label optic vesicles in the untreated and negative control vMO aggregates, however, in the aggregate treated with the GFP translation-blocking vMO, Pax6 labeling is unaffected, suggesting the presence of optic vesicles (Figure 4B).

Next, to determine optimal timing of vMO addition for gene knockdown in these cultures, we tested bath application of the GFP translation-blocking vMO at a concentration of $5 \mu \mathrm{M}$ on days $3,4,5,6$ or 7 ( $n=6$ per time point) and then assessed GFP expression on day 8 . Visual examination of GFP expression in the cultures showed a complete loss of GFP expression with the addition of GFP translation-blocking vMOs at days 3 and 4 compared to untreated and standard negative control conditions. Addition at days 5 and 6 of the GFP translation-blocking vMOs showed partial GFP expression in the stem cell aggregates compared with standard negative control and untreated conditions, whereas addition at day 7 showed no change in GFP expression compared with controls. Therefore, we used day 4 as the time point for all subsequent transfections.

\section{vMO knockdown of the retinal homeobox gene $(R x)$ decreases GFP expression}

Next, we tested the ability of vMOs to knockdown the $R x$ gene in 3D-organoid cultures. $R x$ is important for the initial formation of optic vesicles during eye development and deletion of $R x$ in mice leads to a failure of optic vesicle formation (Mathers et al., 1997). Therefore, we hypothesized that knockdown of Rx in these cultures should prevent optic vesicle formation. We tested both translation-blocking $(\mathrm{n}=30)$ and splice-blocking vMOs $(\mathrm{n}=30)$ targeting $R x$ at a concentration of $5 \mu \mathrm{M}$. Additionally, as a third $R x$ condition, we combined each of the $R x$ targeted morpholinos at $2.5 \mu \mathrm{M}(\mathrm{n}=15)$ to minimize off target effects and check for synergism. 
For comparison, along with the $R x$ conditions we ran untreated, standard negative control VMOs, and GFP translation-blocking vMOs on the same plate. The results show aggregates of similar size in all conditions (Figure 5) with no apparent toxic effects of vMO addition. Morphology and GFP expression were normal in untreated and standard negative control vMO conditions. Since there is no effective commercially available Rx antibody, we used GFP expression as an indirect measure for the efficacy of the vMO Rx knockdown. This was possible because the Rx vMOs disrupt the $R x$ promoter-driven GFP expression within the aggregates. As expected, GFP expression was lost in the GFP translation-blocking vMO condition. In all three Rx knockdown conditions, GFP expression was lost. Confocal imaging using Red MitoTracker to visual all cells of the aggregate in addition to the GFP expression of the vesicles allowed for a more detailed look at the aggregates (Figure 6).

\section{Screening potential gene candidates in 3D organoid culture}

After confirming that vMOs could successfully knockdown gene function in the stem cell aggregates and demonstrating the expected phenotype after Rx knockdown in these cultures, we began using vMOs to investigate the role of the identified candidate genes on optic vesicle development. Translation-blocking vMOs targeting Alx1, Edn1, and Rpl37 were added at $5 \mu \mathrm{M}$ to aggregate cultures on day 4; then on day 8, we assessed GFP expression and the morphology of aggregates in comparison to untreated and standard negative vMO controls. The knockdown of the three candidate genes resulted in three distinctly different phenotypes in the aggregates (Figure 7). Edn1 knockdown ( $\mathrm{n}=12)$ showed robust GFP expression in aggregate outpockets very similar to the untreated $(n=12)$ and control $(n=12)$ conditions. Rpl37 knockdown $(n=12)$ resulted in a loss of GFP expression, a failure of outpockets to form and a large reduction in overall aggregate size. The knockdown of Alx1 $(n=12)$ led to a loss of outpocket formation, but retained normal overall aggregate size. In addition, in the Alx1 knockdown aggregates, there was an alteration of GFP expression. Instead of being confined within 
discrete outpocket regions, GFP expression was shown in small punctate regions within the aggregate.

\section{Discussion}

The development of 3D-organoid cultures has led to new possibilities for research. Organoid culture has some distinct advantages over traditional cell culture in that it allows morphological patterning. In optic vesicle organoid culture, the morphological and temporal development matches that seen in vivo. We wished to take advantage of this system to develop a rapid screen to test genes during development. Here, to enable the rapid screening of genes, we identified a method of gene knockdown (vMOs) that was easily transfected, nontoxic, and did not affect morphological development of the organoids adversely. Further, we tested a gene $(R x)$ with a known optic vesicle phenotype and three genes with unknown roles in optic vesicle development.

\section{vMOs are superior to Accell siRNA for gene knockdown in 3D-organoid culture}

Due to the increased complexity of tissue in 3D culture compared to cell culture, we chose to test two antisense-mediated techniques, Accell siRNA and vMOs, that have modifications for crossing the cell membrane. The Accell eGFP siRNA failed to knockdown GFP expression at any of the concentrations tested, including three times the manufacturer's recommended working concentration. The results suggest that despite being easily transfected and nontoxic, Accell siRNA is not effective as a method for gene knockdown in these 3D-organoid cultures. However, vMOs proved to be a viable and effective method for gene knockdown. Addition of vMOs via bath application was effective in achieving gene knockdown with no toxic effects nor effects on the developing optic vesicles (for controls). 


\section{D optic vesicle organoid culture is well suited to gene knockdown by vMOs}

Four issues have been identified with the traditional use of vMOs: 1) difficulty in injecting precise volumes in small embryos; 2) difficulty in verifying efficacy; 3) the possibility of off-target effects; and 4) toxicity leading to death (Eisen and Smith 2008; Ferguson et al. 2014). In the 3Dorganoid culture, we demonstrate that bath application is a viable method for transfection within these cultures and thus does not require injections into aggregates and issues of precision and reproducibility with small injections. Another challenge with the use of vMOs that is not an issue in 3D optic vesicle organoid culture is toxicity. In vivo application of vMOs has been associated with a problem in toxicity that leads to death in the animals that is hypothesized as being due to oligonucleotide hybridization leading to lethal blood clots (Ferguson et al., 2014), which is not a concern in 3D organoids. No toxicity was noted in any of our cultures that were treated with vMOs, nor were any adverse effects noted on development, suggesting that toxicity is not a concern when vMOs are used following our methods in optic vesicle organoids. Determining knockdown efficiency is important and can be achieved directly using a reliable antibody to assess protein loss or indirectly using a marker such as GFP. We demonstrate the high efficiency of vMO gene knockdown using immunofluorescence on aggregates that were transfected with GFP translation-blocking vMO compared to standard negative control. The issue of verifying efficacy is lessened in our organoid cultures because the stem cells have GFP knocked in at the $R x$ locus and thus allows a visualization of retinal induction. Therefore, measuring endogenous GFP expression in these cultures gives us an indirect measure of knockdown for genes that effect optic vesicle formation. The ability for this indirect measure is important especially in cases where there is no reliable antibody to test the protein loss for the gene being targeted.

The challenge of minimizing off-target effects is present for the use of vMOs whether they are used in vivo or in 3D organoid cultures. There are several ways to minimize off-target effects for 
morpholinos. Eisen and Smith (2008) suggest this is the most important issue with the use of vMOs, and therefore it is essential to use control vMOs with all experiments. For our test experiments, we included a standard negative control condition and a positive GFP-control condition. In addition, to minimize off-target effects, it is recommended to use both spliceblocking and translation-blocking vMOs separately and then in combination at lower concentrations (Eisen and Smith, 2008). This helps to ensure that the resulting phenotype is the product of the target gene being knocked down and not an off-target effect. For the $R x$ gene, we tested splice- and translation-blocking vMOs independently and in combination and observed the same phenotype, a loss of $R x$-GFP expression in all conditions, suggesting the effect was due to the targeted $R x$ knockdown. Another suggestion to assess possible off-target effects is to compare the resulting phenotype with that of a known mutation (Eisen and Smith, 2008). Our $R x$-targeting vMOs are consistent with the $R x$ mouse mutant phenotype (Mathers et al., 1997), in that both show a lack of retinal induction at the optic vesicle stage, which further supports that the phenotype is not the result of off-target effects.

\section{D organoid culture has potential as a screening method for genes involved in organogenesis}

Organogenesis in many systems has now be modeled in organoids (Eiraku and Sasai 2011; Eiraku et al. 2011; Koo et al. 2011; Finkbeiner et al. 2015; Little and Takasato 2015; Chen et al. 2016). These organoids offer the potential to be used as a rapid screening tool for gene candidates to identify genes for subsequent study. To test this possibility, we assessed the effect of vMOs targeted to three different gene candidates in 3D-organoid culture. Translationblocking vMOs were created to target Alx1, Edn1 and Rpl37 protein production. Three different phenotypes emerged. Edn1 knockdown showed a similar phenotype to controls, suggesting that, although it showed differential expression between $R x$-knockouts and controls, it is unlikely absolutely required for optic vesicle formation or alternatively that that knockdown was not 
efficient enough to reduce the protein level a point where a phenotype would appear. The knockdown of Rpl37 decreased overall aggregate size and lacked GFP expression. Therefore, despite the failure of retinal induction, it is unlikely that Rpl37 has specific optic vesicle effects because the decrease in aggregate size would suggest that Rpl37 has more global effects on development. Translation-blocking vMO knockdown of Alx1 led to dispersed and punctate GFP expression, suggesting that retinal induction occurred but the appropriate morphology is lost. These observations suggest that Alx 1 may be involved in the morphological development of the optic vesicle. Evidence supporting this possibility comes from a study showing a human mutation of Alx1 is associated with microphthalmia (Uz et al. 2010).

The addition of vMOs targeted to candidate genes resulted in three independent phenotypes, which suggests that effects observed in the organoids are not the result of non-specific morpholino addition, but instead the effect of specific gene knockdown. Verification studies using a reliable antibody to detect protein levels should be performed to confirmation efficacy of the gene knockdown, especially with Edn1 to rule out failure to sufficiently decrease protein expression as a reason for the lack of difference seen between control and Edn1 vMO aggregates. Further studies using the splice-blocking variant and combinations of the spliceand translation-blocking vMOs targeted to the candidate genes are needed to ensure the phenotypes generated were not the result of off-target effects. General similarity between the ALX1 human mutation and our studies would suggest that the Alx1 knockdown was not due to off-target effects.

In conclusion, this study provides evidence that vMOs are well suited to gene knockdown in optic vesicle organoid culture, with few of the limitations for their use in vivo, and provide a good model for rapidly screening genes involved in development. Vivo-morpholinos have the potential to be a useful tool for rapid gene screening, not only in optic vesicle organoids but also possibly in other organoid systems, although further investigation in those systems is necessary. 


\section{Acknowledgements:}

We thank D. Cole for providing excellent technical assistance and V. Ramamurthy for the mESCs. Imaging experiments and image analysis were performed in the West Virginia University Microscope Imaging Facility, which has been supported by the Mary Babb Randolph Cancer Center and NIH grants P20 RR016440, P30 RR032138/GM103488 and P20

RR016477. This work was supported in part by an RFDG grant from West Virginia University School of Medicine to P.H.M. and the Department of Neurobiology and Anatomy at West Virginia University. 


\section{References}

Bardakjian TM, Schneider A. The genetics of anophthalmia and microphthalmia. Curr Opin Ophthalmol. 2011 Sep;22(5):309-13.

Chen HY, Kaya KD, Dong L, Swaroop A. Three-dimensional retinal organoids from mouse pluripotent stem cells mimic in vivo development with enhanced stratification and rod photoreceptor differentiation. Mol Vis. 2016;22:1077-94.

Cong L, Ran FA, Cox D, Lin S, Barretto R, Habib N, et al. Multiplex Genome Engineering Using CRISPR/Cas Systems. Science (80- ). 2013 Feb 15;339(6121):819-23.

Eiraku M, Sasai Y. Mouse embryonic stem cell culture for generation of three-dimensional retinal and cortical tissues. Nat Protoc. 2011;7(1):69-79.

Eiraku M, Takata N, Ishibashi H, Kawada M, Sakakura E, Okuda S, et al. Self-organizing opticcup morphogenesis in three-dimensional culture. Nature. Nature Publishing Group; $2011 ; 472(7341): 51-6$.

Eisen JS, Smith JC. Controlling morpholino experiments: don't stop making antisense. Development. 2008 May 9;135(10):1735-43.

Ferguson DP, Dangott LJ, Lightfoot JT. Lessons learned from vivo-morpholinos: How to avoid vivo-morpholino toxicity. Biotechniques. 2014 May 1;56(5).

Finkbeiner SR, Freeman JJ, Wieck MM, El-Nachef W, Altheim CH, Tsai Y-H, et al. Generation of tissue-engineered small intestine using embryonic stem cell-derived human intestinal organoids. Biol Open. 2015 Oct 12;4(11):1462-72.

Howell DM, Morgan WJ, Jarjour AA, Spirou GA, Berrebi AS, Kennedy TE, et al. Molecular guidance cues necessary for axon pathfinding from the ventral cochlear nucleus. J Comp Neurol. 2007 Oct 10;504(5):533-49.

Huch M, Koo B-K. Modeling mouse and human development using organoid cultures. Development. 2015 Sep 15;142(18):3113-25.

Koo B-K, Sasselli V, Clevers H, Koo B, Sasselli V, Clevers H. Retroviral Gene Expression Control in Primary Organoid Cultures. Curr Protoc Stem Cell Biol. Hoboken, NJ, USA: John Wiley \& Sons, Inc.; 2013. p. 5A.6.1-5A.6.8.

Koo B-K, Stange DE, Sato T, Karthaus W, Farin HF, Huch M, et al. Controlled gene expression in primary Lgr5 organoid cultures. Nat Methods. 2011 Dec 4;9(1):81-3.

Kretzschmar K, Clevers H. Organoids: Modeling Development and the Stem Cell Niche in a Dish. Dev Cell. 2016 Sep 26;38(6):590-600.

Van Lidth de Jeude JF, Vermeulen JLM, Montenegro-Miranda PS, Van den Brink GR, Heijmans J. A Protocol for Lentiviral Transduction and Downstream Analysis of Intestinal Organoids. J Vis Exp. 2015 Apr 20;(98).

Little $\mathrm{MH}$, Takasato M. Generating a self-organizing kidney from pluripotent cells. Curr Opin Organ Transplant. 2015 Apr;20(2):178-86.

Mathers PH, Grinberg a, Mahon K a, Jamrich M. The Rx homeobox gene is essential for vertebrate eye development. Nature. 1997 Jun 5;387(6633):603-7. 
Meyer JS, Howden SE, Wallace KA, Verhoeven AD, Wright LS, Capowski EE, et al. Optic vesicle-like structures derived from human pluripotent stem cells facilitate a customized approach to retinal disease treatment. Stem Cells. 2011 Aug;29(8):1206-18.

Mojica FJM, Montoliu L. On the Origin of CRISPR-Cas Technology: From Prokaryotes to Mammals. Trends Microbiol. 2016 Oct;24(10):811-20.

Morcos P, Li Y, Jiang S. Vivo-Morpholinos: A non-peptide transporter delivers Morpholinos into a wide array of mouse tissues. Biotechniques. 2008 Dec;45(6):613-23.

Nakano T, Ando S, Takata N, Kawada M, Muguruma K, Sekiguchi K, et al. Self-formation of optic cups and storable stratified neural retina from human ESCs. Cell Stem Cell. 2012 Jun 14;10(6):771-85.

Ohlemacher SK, Iglesias CL, Sridhar A, Gamm DM, Meyer JS. Generation of highly enriched populations of optic vesicle-like retinal cells from human pluripotent stem cells. Curr Protoc Stem Cell Biol. 2015 Feb 2;32:1H.8.1-20.

Ohlemacher SK, Sridhar A, Xiao Y, Hochstetler AE, Sarfarazi M, Cummins TR, et al. Stepwise Differentiation of Retinal Ganglion Cells from Human Pluripotent Stem Cells Enables Analysis of Glaucomatous Neurodegeneration. Stem Cells. 2016 Jun;34(6):1553-62.

Parker SE, Mai CT, Canfield MA, Rickard R, Wang Y, Meyer RE, et al. Updated national birth prevalence estimates for selected birth defects in the United States, 2004-2006. Birth Defects Res Part A Clin Mol Teratol. 2010 Dec;88(12):1008-16.

Pendergraft SS, Sadri-Ardekani H, Atala A, Bishop CE. Three-dimensional testicular organoid: a novel tool for the study of human spermatogenesis and gonadotoxicity in vitro. Biol Reprod. 2017 Mar 17;96(3):720-32.

Ragge NK, Subak-Sharpe ID, Collin JRO. A practical guide to the management of anophthalmia and microphthalmia. Eye. 2007 Oct;21(10):1290-300.

Sasai Y, Eiraku M, Suga H. In vitro organogenesis in three dimensions: self-organising stem cells. Development. 2012 Nov;139(22):4111-21.

Uz E, Alanay Y, Aktas D, Vargel I, Gucer S, Tuncbilek G, et al. Disruption of ALX1 causes extreme microphthalmia and severe facial clefting: expanding the spectrum of autosomalrecessive ALX-related frontonasal dysplasia. Am J Hum Genet. Elsevier; 2010 May 14;86(5):789-96.

Völkner M, Zschätzsch M, Rostovskaya M, Overall RW, Busskamp V, Anastassiadis K, et al. Retinal Organoids from Pluripotent Stem Cells Efficiently Recapitulate Retinogenesis. Stem cell reports. 2016 Apr 12;6(4):525-38.

Voronina V a, Kozhemyakina E a, O'Kernick CM, Kahn ND, Wenger SL, Linberg J V, et al. Mutations in the human RAX homeobox gene in a patient with anophthalmia and sclerocornea. Hum Mol Genet. 2004 Feb 1;13(3):315-22.

Wang P, Mokhtari R, Pedrosa E, Kirschenbaum M, Bayrak C, Zheng D, Lachman HM. CRISPR/Cas9-mediated heterozygous knockout of the autism gene CHD8 and characterization of its transcriptional networks in cerebral organoids derived from iPS cells. Mol. Autism. 2017 Mar 20;8:11. in press doi: 10.1186/s13229-017-0124-1.

Wang T, Wei JJ, Sabatini DM, Lander ES. Genetic Screens in Human Cells Using the CRISPRCas9 System. Science (80- ). 2014 Jan 3;343(6166):80-4. 
Williamson KA, FitzPatrick DR. The genetic architecture of microphthalmia, anophthalmia and coloboma. Eur J Med Genet. 2014 Aug;57(8):369-80.

Zhong X, Gutierrez C, Xue T, Hampton C, Vergara MN, Cao L-H, et al. Generation of threedimensional retinal tissue with functional photoreceptors from human iPSCs. Nat Commun. 2014 Jun 10;5:4047. 
Table 1: Sequences of vMOs

\begin{tabular}{|l|l|l|}
\hline \multicolumn{1}{|c|}{ Gene } & \multicolumn{1}{c|}{ Type } & \multicolumn{1}{c|}{ Sequence } \\
\hline Standard Vivo Control & Negative control & 5' $^{\prime}$-CCTCTTACCTCAGTTACAATTTATA $-3^{\prime}$ \\
\hline$G F P$ & Translation blocking & $5^{\prime}-$ ACAGCTCCTCGCCCTTGCTCACCAT $-3^{\prime}$ \\
\hline$R x$ & Translation blocking & $5^{\prime}-$ CTCGATGCCCGGTTCCCTTCTCCTC $-3^{\prime}$ \\
\hline$R x$ & Splice blocking & $5^{\prime}-$ CAATCCAAGAGCTTACTTACCTGGA $-3^{\prime}$ \\
\hline$A l \times 1$ & Translation blocking & $5^{\prime}-$ CTTCTCGCTCAGAAACTCCATAATC $-3^{\prime}$ \\
\hline$E d n 1$ & Translation blocking & $5^{\prime}-$ ATCACGGGAAAATAATCCATTCTGC $-3^{\prime}$ \\
\hline$R p / 37$ & Translation blocking & $5^{\prime}-$ GACGTTCCCTTCGTCATCTTGCTTC $-3^{\prime}$ \\
\hline & & \\
\hline
\end{tabular}




\section{Figure Legends}

Figure 1. Formation of vesicles expressing Rx-GFP in 3D culture from mouse embryonic stem cells (mESCs).

(A) Schematic of optic vesicle formation from stem cells in 3D culture over the course of 7 days. Adpated from Eiraku et al., 2011. (B) 3D reconstruction from confocal Z-stacks on Day 7 of stem cell aggregates labeled with MitoTracker (red) showing optic vesicle organoid formation expressing Rx-GFP (green).

Figure 2. Schematic of the methods and events in 3D stem cell culture that results in optic vesicle formation.

Adapted from Eiraku \& Sasai (2011) to include the gene knockdown studies presented here.

\section{Figure 3. Accell siRNA treatment in 3D optic vesicle organoid culture.}

(A) Incorporation of fluorescently-tagged Accell siRNA (red) on Day 7 into 3D stem cell aggregates after bath application on Day 4 at four concentrations. (B) Comparison of the expression of Rx-GFP in optic vesicle organoids following the addition of either nonsense control Accell siRNA or Accell GFP siRNA on Day 4 across a concentration range of $0.25 \mu \mathrm{M}$ to $3 \mu \mathrm{M}$ shows no effects on optic vesicle formation or GFP expression. An untreated aggregate is shown for reference.

\section{Figure 4. Day 7 optic vesicle aggregates after the addition of GFP vMO}

(A) Comparison of Rx-GFP expression in optic vesicle organoids after Vivo-morpholino (vMO) addition on day 4. GFP translation-blocking vMOs and a negative control were tested over a range of concentrations from $3 \mu \mathrm{M}$ to $7.5 \mu \mathrm{M}$. Aggregates transfected with the negative control show GFP expression similar to the untreated cultures. Addition of the GFP translation-blocking VMOs resulted in a reduction in GFP expression that was undetectable at concentrations of 5 
$\mu \mathrm{M}$ and higher. (B) Immunofluorescence on sectioned Day 7 aggregates using anti-GFP and anti-Pax6 on untreated, negative control and GFP vMO aggregates. GFP labeling shows GFP expression in optic vesicles in the untreated and negative control vMO conditions but undetectable GFP signal with the addition of a GFP translation-blocking vMO at $5 \mu \mathrm{M}$. Pax6 labeling shows expression in the GFP-positive outpockets in the untreated and negative control vMO conditions. In the aggregate treated with GFP translational-blocking vMOs, Pax6-labeled cells appear in outpockets suggesting the presence of optic vesicles.

Figure 5. Comparison of Day 7 Rx-GFP expression in optic vesicle organoids after addition of $5 \mu \mathrm{M}$ vMOs targeting either GFP or Rx on Day 4.

Phase + Rx-GFP and Rx-GFP fluorescent images are presented to allow the assessment of GFP expression and overall morphology of the aggregate. Aggregates in all conditions appear to be similar in size. Untreated and negative control vMOs show GFP expression within optic vesicles. GFP translation-blocking vMOs show a lack of GFP signal, as do all three Rx Vivomorpholino conditions. (T) indicates a translation-blocking $\mathrm{vMO},(\mathrm{S})$ indicates a splice-blocking $\mathrm{vMO}$ and (S\&T) indicates a combination of splice and translation-blocking vMOs, each at $2.5 \mu \mathrm{M}$ concentration.

Figure 6. Imaging of Day 7 optic vesicle organoids after addition of $5 \mu M$ vMOs on Day 4.

Rx-GFP expression labeling the optic vesicles is shown in green and MitoTracker is shown labeling the aggregate in red. Untreated and negative control vMO conditions show strong RxGFP expression within vesicles. No Rx-GFP expression is observed within the GFP vMO, Rx splice-blocking vMO, Rx translation-blocking vMO or the combination of Rx splice- and translation- blocking vMO. (T) indicates a translation-blocking $\mathrm{VMO},(\mathrm{S})$ indicates a spliceblocking $\mathrm{vMO}$, and (S\&T) indicates a combination of splice and translation-blocking vMO. 
Figure 7. Day 7 optic vesicle organoids after Day 4 addition of $5 \mu \mathrm{M}$ vMOs targeting candidate genes for optic vesicle development.

Phase and Rx-GFP fluorescent images are presented to allow the assessment of GFP expression and overall morphology of the aggregate. In comparison to untreated and negative control vMO, aggregates that received Alx1-targeted vMOs are similar in size but show scattered, punctate Rx-GFP expression (arrows indicate areas of punctate Rx-GFP expression). Addition of Rpl37-targeting vMOs to aggregates resulted in a loss of Rx-GFP expression and decrease in overall aggregate size. Aggregates that were transfected with Edn1-targeted vMOs show similar Rx-GFP expression and overall aggregate size to untreated and control conditions. All vMOs tested here were translation-blocking $(\mathrm{T})$ at $5 \mu \mathrm{M}$. 


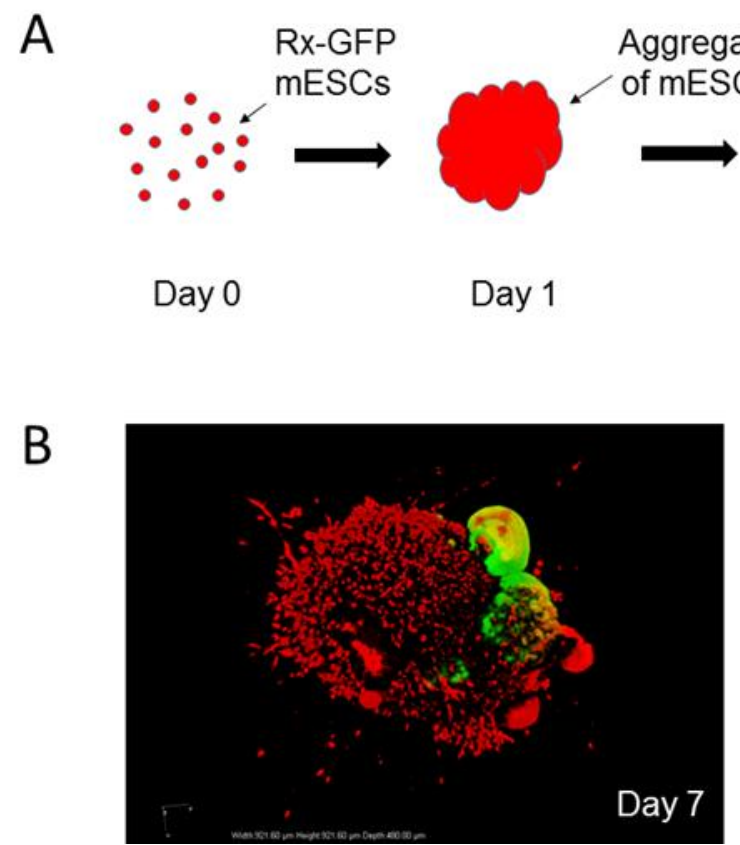

Figure 1. Formation of vesicles expressing Rx-GFP in 3D culture from mouse embryonic stem cells (mESCs). 


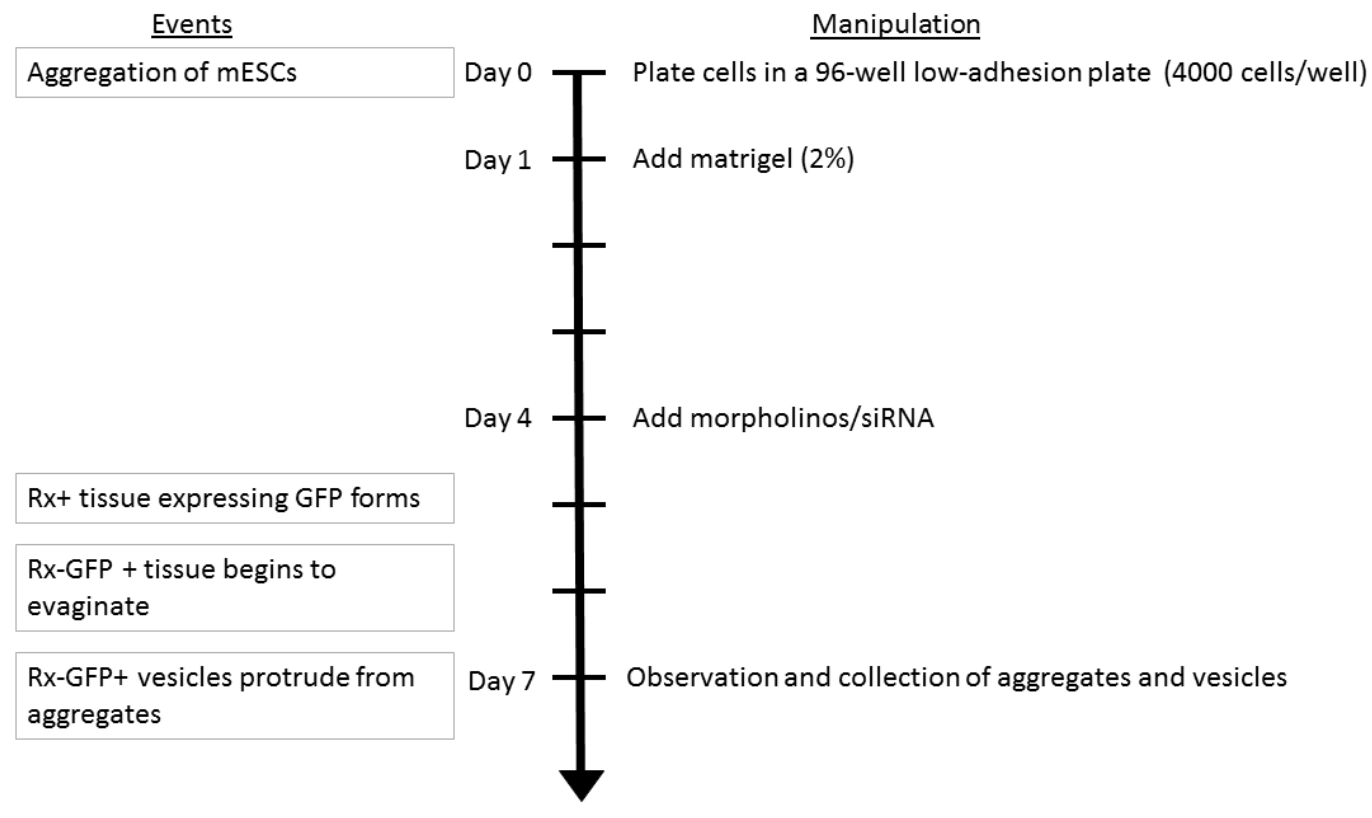

Figure 2. Schematic of the methods and events in 3D stem cell culture that results in optic vesicle formation. 
A

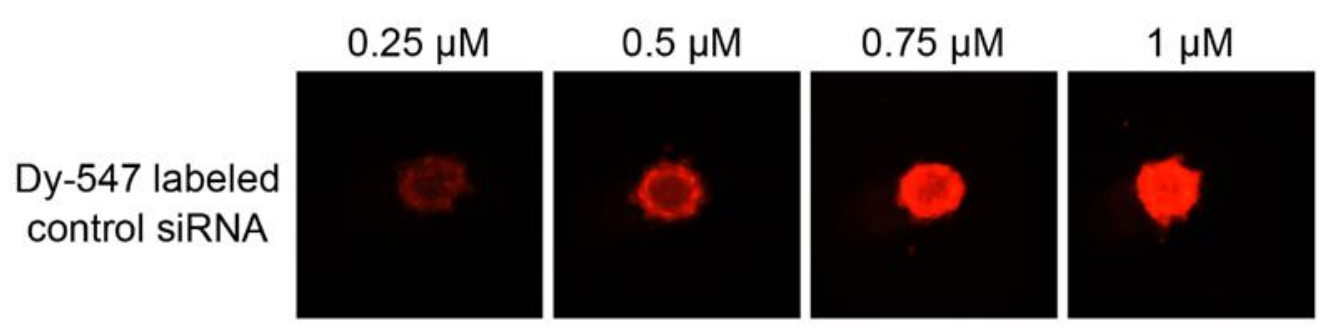

B
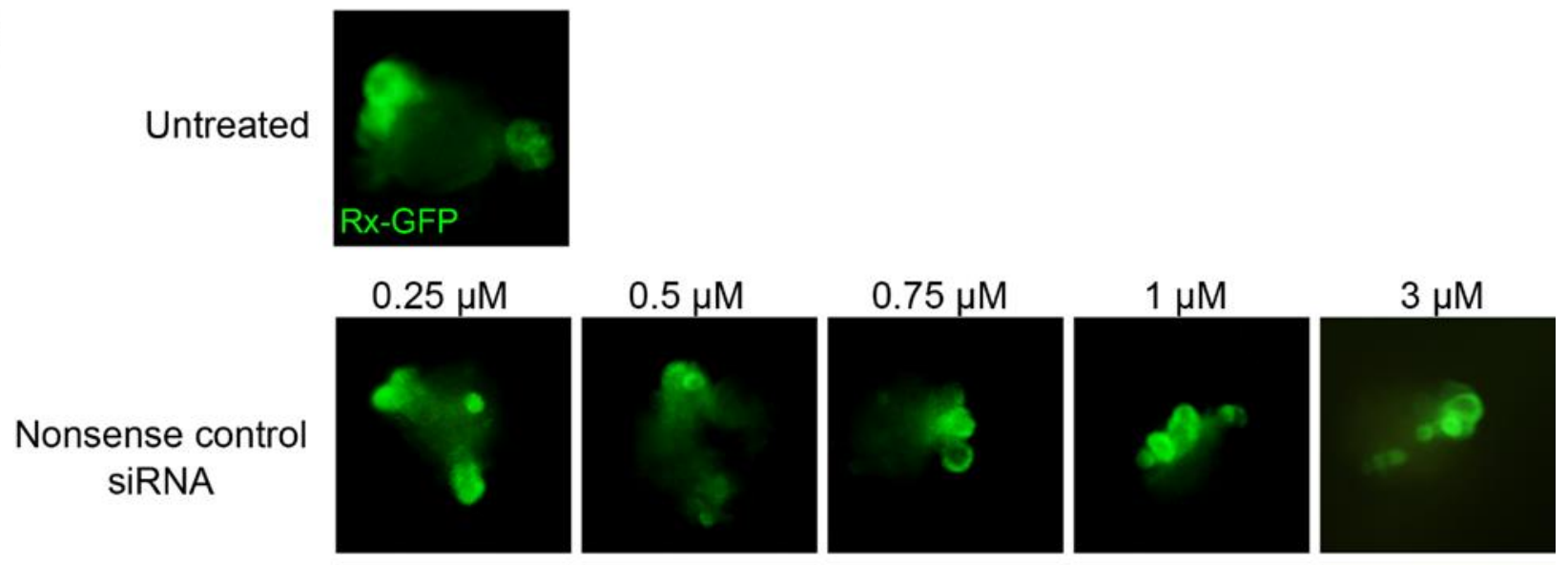

GFP siRNA
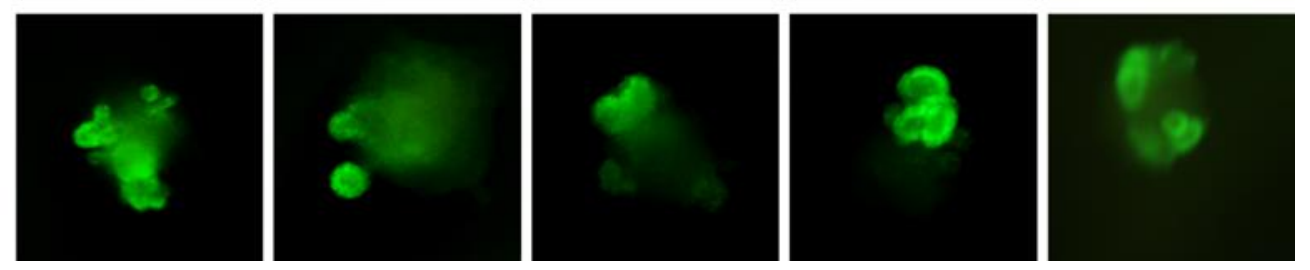

Figure 3. Accell siRNA treatment in 3D optic vesicle organoid culture. 
A

Untreated

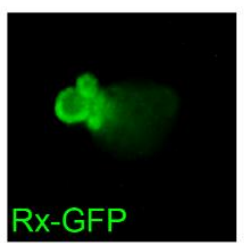

Negative control vMO
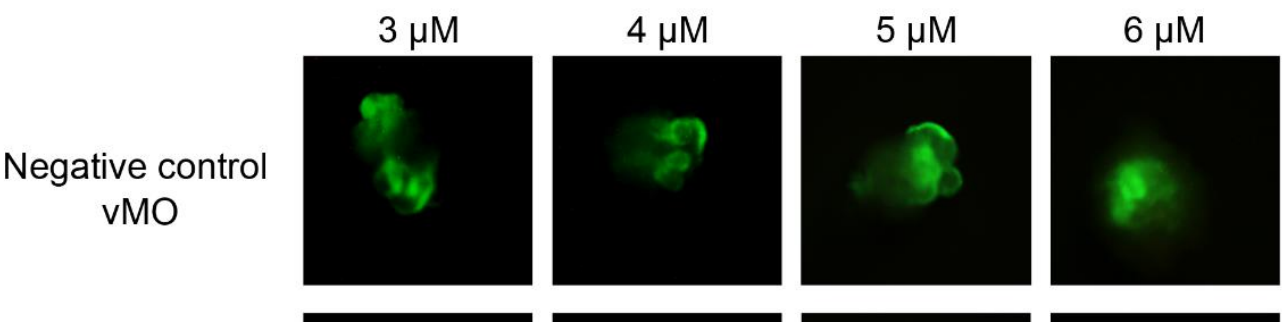

$7.5 \mu \mathrm{M}$
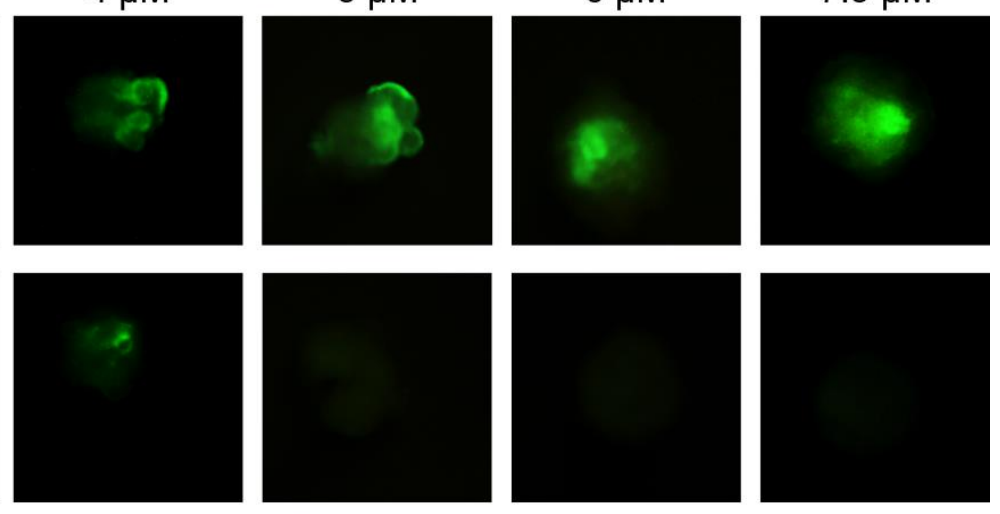

GFP vMO
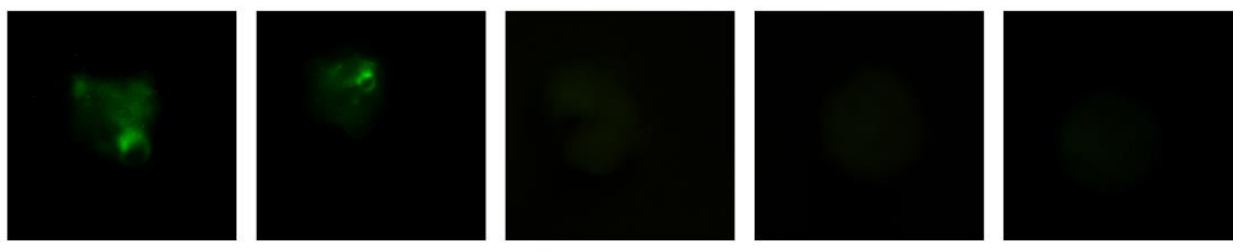

Negative control

B
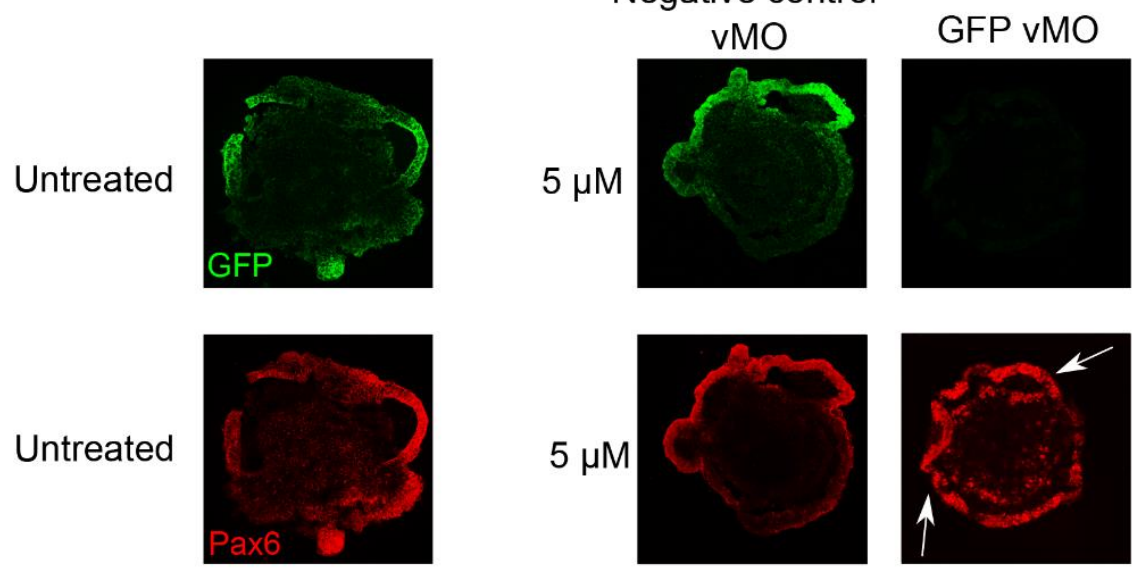

Figure 4. Day 7 optic vesicle aggregates after the addition of GFP vMO 

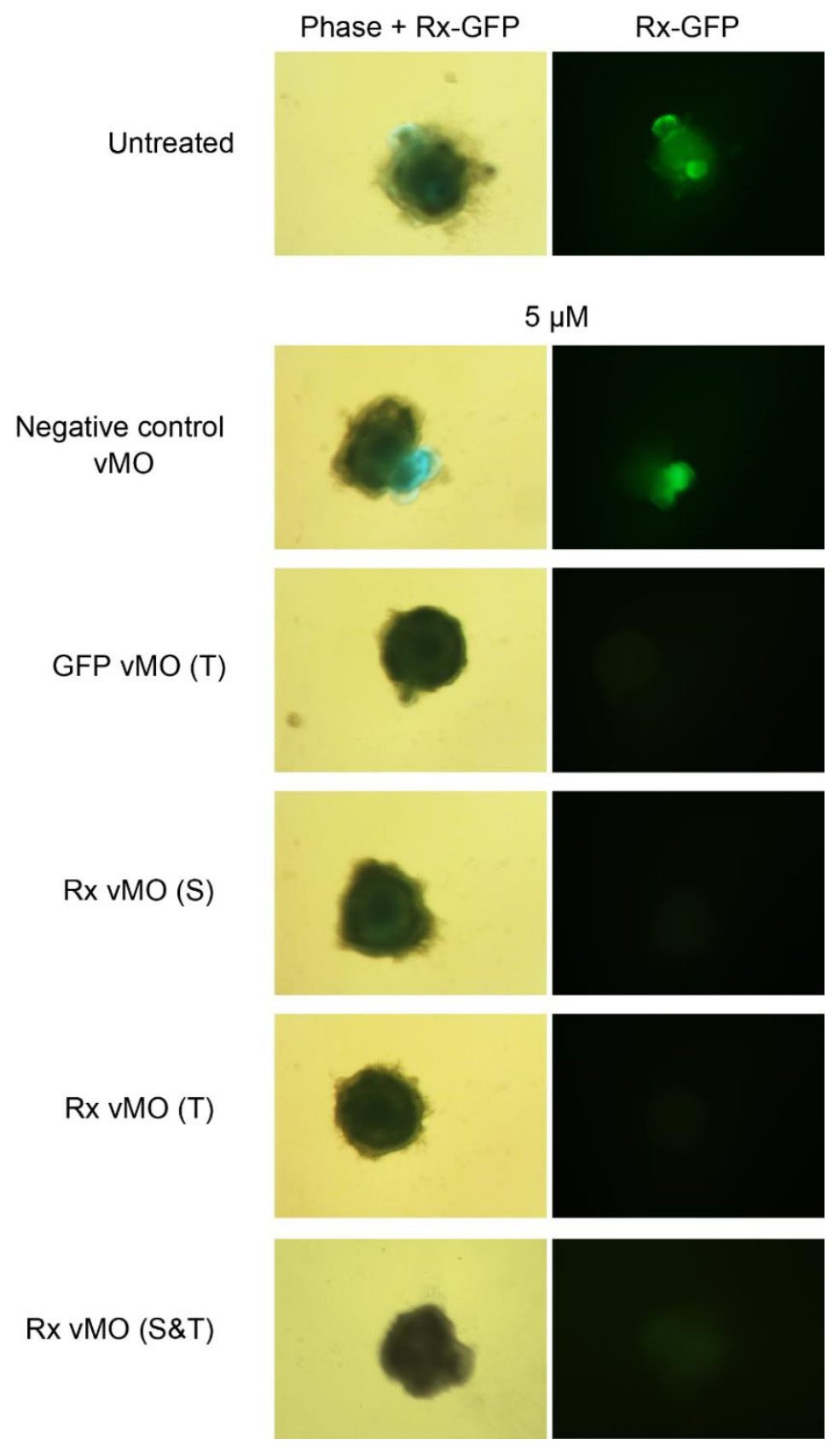

Figure 5. Comparison of Day 7 Rx-GFP expression in optic vesicle organoids after addition of $5 \mu \mathrm{M}$ vMOs targeting either GFP or Rx on Day 4 . 

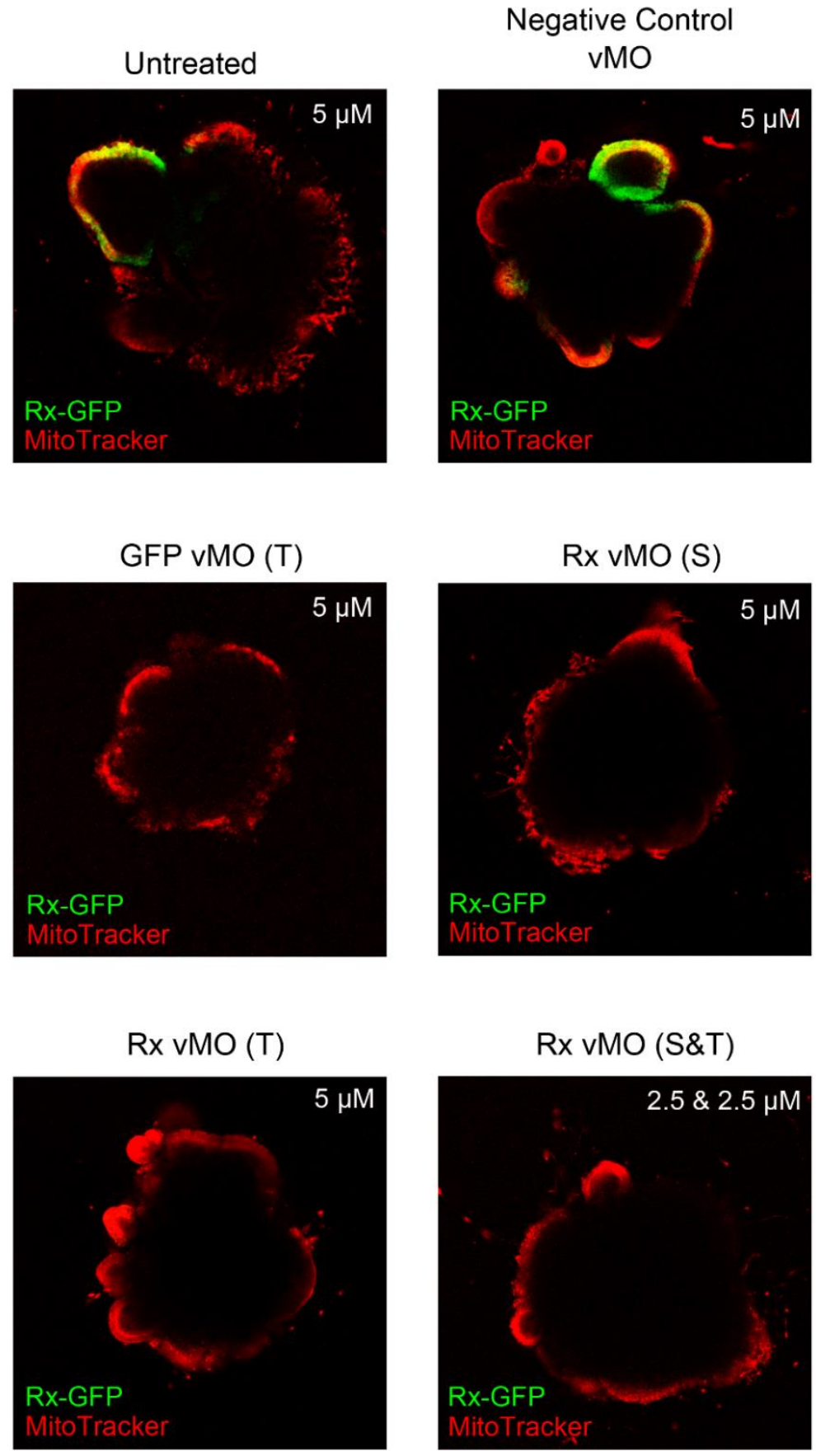

Figure 6. Imaging of Day 7 optic vesicle organoids after addition of $5 \mu \mathrm{M}$ vMOs on Day 4. 


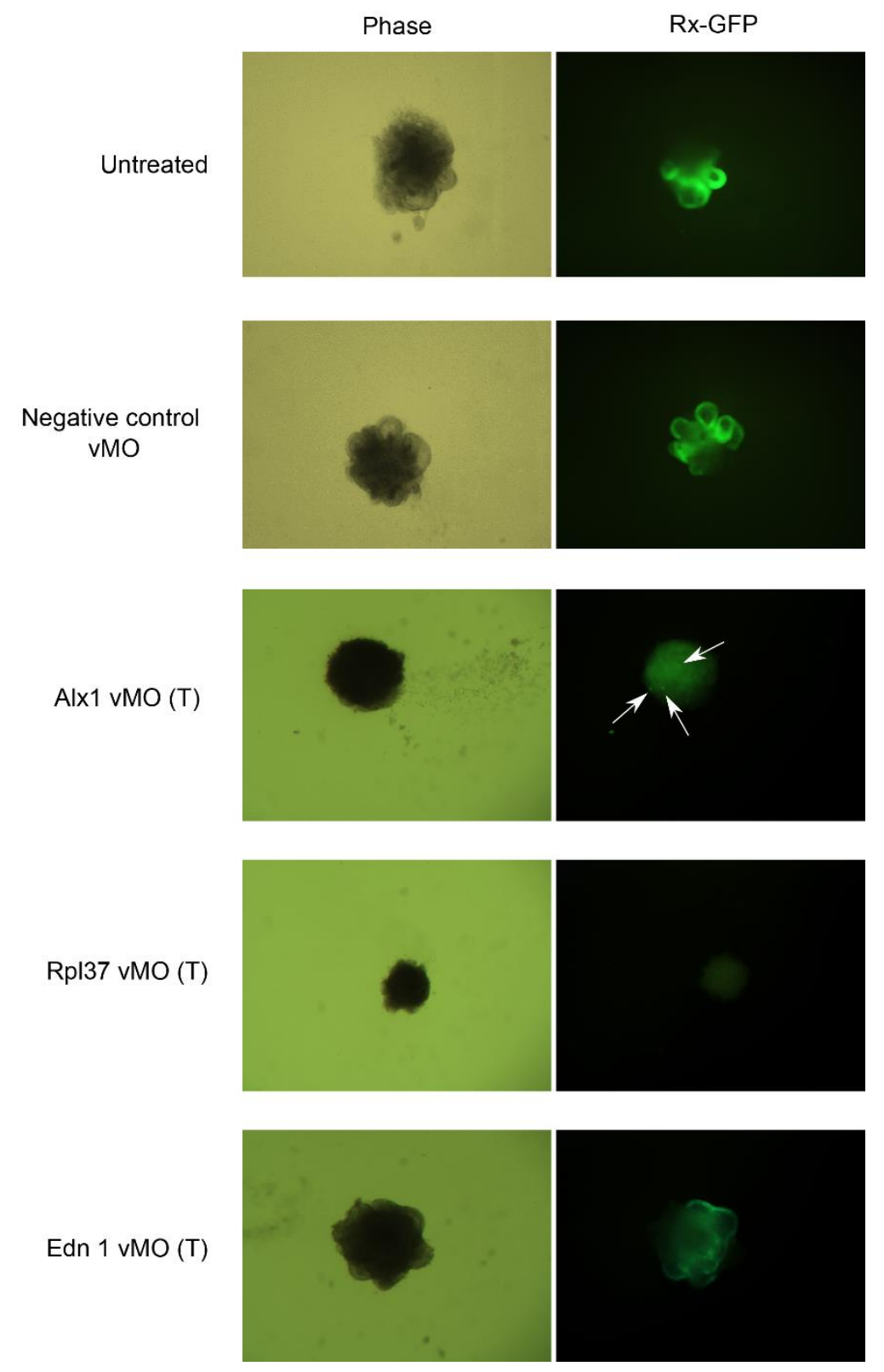

Figure 7. Day 7 optic vesicle organoids after Day 4 addition of $5 \mu \mathrm{M}$ vMOs targeting candidate genes for optic vesicle development. 


\section{Chapter 5:}

Summary, Conclusions and Future Directions 
This dissertation presents studies that examine embryonic retinogenesis. Developing tools to study early eye development and understanding the molecular mechanisms involved are important for 1) increasing our understanding of neural development; 2) understanding ocular malformations, such as anophthalmia; 3) improving cell replacement therapies for retinal diseases; and 4) potentially developing new treatments for eye diseases and blindness. This collection of studies presents two new tools for studying embryonic retinogenesis. In the second chapter, we characterized two new markers of embryonic cone photoreceptors and used these markers in the third chapter to analyze cone specification in the conditional $R x$-deletion retina. In the fourth chapter, we identified an effective gene knockdown method for 3D optic vesicle organoid culture that is useful for studying gene expression and early retinal development.

Early photoreceptor retinogenesis, especially of cone photoreceptors, is not well understood despite its importance. This paucity of information is partially due to a lack of well-characterized cell markers for embryonic cone photoreceptors. Previously, two cone markers were identified, $\operatorname{Tr} \beta 2$ and $R x r \gamma$. Both are regulatory proteins involved in opsin expression (Applebury et al., 2007; Mori, Ghyselinck, Chambon, \& Mark, 2001; Ng, Ma, Curran, \& Forrest, 2009; Roberts, Hendrickson, McGuire, \& Reh, 2005). The data presented here in Chapter 2 indicates that two proteins involved in phototransduction, phosducin and cone transducin $\gamma$, label cones as early as E12.5 and E13.5 respectively and show robust expression in the developing photoreceptor layer. The identification and characterization of these markers is important as it increases the number of markers available to study embryonic cones, and these newly identified markers do not require specific antibody-labeling conditions for their use (unlike $\operatorname{Tr} \beta 2$ and $\mathrm{Rxr} \gamma$ ), making them reliable and easy to use tools. Interestingly, both proteins, while expressed early, are involved in phototransduction. When we examined other proteins involved in the phototransduction cascade, such as cone phosphodiesterase, we did not see embryonic expression at E15.5. Since the mouse retina is not capable of phototransduction until P13-14 
(Hoffpauir, Marrs, Mathers, \& Spirou, 2009), weeks after we see the initial phosducin and cone transducin $\gamma$ expression, it leads to a question of the function of phototransduction-related proteins early in retinogenesis. Studies have shown that phosducin may have some transcriptional regulation abilities (Zhu \& Craft, 2000a, 2000b) and cone transducin $\gamma$ is part of a heterotrimeric G protein complex. Several G protein-coupled receptor signaling pathways are involved in eye development (Reis, Ventura, Kubrusly, de Mello, \& de Mello, 2007; Stenkamp, Frey, Prabhudesai, \& Raymond, 2000). The possibility of a role for phosducin and cone transducin $\gamma$ during early cone histogenesis will require further studies. Phosducin-null mice retain functional photoreceptors although in mature photoreceptors there is a decrease in transducin translocation (Sokolov et al., 2004), suggesting that if phosducin is playing a role during embryogenesis, it is likely part of a redundant mechanism in early photoreceptor development. Unlike the phosducin-null mouse, there is currently no cone transducin $\gamma$ knockout mouse available. Generation of either a germline cone transducin $\gamma$ knockout mouse or a conditional knockout might help determine possible functions during early retinogenesis. Additionally, the combined knockout or knockdown of cone transducin $\gamma$ and phosducin in retinal progenitors could help to ascertain if both proteins in concert have a role in early photoreceptor development. Alternatively these proteins may have no role in early retinogenesis and are just waiting for the remaining phototransduction proteins to be generated.

Using these newly identified early cone markers, we explored the role of $R x$ in photoreceptor development using a Cre-driven conditional knockout model of $R x$. The use of a conditional knockout model was necessary because the $R x$-null mutant fails to form optic vesicles (Mathers, Grinberg, Mahon, \& Jamrich, 1997), and this ocular defect precludes the study of later eye development. Functions of Rx beyond optic vesicle formation have been briefly studied using conditional knockouts of $R x$ in retinal progenitors and show a loss of Otx2 and Crx labeling (Muranishi et al., 2011) Postnatal conditional deletion of $R x$, showed $\mathrm{Rx}$ is involved in the 
maturation and survival of postnatal photoreceptors (Irie et al., 2015), and has the ability to transactivate genes such as Otx2 (Muranishi et al., 2011). These studies provide preliminary evidence of a role for $\mathrm{Rx}$ in photoreceptor development but did not fully explore the functions of $\mathrm{Rx}$ during retinogenesis. In Chapter 3 , we explored the functions of the $R x$ mouse gene during retinogenesis, including in progenitor proliferation and in the generation of embryonic photoreceptors, specifically cones. Our conditional knockout was driven by a Pax6a cre promoter, which induces deletion of $R x$ in the distal portion of the retina starting at E10.5 (Marquardt et al., 2001), the earliest age of retinal cell birth. This deletion leads to changes in retinal lamination, proliferation and cell fate determination. There is a significant reduction in retinal progenitors at $\mathrm{E} 18.5$ in portions of the retina that undergo $R x$ deletion, and examination of cell types at P21 showed a loss of cone photoreceptors, rod photoreceptors, bipolar cells and Müller glia. The loss of rods, bipolar cells and Müller glia in the $R x$-deleted retina are likely the result of the reduction in the number of retinal progenitors, which is probably the result of early cell cycle exit in the retinal progenitors. Rods, bipolar cells and Müller glia are born in the second phase of retinal cell birth (Rapaport, Wong, Wood, Yasumura, \& LaVail, 2004; Young, 1985), making their generation far more susceptible to a decrease of retinal progenitors (Dyer \& Cepko, 2001). Interestingly, cone photoreceptors are also reduced in the $R x$-deleted portion of the retina. Cone photoreceptors are in the early-born phase of retinal birth, and their formation is therefore less likely to be affected by decreasing numbers of progenitors at later embryonic ages. These findings suggest that cones may require $\mathrm{Rx}$ for their initial formation. To explore this possibility, we looked at cone photoreceptor formation at embryonic ages. The data presented in Chapter 3 show a reduction in embryonic cones as evidenced by decreases in the expression of phosducin, cone transducin gamma and Otx2 in the $R x$-deleted retina. The decrease in Otx2 expression is similar to that shown in other $R x$ CKO models (Muranishi et al., 2011). Examination of cell death using activated-caspase 3 shows no elevation in apoptosis in the $R x$-deleted portions of the retina, suggesting that the reduced cone numbers were not the 
result of $R x$-deleted cells dying. The loss of cone photoreceptors in the conditional knockout was not complete, possibly due to the mosaic nature of the Pax6a cre deletion. Therefore, further studies using different cre promoters would be necessary to fully determine if loss of $R x$ leads to a complete loss of cones. A recent study suggests that cone subtype may be determined as early as E12-E15 despite that opsin expression has not begun (Aavani et al., 2017), therefore it is possible that $R x$ is affecting the generation of one specific cone subtype, however, examination of both opsins at P21 in our Rx CKO mice show an absence of cones, suggesting both subtypes require $\mathrm{Rx}$. Additional studies are needed to fully determine the function of $R x$ in photoreceptor generation. Studies of the overexpression of $R x$ in mouse retinal progenitors would help determine if $\mathrm{Rx}$ is sufficient for cone photoreceptor generation.

Currently, the model of cone photoreceptor development proposes a very early role for Rx on Otx2, as Rx can transactivate Otx2 via binding to the EELPOT (Muranishi et al., 2011a). This model proposes that Rx activation of Otx2 leads to the development of both rod and cone photoreceptors (Muranishi et al., 2011b). Otx2 is transiently expressed in many retinal cell types (Baas et al., 2000), and evidence shows that Otx2-positive cells can go on become photoreceptors or bipolar cells (Brzezinski, Lamba, \& Reh, 2010). However, Otx2 lineage analysis has yet to be done so the full range of cell types that can be generated from Otx2positive cells is not yet known. Lineage studies on Otx2 using inducible Cre expression under the control of the Otx2 promoter, with induction starting at E11.5, would help determine the potential of Otx2-positive cells and allow us to better understand cell fate decisions associated with Otx2. Blimp1 expression in Otx2-positive cells determines if the cell becomes a bipolar cell or either a rod or cone photoreceptor (Brzezinski et al., 2010; Katoh et al., 2010). If Rx is involved specifically in cone generation as opposed to broadly regulating photoreceptor formation via actions on Otx2, this raises the question if perhaps $\mathrm{Rx}$ then also has a role later in this pathway after the activation of Blimp1 to specify cone instead of rod fate. Previous 
conditional deletion models of Rx embryonically did not fully assess cell type, cell death or proliferation. Therefore, using different cre lines (such as Chx10 or Crx) or an inducible conditional knockout to delete $R x$ at different embryonic ages and assessing proliferation, cell type, and cell death would help to further understand functions of $R x$ in retinogenesis and which points in the pathway of photoreceptor generation that Rx plays a role. Additionally overexpression of $\mathrm{Rx}$ in photoreceptor precursors may help determine if $\mathrm{Rx}$ plays a specific role directly in all photoreceptor (rod and cone) generation or solely cone photoreceptor generation.

In Chapter 4, we assessed potential methods for gene knockdown within optic vesicle organoid cultures and then used the best-suited method to examine the effects of candidate genes for optic vesicle development on these optic vesicle organoids. In these cultures, optic vesicles are generated from pluripotent stem cells in a stepwise process that mimics in vivo development in both timing and morphology (Eiraku et al., 2011; Eiraku \& Sasai, 2011). We compared Accell siRNA and vMOs, which are two methods for antisense-mediated gene knockdown that contain modifications for in vivo applications. Both antisense oligomers were incorporated into our cultures after bath application, but only vMOs were able to effective knockdown our test gene, GFP. Addition of these test vMOs did not affect development of the optic vesicle nor were there any toxic effects. Next, we used vMOs targeting $R x$ transcripts to analyze gene knockdown functionally. Rx is necessary for optic tissue induction and evagination. Retinal tissue induction was lost using translation-blocking and splice-blocking vMOs targeted to the $R x$ transcript, similar to the $R x$ knockout mouse (Mathers et al., 1997). These data suggest that vMOs in optic vesicle organoid culture are effective for exploring gene function during optic vesicle development. Using vMOs, we screened three candidate genes that were identified in a microarray comparing control vs. optic vesicle-deficient forebrains. Three separate phenotypes emerged from the knockdown of these genes. Organoids where Edn1 is knocked down appear similar to controls, suggesting that manipulation of Edn1 has no effect on optic vesicle 
development or potentially that the concentration used was not high enough to achieve a significant knockdown. Organoid cultures where Rpl37 was knocked down show much smaller aggregates and no optic vesicle outpockets, suggesting a more global effect on the cultures than an optic vesicle-specific effect. Alx1 knockdown in organoid cultures results in a change in the distribution of retinal tissue (as marked by the $R x$-driven GFP expression), suggesting that Alx1 may be involved in optic vesicle development. Further studies are warranted to confirm these findings. Immunofluorescence of Alx1 on control and Alx1 knockdown organoids using an Alx1 antibody should be performed to confirm that Alx1 was successfully knocked down. In addition, use of both translational and splice blocking vMOs independently and together to help ensure that the resulting phenotype is the product of Alx1 knockdown and not an off-target effect. Germline knockout of $A / x 1$ leads to severe craniofacial defects, and therefore, creating a conditional knockout mouse model would be necessary to investigate eye-specific effects. Further, to get a better understanding of how the knockdown affected optic vesicle development, quantification of GFP as a measure of retinal induction and labeling of cell types would be beneficial. Overall the results of Chapter 4 suggest that vMOs can be used successfully in optic vesicle organoid cultures and can be used as a rapid screen for genes involved in optic vesicle formation. This work may have implications beyond studying the genetics of optic vesicle development in that the ability to use vMOs for gene knockdown in 3D culture may extend to other organoids, such as differentiated retina, brain or liver. Currently, gene knockdown in other organoids has only been done with viral vectors (Koo et al., 2011, 2013), which is more expensive and time-intensive then bath application of vMOs. This method may prove to be a very useful tool for studying gene function in developing organs, although further testing is necessary to ensure no developmental or toxic effects occur in other organoid cultures. 


\section{References}

Applebury, M. L., Farhangfar, F., Glösmann, M., Hashimoto, K., Kage, K., Robbins, J. T., ... Zhang, H. (2007). Transient expression of thyroid hormone nuclear receptor TRbeta2 sets S opsin patterning during cone photoreceptor genesis. Developmental Dynamics : An Official Publication of the American Association of Anatomists, 236(5), 1203-12. http://doi.org/10.1002/dvdy.21155

Baas, D., Bumsted, K. M., Martinez, J. A., Vaccarino, F. M., Wikler, K. C., \& Barnstable, C. J. (2000). The subcellular localization of Otx2 is cell-type specific and developmentally regulated in the mouse retina. Brain Research. Molecular Brain Research, 78(1-2), $26-37$.

Brzezinski, J. A., Lamba, D. A., \& Reh, T. A. (2010). Blimp1 controls photoreceptor versus bipolar cell fate choice during retinal development. Development (Cambridge, England), 137(4), 619-29. http://doi.org/10.1242/dev.043968

Dyer, M. A., \& Cepko, C. L. (2001). Regulating proliferation during retinal development. Nature Reviews Neuroscience, 2(5), 333-342. http://doi.org/10.1038/35072555

Eiraku, M., \& Sasai, Y. (2011). Mouse embryonic stem cell culture for generation of threedimensional retinal and cortical tissues. Nature Protocols, 7(1), 69-79. http://doi.org/10.1038/nprot.2011.429

Eiraku, M., Takata, N., Ishibashi, H., Kawada, M., Sakakura, E., Okuda, S., ... Sasai, Y. (2011). Self-organizing optic-cup morphogenesis in three-dimensional culture. Nature, 472(7341), 51-56. http://doi.org/10.1038/nature09941

Hoffpauir, B. K., Marrs, G. S., Mathers, P. H., \& Spirou, G. A. (2009). Does the brain connect before the periphery can direct? A comparison of three sensory systems in mice. Brain Research, 1277, 115-29. http://doi.org/10.1016/j.brainres.2009.02.050

Irie, S., Sanuki, R., Muranishi, Y., Kato, K., Chaya, T., \& Furukawa, T. (2015). Rax Homeoprotein Regulates Photoreceptor Cell Maturation and Survival in Association with Crx in the Postnatal Mouse Retina. Molecular and Cellular Biology, 35(15), 2583-2596. http://doi.org/10.1128/MCB.00048-15

Katoh, K., Omori, Y., Onishi, A., Sato, S., Kondo, M., \& Furukawa, T. (2010). Blimp1 suppresses Chx10 expression in differentiating retinal photoreceptor precursors to ensure proper photoreceptor development. The Journal of Neuroscience : The Official Journal of the Society for Neuroscience, 30(19), 6515-26. http://doi.org/10.1523/JNEUROSCI.077110.2010

Koo, B.-K., Sasselli, V., Clevers, H., Koo, B., Sasselli, V., \& Clevers, H. (2013). Retroviral Gene Expression Control in Primary Organoid Cultures. In Current Protocols in Stem Cell Biology (p. 5A.6.1-5A.6.8). Hoboken, NJ, USA: John Wiley \& Sons, Inc. http://doi.org/10.1002/9780470151808.sc05a06s27

Koo, B.-K., Stange, D. E., Sato, T., Karthaus, W., Farin, H. F., Huch, M., ... Clevers, H. (2011). Controlled gene expression in primary Lgr5 organoid cultures. Nature Methods, 9(1), 81-3. http://doi.org/10.1038/nmeth.1802

Marquardt, T., Ashery-Padan, R., Andrejewski, N., Scardigli, R., Guillemot, F., \& Gruss, P. (2001). Pax6 is required for the multipotent state of retinal progenitor cells. Cell, 105(1), 43-55. 
Mathers, P. H., Grinberg, a, Mahon, K. a, \& Jamrich, M. (1997). The Rx homeobox gene is essential for vertebrate eye development. Nature, 387(6633), 603-7. http://doi.org/10.1038/42475

Mori, M., Ghyselinck, N. B., Chambon, P., \& Mark, M. (2001). Systematic Immunolocalization of Retinoid Receptors in Developing and Adult Mouse Eyes. Investigative Ophthalmology \& Visual Science, 42(6), 67-1318.

Muranishi, Y., Terada, K., Inoue, T., Katoh, K., Tsujii, T., Sanuki, R., ... Furukawa, T. (2011). An essential role for RAX homeoprotein and NOTCH-HES signaling in Otx2 expression in embryonic retinal photoreceptor cell fate determination. The Journal of Neuroscience : The Official Journal of the Society for Neuroscience, 31(46), 16792-807. http://doi.org/10.1523/JNEUROSCI.3109-11.2011

Ng, L., Ma, M., Curran, T., \& Forrest, D. (2009). Developmental expression of thyroid hormone receptor beta2 protein in cone photoreceptors in the mouse. Neuroreport, 20(6), 627-31. http://doi.org/10.1097/WNR.0b013e32832a2c63

Rapaport, D. H., Wong, L. L., Wood, E. D., Yasumura, D., \& LaVail, M. M. (2004). Timing and topography of cell genesis in the rat retina. The Journal of Comparative Neurology, 474(2), 304-24. http://doi.org/10.1002/cne.20134

Reis, R. A. M., Ventura, A. L. M., Kubrusly, R. C. C., de Mello, M. C. F., \& de Mello, F. G. (2007). Dopaminergic signaling in the developing retina. Brain Research Reviews, 54(1), 181-8. http://doi.org/10.1016/j.brainresrev.2007.01.001

Roberts, M. R., Hendrickson, A., McGuire, C. R., \& Reh, T. A. (2005). Retinoid X receptor (gamma) is necessary to establish the S-opsin gradient in cone photoreceptors of the developing mouse retina. Investigative Ophthalmology \& Visual Science, 46(8), 2897-904. http://doi.org/10.1167/iovs.05-0093

Sokolov, M., Strissel, K. J., Leskov, I. B., Michaud, N. A., Govardovskii, V. I., \& Arshavsky, V. Y. (2004). Phosducin facilitates light-driven transducin translocation in rod photoreceptors. Evidence from the phosducin knockout mouse. The Journal of Biological Chemistry, 279(18), 19149-56. http://doi.org/10.1074/jbc.M311058200

Stenkamp, D. L., Frey, R. A., Prabhudesai, S. N., \& Raymond, P. A. (2000). Function for Hedgehog genes in zebrafish retinal development. Developmental Biology, 220(2), 23852. http://doi.org/10.1006/dbio.2000.9629

Young, R. W. (1985). Cell differentiation in the retina of the mouse. The Anatomical Record, 212(2), 199-205. http://doi.org/10.1002/ar.1092120215

Zhu, X., \& Craft, C. M. (2000a). Modulation of CRX transactivation activity by phosducin isoforms. Molecular and Cellular Biology, 20(14), 5216-26.

Zhu, X., \& Craft, C. M. (2000b). The carboxyl terminal domain of phosducin functions as a transcriptional activator. Biochemical and Biophysical Research Communications, 270(2), 504-9. http://doi.org/10.1006/bbrc.2000.2414 


\section{Helen M. Rodgers}

29 Laverendrye Cres. Portage la Prairie, MB, R1N 3E6, Canada

hmlrodgers@gmail.com, 304-669-3656

\section{EDUCATION}

Ph.D.
Biomedical Sciences -
Neuroscience
2017
M.A.
Psychology - Behavioral
Neuroscience
2008

B.A. hons.

Psychology

2005

\author{
West Virginia University School of Medicine, Morgantown, WV \\ Dissertation: The role of $\mathrm{Rx}$ in embryonic retinogenesis: determining \\ genetic influences on optic vesicle formation and photoreceptor cell \\ fate. \\ Advisor: P. Mathers \\ University of Manitoba, Winnipeg, MB \\ Thesis: The Genetically Obese Mouse's Response to Thermal \\ Nociception: Effects of Aging and Leptin Replacement \\ Advisor: L. Wilson \\ University of Manitoba, Winnipeg, MB \\ Thesis: Tail-Flick Thresholds: Do They Differ Between Genetically \\ Obese (B6V - lep ${ }^{o b}$ ) and Lean (B6V - +/?) Mice \\ Advisor: L. Wilson
}

\section{TEACHING EXPERIENCE}

Course
coordinator/lecturer
Spring 2015

Teaching Assistant Spring 2015

\author{
Teaching Practicum \\ Spring 2013
}

\section{Grader/Marker 2007-2008}

West Virginia University School of Medicine, Morgantown, WV Graduate Medical Neurobiology(NBAN793), Dept. of Neurobiology and Anatomy

Assisted in course development and design. Responsible for lecture planning, developing course syllabus, learning objectives and course schedule. Involved in exam creation, and grading. Organized and assisted other lecturers. Responsible for course administrative duties including course website, gradebook and acted as the resource person to resolve issues such as student questions, late assignments and timetable conflicts. In addition, taught $4-2$ hour lectures.

West Virginia University School of Medicine, Morgantown, WV Medical Neurobiology(CCMD775), Dept. of Neurobiology and Anatomy Assisted in the neuroanatomy lab with 107 medical and graduate students. Helped set up models/specimens and prepared brain sections, including deep brain dissections. Assisted students during lab.

West Virginia University School of Medicine, Morgantown, WV Teaching Practicum, Dept of Physiology and Pharmacology Learned teaching techniques, and pedagogical theory. Prepared and gave lecture in undergraduate physiology.

University of Manitoba, Winnipeg, MB Brain and Behavior (Psyc2360), Dept of Psychology Assisted in the invigilation and grading of exams for 1 section with 50 students. Responsible for gradebook and acted as a resource person to answer student questions. 


\author{
Grader/Marker \\ 2005-2008
}

Grader/Marker

2005-2007
University of Manitoba, Winnipeg, MB

Introduction to Psychology (Psyc1200), Dept of Psychology

Assisted in the creation, invigilation and grading of exams/ assignments for 4 sections with 50-120 students. Organized and lead small study groups. Developed a course website. Responsible for gradebook, and acted as a resource person to answer student questions and resolve issues such as late assignments and missed exams.

University of Manitoba, Winnipeg, MB

Physiological Psychology (Psyc3330), Dept of Psychology

Assisted in the creation, invigilation and grading of exams for 1 section with 50 students. Responsible for gradebook and acted as a resource person to answer student questions.

RESEARCH EXPERIENCE Doctoral Research 2009- April 2017

\section{Research Assistant 2007-2008}

\author{
Laboratory Animal \\ Technician \\ 2006-2008
}

\author{
Master's Research \\ 2005-2008
}

Honors Research 2004-2005
West Virginia University School of Medicine, Morgantown, WV

$P$. Mathers Lab, Depts of Otolaryngology, Biochemistry and Ophthalmology

Responsible for mouse room management, genotyping, and lab ordering. Collaborated with $\mathrm{PI}$ on experimental design and responsible for data collection and analysis. Trained and supervised undergraduate students.

University of Manitoba, Winnipeg, MB

B. Kops (Supervisor), Dept of Continuing Education

Responsible for data entry and analysis on a project examining the role of web applications and learning.

University of Manitoba, Winnipeg, MB

T. Lyttle (Supervisor), Dept of Psychology Animal Care Facility

Assisted in maintaining animal care facility. Responsible for animal husbandry for mice, rats, zebrafish, ducks and budgies as well as sanitation of animal rooms and surgery suites.

University of Manitoba, Winnipeg, MB

L. Wilson (Advisor), Dept of Psychology

Collaborated with PI on experimental design and was responsible for behavioral testing, small animal surgery, data collection and analysis. Trained and supervised undergraduate students.

University of Manitoba, Winnipeg, MB

L. Wilson (Advisor), Dept of Psychology

Evaluated the pain response differences of obese and lean mice.

Collaborated with PI on experimental design, collected and analyzed project data.

\section{PUBLICATIONS}

2017 Rodgers HM. The interrelationship of obesity, pain and diet/nutrition. Watson, RR. Nutritional Modulators of Pain in the Aging Population. [Book Chapter]

2016 Rodgers HM, Belcastro M, Sokolov M, Mathers PH. Embryonic markers of cone differentiation. Molecular Vision, in press. 
2014 Rodgers HM, Liban S, and Wilson LM. Attenuated pain response of obese mice $\left(\mathrm{B} 6 . \mathrm{Cg}-\mathrm{lep}^{\mathrm{ob}}\right.$ ) is affected by aging and leptin but not sex. Physiology \& Behavior, 17, 80-5.

2013 Lu F, Kar D, Gruenig M, Zhang ZW, Cousins M, Rodgers HM, Swindell EC, Jamrich M, Schuurmans C, Mathers PH, and Kurrasch DM. Rax is a selector gene for mediobasal hypothalamic cell types. Journal of Neuroscience, 33, 259-72

\section{PAPERS SUBMITTED/ IN PREPARATION}

Rodgers $\mathrm{HM}^{\star}$, Huffman VJ*, Voronina VA, Lewandoski M, and Mathers $\mathrm{PH}$. The role of the homeobox gene $\mathrm{Rx}$ in the maintenance of retinal cell proliferation and photoreceptor cell fate decision. [Research article to be submitted Spring 2017]

Rodgers HM, and Mathers PH. Antisense-mediated gene knockdown in 3D organoid culture: a method for exploring optic vesicle development

[Research article to be submitted Summer 2017]

\section{ORAL PRESENTATIONS}

\section{Rodgers HM}

Using Vivo-Morpholino's for Gene Knockdown in 3D Optic Vesicle Culture.

Departmental seminar for the Neuroscience Graduate Program, Morgantown, WV

2013 Rodgers HM

Genetic Influences on Optic Vesicle Formation and Neural Cell Fate Decisions in the Vertebrate Retina.

Departmental seminar for the Neuroscience Graduate Program, Morgantown, WV

2011 Rodgers HM

Cell fate determination in retinal neurogenesis: a potential role for $R x$.

Department of Biochemistry Research Forum Seminar, Morgantown, WV

2011 Rodgers HM

Molecular cues needed in the generation of retinal neurons using embryonic and induced pluripotent stem cells.

Departmental Seminar for the Neuroscience Graduate Program, Morgantown, WV

2007 Rodgers HM

How to work effectively with your instructor.

Invited panel speaker for the Faculty of Arts Teaching Assistant Orientation, University

of Manitoba, Winnipeg, MB

\section{SELECT POSTER PRESENTATIONS}

\section{Rodgers HM and Mathers PH}

Anti-sense Mediated Gene Knockdown in 3D Optic Vesicle Organoid Culture.

American Society for Cell Biology, New Orleans, LA.

2012 Rodgers HM, Huffman VJ, and Mathers PH

The role of $R x$ in cell fate decisions during retinogenesis.

American Society for Cell Biology, San Francisco, CA

2008 Rodgers HM and Wilson LM

Tail-flick latency over the lifespan of B6V - lep ob mice: leptin replacement. International Society for Developmental Psychobiology, Washington, DC 
2008 Rodgers HM and Wilson LM

Obesity, Diabetes, and Aging: An Important Triad in Altered Pain Sensations?

Canadian Association for Neuroscience, Montreal, QC

2004 Wilson LM and Rodgers HM

Tail-Flick Analgesia in Genetically Obese (B6V - lep ${ }^{\circ b}$ ) and Lean (B6V - +/?) Mice.

North American Association for the Study of Obesity, Las Vegas, NV

\section{ACADEMIC HONORS AND AWARDS}

- American Society for Cell Biology Travel Award, 2012

- West Virginia University Office of Research and Graduate Education Travel Award, 2012

- Jack MacDonnell Scholarship for Research in Aging, Centre on Aging, 2006

- Dean's Honor list, University of Manitoba

- Faculty of Arts General Scholarship, University of Manitoba, 2001

- Elizabeth May Markle Scholarship, University of Manitoba, 1999

WORKSHOPS AND SEMINARS ATTENDED

- Preparing Educators to Teach Medical Students, West Virginia University School of Medicine, Morgantown, WV, April 2015

- Scientific Teaching Workshop: Bringing the Rigor of Science to the Classroom, Nov 2014, West Virginia University, Morgantown, WV

- University Teaching 101 Course by Johns Hopkins University, Verified Certificate, Coursera, 2014

- Anesthesia/Surgery and Post-Op Care Wet Lab, Feb. 2006, University of Manitoba, Winnipeg, MB

- Laboratory Mouse Wet Lab, Feb. 2003, University of Manitoba, Winnipeg, MB

\section{PROFESSIONAL SERVICE}

- Neuroscience Graduate Student Organization, West Virginia University

- 2014-Sept 2016, Historian

- Jan. 2015-Aug 2015, Vice President

- Neuroscience Graduate Program Curriculum Committee, West Virginia University

- 2014-2016, graduate representative

- WVU Center for Neuroscience Blitz Organizing Committee, West Virginia University

- 2012-2015, graduate representative

- Appalachian Regional Cell Conference, Charleston, WV

- Oct. 2012 - Poster judge

- Department of Psychology, University of Manitoba

- 2006-2008 Animal Care Committee, graduate representative

- 2005-2006 Examination and Evaluation Committee, graduate representative

- 2004-2005 Curriculum and Instruction Committee, undergraduate representative

- 2003-2004 Research and Scholarship Committee, undergraduate representative

- 2002-2003 Rules and Procedures Committee, undergraduate representative

- 2001-2002 Research and Scholarship Committee, undergraduate representative 